\title{
The Politics of Retirement Savings Taxation: \\ A Trans-Tasman Comparison
}

\author{
By \\ Lisa Marriott
}

\begin{abstract}
A thesis
submitted to the Victoria University of Wellington in fulfilment of the requirements for the degree of

Doctor of Philosophy

in Accounting
\end{abstract}

Victoria University of Wellington

2008 


\section{$\underline{\text { Table of Contents }}$}

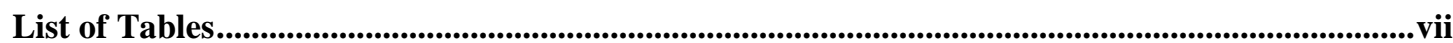

List of Figures ...........................................................................................................................

Abstract ..................................................................................................................................................

List of Acronyms ..........................................................................................................................................

Acknowledgements ................................................................................................................................ii

Chapter 1: Introduction.............................................................................................................................. 1

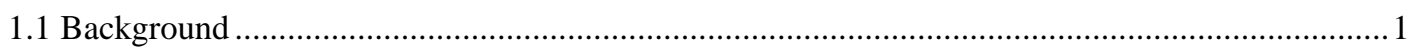

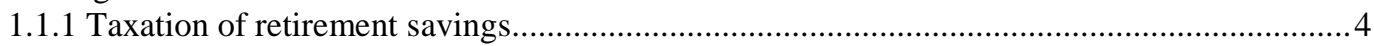

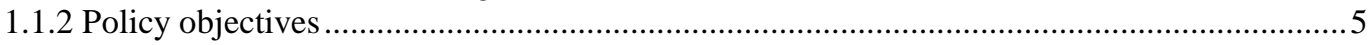

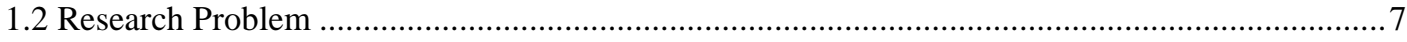

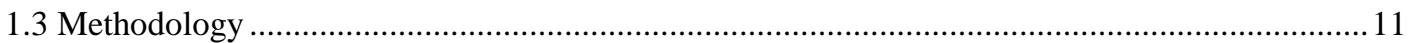

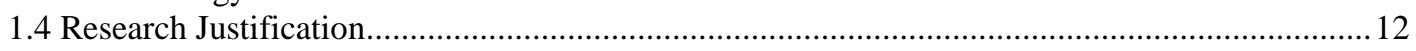

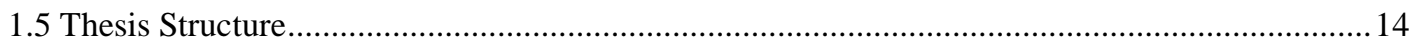

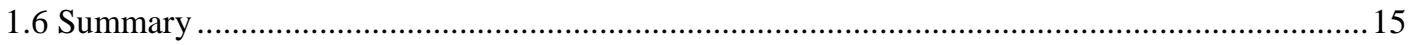

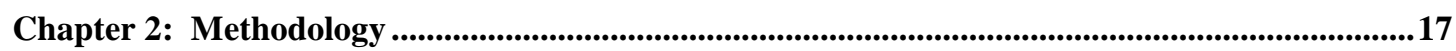

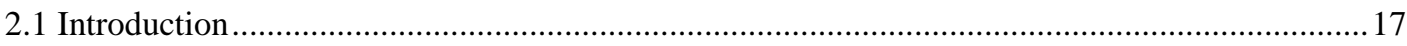

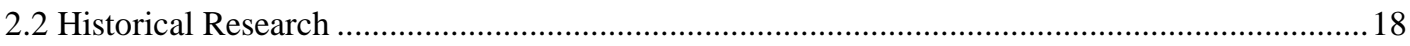

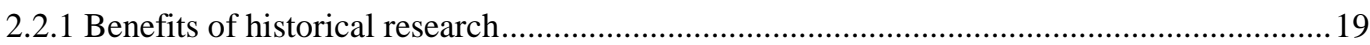

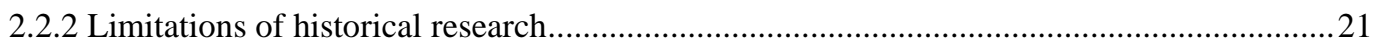

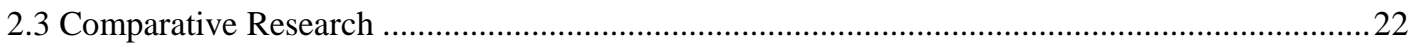

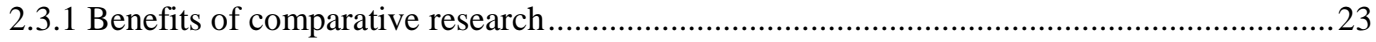

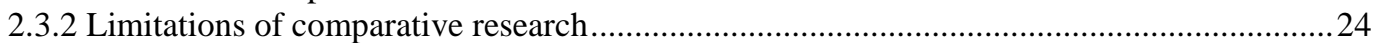

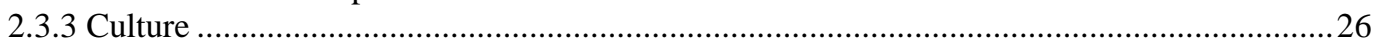

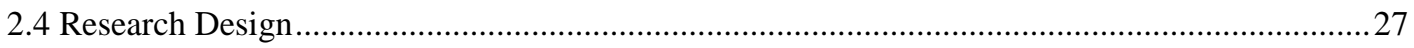

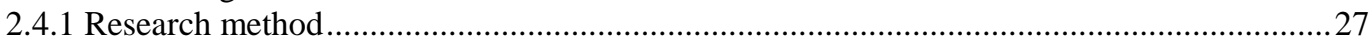

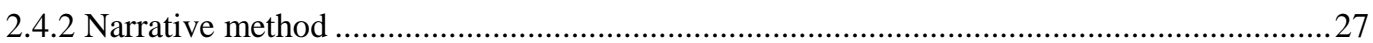

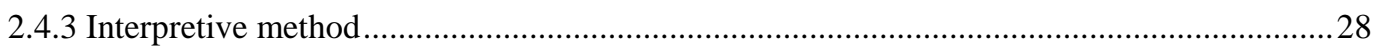

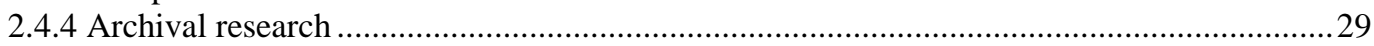

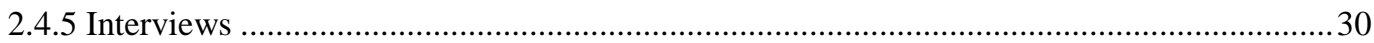

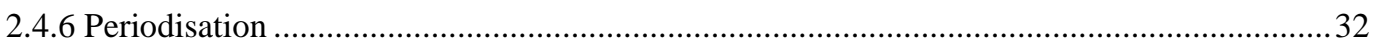

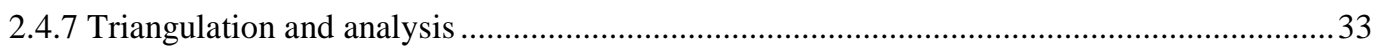

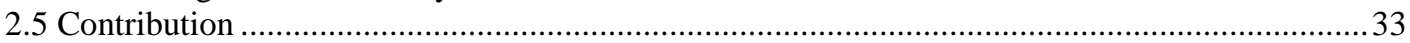

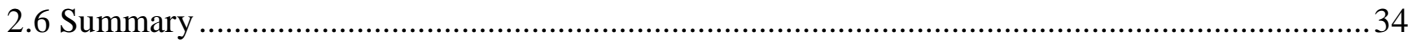

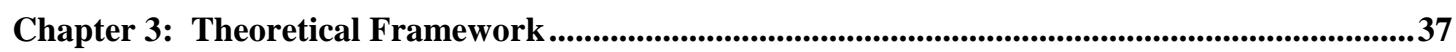

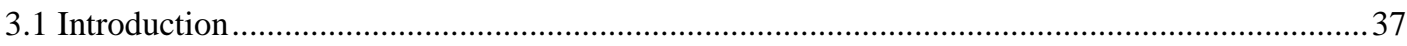

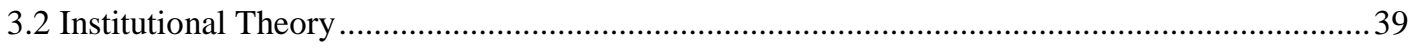

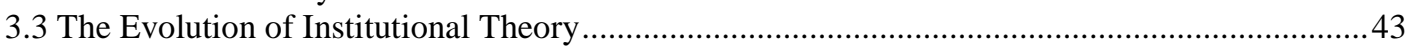

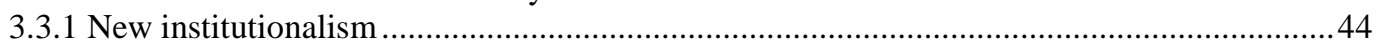

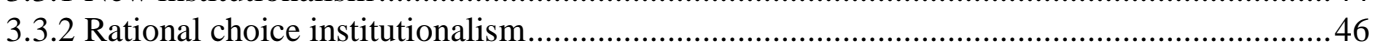

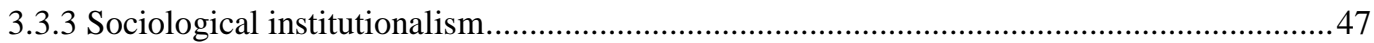

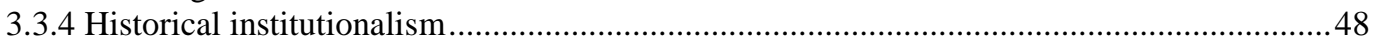

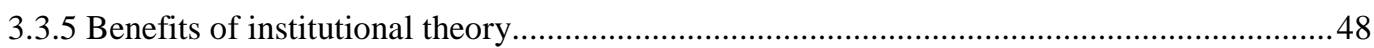

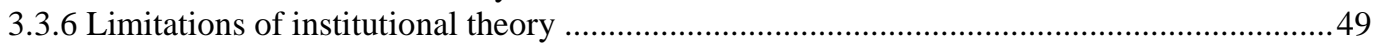

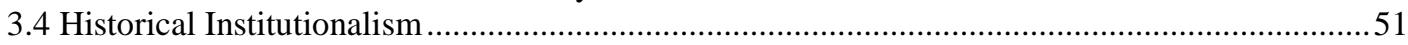

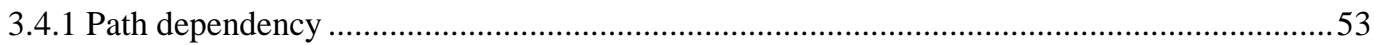

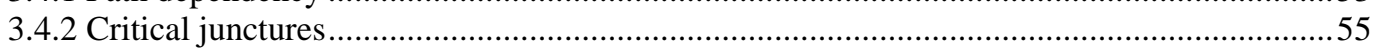

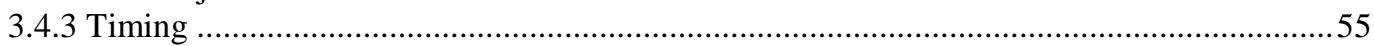

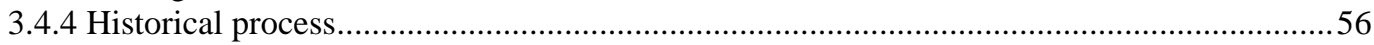

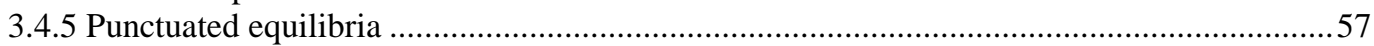

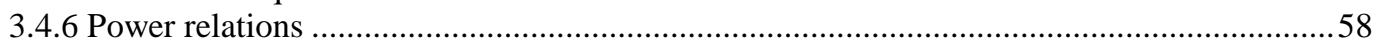

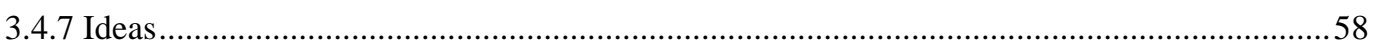

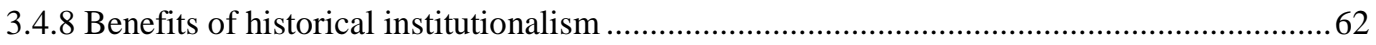




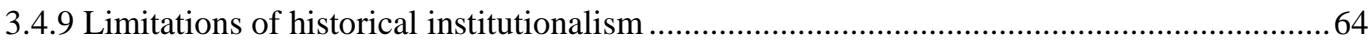

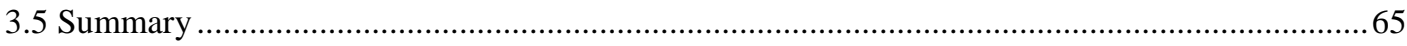

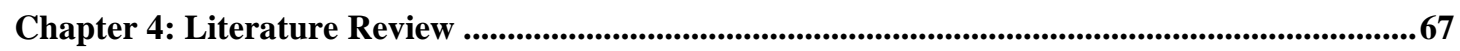

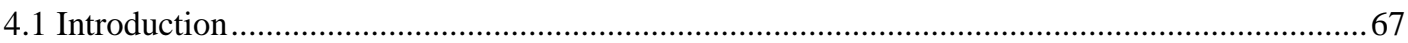

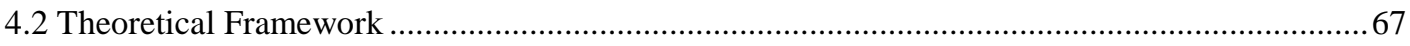

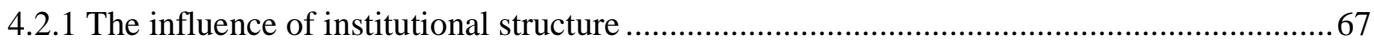

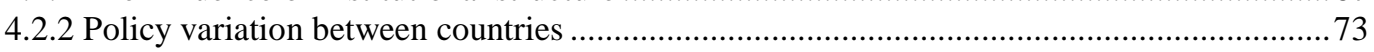

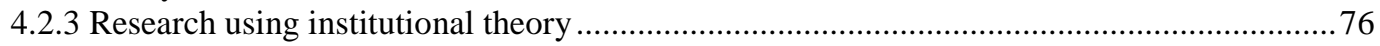

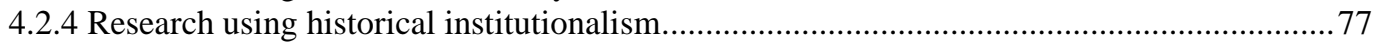

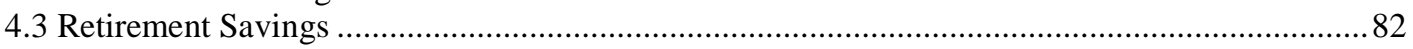

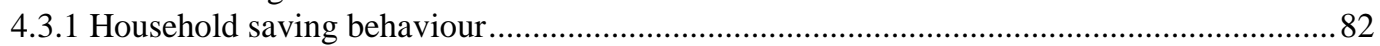

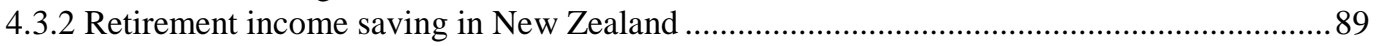

4.3.3 Retirement income saving in Australia .......................................................................91

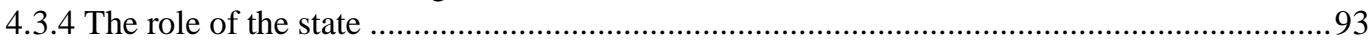

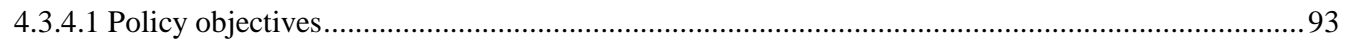

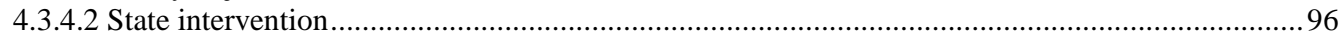

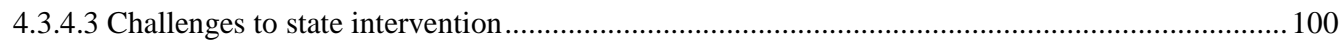

4.3.5 Comparisons of retirement income savings ........................................................ 101

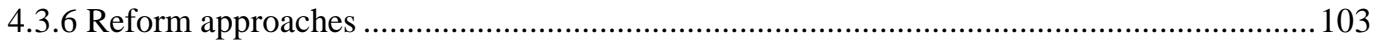

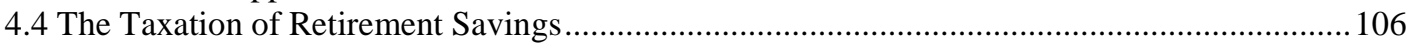

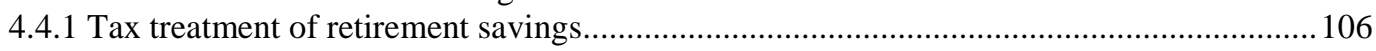

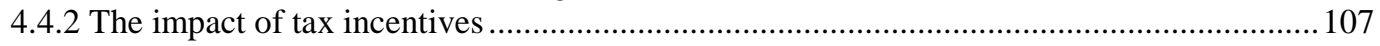

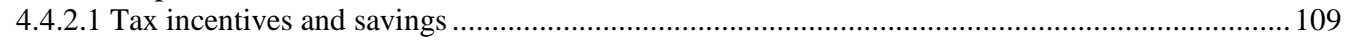

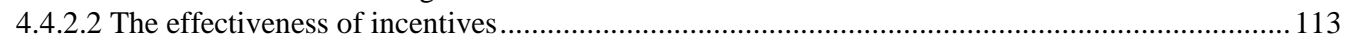

4.4.2.3 Behavioural and equity issues of tax incentives .................................................................. 114

4.4.3 Taxation of retirement savings in New Zealand ............................................................ 116

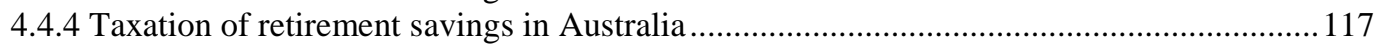

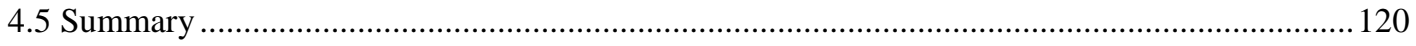

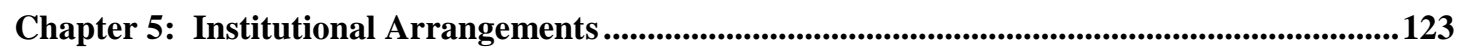

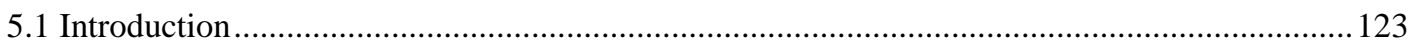

5.2 Institutional Arrangements: New Zealand ............................................................ 124

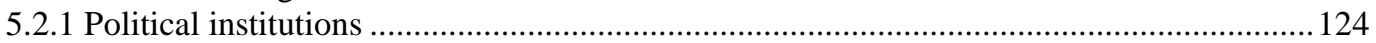

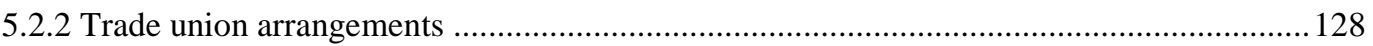

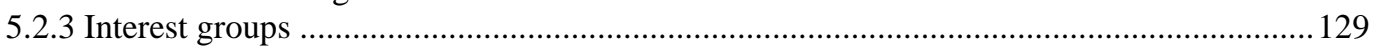

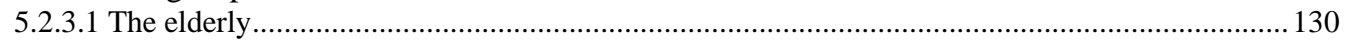

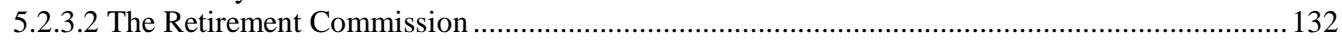

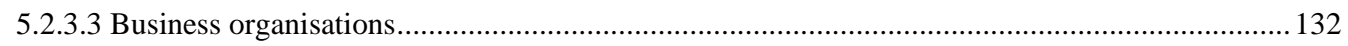

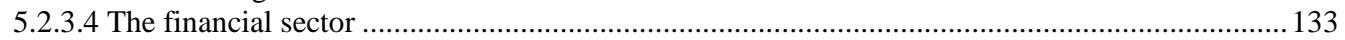

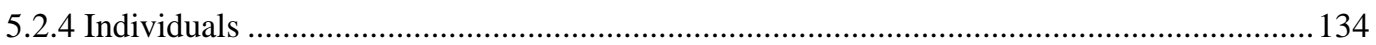

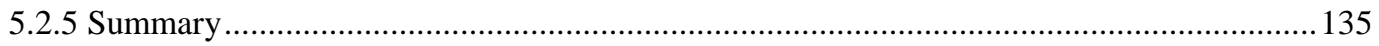

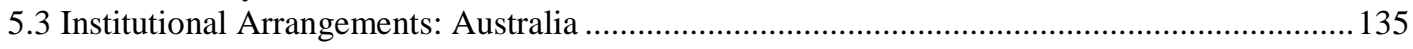

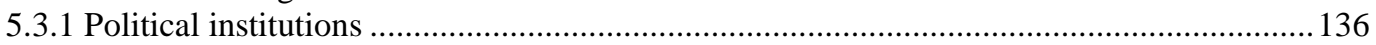

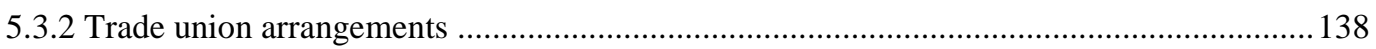

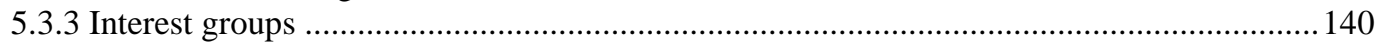

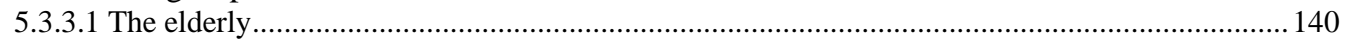

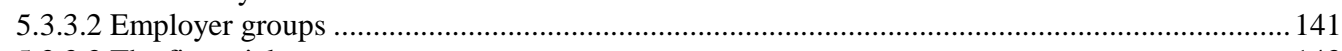

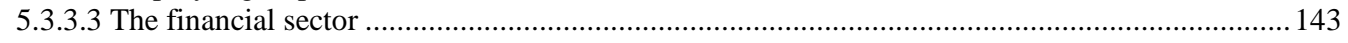

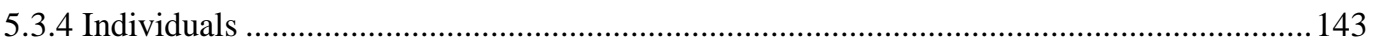

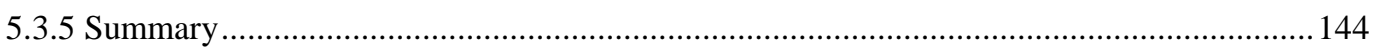

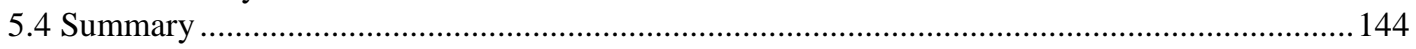

Chapter 6: The History of Retirement Savings Taxation in New Zealand..................................147

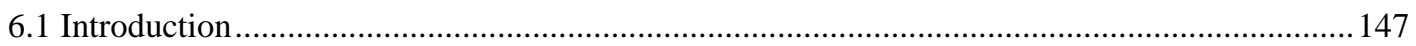

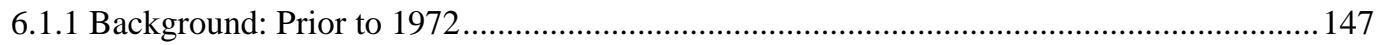

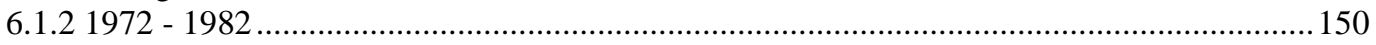

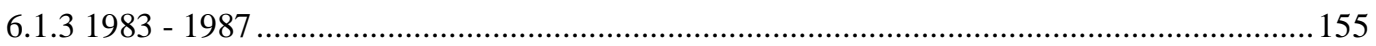

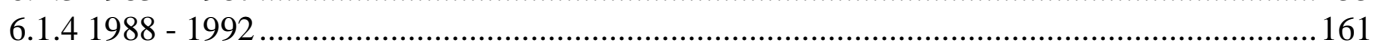

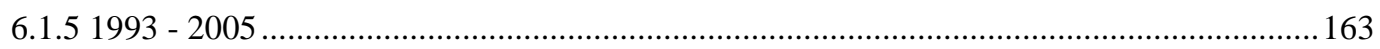

6.1.6 2006 Tax treatment of retirement savings......................................................... 167 


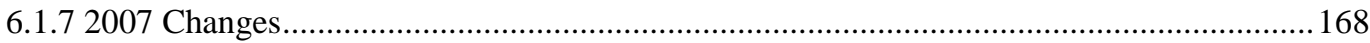

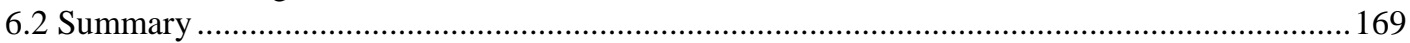

Appendix 6.1: Primary Events in New Zealand Retirement Savings History ................................ 171

Chapter 7: The History of Retirement Savings Taxation in Australia ..........................................173

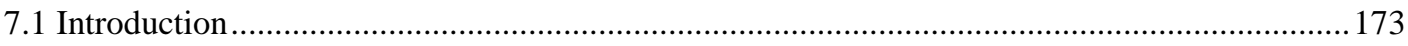

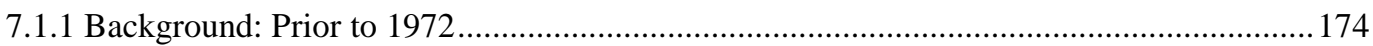

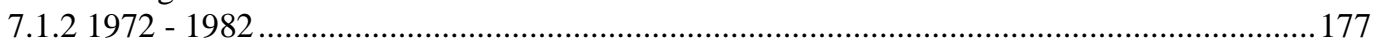

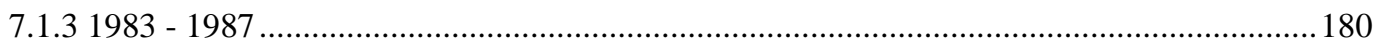

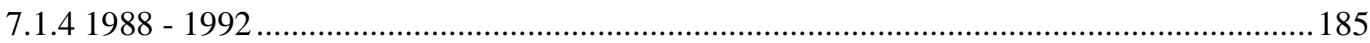

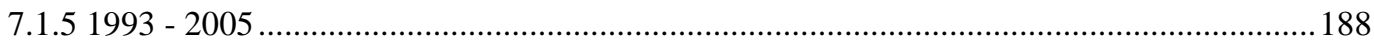

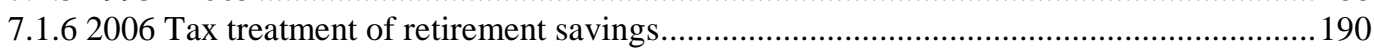

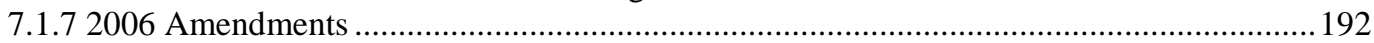

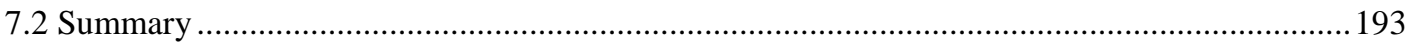

Appendix 7.1: Primary Events in Australian Retirement Savings History ................................... 195

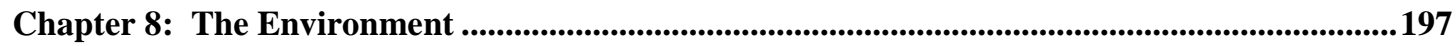

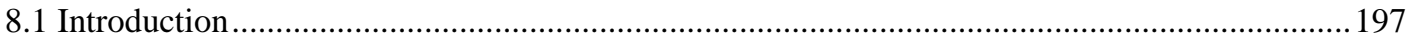

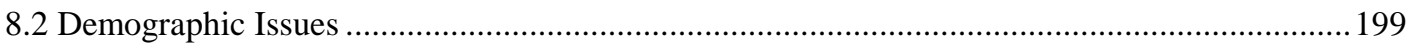

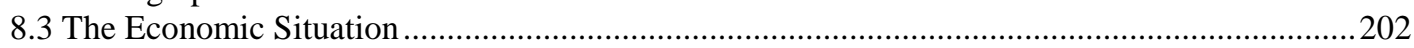

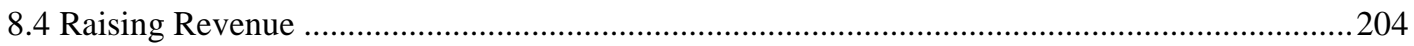

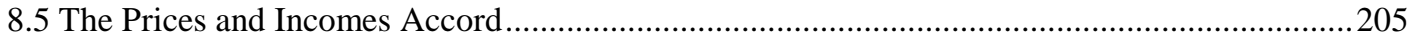

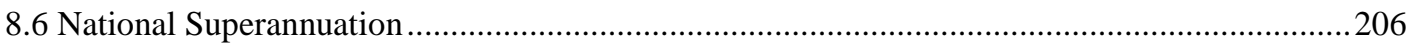

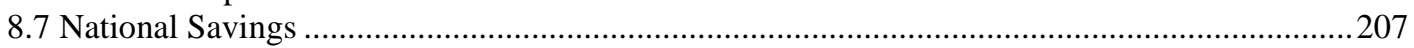

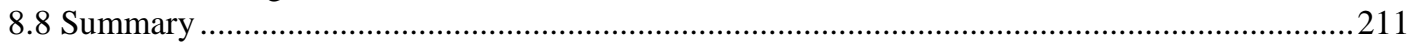

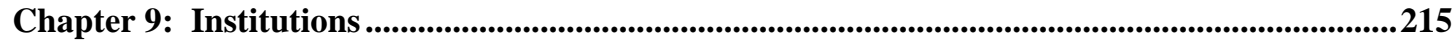

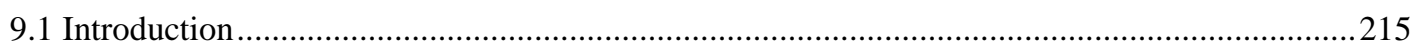

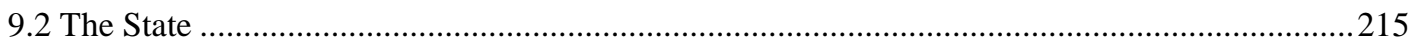

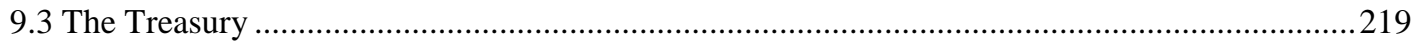

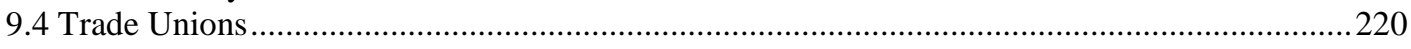

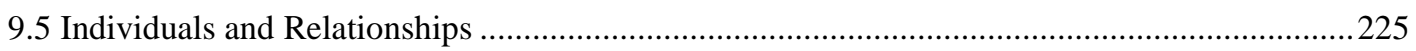

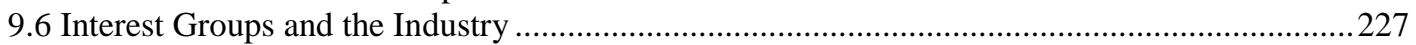

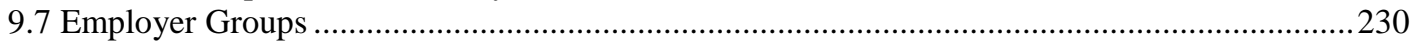

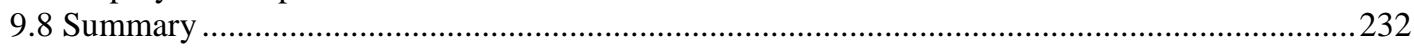

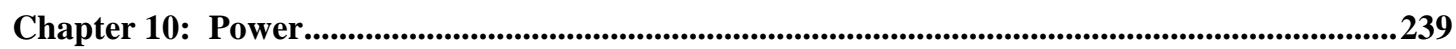

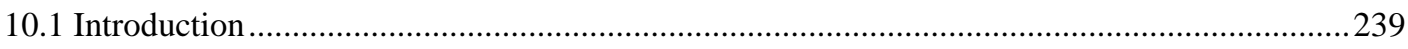

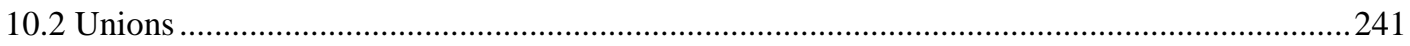

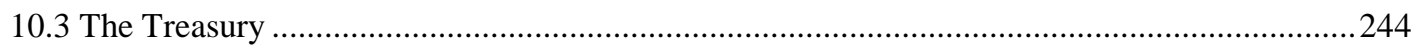

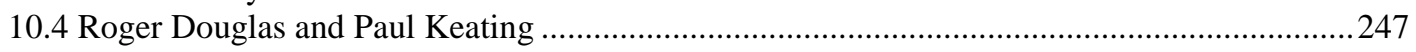

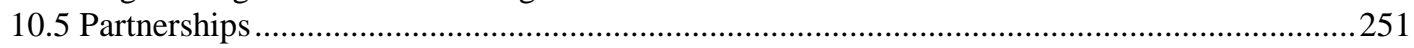

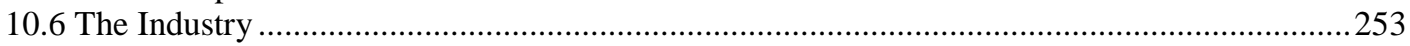

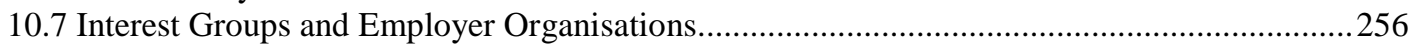

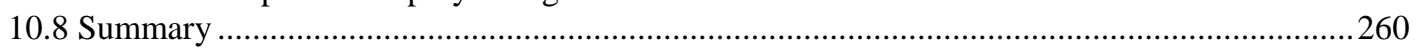

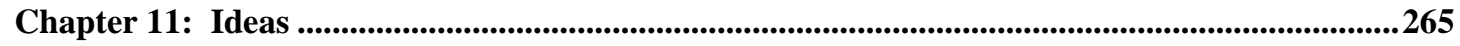

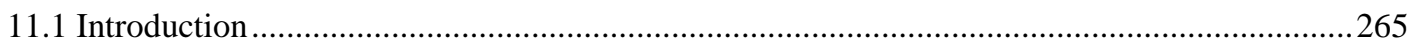

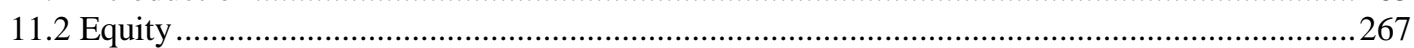

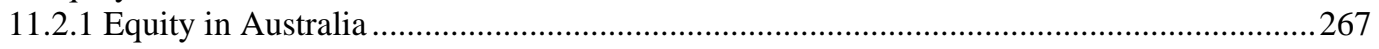

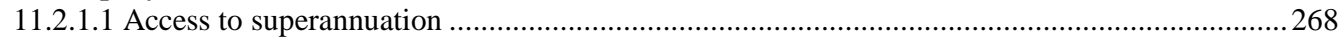

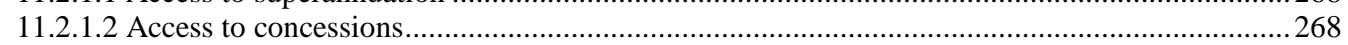

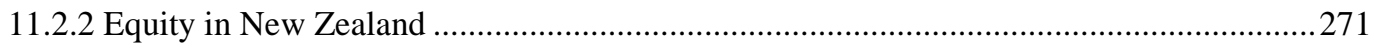

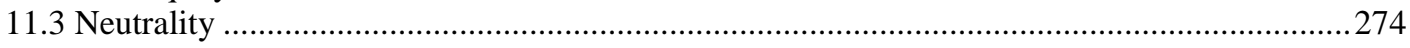

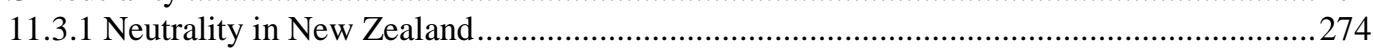

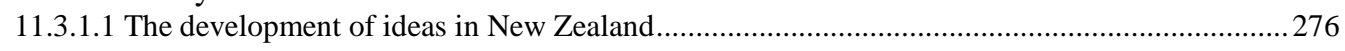

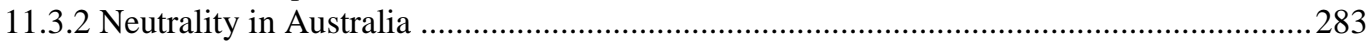

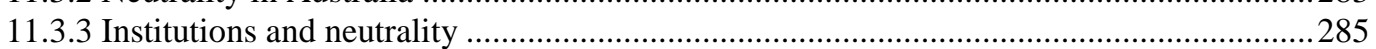

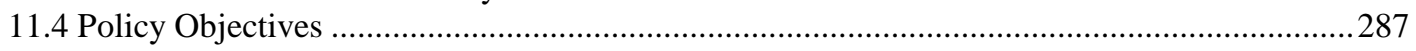

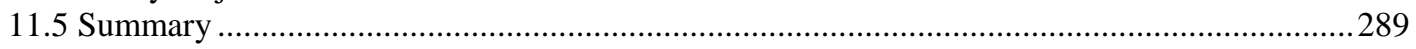




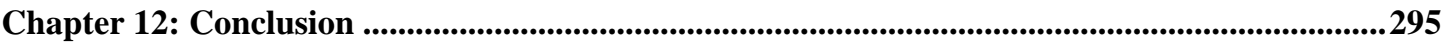

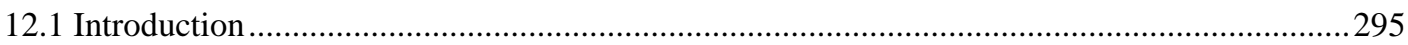

12.2 Retirement Savings Taxation Policy in New Zealand and Australia .......................................296

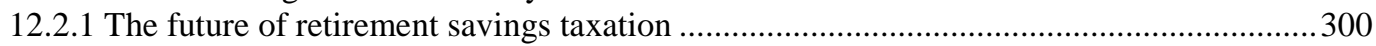

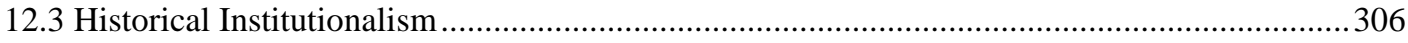

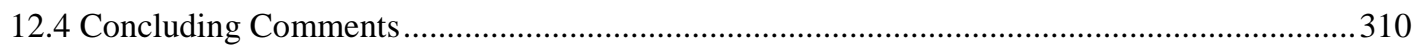

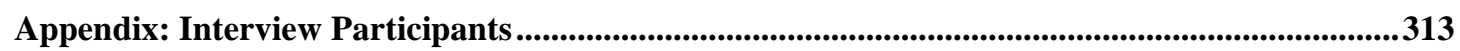

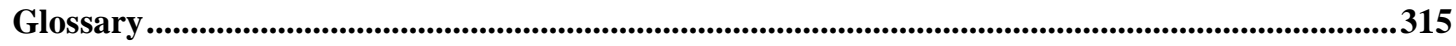

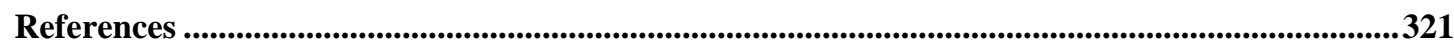




\section{List of Tables}

Table 1.1: Tax Treatment of Private Pensions in Selected OECD Countries ..........................................5

Table 1.2: Gross Replacement Rates by Earnings Level...................................................................... 10

Table 4.1: Household Savings Rates in Selected OECD Countries (per cent of household disposable income)

Table 8.1: Projected Population Distributions and Old-Age Dependency Ratios of Selected OECD Countries

Table 9.1: Superannuation Coverage by Industry and Sector............................................................224

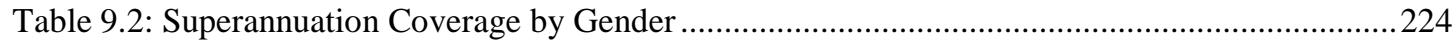

Table 11.1: 1988 Salary Distribution of AMP and National Mutual Superannuation Scheme Members

Table 11.2 Distribution of Superannuation Tax Benefits Received from the Superannuation Contribution Personal Exemption.

\section{List of Figures}

Figure 1.1: Key Changes to Retirement Savings Policy 1972 - 2007....................................................

Figure 1.2: Projected Demographic Changes .......................................................................................

Figure 12.1: Net Tax Cost Per Unit of Contribution to a Retirement Savings Plan ..............................303

Figure 12.2: Effective Tax Rates on Private Pension and Benchmark Saving .......................................303 


\begin{abstract}
The thesis makes two primary contributions. The first is in the provision of a comprehensive historical account of the events, personalities and environment that formed the policy for the taxation of retirement savings in New Zealand and Australia. This historical account is analysed through institutional frameworks to explain the antecedents that have resulted in the retirement savings taxation policy outcomes that exist in the two countries at the present time. The second key objective of the research, in using institutional theory to assist with the first objective, is to provide some insights into the utility of institutional theory, and historical institutionalism in particular, in this comparative case study.
\end{abstract}

The different retirement savings policies that were implemented in the mid to late 1980s in New Zealand and Australia have resulted in substantially different levels of retirement savings in each country. New Zealand's retirement savings figures and participation in occupational superannuation are among the lowest in the OECD. Conversely, Australia now has the fourth largest managed fund pool in the world, and the largest in Asia. Australian retirees can expect to have an income of $70-80$ per cent of their final retirement income, after 40 years of Superannuation Guarantee participation. Retiring New Zealanders, assuming National Superannuation continues unchallenged, will receive a minimum of $60-65$ per cent of the average wage. The difference in standard of living that these amounts will support is significant. Retiring Australians will be advantaged with some relationship between their pre-retirement and retirement income. This is a benefit many retiring New Zealanders will not receive.

The research findings indicate that the key independent variables highlighted in this research (the environment, institutions, power and ideas) contribute a contestable explanation to the policy directions adopted in each country. The thesis argues that the concept of ideas is the key dimension that shaped the retirement savings taxation policy in the 1982 to 1992 period in New Zealand and Australia.

The use of a coherent ideology facilitated the communication of a consistent world view in both countries, and provided a set of established ideas to support the direction 
adopted. This assisted with validation for trade-offs incurred in the policy process. The investigation of institutional factors highlighted the lack of potential for interest groups to make their voices heard. Conversely, the privileging of certain interest groups, those aligned with the prevailing ideas, was also prevalent. The institutions with the strongest influence on the policy process were those that, through historical events or historical opportunity, had preferences that were aligned with the state.

This case study indicates that historical institutionalism has less utility for the study of a more detailed component of policy, rather than broader structural policy reform, as typically used in other studies. Thus, it is suggested that the utility of historical institutionalism may be reflected by the level of detail both undertaken in the research and desired from the research output. The indication that historical institutionalism may have greater utility for larger case study analyses may have application for future research. 


\section{List of Acronyms}

This section expands some of the acronyms used in the thesis.

ACOSS: Australian Council of Social Services

ACTU: $\quad$ Australian Council of Trade Unions

ALP: $\quad$ Australian Labor Party

BCA: $\quad$ Business Council of Australia

CAI: Confederation of Australian Industry

CTU: $\quad$ New Zealand Council of Trade Unions

ETP: $\quad$ Eligible Termination Payment

LP: $\quad$ Australian Liberal Party

NZBR: $\quad$ New Zealand Business Roundtable

NZSS: $\quad$ New Zealand Superannuation Scheme

OECD: Organisation for Economic Co-operation and Development

PRG: $\quad$ Periodic Report Group

RBL: $\quad$ Reasonable Benefit Limit

SGC: $\quad$ Superannuation Guarantee Charge

SGL: $\quad$ Superannuation Guarantee Levy

SPWG: $\quad$ Savings Product Working Group

SSCWT: $\quad$ Specified Superannuation Contribution Withholding Tax 


\section{Acknowledgements}

I was told at the outset of this thesis that a $\mathrm{PhD}$ is a lonely road. Having reached the end of this road, this is a sentiment I would not challenge. However, while the thesis is my own creation, there are numerous people without whom the journey would not either have been completed or have been the rewarding experience that it became. Firstly, for reasons too many to enumerate, I owe an enormous debt of gratitude to my two supervisors; Professor Kevin Holmes and Associate Professor David White. Their expertise, support and commitment over the past three years was both humbling and inspirational.

I have benefited from generous grants and scholarship funding from Victoria University of Wellington, Education New Zealand, the New Zealand Institute of Chartered Accountants and the Social Policy Evaluation and Research unit of the Ministry of Social Development. Without these grants and scholarships the research would not have been possible. In addition, I am grateful to the Law School at Australian National University for supporting me during my time researching in Australia.

I am especially appreciative of the individuals that participated in interviews for the research. As these people were assured of anonymity for their contributions, they cannot be named and perhaps more appropriate acknowledged. However they were, without exception, extremely generous with their time and information and provided a depth to this thesis that would otherwise not have been achieved.

I am indebted to the academics who provided the opportunity to discuss my research at conferences, $\mathrm{PhD}$ colloquiums and many other venues. They are too numerous to mention, but their wide range of input was influential and the direction of the thesis reflects many of their comments and suggestions. In particular, I am thankful for the valuable and detailed comments received from three $\mathrm{PhD}$ examiners. 
Finally, my heartfelt gratitude to my colleagues at the School of Accounting and Commercial Law, Victoria University of Wellington, who provided ongoing support. Again, they are too numerous to individually acknowledge, but their faith in my ability to complete this thesis provided the ongoing motivation necessary throughout much of the process. 


\section{Chapter 1: Introduction}

Carmichael and Plowman suggest that there are few areas of public policy that impact more directly on individual lifetime welfare than those related to retirement income (1985:130). The topic of retirement income and, as a consequence, retirement saving poses a challenge to governments throughout the OECD. The issue is complex and multi-faceted with countries facing ageing populations and concomitant societal pressures such as housing, health and financial support.

New Zealand and Australia have adopted different approaches to retirement saving and its associated taxation. Two primary differences exist: New Zealand offers little in the way of incentives for retirement savings and there is no compulsion for retirement savings, ${ }^{1}$ while Australia provides highly concessionary tax incentives and a mandatory occupational retirement savings scheme exists.

The thesis investigates the taxation of retirement savings in New Zealand and Australia over the 35-year period from 1972 to 2007. The primary objective is to explain the antecedents that have resulted in the different policy outcomes that exist in the two countries at the present time. A historical perspective is adopted, with an institutional based theoretical framework used for analytical purposes.

This chapter provides an introduction to the topic of retirement savings, and the tax treatment thereof, in New Zealand and Australia. Policy objectives behind retirement savings and taxation are discussed, and the research problem and methodology are briefly outlined. The section concludes with justification of the research topic and an outline of the thesis.

\subsection{Background}

Among other terminology, New Zealand's retirement income policy has been labelled a 'political football' and a 'bold experiment'. The suitability of such terminology can

\footnotetext{
A small tax incentive was introduced in July 2007 with the introduction of KiwiSaver accounts. While the KiwiSaver scheme is optional, individuals must 'opt-out' when changing employment if they do not wish to participate. The KiwiSaver scheme is discussed in more detail in chapter six.
} 
be seen when reviewing just a small proportion of the changes in retirement savings policy in New Zealand since 1970. These changes include introduction of a compulsory saving scheme, removal of the compulsory saving scheme, increases in the levels of superannuation payments, reductions in the levels of superannuation payments, introduction of a surcharge, removal of the surcharge, introduction of a pre-funding scheme, removal of all tax incentives for retirement savings and reintroduction of a small tax incentive. ${ }^{2}$ Superannuation has been called the most contentious political issue in the history of New Zealand welfare' (Palmer 1977:9) and it could be argued that 30 years later this claim remains valid.

In common with New Zealand, Australia has also made a number of changes to its retirement savings policy. These changes include the introduction and removal of surcharges for higher income earners, the removal and re-introduction of means testing, the introduction of a mandatory occupational retirement savings scheme and numerous changes to the tax treatment of retirement savings. The retirement provisions in Australia, particularly in relation to taxation, have historically been complex, although recent amendments to retirement savings policy in 2006/2007 have made attempts to reduce this complexity. ${ }^{3}$ Perhaps the changes in both countries in relation to the two key elements of compulsion and incentives are best illustrated diagrammatically as outlined in Figure 1.1.

Following a long period of similar approaches to retirement savings, New Zealand and Australian policy diverged in the mid-1980s. ${ }^{4}$ New Zealand has rejected the widely used World Bank three-tier model for retirement savings. The three tiers are state provision, compulsory occupational schemes and private voluntary savings (World Bank 1994:15). All OECD countries have developed first-tier schemes,

2 These changes are discussed in greater detail in chapter six.

3 For example, Wills and Ross (2002:12) claim that in 1999 there were 786 changes in legislation and regulations affecting superannuation.

4 A survey of 134 countries in 1979 (by the US Department of Health and Human Services, Social Security Programs throughout the World 1979), found only four countries in the world did not use a contributory or social insurance method of financing their old age programs; two of these were New Zealand and Australia (Forward 1983:2). 
although these are of different types, including social assistance, separate targeted retirement income programmes, basic pension schemes and minimum pensions within earnings related plans. ${ }^{5}$ All OECD countries, with the exception of New Zealand and Ireland, also have contributory state schemes and extensive state involvement in private superannuation arrangements.

Figure 1.1: Key Changes to Retirement Savings Policy 1972 - 2007

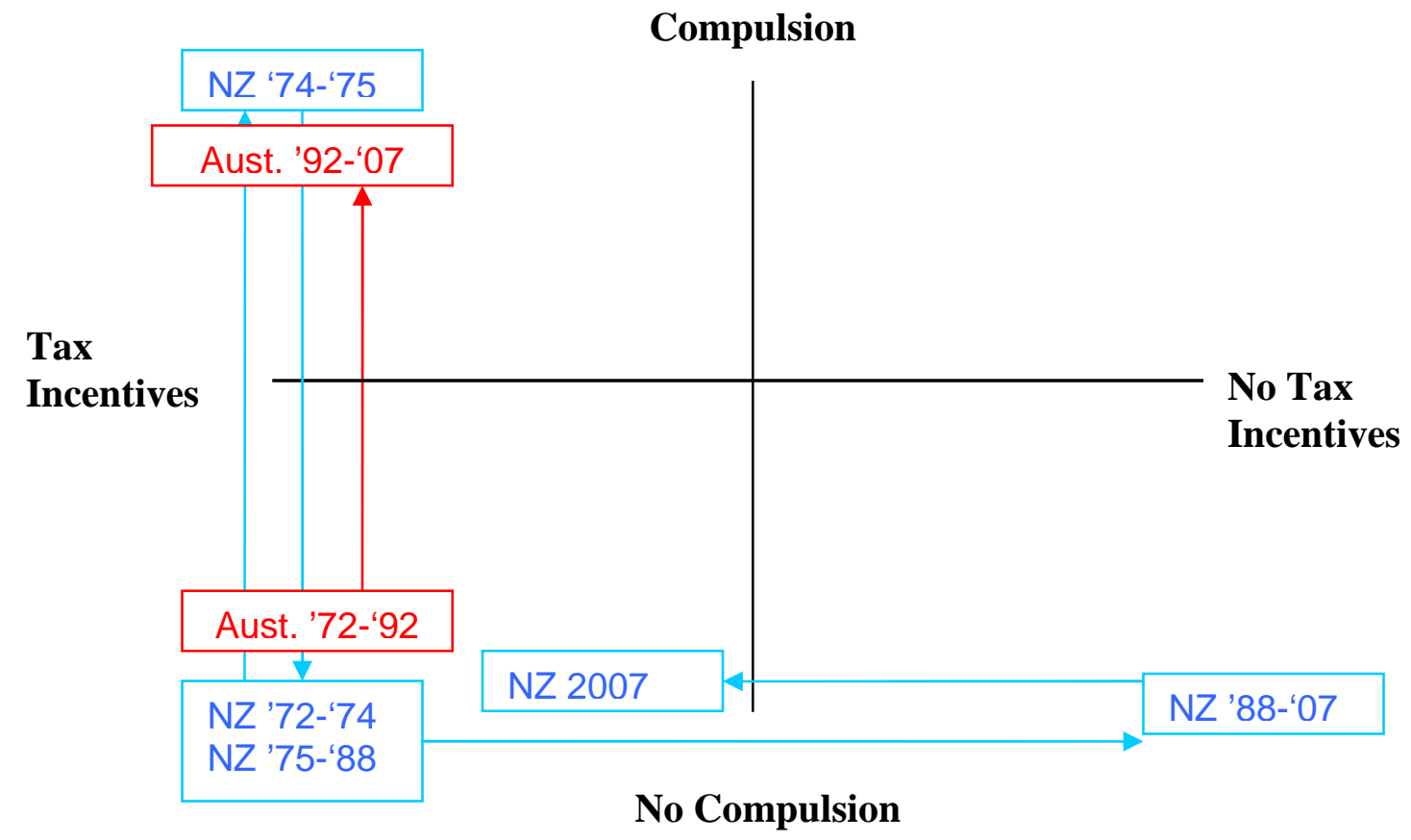

New Zealand's approach towards retirement savings and its taxation is highly unusual among OECD countries. New Zealand operates a two-tier system: a basic state pension paid from general revenue and voluntary private savings. There are no compulsory saving schemes or broad tax incentives within the New Zealand system.

The Australian pension system has three tiers, with two tiers of state involvement. The first tier is a means tested pension. The second tier is the Superannuation Guarantee Levy (hereafter referred to as the Superannuation Guarantee), which requires employers to provide superannuation cover for workers who have earnings above a specific threshold. Among OECD countries, Australia has the largest For further detail on these schemes refer OECD (2005:22). 
mandatory defined contribution scheme, where employers pay nine per cent of their employees' earnings into a pension account. ${ }^{6}$ In addition voluntary private savings schemes exist.

\subsubsection{Taxation of retirement savings}

From a taxation perspective, most income tax systems in OECD countries give preferential treatment to pensions. Such preferential treatment may take the form of tax relief on a portion of, or all, pension income received, or the taxation system may privilege those receiving pensions in the form of additional allowances or zero-rate personal income tax bands. In addition, tax concessions generally exist to encourage individuals to save for their retirement.

The levels of taxation applied at various stages distinguish different taxation arrangements. Typically these are referred to in the order of contributions, investment earnings and withdrawals; $T$ refers to fully taxed; $E$ is tax exempt; and $t$ refers to concessionary taxation. The system of taxation in New Zealand for retirement income savings is known as 'TTE' referring to taxed contributions, taxed investment income and exempt benefits. ${ }^{7}$ This scheme, introduced in 1988, provides no preferential tax treatment for retirement savings. No other OECD country has opted for this system. The focus of the New Zealand TTE regime is tax neutrality, meaning that superannuation savings are treated from a tax perspective in the same manner as other forms of savings.

The Australian model is ' $\mathrm{ttE}$ ' as contributions and investment earnings are taxed, but at preferential rates to other forms of savings. Withdrawals from taxed funds by individuals aged over 60 years are tax exempt. These arrangements were

6 Exemptions exist for some employees such as those with low earnings, or those under the age of 18 and working less than 30 hours a week. A government co-contribution scheme directly targeting lower-income earners was introduced in July 2004, which provides a subsidy of $\mathrm{A} \$ 1.50$ for every $\mathrm{A} \$ 1.00$ invested in a superannuation fund by those earning below $\mathrm{A} \$ 28,000$.

7 A small tax incentive was introduced in April 2008 in conjunction with the KiwiSaver scheme. More details on this are outlined in chapter six. 
implemented in July 2007. Table 1.1 outlines the tax treatment of retirement savings among OECD countries. The table indicates that an EET approach is the most common system among OECD countries. New Zealand and Australia both stand out as outliers in their approach to the taxation of retirement savings.

Table 1.1: Tax Treatment of Private Pensions in Selected OECD Countries ${ }^{8}$

\begin{tabular}{|c|c|c|c|c|}
\hline \multicolumn{2}{|c|}{ EET } & ETT & \multicolumn{2}{|c|}{ TTE } \\
\hline $\mathrm{EEt}$ & EET & & TTE & $\mathrm{ttE}$ \\
\hline Belgium & Austria & Denmark & New Zealand & Australia \\
\hline France & Canada & Italy & & \\
\hline Germany & Finland & Sweden & & \\
\hline Ireland & Greece & & & \\
\hline Japan & Iceland & & & \\
\hline Korea & Netherlands & & & \\
\hline Mexico & Norway & & & \\
\hline Portugal & Poland & & & \\
\hline Slovak Republic & Switzerland & & & \\
\hline Spain & United States & & & \\
\hline Turkey & & & & \\
\hline United Kingdom & & & & \\
\hline
\end{tabular}

While the historical component of this research covers the 35-year period from 1972 to 2007 , it necessarily concentrates on periods where fundamental changes occurred or decisions were made; for example, the current tax treatment of retirement income savings in both countries is largely reflective of changes made in the periods from 1982 to 1983,1987 to 1988 and 1991 to 1992 . Thus the decade between 1982 and 1992 forms the primary focus of analysis in the thesis.

\subsubsection{Policy objectives}

Superannuation schemes typically have two main objectives: prevention of hardship in old age and helping workers maintain living standards during retirement by

$8 \quad$ Adapted from Yoo and de Serres (2004) and OECD (2007). 
replacing income from work at an adequate level (OECD 2005:16). Most countries pursue both these goals in their superannuation policy.

Australian retirement policy encompasses both these objectives. The aims are typically outlined as firstly ensuring that all Australians have an adequate and secure income in retirement and secondly encouraging those in the workforce to save for their retirement to have a higher standard of living than that which would be achieved on the state provided age pension alone. The objectives of retirement income policy in Australia are not often challenged as they are generally supported by most interest groups. The second objective, while having moved away from 'income maintenance', continues to emphasise the importance of ensuring an adequate standard of living in retirement.

Various New Zealand Treasury documents ${ }^{9}$ have outlined the policy objective for retirement savings in New Zealand as encouraging increased private sector provision for retirement and assisting workers to have a better standard of living in retirement. In other documents the government is quoted as being 'intent on promoting retirement savings amongst employees' ${ }^{10}$ However, it appears from the policy tools adopted since 1988 (the absence of tax incentives together with a universal pension) that the primary objective pursued in New Zealand is that of poverty alleviation.

Taxation is a critical area in politics. As observed by many researchers it determines who gets what, and how this is funded. Taxation policy has the potential to affect economic growth, business cycles, the proportion of private wealth and income received by individuals, and the distribution of collective costs and benefits (Hansen 1983:3). Furthermore, tax policies are a key mechanism of funding social policy objectives, as well as macroeconomic and microeconomic goals. While the objectives of taxation policy are primarily to raise and distribute revenue, beyond this point they are not absolute. However, it is generally agreed that the elements of economic and

\footnotetext{
$9 \quad$ For example, Scobie, Gibson and Le (2004).

10 Media statement 5 November 2003 from the Prime Minister and the Minister of State Services, announcing a new retirement savings scheme for public sector employees.
} 
administrative efficiency together with equity are included. Further objectives may include stability, sustainability or neutrality.

\subsection{Research Problem}

With forecast ageing populations, the issue of retirement income policy has been pushed to the forefront of many OECD countries' agendas over the last two decades. Along with all OECD countries, New Zealand and Australia are faced with ageing populations projected to peak around the middle of the $21^{\text {st }}$ century. However, as the population ages, it is not forecast to replace itself at the same rate; accordingly, numbers in the traditional working age group will decrease. Figure 1.2 outlines demographic projections for Australia; New Zealand figures are almost identical. This indicates that populations aged over 65 are forecast to almost double by the middle of the century.

\section{Figure 1.2: Projected Demographic Changes}
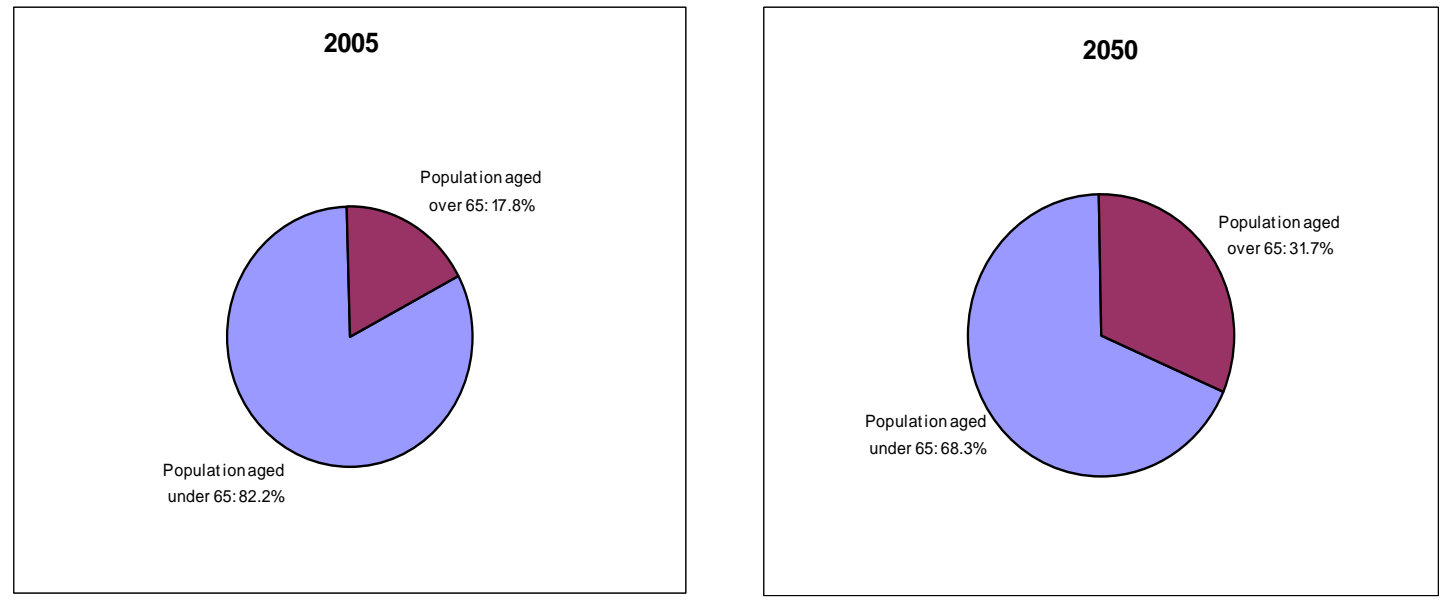

The different approaches to retirement savings and its taxation in New Zealand and Australia result in significantly different levels of state provided minimum retirement benefits and levels of savings accumulated through superannuation vehicles in the two countries. $^{11}$ New Zealanders are lagging behind their Australian counterparts in a

11 The average minimum retirement benefit across OECD countries is 29 per cent of average earnings (OECD 2005:28). The New Zealand benefit is 38 per cent of average earnings, while the Australian benefit is 23 per cent (OECD 2005:28). 
number of measures of saving statistics, including superannuation. Moreover, the difference in levels of savings through traditional superannuation funds is becoming more pronounced with time.

Savings in managed superannuation funds in Australia were A \$1.3 trillion in 2007 while such savings in New Zealand was A $\$ 22$ billion (NZ\$25 billion). ${ }^{12}$ Taking into account that the Australian economy is approximately five times larger than that of New Zealand, the figures still reflect over ten times the total savings in Australian superannuation funds compared with New Zealand. Contributions to superannuation funds show a similar picture, with contributions of over A $\$ 100$ billion in Australia and $\mathrm{A} \$ 2$ billion in New Zealand in 2006-07. ${ }^{13}$

In 2007 over 90 per cent of the Australian workforce was covered in superannuation schemes. In New Zealand the equivalent was 13.4 per cent of private and public sector employees with employer supported occupational superannuation schemes. ${ }^{14}$ The New Zealand figures are likely to reflect, among other factors, the generous state provision of superannuation, the absence of taxation incentives to save for retirement and the lack of compulsion for retirement savings.

There is little to indicate that New Zealanders save through other vehicles instead of traditional superannuation funds. ${ }^{15}$ Research from Statistics New Zealand (2001) shows that superannuation funds in New Zealand rank as the sixth equal form of wealth (with bank accounts), measured as a proportion of total asset value held. In New Zealand 21 per cent of the population held superannuation assets with an

12 New Zealand Government Actuary (2007) and Rice Warner Actuaries, Media Release, November 2007, www.ricewarner.com, viewed December 2007.

$13 \quad$ Ibid.

14 New Zealand Government Actuary (2007). It is acknowledged that this figure has significantly increased with the introduction of KiwiSaver accounts in 2007. KiwiSaver is discussed later in the thesis.

15 For example, in 2003-04 13.2 per cent of Australian household assets were invested in property other than an owner occupied house (Australian Bureau of Statistics 2006a:153). In New Zealand eight per cent of asset values were made up of property investments other than an owner occupied house (Statistics New Zealand 2001:60). 
average value of NZ\$25,000 (Statistics New Zealand 2001:60). In Australia superannuation is the second primary source of wealth, following investment in an owner-occupied house. Almost all personal saving in Australia is directed either through superannuation or into owner occupied housing (Bateman and Piggott 1997:24). ${ }^{16}$ Superannuation funds were the largest financial asset held by households, with an average household value of A\$87,000 in 2003-2004 (Australian Bureau of Statistics 2006a:152). In addition, in Australia superannuation assets were the largest source of wealth for the lowest income earners (Statistics New Zealand, 2001:116).

When considering retirement income savings as a proportion of overall wealth, New Zealanders lag behind their counterparts in Canada, the United States and Australia. Data from the Household Savings Survey (Statistics New Zealand 2001:115) shows that superannuation assets in New Zealand make up six per cent of the total value of all assets. In Canada the equivalent level is 15 per cent, in the United States it is 11 per cent, and in Australia 22 per cent of all assets are in the form of superannuation savings. The low proportion of assets that New Zealanders have chosen to invest in retirement schemes is likely to reflect the different approach to retirement savings policy adopted.

Table 1.2 provides the gross replacement rates of earnings at three different earnings levels among OECD countries (half, average and double average earnings). Calculations assume a single person working for a lifetime and are based on 2002 values of pensions. The OCED average at each point (half, average and double earnings) is 72.5 per cent, 56.9 per cent and 47.6 per cent respectively. New Zealand has gross replacement rates of 75.1 per cent, 37.6 per cent and 18.8 per cent, respectively. Australia has gross replacement rates of 65.1 per cent, 40 per cent and 26.2 per cent, respectively. While both countries are below the OECD average, New Zealand is particularly low, ranking at $4^{\text {th }}$ lowest for average earnings and $2^{\text {nd }}$ lowest for double average earnings. This measure may be used as an indicator of the extent

16 Property is favoured over other forms of saving as income flows are likely to be more regular and because capital gains are indexed for tax purposes, making bonds less attractive in Australia (Bateman and Piggott 1997:24). In addition, investment assets held prior to 1987 remain free of capital gains tax. 
to which the current system is likely to maintain standards of living into retirement. For middle- and higher-income earners in New Zealand it is apparent that the existing arrangements will not preserve living standards in retirement. While Australia is also below the OECD average at all earnings levels, this is forecast to improve with longterm participation in the Superannuation Guarantee.

Table 1.2: Gross Replacement Rates by Earnings Level ${ }^{17}$

\begin{tabular}{|l|l|l|l|}
\multicolumn{2}{|c}{$\begin{array}{c}\text { 0.5 x Average } \\
\text { Earnings }\end{array}$} & \multicolumn{1}{c}{ Earnings } & \multicolumn{2}{c|}{ Earnings } \\
\hline Australia & $\mathbf{6 5 . 1}$ & $\mathbf{4 0 . 0}$ & $\mathbf{2 6 . 2}$ \\
\hline Austria & 78.3 & 78.3 & 64.3 \\
\hline Belgium & 61.6 & 40.7 & 26.2 \\
\hline Canada & 72.4 & 42.5 & 21.3 \\
\hline Czech Republic & 70.5 & 44.4 & 25.4 \\
\hline Denmark & 82.4 & 43.3 & 23.8 \\
\hline Finland & 80.0 & 71.5 & 71.5 \\
\hline France & 84.2 & 52.9 & 47.4 \\
\hline Germany & 47.3 & 45.8 & 37.6 \\
\hline Greece & 84.0 & 84.0 & 84.0 \\
\hline Hungary & 75.4 & 75.4 & 75.4 \\
\hline Iceland & 85.5 & 52.8 & 41.3 \\
\hline Ireland & 61.3 & 30.6 & 15.3 \\
\hline Italy & 78.8 & 78.8 & 78.8 \\
\hline Japan & 69.2 & 50.3 & 36.9 \\
\hline Korea & 60.9 & 40.6 & 29.3 \\
\hline Luxembourg & 115.5 & 101.9 & 95.2 \\
\hline Mexico & 39.1 & 36.0 & 34.4 \\
\hline Netherlands & 68.7 & 68.3 & 68.3 \\
\hline New Zealand & $\mathbf{7 5 . 1}$ & $\mathbf{3 7 . 6}$ & $\mathbf{1 8 . 8}$ \\
\hline Norway & 65.3 & 52.6 & 38.4 \\
\hline Poland & 56.9 & 56.9 & 56.9 \\
\hline Portugal & 103.1 & 66.7 & 65.5 \\
\hline Slovak Republic & 48.6 & 48.6 & 48.6 \\
\hline Spain & 81.2 & 81.2 & 76.7 \\
\hline Sweden & 87.8 & 64.8 & 66.2 \\
\hline Switzerland & 62.8 & 58.2 & 33.1 \\
\hline Turkey & 96.2 & 37.2 & 71.9 \\
\hline United Kingdom & 67.4 & 38.6 & 22.5 \\
\hline United States & 49.6 & $\mathbf{5 6 . 9}$ & 28.1 \\
\hline OECD average & $\mathbf{7 2 . 5}$ & $\mathbf{4 7 . 6}$ \\
\hline & & & \\
\hline
\end{tabular}

17 Source: Whiteford and Whitehouse (2006:87). Figures are based on compulsory pension programmes for men as a percentage of pre-retirement earnings. 
Given this background, the primary research questions addressed in this thesis are:

- How and why did the New Zealand and Australian governments adopt different solutions to the common issue of the taxation of retirement savings?

- How well do institutional frameworks explain the different approaches to the taxation of retirement savings adopted in New Zealand and Australia?

- To what extent did the New Zealand and Australian governments enact taxation policy that privileged some groups above others?

- How have institutional structures combined with other factors to influence the formation of taxation policy and broader retirement income policy?

As a natural corollary of the research, a number of additional insights are gained. These include an explanation of the antecedents of current policy in order to gain an understanding of the political, social and historical context in which current policy emerged. In addition, the research permits some tentative suggestions to be made on the likely future of retirement savings policy in each country.

\subsection{Methodology}

This thesis investigates the taxation of retirement income savings in New Zealand and Australia, following a historical comparative approach. A comparative approach is adopted to assess the validity of interpretations of specific or unique political phenomena (Hopkin 2002:252). It is likely that there are a number of explanations for the different approaches adopted by New Zealand and Australia. Assessing these potential explanations requires the theoretical underpinnings of each option to be analysed and tested comparatively. In addition, the comparative case study approach provides a richness of detail that is unlikely to be gained through a single case study.

The historical approach is used to highlight previous influences on current policy. Eccleston (2004:26) claims that almost every aspect of the policy process is influenced by past policy decisions:

The power and interests of key actors are shaped by political, cultural and economic legacies, while the institutions and practices that influence political decision making are themselves the product of historical events. This has led many policy analysts to argue that one must look to the past in order to understand the future. 
Accordingly, it is necessary to consider economic and social factors, historical events and political influence during the time period investigated, in order to verify the institutional environment that has formed the current tax policy for retirement savings. The comparative approach allows examination of the influence of economic, social and political environments where policy approaches are different.

An institutional theoretical framework is used in the thesis. The institutional framework is used to study political and social institutions in New Zealand and Australia, and to assess the influence of institutional factors on policy formation in relation to the taxation of retirement savings. The adoption of institutional frameworks facilitates analysis of how the state, interest groups and individuals, impact on the tax policy area, and the degree to which policy outputs reflect the preferences and influence of such groups. A more detailed discussion on the methodology can be found in chapter two.

\subsection{Research Justification}

Recent years have seen a wave of pension reforms across OECD countries motivated by concerns about the financial sustainability of pension systems with forecast ageing populations (OECD 2005:16). There is disagreement among commentators as to whether the populations in New Zealand and Australia are saving sufficient amounts to enjoy the standard of living they desire upon retirement. However, there is general agreement that the household saving rate in New Zealand is low, with a current declining tendency (e.g. IMF 2003; Thorp and Ung 2000), but the question of whether it is 'too low' is frequently debated.

Analysis undertaken by the IMF of savings estimates suggests there are not significant impediments or distortions in New Zealand that would give rise to a saving problem unless households were mistaken in their expectations that future pension costs would be met by the government without major increases in taxes or reductions in benefits (IMF 2003:17). Conversely, Australian research (e.g. Wills and Ross 2002:12) has found that people in Australia are not saving enough to have the standard of living 
that they expect in retirement, and savings for retirement need to be increased beyond the mandated nine per cent levels currently in place.

There are a number of factors leading to the concern about savings rates. Insufficient levels of domestic savings can restrict investment, which then leads to reduced capital accumulation (Claus and Scobie 2002:1). Low levels of domestic savings are likely to lead to increased use of foreign savings, which will increase the current account deficit. New Zealand and Australia consistently run current account deficits, indicating that national savings is insufficient to fully fund new investment (Australian Bureau of Statistics 2003; Goh 2005). In the absence of greater national savings the future investment needs of each country will continue to require foreign capital. This reliance on foreign capital markets has the potential to increase the sensitivity of the New Zealand and Australian economies to changes in global or domestic economic circumstances. Perhaps the most obvious area of concern is that inadequate levels of saving may impact on increased state reliance in areas such as health and retirement. While there is some debate as to the sufficiency of retirement savings in New Zealand and Australia, there is no disagreement over the importance of the policy issues of retirement income savings and its taxation.

This thesis does not attempt to analyse the sufficiency of retirement income savings in New Zealand or Australia. Instead the thesis highlights the antecedents to the current policy approaches, focusing on the tax policy rationale behind the directions taken in the two countries and assessing the intent behind the policies adopted. The OECD (2005:16) claims that the complex structures and rules associated with pension systems make comparison of retirement income regimes difficult. However, the OECD also suggests that sharing the experience of pension reform and its impact provides valuable information to policy makers. In addressing this topic, the thesis provides an outline of the debates that have occurred on the topic of tax policy and retirement savings. In addition it provides some tentative explanations for the outcomes that arose from the time period investigated. 
In order to fully understand the current issues, and how these may be addressed, it is essential to explore the historical events that have formed the present. The complexity of the situation explored, combined with the changing characteristics of the institutions investigated facilitate a historical and qualitative approach. To place appropriate emphasis and factual interpretation on the meanings and interactions of institutional players it is necessary to form a picture of the qualitative features of the environment. This facilitates awareness of the full range of causal factors that led to the current outcomes. In adopting a comparative research design there is a desire to 'make sense' of the situations in New Zealand and Australia, and to highlight the contribution of institutional variables in producing policy outcomes.

\subsection{Thesis Structure}

The thesis commences in chapter two with a discussion of the methodology used. Chapter three provides a detailed examination of the properties, strengths and weaknesses of the theoretical framework adopted in the thesis. The literature review is outlined in chapter four, commencing with a discussion of the theoretical framework that guides the thesis, followed by a synopsis of historical research that has been undertaken on taxation in New Zealand and Australia, as well as relevant research on the topic of retirement income savings. In addition, the broad objectives of taxation, the evolution of the tax policy for retirement savings and the issues that emerged in New Zealand and Australia are discussed.

Chapters five, six and seven provide the context for the analysis that follows. Chapter five outlines the institutional arrangements in each country. Chapters six and seven present a chronological summary of the significant changes to the taxation of retirement savings within the context of broader retirement savings policy in New Zealand and Australia, respectively.

Chapters eight through to eleven analyse the data collected and concentrate on explaining the antecedents of the policy decisions, drawing conclusions from the data. The chapters are structured to represent the four key explanatory variables that have emerged from the data: the environment, institutions, power and ideas. The final chapter, chapter twelve, outlines the lessons learned from the research. 


\subsection{Summary}

The thesis has two primary objectives. Firstly, it provides a historical account of the development of the tax treatment of retirement savings in New Zealand and Australia over the period from 1972 to 2007 . The historical analysis includes an explanation of both how and why New Zealand and Australia came to different policy solutions to a common policy 'problem'.

An institutional theoretical framework is used in the thesis. The institutional framework is used to study the structure and operation of political, economic and social institutions in New Zealand and Australia and to evaluate the influence of institutional factors, within broader environmental factors, on policy formation in relation to the taxation of retirement savings in the two countries. The use of institutional frameworks leads to the second aim of the thesis, which is, through the use of institutional theory in the analysis, to provide an account of the utility of historical institutionalism in this case study. 


\section{Chapter 2: Methodology}

\subsection{Introduction}

The methodology adopted to investigate the different tax treatments of retirement savings in New Zealand and Australia is a historical comparative case study. An institutional theoretical framework is used for analytical purposes. The methodology is augmented and strengthened by reference to a range of disciplines, such as public policy, history and political science, where required. Reference to a broad range of disciplines is intended to provide greater insight into the topic and increase the validity of the approach used. The inter-disciplinary approach adopted in the thesis is necessitated both from the multi-disciplinary nature of the topic under investigation and from the intended contribution to the policy debate, which is the aim of the research.

Data was collected from both primary and secondary sources. Primary sources included archival records, submissions to government committees and media reports. Secondary sources included academic and practitioner commentary on the policy changes over the time period investigated, government documents and interest group publications. An important primary source of data came from the use of semistructured interviews. Forty-seven interviews were undertaken in total in both countries with individual actors who played influential roles in the policy formation process in the 1982 to 1992 period. Not all interviews are used in the written analysis, but they have all been useful in providing insights into the environment and clarifying historical details in written documents.

The chapter commences with a discussion of historical research, including the benefits and potential limitations of this research approach. Further methodological dimensions of the research are also outlined, including the advantages and disadvantages of comparative research, together with the issue of culture when undertaking comparative work. The research design and the research method are reviewed and the chapter concludes with an outline of the contribution the thesis provides. 
It is often argued that comparative study is potentially the most important of all (e.g. Nobes and Parker 2002:8). This claim results from the ability of a country to improve its own processes by observing how other countries have responded to similar problems. New Zealand and Australia are well placed for comparative study. They are both successful southern-hemisphere Commonwealth countries with similar demographic profiles, social policy objectives and British colonial heritage. Both countries have parliamentary governments, small populations and relative ethnic homogeneity. Furthermore, the two countries have close trade relationships and considerable trans-Tasman exchanges of populations; both of which are assisted by geographical proximity.

It is never possible to undertake comparative macro-level research in identical settings, but with similar economic, social and legal systems New Zealand and Australia are believed to be as suitable as any other possible pairing for comparative purposes. ${ }^{18}$ McLean (2003:14) claims that 'these two have more in common with one another than either has with any other country on the planet ... they are probably simply more alike than any other two separate nations'. In addition, McLean (2003:15) suggests that:

There are strong personal and social affinities between the two peoples and close links by modern transport; both are liberal, moderate democracies, fortunate and successful states with a far-reaching network of co-operation between them; there are no divisive legacies of bitterness or wars: there is nothing of a racial, religious, ethical or linguistic character to provide any pretext for apart-ness.

\subsection{Historical Research}

The thesis contains elements of political, economic and social history: political history in relation to the tax policies introduced by the New Zealand and Australian governments, economic history to investigate the background from within which policies are structured and social history to contextualise the issue of retirement savings.

18 Studies (e.g. Peetz 1998) have successfully compared Australia and New Zealand. Peetz (1998:157) argues that there is only one country that is suitable for comparison with Australia and that is New Zealand. 
A number of perspectives and definitions of historical research exist. Jenkins (1991:6) claims history is a series of discourses about the world, which do not create the world; instead they give meaning to it. Carr (1961:81) posits that 'the study of history is a study of causes'. Other researchers suggest that history is enquiry of the past (Jenkins 1991:6) or that history is the study of the elusive concept called time (Lee 1990:3). To a greater or lesser extent, this thesis encompasses all these dimensions. The thesis takes the form of a narrative, examining the historical causes, constraints and influences over a 35-year period that have led to the current policy approach for retirement savings taxation in New Zealand and Australia.

As historical research focuses on the question of how events came to occur, it is the appropriate method by which to analyse the historical antecedents to current situations. Noted scholars have argued that past and present events are inexorably linked (e.g. Fleischman and Tyson 1997:93). Typically the study of history is credited with the ability to help us understand the past, provide an appreciation of how current practices are developed and help to put the practices into perspective (Goldberg 1974:410; Fleischman and Radcliffe 2003:19). The path dependency claims of institutional theory (discussed in chapter three) provide the frameworks from within which these claims of historic influence on future events are analysed.

The primary objectives of conducting historical research are the development of perspectives about current problems (Previts and Bricker 1994:626) and providing information to assist in explaining the present day situation (Avi-Yonah 2003:4). The focus of the thesis is on explaining the historical events that resulted in the current taxation of retirement savings in New Zealand and Australia, rather than producing widely generalisable research.

\subsubsection{Benefits of historical research}

While historical research is frequently justified solely on the basis that it attempts to understand the past for its own sake (e.g. Napier 1989:230), a variety of more constructive benefits are attached to the approach. One frequently cited benefit is the ability to search for discontinuities and perform sequential evaluation from the past to 
the present (Merino, 1998:606). This may lead to enhanced understanding of current practices.

Some historical researchers argue that evaluation of historical events enables identification of directions that may be taken in the future. Conversely, historical researchers also argue that the past is not an indicator of the future. While it is not argued that any element of Orwellian 'control' can be gained from historical analysis, an analysis of the past may provide a better understanding of the mistakes of the past, and perhaps provide insight into the present. Merino (1998:606) claims that historical analysis often enables a researcher to detect expected events that failed to occur. In turn, this may highlight any unintended consequences from an event (Merino and Mayper 1993:244), which may contribute to our understanding and add to the explanatory power of historical research.

Parker (1997:112) suggests a number of possible uses for historical studies. These include the potential to reveal parties, practices and outcomes previously ignored. Alternatively, historical research can challenge and potentially overturn beliefs or traditions, and offer some indicators of precedents and previous experiences that may impact on future policies. Furthermore, adopting a historical focus allows attention to be paid to events that may be significant, but are slow-moving. This may be particularly relevant when investigating policy development, which can evolve in an incremental manner. In the absence of a historical perspective the potential arises for significant elements to be omitted from the analysis.

The important role that history has to play in understanding taxation is observed by Avi-Yonah (2003:3), noting that the evolution of tax law has not been a linear progression. Avi-Yonah suggests that tax policy has tended to be more cyclical, with ideas trialled, abandoned and then frequently re-implemented. This is a pattern that can clearly be seen in the policy development for retirement savings taxation in New Zealand, although it is less prevalent in Australia. 


\subsubsection{Limitations of historical research}

Along with the benefits of historical research discussed above, a number of limitations have been suggested in relation to accounting research undertaken with a historical perspective, including the view that 'claims of objectivity are dysfunctional' (Merino 1998:604). Historical study inevitably involves 'relatives rather than absolutes; broad rather than narrow views; generalisations rather than specifics; and partial rather than total truths' (Lee 1990:4). One suggestion is that objectivity for the historian has a different meaning to that of the scientist or positivist (Parker, 1997:134), whereby it signifies an attempt to represent events as they really were. Parker's view of objectivity implies that researchers will attempt to isolate their philosophical paradigms, political views and social perspectives in order to produce a research output that is representative of history.

A further weakness, but one that is not specific to historical research, is that any perspective is 'always filtered through the lenses of language, gender, social class, race and ethnicity' (Denzin and Lincoln 2005:21). Accordingly, historical accounts will also have a certain subjectivity, which is suited to, and to some extent expected of, the account provided. Most researchers concur that there are no objective observations; rather observations are socially situated in the world of the observer and the observed. The most objective history will inevitably remain a selection undertaken by the researcher and interpreted with the particular beliefs of that researcher.

The need exists to select from the infinite supply of facts those that are most significant for the purpose. In addition, the facts selected for representation of events are subject to the prioritisation of the researcher. Furthermore, when conducting historical research the facts and explanations of facts will always be incomplete (Lee 1990:4). Potential issues include the quality of records kept, where information desired may be damaged, destroyed or mislaid, or may not have survived the passing of time (Fleischman and Tyson 2003:35).

The potential exists for belief transference in historical research (Fleischman and Tyson 2003:41; Merino and Mayper 1993:246). Belief transference occurs when a 
researcher attributes current concepts to prior periods, and can be problematic when a theoretical framework is used to explain an historical event. Accordingly, when selecting a theoretical framework the theoretical assumptions must reasonably reflect conditions in the particular time period or the theory will have limited explanatory power (Merino and Mayper 1993:245). The choice of institutional theory, and in particular historical institutionalism, to guide the analysis in the thesis is intended to ameliorate the potential for belief transference through the allowance made for historical contingency and timing within the institutional framework. Institutional theory and historical institutionalism are discussed in detail in chapter three of the thesis.

The primary limitation of conducting historical research is the subjective nature of the output. This subjectivity would appear to be inevitable, and is captured by Stanford (1986:27) who writes that 'the dilemma of historians is that they want to see the past "as it actually was" but can see it only through the medium of their own and other peoples ideas'. Most historians acknowledge that researcher awareness of the limitations of historical research may assist in ameliorating their influence on the research output. In addition the research design allows for triangulation of the data, which will increase the robustness of the analysis. Triangulation is discussed in greater detail in section 2.4 .7 of this chapter.

\subsection{Comparative Research}

The thesis adopts a historical comparative methodology to explore the antecedents to the current taxation treatment of retirement savings in New Zealand and Australia. The key concept of comparative research is the selection and analysis of similarities and differences of two or more phenomena, with the aim of providing an explanation of the similarities or differences found.

As it is not possible to conduct a precise experiment in the area of policy formation, and it is similarly not possible to find countries that are identical in all respects except for the one factor under investigation, the comparison of countries with similar political systems provides some contextual similarities from which to start interpretation. It is suggested that comparative studies work well when a small 
number of countries are compared over time and examines how countries differ in their response to common problems (Hague, Harrop and Breslin 1992:40).

Comparisons are used in this thesis to identify and clarify patterns that are unique, as well as common, in New Zealand and Australia. In addition, the comparative exercise using New Zealand and Australia highlights the reasons behind why New Zealand did not follow the direction of Australia and why Australia did not follow the path of New Zealand.

\subsubsection{Benefits of comparative research}

A number of the benefits attributed to comparative research are similar to those associated with historical research; for example, both comparative research and historical research are credited with allowing traditionally accepted explanations for events to be questioned and tested. In addition, comparative research and historical research both claim to highlight differences in national systems. Nonetheless a number of unique benefits are also apparent.

French historian Bloch (1967:52) claims that the most obvious benefit that may be gained from a comparison between facts drawn from different societies is to discern the mutual influences exercised by these groups. Many researchers argue that countries learn from one another, and accordingly one of the benefits of undertaking comparative research at a national level stems from societal learning from comparing different behaviours in similar or diverse contexts (e.g. Grew 1980; Zeff 1971). Hence, undertaking in-depth international comparative research provides some insights into the extent to which learning has transferred between New Zealand and Australia.

The risk of studying any practice in isolation of broader international developments is to ignore a range of different dimensions that may enrich the research output. This may be considered of growing relevance with increasing globalisation. However, Bloch was arguing over 50 years ago (1953:501) that the primary benefits from comparison of societies is identification of the influences that different societies exert on one another. Thus, rising inter-dependence between countries, and similar 
challenges faced by countries and not necessarily responded to in similar manners, indicates the potential value from researching developments between countries.

Parker (1971:29) writes of the potential to learn from observing how other countries have reacted to problems that, particularly in more developed nations, often do not differ widely. However, comparative international historical research does not seek only similarities. Bloch (1967:58) writes that the comparative method should involve interest in the perception of differences. The adoption of the comparative historical approach in the thesis is primarily linked to the differences seen in the extant taxation treatment of retirement savings in New Zealand and Australia and more specifically with the divergent approaches adopted as a result of policy development over the past twenty years, subsequent to the evolution of relatively similar policy prior to the mid1980s. The comparative analysis of the two countries benefits from the different perspectives each country brings and provides a greater opportunity for learning.

\subsubsection{Limitations of comparative research}

As with historical research, limitations exist in relation to comparative research. These include the view of Stanford (1994, cited in Carnegie and Napier 2002:633) that historians cannot know sufficient information about a specific historical event to allow meaningful comparison with another event, and accordingly cannot classify historical events with certainty. Similarities and differences found may be the result of different variables. While this possibility is acknowledged, the historical events addressed in this thesis may be categorised as those of 'recent history'. Individuals involved in the making of the history are available for interviews and consultative purposes, which assists in increasing the validity of the research.

Comparative analysis between countries significantly increases the variance to be explained (Teune 1978:47). Furthermore, it is difficult to test arguments rigorously across a complete population, given the significant information requirements of comparative historical research (Amenta 2003:103). While extending the research parameters to a cross-country approach undoubtedly increases the complexity of the topic, the perceived benefits from the approach are believed to outweigh the limitations. The potential for learning increases significantly through the inclusion of 
both New Zealand and Australia in the research. In addition, the topic is sufficiently narrow in scope to allow for meaningful comparison.

The question of the extent to which the level of country or nation provides a meaningful unit of analysis is raised by Mair (1996:324). The difficulties highlighted by Mair include the difficulty of establishing what is specific to the national environment in an increasingly international environment. Mair argues that it is difficult to isolate elements that remain within the control of one country. A further issue raised relates to the potential for countries to change over time, and accordingly cross-temporal variation may also exist. The use of a 35-year research period and consideration of a wide range of potentially influencing factors (social, political and economic) have been encompassed as part of the research method in order to address the issues raised by Mair. The potential for globalisation to influence policy formation is an important point and one that is explored in the interviews undertaken as part of the data collection process. ${ }^{19}$

Comparison is necessarily limited by the differences in political, economic and social structures in New Zealand and Australia. It is not possible to hold everything else constant while only the tax treatment of retirement savings is tested. As Skocpol (1979:39) stresses, comparative historical analysis is no substitute for theory. Comparative historical analysis can only be applied with the aid of theoretical concepts. Accordingly, historical institutionalism is used as a theoretical framework for analytical purposes in the thesis.

The recognised limitations of comparative and historical research, along with the research design method (discussed in greater detail in section 2.4) do not permit any strong claims to be made about the generalisability of the research. Nonetheless, comparative research provides greater generalisability than a single case study analysis. Thus, the aim of the thesis is to provide general explanations of events, which are feasible with the methodology adopted.

19 Interview respondents were asked about the extent to which international developments influenced policy development. 


\subsubsection{Culture}

Researchers have noted the importance of culture (together with political, economic and social influences) in shaping the context in which policy operates (e.g. Carnegie and Napier 2002; Eddie 1991; Fechner and Kilgore 1994; Gray 1988; Ricoeur 1965). Culture is a variable that can complicate comparative international research.

Culture has been defined in many ways, although typically it is considered as the 'collective programming of the mind which distinguishes the members of one group or society from those of another' (Hofstede 1984:82). Culture can be considered to reflect the way that people look at the world and their role in it.

The most frequent mode of political structure has been the nation-state, hence the emergence of the concept of national culture. The use of Australia and New Zealand as comparative cases corresponds to both the nation state definition and the country or state definition, as defined by territorial boundaries.

Bloch (1953:496) writes that two conditions must be fulfilled in order to have historical comparison: a certain similarity between observed phenomena, and a certain dissimilarity between the environments in which they occur. The claim of similarity between Australia and New Zealand stems from research undertaken by Hofstede $(1984)^{20}$ and Gray (1985, cited in Fechner and Kilgore 1994). These studies find New Zealand and Australia to have significant similarities in most of the variables investigated. Further research on tax policy development undertaken by Peters (1991) groups OECD countries into four 'clusters' based on politics, culture, economic and social structure parameters. This study placed New Zealand and Australia in the same group, with similar characteristics of tax policy.

20 Criticisms of Hofstede's approach, including the units of comparison, are acknowledged. For further discussion, see Baskerville (2003). Reference to Hofstede in the thesis reflects adequacy for comparison, rather than support for Hofstede's methodology. 


\subsection{Research Design}

The thesis uses the 'most similar systems' research design. This method is based on the idea that within similar 'systems' a number of theoretically significant differences will be found, and these differences can be used for explanatory purposes (Ragin, Berg-Schlosser and de Meur 1996:755). Most comparative studies take as their point of departure the known differences among countries (Przeworski and Teune 1970:31).

\subsubsection{Research method}

This thesis consists of qualitative research. Qualitative research is 'a situated activity that locates the observer in the world', consisting of interpretive practices that 'make the world visible' in their natural environment (Denzin and Lincoln 2005:3). In the thesis visibility is achieved through primary source representations, including archival records and interviews.

The potential for a cross-country comparison to produce complex relationships which may limit the discovery of meaningful causal relations is acknowledged. The difficulty lies in isolation of a factor, or a number of factors, that appear to produce (or are strongly associated with) changes in the dependent variable (Peters 1998:29). In this case the dependent variable is the different tax treatment of retirement savings in New Zealand and Australia. Accordingly, a primary concern of this research design is to exclude, to the extent possible, the confounding factors in the relationship between variables in the taxation treatment of retirement savings. Peters (1998:29) claims that this may be alleviated through the use of theory to identify the most likely source of confounding variance. Thus, adoption of a historical institutionalism theoretical framework is intended to mitigate, as much as possible, the potential for confounding variables by providing a framework for analysis.

\subsubsection{Narrative method}

A narrative approach is adopted in this thesis. The narrative approach is the traditional method of historians (Funnell 1998:146). Typically a narrative approach identifies a person, idea or event and traces this concept over a number of years. Narrative enquiry establishes or describes items of fact, with the aim of conveying 
understanding of the various intents or beliefs that reflect the 'reality' to those involved in the event. It is claimed that narrative has been accepted as the unavoidable, natural means to write history (Funnell 1998:142). However, there are differing views about the merits of narrative enquiry; for example, Lister (1983:50) writes that the account of an event must be suggestive, and must point toward generalisation, if it is to be more than trivial. Accordingly, while not suggesting the possibility of generalisation due to the complex interactions that are observed in the case study, the thesis provides more than a simple chronological ordering of past events.

As with historical research, the key criticism of a narrative approach is the potential to privilege certain perspectives, through the elimination of selected information. While this potential for particular information to be privileged or excluded undoubtedly exists, awareness of this possibility and triangulation in the research design is intended to assist with management of this potential issue.

\subsubsection{Interpretive method}

In adopting a constructivist epistemological stance the thesis highlights differences in the development of taxation, within the individual social contexts of New Zealand and Australia. Qualitative researchers stress the socially constructed nature of reality, which is the relationship between the researcher, what is studied and the situational constraints that shape inquiry (Denzin and Lincoln 2005:10). ${ }^{21}$ The thesis seeks answers to questions that focus on how social experience is created and given meaning.

An interpretive approach is adopted in this research. Interpretation seeks to understand the meanings that actors attach to their social situations, their own actions and the actions of others (White 1994:45). A concerted effort has been made to understand the research topic as 'it really is' and to recognise the fundamental nature

21 Crotty (1998:64) claims that the foundation of construction is that there is no objective truth waiting for us to discover it. Rather, 'truth' is discovered from engagement with the world; 'meaning is not discovered, but constructed' (Crotty 1998:9). Accordingly, different 'realities' will exist, which will each relate to the individual that provided the constructions. 
of the subject, according to the interpretive paradigm. Thus, in this research considerable use is made of interview quotes in particular, to draw out the contrasting positions of the two countries and to allow the data to 'speak for itself'.

The interpretive paradigm encompasses a wide range of philosophical and sociological perspectives through which it shares the common characteristic of attempting to understand and explain the social world primarily from the point of view of the actors directly involved in the social process (Burrell and Morgan 1979:227). Accordingly, the interpretive paradigm is that most likely to provide the insights desired from the research methodology and approach.

\subsubsection{Archival research}

Archived records are the product of 'the chance survival of some documents and the corresponding chance loss or deliberate destruction of others' (Evans 1997:87). However, documents are not archived randomly or arbitrarily. Generally, archived documents are those that are legally required to be kept by legislation, under the Archives Act 1957, the Local Government Act 1974 or the more recently passed Public Records Act 2005 in New Zealand or the Archives Act 1983 in Australia.

Documents from Australia were predominantly located in the Australian National Library. Due to the recent time period under investigation it was not possible to access some archival material in Australia. This is not considered problematic as the primary documents that were not sighted were government documents, such as Cabinet Papers, briefings and internal government discussion documents. In Australia significant commentary occurred in the public domain on the various changes to the policy in relation to retirement savings taxation policy, which provides an alternative source of information. Documents such as submissions to Select Committees in Australia were made available and these formed an important part of the analysis.

Newspapers and journals in both New Zealand and Australia were used to supplement the analysis, as were articles and commentary on the debates of the time. In New Zealand archival documents were also used for analytical purposes. These included submissions to the Consultative Committee on Superannuation, Life Insurance and 
Related Areas in 1988, as well as Cabinet Committee papers, budget reports, internal New Zealand Treasury correspondence and papers, and ministerial statements. Additional papers were provided by the New Zealand Treasury and through the Official Information Act 1982.

\subsubsection{Interviews}

The methodology adopted in this research is archival research combined with interviews with individuals involved in policy development to 'triangulate' the information found in primary source documents. The use of interviews provides the opportunity to investigate aspects of historical experience that may not be documented elsewhere. Accordingly, through the insights of eyewitness accounts, interviews provided rich evidence about past events. The interview process involved semi-structured questions on individuals' involvement in the policy process, their perceptions of this process and their perspectives on the key dominant influences or constraints.

As well as creating a record where none exists, interviews can supplement existing records. Furthermore, interviews have the potential to reveal disagreements or disputes that may not be recorded in documents. This critical perspective acknowledges that by focusing on individual experiences and interpretations, interviews can provide an alternate viewpoint on the traditionally accepted explanation of history. Thus, interviews have the potential to clarify other forms of history or to challenge conventional views.

A number of criticisms and drawbacks have been connected to interviews. These include the potential for distortion of memory over time and the personal bias of participants. Furthermore, interviews have the potential to privilege some viewpoints above others. However, as acknowledged by Thomson and Gauld (2001:194) this problem is shared by many research methods, both quantitative and qualitative. The broader contextual environment and the utilisation of a wide range of data sources is intended to mitigate, to the extent possible, any potential privileging of perspectives. 
Interviews were undertaken with individuals in New Zealand and Australia who were involved in policy decision making during the 35-year period under investigation, with a particular focus on those who were influential between 1982 and 1992. Participants included:

- commentators of the time (academic and non-academic);

- senior trade union officials;

- senior public sector officials;

- members of the Consultative Committee on Superannuation, Life Insurance and Related Areas in New Zealand in 1988, the Task Force on Private Provision for Retirement in 1992 in New Zealand and the Senate Select Committee on Superannuation in Australia in 1992;

- members of parliament, including cabinet ministers;

- employer group representatives; and

- industry group representatives.

Participants were chosen because of their involvement in the policy development process in the time period investigated in the thesis. It is believed that the participants are sufficiently diversified in their positions and perspectives to alleviate particular individual biases and increase the likelihood of a balanced view.

A total of 47 interviews were digitally recorded and transcribed. Copies of the transcripts were sent to interview respondents, and feedback was requested on any errors of interpretation. The interviews were semi-structured, focusing on elements of the research questions addressed in the thesis. Interview participants were assured of confidentiality of their information and accordingly no individuals are identified in any elements of this research. However, brief details of the 33 interview participants used in the analysis are outlined in the Appendix.

The interview data has provided unique insights into this case study, which would not have been possible through the use of primary or secondary source documents alone. It was unusual for interview accounts to provide dissenting views from the literature, increasing the validity of the research. However, the real benefit achieved was the level of detail that was provided by individual actors, which did not exist in the 
written documents. Interviews emphasised details of complex interactions and debates that facilitated the analysis later in the thesis.

\subsubsection{Periodisation}

One of the key analytical tools used in historical research is that of periodisation. Periodisation allows sense to be made of historical events over an extended time frame by separating the chronology into specified time divisions. Research has shown (e.g. Pierson 1996:126) that attempts to illustrate social processes at a single point in time produce a 'snapshot' view that may be distorted in important areas. Accordingly, it is necessary to investigate the temporal aspects of policy development.

The thesis focuses on three key periods in New Zealand and Australian history, when significant changes were made to either the tax treatment of retirement savings or retirement savings policy more generally:

1. 1981 - 1983: During this period changes were made to the tax treatment of retirement lump sum payments in both countries. This period provides an initial point for analysis as retirement savings taxation policies in New Zealand and Australia were similar.

2. 1987 - 1988: This is the key period where the policy divergence in the two countries became apparent as New Zealand removed all tax incentives for retirement savings, while Australia continued to provide generous tax incentives together with encouragement of occupational superannuation through the Prices and Incomes Accord. ${ }^{22}$

3. 1991 - 1992: This period confirmed both the involvement of the state in retirement income provision in Australia with the introduction of compulsory retirement savings, and the absence of involvement of the state in retirement savings policy in general in New Zealand.

Justification of the use of a 35-year time period stems from the frequently slowmoving but often significant policy changes that have occurred in both Australia and

22 The Prices and Incomes Accord is discussed in chapter seven. 
New Zealand in relation to retirement income savings policy and its concomitant taxation. The use of a 35-year period provides the contextual background, which is an important historical influence contributing to the directions adopted in each country. Accordingly, it is necessary to investigate several decades to capture sufficient detail to appropriately assess the influencing factors in the policy development process

\subsubsection{Triangulation and analysis}

Triangulation is the process of using multiple information sources to clarify meaning (Stake 2000:443). Triangulation can assist with reducing the likelihood of misinterpretation and accordingly enhances research credibility. The collection of data from primary source documents where possible, in combination with interviews, assists with clarification of potential subjectivity within particular data sources.

Triangulation also assists with the external validity of the research, through the mix of various measures. Interviews alone may be argued to be an obtrusive measure that produces distorted results due to the participant's awareness of their participation. However, interviews combined with archival research and secondary source documents provide greater validation of the research results. To provide greater assurance, the research highlights the ideas of the time periods under investigation and the many potential influences that impacted on the outcomes.

The qualitative data computer program NVIVO was used for analytical purposes. All interviews and primary and secondary source documents were coded in NVIVO to assist with increasing the validity of the research output through the use of an accepted research tool for categorisation.

\subsection{Contribution}

Methodologically, the thesis offers a comparatively informed historical study of the development of the tax treatment of retirement savings in New Zealand and Australia. The topic of taxation history, and the area of retirement savings from both a taxation and a general historical perspective, are fields that are neglected in the existing literature. To date, no research has systematically compared the taxation treatment of 
retirement savings in New Zealand and Australia across a period of time. Similarly, no research has constructed a narrative of the complex interactions among the institutions involved in the formation of extant policy. Through undertaking a comparative historical research approach to the topic of retirement savings taxation, this thesis adds to the current policy debate and provides lessons that are relevant to modern tax policy makers. The narrative is intended to provide insight into problems that have been identified in the development of taxation policy for retirement income savings and, accordingly, it fills a gap in the current body of knowledge.

There is benefit to be gained from research that adopts a broader perspective, investigating social, political and economic variables across traditional national boundaries. While generalisation is limited from the methodological approach of the thesis, replication of such studies raises much potential for debate on the topic of institutional influence within policy formation. The methodology utilised in the thesis will enhance understanding of social policy development by providing a temporal aspect to a topic that is typically approached solely from a current perspective. This, in turn, provides insights into the predictability of the impact of particular policies. In addition, the thesis highlights the nature of the policy making systems in New Zealand and Australia, together with unanticipated consequences of the policy. While the research does not claim predictive capability, the development of more appropriate theory for policy predictions may be assisted by comparative research.

\subsection{Summary}

The thesis describes and analyses the developments of the taxation treatment of retirement income savings in New Zealand and Australia from 1972 through to 2007. The narrative commences with descriptions of the economic, social and political frameworks in the time periods discussed, primarily using secondary source documents. This is followed by a more in-depth investigation of the taxation treatment of retirement income savings and changes that occurred in the $1982-1992$ period, using primary source documents, including interviews. The interpretive analysis results from a 'compare and contrast' approach between the two countries 
investigated, using an institutional theoretical framework to assist in analysing and explaining the different approaches adopted in New Zealand and Australia.

This chapter has outlined the methodology that this research adopts, including elements of research design and research method. The following chapter provides a detailed outline of the theoretical framework used in this thesis: historical institutionalism. 


\section{Chapter 3: Theoretical Framework}

\subsection{Introduction}

This chapter provides a comprehensive review of the theoretical framework used in the thesis: institutional theory. The chapter commences with a discussion of the evolution of institutional theory and its primary characteristics. It also discusses the common forms of institutional theory, the methodological tools typically associated with each of them, and their strengths and weaknesses. A detailed analysis of the specific framework used in the thesis (historical institutionalism) follows, outlining its features, benefits and limitations.

The term 'theory' has several potential meanings. Those suggested by Gernon and Olusegun Wallace (1995:57) include an explanatory system in which propositions are set forth, a taxonomy or classificatory scheme or a conceptual framework which provides for the orderly arrangement and examination of data. Carnegie and Napier (1996:13) argue that the choice of theoretical perspective in historical research is not prescriptive, writing: 'if a researcher believes that a particular theory helps to explain the phenomena under discussion, then there appears to be no a priori reason for excluding that theory from being applied'. For the purposes of the thesis, reference to the theoretical framework relates to a conceptual framework that facilitates analysis of the significant historic similarities and differences that are found in the New Zealand and Australian tax treatment of retirement savings.

A number of factors have been considered in selection of the theoretical framework for the thesis. A variety of theoretical frameworks have the potential to provide insights into this comparative case study. These approaches include:

- A positivist perspective utilising economic theories to assist with the analysis of elements of policy formation. However formal economic theories are generally based on assumptions that simplify situations, such as the presence of utility-maximising, rational actors. Hansen (1983:34) claims that economic theories seldom take into account variations of behaviour and the social context in which behaviours occur is typically ignored. In addition, individualistic models such as rational choice do not explain individual 
choices or social outcomes (Goodin 1996:15). Due to the behavioural aspects inherent in the thesis research questions, economic analysis is less likely to capture the richness inherent in the data used for analytical purposes.

- The public finance approach, which is claimed to avoid the empirical difficulties of economic policy making by building normative theories of public choice based on restrictive assumptions (Hansen 1983:15). Public good theories model public preferences under different fiscal choice scenarios. However, as with economic theories, the adoption of modelling techniques limits the potentially rich analysis that can be obtained with more qualitative research methods.

- The theories of public choice to consider the most rational options for policy makers and how taxation may be manipulated to maximise electoral gains (Radaelli 1999:134). Public choice studies the decision making behaviour of politicians, voters and bureaucrats from an economic perspective. Frequently it is considered as a link between political science and economics. However, the foundations on which public choice theory is based include assumptions such as voter ignorance and a lack of competition in the political market. These assumptions, as with those in the aforementioned economic based theories, are likely to limit the analytical output from the data collected.

- Drawing on the theories of political science, which claim to explain change through elements that play a key influence in policy development such as inertia, incrementalism and administrative evolution. Proponents of this institutional approach argue that to understand variation in social systems, political institutions are the most important explanatory factors, not social or economic variables (Rothstein 1996:144).

While each of the approaches has strengths and limitations, institutional theory is believed to offer the greatest potential for the analysis of the tax treatment of retirement savings. This argument stems from the belief that any political theory of taxation must consider the policy process and the policy makers, i.e. politicians and 
bureaucrats (Hansen 1983:25). Furthermore, Steinmo (1993:10) claims that political leadership and the structure of national political institutions are key factors in taxation policy change. Accordingly, institutional theory, which originated in the field of political science, has been utilised as the theoretical framework for the analysis undertaken in the thesis. Institutional theory is used in the thesis to study the structure and operation of political and social institutions in New Zealand and Australia, and to assess the influence of institutional factors on policy formation in the two countries.

\subsection{Institutional Theory}

Institutional theory is widely employed in disciplines ranging from history and sociology, through to economics and political science. In its simplest form, institutional theory may be thought of as a focus on the effects of institutions on political outcomes, such as policy formation.

A wide range of definitions exist for what institutional theory encompasses and what can be classified as an 'institution'. Institutional theory follows 'distinctive forms, processes, strategies, outlooks, and competencies as they emerge from patterns of organizational interaction and adaptation' (Selznick 1996:2). Selznick suggests that it is necessary to understand these patterns to explain environmental responses. Meanwhile, Thelen and Steinmo (1992:2) write that institutional theory covers 'the whole range of state and societal institutions that shape how political actors define their interests and that structure their relations of power to other groups'. Alternatively, the theory may include features of institutions such as relations among government departments or the structure and organisation of interested groups such as trade unions. Ultimately, the boundaries and definition accepted will depend on 'the theoretical question of interest, the time scale posited and the pragmatics of a research project' (Crawford 1995:582).

'Institutions' may adopt a number of forms including formal government structures, legal institutions or social institutions. Social institutions are common in all societies, and exist to manage the 'basic universal problems of ordered social life' (Sills 1968:409). North (1990:3) argues that institutions are 'the rules of the game in a society or, more formally, are the humanly devised constraints that shape human 
interaction'. A further important concept within institutional theory is the claim that 'institutions define individual, group and societal identities, what it means to belong to a specific collective' (March and Olsen 1989:17). Accordingly, institutions may be thought of as influencing the identity of society and a necessary feature to investigate to help explain historical change.

Hall's (1986:19) definition of the concept of institutions is frequently cited, and often claimed as the most comprehensive definition: 'the formal rules, compliance procedures, and standard operating practices that structure the relationship between individuals in various units of the polity and economy'. While Hall's definition is widely accepted, it has been criticised for being so broad as to leave nothing out (Steinmo 1993:12). Steinmo argues that such a wide definition dilutes the concept and 'undermines its analytic utility' (Steinmo 1993:12). For the purposes of this thesis a mid-range definition is adopted, which includes both formal and informal organisations, necessarily extending to institutional rules. ${ }^{23}$ In part, this is in acceptance that research using historical institutionalism frequently adopts a broad view. $^{24}$

Institutional theory does not claim that political institutions are neutral (Bulmer 1998:369; Steinmo 1993:7). Institutions influence policy making, privileging some interests and directing influence in certain directions. While it is not suggested that institutions are the primary explanatory variable in politics, they do form a context from which political events evolve. Therefore the institutional structures within any country will influence the policy initiatives undertaken by politicians and bureaucrats (Skocpol 1992:527). The reasons behind this range from individual career interests, through to political alliances or intent to gain support of interest groups. Bureaucrats may also be important to the extent that policy development arises from a problemsolving process, which bureaucrats may have significant responsibility for, or over which they have influence. It is necessary to take into account the behaviours of politicians and bureaucrats in the policy process as both elected and appointed

\footnotetext{
$23 \quad$ As noted by Steinmo (2001:1) 'in the broadest sense, institutions are simply rules. As such, they are the foundation of all political behaviour'.

$24 \quad$ Refer to section 3.4 of this chapter for further discussion on historical institutionalism.
} 
officials are 'not merely agents of other social interests, they are actors in their own right, enabled and constrained by the political organizations within which they operate' (Skocpol 1992:41). The dimensions of individual influence and institutional power are investigated in chapters nine and ten of the thesis.

Skocpol (1992:41) claims that 'states are authoritative and resourceful organisations ... they are sites of autonomous action, not reducible to the demands or preferences of any social group'. Accordingly, both politicians and bureaucrats will have ideas and interests of their own, and they will 'devise and work for policies that will further those ideas and interests, or at least not harm them' (Skocpol 1992:41). Skocpol further claims that political leaders are likely to adopt policy initiatives that will be advantageous to them in their political struggles. Accordingly, the thesis incorporates the role of politicians and bureaucrats in both countries in the policy development process. The concept of ideas is explored in chapter eleven.

A key point in institutional theory is that institutions themselves do not determine behaviour, instead they provide a context that assists in understanding why actors make the choices that they do (Immergut 1998:31). Institutional constraints encourage or discourage certain types of decision making processes that then impact on the capability of governments to make strategic policy choices (Weaver and Rockman 1993a:9). Furthermore, institutions influence outcomes from the policy making process, through the determination of constraints and rules. Therefore, the adoption of an institutionalist focus involves taking into account the way that interests and ideas within an institutional context shape and determine the conduct of policy making and policy makers (Parsons 1995:333).

A frequently cited example of such a constraint is the presence of 'veto points'. Thelen and Steinmo (1992:6) define veto points as areas of institutional vulnerability in the policy process, such as instances where opposition or influence groups can frustrate the policy outcome. Thelen and Steinmo (1992:6) claim that these veto points vary between countries and are dependent on how different parts of the policy making process are linked; for example, they may be incurred in intermediate institutions that shape political strategies or they may be seen in the ways that institutions structure power relations among influence groups. Furthermore, internal 
institutional processes affect the distribution of power within the institution itself (March and Olsen 1989:17; Thelen 1999:384). Thelen (1999:394) writes that:

institutions are not neutral coordinating mechanisms but in fact reflect, and also reproduce and magnify, particular patterns of power distribution in politics ... political arrangements and policy feedbacks actively facilitate the organisation and empowerment of certain groups while actively disarticulating and marginalising others.

Different veto points are encountered in the policy making processes in New Zealand and Australia, due to both the privileging of different institutions, the different institutional structures and the different power dynamics in each country.

Hall (1992:108) discusses the struggle for power and resources that exists among various social groups, which can influence policy formation. Hall claims this struggle is often mediated by political and economic institutions, which influence the direction that the policy takes. Furthermore, the ability of political and economic institutions to privilege some groups above others results in an ability to influence policy formation. Institutional theorists (e.g. Hall 1986; Thelen and Steinmo 1992) argue that institutional factors can influence policy outcomes in two ways. Firstly, the institutional structure of policy making can affect the degree of power that an actor, or group of actors, will have in policy formation. Secondly, an institutional position affects the interests of the individual actor, by establishing the institutional responsibilities and relationships with other actors. Thus, institutional factors influence both the level of influence an actor may have on policy formation and the likely form that this influence will take (Hall 1986:19).

Pierson (1994:40) continues this debate when he writes: 'if interest groups shape policies, policies also shape interest groups'. Pierson claims that policies provide incentives and resources that may act to facilitate or restrict the formation or expansion of particular interest groups. In addition, Skocpol (1992:527) argues that the institutional arrangements within a state affect the groups within society that become involved in politics and policy development. Skocpol claims the relative degree of success achieved relates to the fit between the government institutions, and the goals and organisational capacities of the interest groups seeking to influence policy making. Interest group activity often follows implementation of a particular 
public policy, rather than occurring prior to adoption (Pierson 1993:598). Accordingly, the timing of such activity may relate to the incentives that either facilitate or restrict the activities of interest groups. These dynamics are clearly seen in the evolution and influence of different interest groups in New Zealand and Australia.

Institutions do more than just communicate the preferences of particular interest groups; rather they collect and ultimately change them (Hall 1986:232). Immergut (1998:7) similarly writes that 'depending on how individual wills are pooled for collective decisions, the final results may reflect the common good, or they may be distorted'. According to Hall (1986), the resulting policy may not be representative of conflicts, as institutions effectively dilute these struggles. However, institutions are ultimately shaped by the historic struggles that have helped form their ultimate shape and direction. Similarly, ideological appeals can act to bind individuals to an organisation (Hall 1986:272), with many politicians and bureaucrats building policy on ideas with which they are already familiar. The concept of ideas is explored in chapter eleven of the thesis.

\subsection{The Evolution of Institutional Theory}

Institutional theory has evolved from an initial focus on the political practices of a state to include a greater focus on behavioural elements. Around the time of the Second World War an institutional approach was the most frequently used framework for the analysis of the political or policy environment (Apter 1996:374). However, from the late 1950s the focus moved from the use of the state for analysis to increased attention on behaviour. This created a move towards an understanding of a positive, rather than a normative, view of individual behaviour.

Institutional theories have changed significantly over the past 30 years in the wake of criticisms attached to the original institutional theories. These criticisms included that they were limited in terms of both scope and method, and had a restricted understanding of the subject matter. Peters (1999:3) describes 'old institutionalism' as, among other things, normative, structuralist, historicist (concerned with how 
contemporary political systems were embedded in their historical development), and legalist (concerned with law and the central role of law in governing).

The field of institutional theory is now defined by two main approaches: 'new institutionalism' and 'old institutionalism'. The approach of old institutionalism was to consider how the nature of governing institutions could structure the behaviour of individuals towards a better end (Peters 1999:3). Old institutionalism consisted of 'detailed configurative studies of different administrative, legal, and political structures' (Thelen and Steinmo 1992:3). The rationale supporting old institutionalism was that the irrational nature of individual behaviour required political institutions to be formed in order to achieve a collective purpose. Old institutionalism was normative in nature, concerned with how behaviour was determined by structure, and focused on the central role of law in governing (Thelen and Steinmo 1992:3). However, old institutionalism did not encourage the development of concepts that would facilitate comparative research and advance explanatory theory.

'New institutionalism' emerged in response, with a wider definition of the subject matter and more diverse theoretical frameworks. New institutionalism has emerged as one of the most prominent research agendas in the field of comparative politics, political economy and public policy (Steinmo and Tolbert 1998:1). The forms of institutional theory that are widely in use today are concerned with the role of institutions within society, as well as less formal institutional networks in the formation of policy (Hall 1986:20).

\subsubsection{New institutionalism}

In the 1950s and early 1960s old institutionalism became increasingly marginalised, with the suggestion that formal laws, rules and structures did not explain actual behaviour or policy outcomes. With the emergence of the 'new institutional' approach, it was argued that analysis should focus on the informal distributions of power, attitudes and political behaviour (Thelen and Steinmo 1992:3). The emphasis on observable behaviour became the focus of the behavioural approach and is the point of departure for new institutionalism (Immergut 1998:1; Selznick 1996:2). New 
institutionalists do not believe that behaviour is a sufficient basis for explaining the processes and outcomes of government. The foundation of this belief is that behaviour occurs within the setting of institutions and accordingly can only be understood through analysis of the institutional influence.

The phrase 'new institutionalism' was coined by March and Olsen (1984) and has been particularly associated with comparative political economy research (Thelen and Steinmo 1992:1). New institutionalism argues that preferences and meanings develop in politics, and indeed all disciplines, through a combination of 'education, indoctrination, and experience' (March and Olsen 1984:738). Accordingly, preferences should not be considered as relating entirely to external causes and should also be expected to change.

The concept of explaining change through new institutional theory (hereafter referred to as 'institutional theory') starts from the premise that institutions identify and adapt to changing circumstances in their environment through a process of learning (Peters 1999:33). Threats and opportunities to established behaviour or policy occur from changes in the environment. This contrasts with the old institutional approach, which claims a highly focused reform process, while the new institutionalist approach indicates an almost random nature of change. From this perspective, public institutions can misinterpret the signals from society and accordingly respond in dysfunctional ways (Peters 1999:33). However, under the new institutionalist model of change, institutions will have multiple opportunities to adjust their behaviour. The concept of change in institutional theory and historical institutionalism is discussed further in sections 3.3.6 and 3.4.9 of this chapter.

There are a number of variants of new institutionalism, all with different research approaches, but all aiming to explain the role that institutions play in determining social outcomes. ${ }^{25}$ Conventionally, these are categorised into three institutionalisms:

$25 \quad$ Peters (1999:3) identifies six approaches, including normative institutionalism, rational choice institutionalism, historical institutionalism, empirical institutionalism, international institutionalism and societal institutionalism. Similarly Powell and DiMaggio (1991:2) write that there are many new institutionalisms, highlighting economics, organisation theory, political science and public choice, history and sociology, all with the common conviction 
rational choice instituionalism, sociological institutionalism and historical institutionalism, with roots in the disciplines of economics, sociology and political science, respectively. Despite the different social science origins, the three variations on new institutional themes are essentially complementary and a number of similarities exist between the three approaches, including:

- recognition of the importance of intentions for explaining action (Torfing 2001:281);

- concern with the difficulties of ascertaining what individuals want and when the preferences expressed in politics and policy are influenced by the institutional contexts in which the preferences are detailed (Immergut 1998:30);

- the perspective that preferences and identities are influenced by institutions; and

- a central focus on how institutions affect the behaviour of individuals. ${ }^{26}$

\subsubsection{Rational choice institutionalism}

The rational choice approach replaced the behavioural approach that dominated from the 1950 s to the 1970 s. Rational choice institutionalism primarily researches formal institutions, which are viewed as constraining the behaviour of actors. Institutions are seen to hold the solutions to collective action and coordination problems. While maintaining the focus on social and political action, the rational choice approach was aimed at explaining these actions (Torfing 2001:281). The rational choice approach argues that self-interested actors will make decisions and create institutions that will reduce their political or economic costs relative to the benefits gained (Campbell 1997:15).

that institutional arrangements and social processes matter'. However, most researchers recognise the three primary approaches outlined here (e.g. Campbell 1997, Hall and Taylor 1996).

26 The discussion on the variations of institutional theory in this chapter, with the exception of historical institutionalism, is necessarily brief. For a more in-depth insight into rational choice institutionalism and sociological institutionalism, refer to Hall and Taylor (1996). 
Rational choice institutionalists isolate the issue of preference formation theoretically, through the assumption that political actors are rational and will act to maximise their self-interest. Criticisms attached to the rational choice approach include that it does not allow for the changing nature of preferences and that its treatment of social institutions does not take into account that institutions reflect the cumulative experience of a community (Knight 1992:17). Further criticisms include a lack of focus on power relationships, no ability to explain sub-optimal decision making and difficulty in addressing issues at the macro-level (Pierson and Skocpol 2000:11). In addition, rational choice institutionalism has been accused of producing elegant theories, while generating little to explain real observed events (Thelen 1999:372).

\subsubsection{Sociological institutionalism}

Sociological institutionalism (also known as 'organisation theory' or 'sociological constructivist institutionalism') includes organisational analysis, as well as various forms of discourse theory (Torfing 2001:282). Sociological institutionalism is a response to behaviouralism, which focuses on explaining behaviours in an objective, quantified manner. Instead, sociological institutionalism starts with society and the view that institutions are collective outcomes, not the sum of individual interests (Thelen 1999:386). This perspective is ontologically grounded in constructivism, as institutions are viewed as socially constructed. Sociological institutionalism adopts a broad definition of institutions and argues that inherent limits of knowledge restrict rational decision making. As a result, institutional rules, processes or standard operating procedures allow individuals to make decisions. Accordingly, within sociological institutionalism behaviour does not express individual preference; instead it is the result of 'various coping devices that individuals adopt to overcome their cognitive limits' (Immergut 1998:15).

As found by Steinmo (2008a:163) individuals are not viewed as self-interested, as in rational choice institutionalism, but are more likely to follow a logic of appropriateness'. In this branch of institutional theory, institutions influence how individuals view the world and how they act within it. 


\subsubsection{Historical institutionalism}

Historical institutionalism is known for drawing on the work of Marx and Weber. ${ }^{27}$ However, within historical institutionalism there can also be found comparative political theorists and sociological historians (Torfing 2001:282). In contrast to the rational choice and organisational theory approaches, historical institutionalists adopt a focus on the 'relations between politics, state and society in various countries and historical periods' (Immergut 1998:18).

Historical institutionalists find the strict rationality assumptions in the rational choice approach confining (Thelen and Steinmo 1992:7). The historical institutionalist approach typically investigates relations between institutions and how these shape the outcomes of interest (Pierson and Skocpol 2000:15), rather than focusing on a single institution, as is frequently the case in the rational choice approach. In addition, historical institutionalism goes further than the rational choice approach in explaining the historical impact of policies and institutions on future policy development (Torfing 2001:296) and is more likely to focus on a small number of cases that have some commonality (Thelen 1999:373). Accordingly, historical institutionalism has a strong fit with the methodological approach of the thesis. Historical institutionalism is discussed in greater detail in section 3.4.

\subsubsection{Benefits of institutional theory}

Hall and Taylor (1996:949) claim that all the institutionalist views advance our understanding of the political world, with each having strengths and weaknesses, and providing different insights. The importance of institutions when looking at when and how institutions influence policy formation is widely claimed (e.g. Weaver and

27 Historical institutionalism is typically considered to be derived from the historical materialism of Marx and the comparative institutional history of Weber (Campbell 1997:21). Weber is known for outlining the concept of bureaucracy and its role in the structure of human activity in the modern world. Weber argues that states are 'compulsory associations claiming control over territories and the people within them' (Skocpol 1985:7), and that socialism would need more officials to administer a collectivised economy and society (Schwarzmantel 1987:7). Conversely, Marx believed that socialism would eventually abolish the state and that society would govern itself. 
Rockman 1993a:40). The approach is widely used in comparative politics with frequent observations about institutions, how they vary between countries and how they cluster into institutional patterns.

A number of claims from well-known researchers point to the benefit and applicability of institutional theory to the topic of the thesis; for example, Peters (1999:73) claims that the historical institutionalist approach has an explicit purpose to deal with the demands of differences across different political systems. Furthermore, Eccleston (2004:15) argues that a potentially insightful approach to explaining differences in tax policy has been to 'explore the institutional determinants of state capacity'.

Hall (1986:232) highlights a number of factors that emphasise the importance of institutional theory. Firstly, policy is typically formed in response to pressure from interest groups, but the level of influence and force with which the interests are demonstrated is reliant on the structures of the institution from which they arise. Secondly, the interests of individual actors will be influenced by the organisation of the institutional structures from within which they operate. Thirdly, as policy making is typically a collective exercise, the outcome is not the product of individuals, but rather of institutions that reflect the influence of a number of individuals.

\subsubsection{Limitations of institutional theory}

Despite the apparent acceptance of the application and utility of new institutional theory in relation to historical or comparative studies, a number of criticisms have been attached to the framework; for example, Peters (1999:33) argues that the new institutionalist perspective does not effectively explain the development of institutions, claiming that to provide a useful alternative to the more individualistic explanations of political life, a theory must be able to say how the institutions came into being. Furthermore, Peters claims that the outcomes seen may be the result of normal incremental patterns of policy-making found in most industrialised democracies, rather than an explicit influence of institutions over those policies' (Peters 1999:64). This is not perceived to be a significant issue as this thesis is not primarily concerned with the development of institutions per se. Rather, the focus is 
on how the institutional arrangements have resulted in different policy solutions to common policy problems in Australia and New Zealand.

It has been suggested that institutional frameworks may explain policy outcomes during periods of stability, but they may not be as effective in explaining periods of change. Thelen and Steinmo (1992:15) pursue the difficulty that institutional theory has in explaining change when they write that 'the problem with this model is that institutions explain everything until they explain nothing'. The point made by Thelen and Steinmo is that at the moment of institutional breakdown, the 'logic' of the institutional argument moves from 'institutions shape politics' to 'politics shape institutions'. This different conception of the relationship then serves to 'obscure the dynamic interaction of political strategies and institutional constraints' (Thelen and Steinmo 1992:15). Thelen and Steinmo argue that a more dynamic model is required to capture the interplay between the two variables over time.

As outlined above, it is not possible to claim that institutions are the only influence on policy outcomes, although many writers argue that institutional factors have a significant impact on state capacity and political outcomes (e.g. Eccleston 2004:15). Accordingly, it is necessary to analyse the significance of institutional variables in conjunction with other factors that are generally regarded as influencing the policy making process, such as economic conditions, international political systems and policy paradigms (Eccleston 2004:24). Along with consideration of the domestic political structures, this thesis will also take into account other influencing variables, such as prevailing economic or social factors that are likely to have played a part in the outcome of policy formation at particular junctures. These environmental factors are discussed in chapter eight. The use of an institutional framework does not restrict this analysis; rather, it facilitates the task. Indeed, Skocpol (1985:7) claims that the state should not be expected to explain everything; other organisations also form social relationships and impact on political arrangements, and accordingly a comprehensive analysis must explore activities that interact with the state.

A problem with an institutionalist analysis is that institutions are treated as static variables (Steinmo 1993:12). Steinmo suggests that institutional approaches are better at explaining what is not possible in a given institutional context than what is 
possible. The primary criticism is that comparative institutional analysis tends to focus on 'comparative statics' and investigating how policy outcomes between countries are different because of their stable institutional configurations and constraints. Steinmo claims the issue may be avoided through the adoption of a historical account of the development of tax policy outcomes and the political institutions that write tax law. Steinmo (1993:12) argues:

understanding the ways in which domestic political institutions shape policy choices goes a long way toward helping us understand why, given certain choices, one country takes one path and another country takes another. But looking at these political institutions rarely tells us why these choices were available or necessary in the country in the first place.

The issues raised by Steinmo are mitigated, to the extent possible, by the use of a 35year time period, which allows social, political and economic environmental changes to be considered, together with the policy changes. In addition, the use of interview and archival research methods in conjunction with institutional theory is aimed at allowing the background of these choices to be made transparent.

\subsection{Historical Institutionalism}

The thesis uses the 'historical institutionalism' branch of new institutionalism as a theoretical framework. Over the past 20 years, historical institutionalism has become one of the most influential theoretical perspectives in social policy research (Beland 2005:1).

Historical institutionalists view the institutional organisation of the political economy as the 'principal factor structuring collective behaviour and generating distinctive outcomes' (Hall and Taylor 1996:937). Beland (2005:3) defines historical institutionalism as:

Grounded in the assumption that political institutions and previously enacted public policies structure the political behaviour of bureaucrats, elected officials and interest groups during the policy-making process. This approach views the polity as the primary locus for action, yet understands political activities, whether carried by politicians or by social groups, as conditioned by institutional configurations of governments and political party systems. Political institutions create constraints and opportunities for those involved in policy-making. 
Pierson and Skocpol (2000:3) argue that there are three important features that characterise historical institutionalism:

1. historical institutionalists 'address big, substantive questions that are inherently of interest to broad publics as well as to fellow scholars';

2. historical institutionalists 'take time seriously, specifying sequences and tracing transformations and processes of varying scale and temporality'; and

3. historical institutionalists 'analyze macro contexts and hypothesize about the combined effects of institutions and processes', rather than examining just one institution or process in isolation. ${ }^{28}$

A further characteristic of historical institutionalism relates to the claim that motivations of actors are institutionally determined (Campbell 1997:21). Thus, research using historical institutionalism will frequently investigate how institutional factors shape preferences and interests, which in turn impact on the distribution of power and the direction adopted by political actors. Historical institutionalism allows for individuals to have motivations that are not always self-interested, which is a significant departure from the rational choice approach (Campbell 1997:22).

A feature of historical institutionalism is the claim that institutions influence how groups define their political interest. Rothstein (1996:146) argues that most approaches agree that institutions influence actors' strategies, writing 'this is obvious from the fact that institutions determine: (a) who are the legitimate actors; $(b)$ the number of actors; (c) the ordering of action; and to a large extent (d) what information actors will have about each other's intentions'. Hall and Taylor (1996:939) suggest that institutions provide 'templates' for how the world is interpreted:

The individual is seen as an entity deeply embedded in a world of institutions, composed of symbols, scripts and routines, which provide filters for interpretation, of both the situation and oneself, out of which a course of action is constructed. Not only do institutions provide strategically useful information, they also affect the very identities, self-images and preferences of the actors.

28 Comparative historical research is also claimed to be particularly effective in addressing these macro-level questions (Amenta 2003:92; Skocpol 1979:36). 
As with broader institutional theory, an important concept within historical institutionalism is that institutions may constrain politics, but they are never the sole 'cause' of outcomes (Thelen and Steinmo, 1992:3). Historical institutionalism does not claim that institutional constraints are the only influence on policy outcomes, and is open to the myriad of other variables that play a part in policy formation. Thelen and Steinmo (1992:16) identify four potential sources of 'institutional dynamism', meaning situations where observed variability in the impact of institutions over time, but within countries, can be seen. These are:

1. broad changes in the socio-economic or political context;

2. changes in the political balance of power;

3. a shift in the goals or strategies being pursued within existing institutions; and

4. when political actors adjust their strategies to accommodate changes in the institutions themselves.

All these sources are investigated in this thesis. This openness to such variables found within historical institutionalism increases the potential for a rich, informative outcome from the complexity of political situations from research adopting a historical institutional approach. Of particular relevance to the thesis is the influence of institutions on individual preferences, together with the dimension of power.

A number of features are typically linked to historical institutionalism. These are discussed in the following sections.

\subsubsection{Path dependency}

Path dependency is one of the fundamental features of historical institutionalism. The theory behind path dependency is that the policy choices made when an institution is being formed, or when a policy is initiated, will have a continuing or constraining influence over the policy into the future (Peters 1999:63). However, institutions may resist change due to the certainty associated with the extant arrangements. One of the factors behind the path dependency argument is the considerable political risk associated with the implementation of new policy. 
In a strict 'path dependency' process 'outcomes at a critical juncture trigger feedback mechanisms that reinforce the recurrence of a particular pattern into the future' (Pierson and Skocpol 2000:6). However, whereas path dependency is a path that must be followed, historical institutionalism tends more towards evolution in that it possible to alter the path of a particular policy, but a significant level of political pressure is required to do so (Peters 1999:65). Furthermore, historical institutionalism claims that the range of potential directions that the policy may adopt is restricted by the formative period of the institution. Agreed norms, rules and practices can become 'self-reinforcing processes' where the cost of policy amendment increases with each further step of policy development, due to the resources invested in that path (Davies 2004:572).

Historically oriented researchers are those most concerned with the study of path dependent sequences (Mahoney 2000:509). The rationale behind this claim is that a historical approach focuses on timing and the unfolding of processes typically over a long period of time, which allows the presence of path dependent sequences to be highlighted. Path dependency within historical institutionalism manifests itself as a belief that individual preferences are not transmitted to political leaders solely via interest groups and political parties; rather, the 'representation of interests is shaped by collective actors and institutions that bear traces of their own history' (Immergut 1998:18). Path dependency arguments can provide a powerful corrective case to counteract the tendency to assume 'functionalist explanations' for certain social and political outcomes (Pierson and Skocpol 2000:7).

The concept of increasing returns is linked to path dependency through the increasing likelihood that policy will continue on the same path with successive moves in the same direction due to the relative benefits of the extant policy, when contrasted with other options. Due to the potential for increasing returns and path dependency in the policy process, the thesis focuses on the critical junctures that have changed the taxation policy of retirement savings, together with the specific factors that have been the primary trigger for the change. As identified by Hall and Taylor (1996:942) the difficulty is identifying the points to classify as a 'critical juncture'. This is discussed in the following section. 


\subsubsection{Critical junctures}

Critical junctures are major transitions in institutional life that shape politics and policy formation into the future (Collier and Collier 1991:27). These critical junctures can relate to a brief period in which a policy direction is taken, or it can be an extended period of change. Frequently 'the critical juncture is intertwined with other processes of change' (Collier and Collier 1991:27).

The critical junctures identified in the thesis relate to points where there is significant policy change, such as the removal of tax incentives for retirement savings in New Zealand or the implementation of the compulsory occupational superannuation savings scheme in Australia. To be classified as a critical juncture, the events are necessarily large with significant societal impact. In addition, a juncture is critical if once a particular option is selected it becomes more difficult to return to a point where other alternatives are available (Mahoney 2000:513).

Historical institutionalism affords greater attention to 'critical junctures and longterm processes' whereas other approaches tend to focus on short periods of time or short-term processes (Pierson and Skocpol 2000:1). Accordingly, historical institutionalism is claimed to have the benefit of highlighting the 'overarching contexts and interacting processes that shape and reshape states, politics, and public policymaking' (Pierson and Skocpol 2000:1). This macro-historical approach of analysis of critical junctures is a key reason for the adoption of historical institutionalism in the thesis. The retirement savings policy environment in New Zealand and Australia has numerous critical junctures, some more significant than others. Nonetheless, an approach that allows for analysis of periods of stasis, together with periods of change is appropriate, and necessary, for the research topic.

\subsubsection{Timing}

Historical institutionalism views institutions as the 'legacy of concrete historical processes', thereby allowing questions of temporality into the analysis (Thelen 1999:382). The importance of timing is highlighted by a number of researchers (e.g. Heclo 1974; Peters 1991). Modern social policy is the end result of a complex set of historical changes, and to appreciate the cumulative effect of institutions on social 
policy it is necessary to investigate historical processes over time, rather than investigating events in isolation (Heclo 1974:14).

Pierson and Skocpol (2000:5) argue that a particular characteristic of historical institutionalism is its stance in relation to history, claiming that the approach does not just consider the past, rather it looks at processes over time. This investigation of processes over time allows for a wider range of experiences to be considered. The benefit with this approach stems from the relatively infrequent and often slow-moving occurrence of some of the significant policy changes. Thus, it becomes necessary to investigate a long period of time to encompass all the influencing effects that may contribute to a particular policy output.

When examining the politics of tax policy, it is important to be aware of 'the temporal as well as the ideological dimension of political actions' (Peters 1991:11). Therefore, the thesis incorporates a 35-year period to capture any issues that may be more effectively explained with a broader temporal perspective.

\subsubsection{Historical process}

Historical institutionalism places a greater emphasis on historical process, rather than the equilibrium order found in rational choice institutionalism (Thelen 1999:384). Historical institutionalists argue that as institutions shape strategies and goals, they in turn structure political situations and influence political outcomes. This allows insight into 'intermediate' variables that may help to explain the contingent nature of policy development. Immergut (1998:20) develops this notion, suggesting:

our understanding of particular events and developments is constrained by the large role played by chance. Quirks of fate are responsible for accidental combinations of factors that may nevertheless have lasting effects. In addition, self-conscious political actors ... can divert the supposedly ineluctable march of progress onto unexpected paths. Such contingent developments stand beyond logic and can only be grasped through historical analysis.

Evans, Rueschemeyer and Skocpol (1985:348) continue the discussion on historical process when they argue that a historical approach is necessary when considering institutions, as nation states share the features of historical persistence and continuity, 
which is typically attributed to historical research. Generally, the structure of state organisation and the relationship of that organisation to interest groups often endures through major crises and attempted reorganisation.

Researchers using an historical institutionalist approach tend to ask questions about historically situated outcomes of broad interest (Pierson and Skocpol 2000:4). Moreover, researchers using the historical institutionalist perspective often ask why an event occurred, or did not occur, and why 'certain structures or patterns take shape in some times and places but not others' (Pierson and Skocpol 2000:4). This thesis addresses both of these concepts and also fits within Pierson and Skocpol's claim that the focus of historical institutionalism is on explaining variations in important or surprising patterns or events, with the problems often stemming from previously unexplained variations in real-world situations.

\subsubsection{Punctuated equilibria}

A further feature of historical institutionalism is the treatment of change through the notion of 'punctuated equilibria'. The concept of punctuated equilibria stems from the evolutionary theory of biology. Under the concept of punctuated equilibria there is an expectation that for most of its existence an institution or policy will exist in a state of equilibrium, in accordance with decisions made at its origin or the past point of punctuation. The equilibria are not necessarily permanent and institutions are considered capable of change (Peters 1999:68).

The concept of punctuated equilibria has been used in studies of public policy in relation to policy change (Peters 1999:68) and is widely accepted among institutional theorists (Thelen and Steinmo 1992:15). When used within studies of policy development, punctuated equilibria can indicate different rates of change in social and political structures over time (Krasner 1984:240). As Krasner highlights, it is important to distinguish between periods of policy creation and those of policy stasis. The factors that explain why a set of arrangements is created may be quite distinct from those that explain why it has endured over time; for example, punctuated equilibrium tends to indicate that new structures may evolve during times of crisis with periods of stasis prominent during other periods. 


\subsubsection{Power relations}

A notable feature of historical institutionalism is the prominent role that power relations play in analyses adopting the approach (Hall and Taylor 1996:940). Hall and Taylor argue that historical institutionalism has been particularly focused on the way in which institutions distribute power unevenly across groups, writing:

Rather than posit scenarios of freely-contracting individuals, for instance, they are more likely to assume a world in which institutions give some groups or interests disproportionate access to the decision-making process; and, rather than emphasise the degree to which an outcome makes everyone better off, they tend to stress how some groups lose while others win.

Immergut (1998:22) uses the example of how political institutions and government policies may facilitate the organisation of interests by recognising particular interest groups or recognising the legitimacy of particular claims. This argument stems from the belief that public policy is not influenced by the "neutral and convergent exigencies of modernization' (Immergut 1998:18). As institutional factors impact on the political and policy making processes, the result is that some interests will be privileged at the expense of others.

A further point is raised by Skocpol (1992:531) who claims that policies can reshape institutions, making some future developments more likely, and limiting the potential of others. This may result from historical patterns of resource allocation. Historical financial support for a policy initiative may result in the privileging of one group over another, and accordingly may act to influence those who have power in policy formation in the future.

Power is an important dimension in the thesis. Investigation of historical process indicates that power distribution among central actors and interest groups in both New Zealand and Australia was a significant contributing factor to the policy decision making of the time period investigated. This dimension is explored in chapter ten.

\subsubsection{Ideas}

The concept of ideas within historical institutionalism, and within new institutional theory more generally, is presently causing considerable discussion among the political science community. There is general agreement among researchers that 
policy ideas are formulated within an institutional context (e.g. Steinmo 2008b:231). However, not all disciplines have recognised the potential influence of ideas in the policy making process; for example, Steinmo (2008a:169) finds 'Marxism, rational choice, pluralism alike all assume that interests are the driving forces of politics, and that ideas are either justifications or simply "noise”'. The obvious difficulties attached to the measurement of ideas provide some justification for this position among many disciplines.

Blyth (1997:229) suggests that greater acceptance of ideas within institutional theory is 'simply a reaction to the limitations of the "new institutionalisms" which emerged in the late 1980s'. Some years later, Blyth (2003) suggests that historical institutionalists (along with other forms of institutionalism, such as rational choice) turned to ideas to assist with clarification of change within institutions, which institutional theory was struggling to explain. In addition, Appel (2000) suggests that the lack of attention afforded to ideas is, in part, due to the rational choice foundations of the typical methodological approach in political science. However, historical institutionalism, as found by Steinmo (2008a:169), is not 'wedded to a particular grand theory or to a specific methodology', thereby providing for greater acceptance of the concept of ideas for analytical purposes.

The inclusion of ideas within institutional theory has not found favour with all researchers. Blyth (1997:229), for example, is critical of the attempt to try to accommodate ideas within the theory, suggesting that 'this renewed interest in ideas in political economy marks neither a progressive extension of the institutionalist research program nor a serious examination of the role of ideas in the realm of political economy'. Despite this criticism, Blyth (2002:10) accepts that economic ideas are 'causally powerful' as they are not only reflecting historical events, they are 'also constructions that allow agents to define a crisis as a crisis, and thereby both plan and politic their way forward'.

Much of the discussion in relation to ideas has come from rational choice institutionalists. In particular, rational choice has challenged the concept of selfinterest within rational choice institutionalism and how individual interests are revealed through institutional processes. However, a number of historical 
institutionalists have considered how the ideas of individual actors impact on how interests are defined in the first instance (e.g. Campbell 2002). In addition, Steinmo (2008b:224) claims that “ideas” are not derivative of the interests, instead interests may be constructed in a particular way to justify specific ideas'.

Hall (1992:91) suggests that the impact of institutions is best situated 'within $a$ broader matrix of competing interests and ideas'. Hall asserts that interests and ideas interact in a number of ways, including providing incentives to encourage certain forms of behaviour and in making 'the expression of political views more or less viable for certain groups' (1992:91), thereby affecting the power held within certain institutions. Perhaps the most important argument raised by Hall is the institutionalisation of certain behaviours, which constrain the potential for new ideas to be conveyed.

Ideas may also help in communicating the need for change and how this change can be structured. Blyth (2002:38) asserts that 'change can reconstitute those interests by providing alternative narratives through which uncertain situations can be understood'. Thus, a benefit from utilising ideas to validate change is in both defining the policy issue and also in providing a solution to the issue.

Steinmo (2008b:196) claims that ideas are both generated within a policy context and this policy context is the result of historic ideas. Therefore, in order to understand policy outcomes, it is necessary to explore historic policy ideas and their evolution in practice. Steinmo (2003:207) also suggests that policy ideas play an important role in the selection process between policy alternatives. These arguments are made within the broad framework of institutional theory. As found by Campbell (2002:30), 'many researchers have argued that the formal rules and procedures governing policymaking affect which ideas penetrate the policy-making process and are adopted and implemented as policy', thereby affecting the extent to which ideas can shape the policy environment.

In addition, it has been suggested that some policy ideas have a greater 'fit' to a particular political, economic or social environment. To some extent, this 'fit' is a function of historic events. Steinmo (2008b:221) finds that 'what we want is 
fundamentally framed by what we can imagine achieving and what we can imagine achieving is informed by what we have done before'. Thus, ideas are not limited to influencing previous policy choices; they also include new policy options or historic ideas that regain new currency in a changed environment. Steinmo (2008b:223) describes these policy ideas as 'problem solutions'.

When observing policy developments in the taxation of retirement savings over the last century, there are apparent patterns of different policy ideas that govern certain periods. In the first 40 years of the $20^{\text {th }}$ century, the policy aim was to provide a minimum standard of living for those likely to be most disadvantaged in their old age. The subsequent 30 -year period had a greater focus on universality of provision. The final 30 years (in most OECD countries) moved towards encouraging individuals who could save for their retirement to do so, with increasing levels of state involvement in the process. These contrasting periods represented the distinctive philosophies that were driving broader policy changes at the time; philosophies that were built on historic policy ideas combined with historic policy experience. Steinmo (2003:229; 2008b:197/223) suggests that there is a number of reasons why these ideas may change over time, including:

- new information is received that challenges the status quo;

- there may be inconsistencies in extant beliefs;

- changed contexts provide for different approaches;

- balances of power may change; or

- individuals may be persuaded that a different approach is preferable.

One of the primary findings from the recent focus on ideas in historical institutionalism is that ideas 'give content to preferences and thus make action explicable' (Blyth 2003:702). However, an important issue with the potential for ideas is that they can be used by individuals to provide validation in policy debates. This can clearly be seen in both the New Zealand and Australian contexts and is discussed in more detail in chapter eleven. As historical institutionalism has become more accepting of the influence of ideas, and ideas are a primary explanatory factor in the different approaches to the taxation of retirement savings adopted in New Zealand and Australia, chapter eleven enters into considerable discussion on the concept of 
ideas within the thesis. In particular, focus is given to how and why it is that one set of ideas is privileged above another.

\subsubsection{Benefits of historical institutionalism}

A number of benefits are attributed to the use of historical institutionalism as a theoretical framework. These include the suggestion that the historical institutionalist approach 'makes powerful contributions to ... understandings of government, politics, and public policies' and historical institutionalists 'probe uneasy balances of power and resources, and see institutions as the developing products of struggle among unequal actors' (Pierson and Skocpol 2000:3; 2000:12).

Typically, historical institutionalists will adopt macro-level analysis, taking into consideration a number of institutional influences. There is no attempt within historical institutionalism to find a rational situation or event; instead, the focus is on the interactions between multiple institutions and processes. Accordingly, historical institutionalism provides rich insights into qualitative research methods and historical institutionalism can be used for analysis purposes in a wide range of scenarios.

One of the primary reasons for adopting institutionalist frameworks in the thesis is the ability to explain why some policy arrangements have been stable over time, as well as why variation can be seen between Australia and New Zealand. This benefit is captured by Thelen and Steinmo (1992:14) who claim that historical institutionalism is particularly helpful in highlighting cross-national differences, and the patterns of policy development over time within individual countries. Immergut (1998:30) adds to the discussion when claiming that 'by tracing changing definitions of interests through time and across cultures, the impact of institutions on the construction of interests can be studied without imposing arbitrary, "objective" definitions of interests'. This approach allows issues of representation and political bias to be highlighted and analysed.

An institutional approach permits investigation of the relationship between political actors as objects and as agents of history (Thelen and Steinmo 1992:11). Institutions that are at the centre of historical institutional analysis, which can take any form from 
a political party through to employer groups, can influence political strategies in important ways. Accordingly, investigation of the differences in institutional arrangements, together with examination of the different approaches in taxation of retirement income savings, has the potential to highlight the influence of interested parties and how these influences have shaped the policy process.

Historical institutionalism is an effective way to identify institutional influences that political actors are likely to follow, such as organisational interests, rather than defining them as aggregations of individual interests (Kato 1996:6). In addition, Kato claims that most studies using historical institutionalism rely on a comparative analysis of political processes or the comparison of historical cases. The thesis adopts components of both of these approaches.

There is also the potential for the research to draw attention to groups that were privileged during the policy process. The use of institutional frameworks helps in understanding the ways in which different kinds of political officials have promoted particular social policies and with varying degrees of success (Skocpol 1992:46). In addition, a historical institutionalist approach can show how power relations can be reinforced over time, and thus become embedded in organisations, institutions and the political process itself (Pierson and Skocpol 2000:6).

The additional element that historical institutional analysis assists with is consideration of the historical formative influences on institutions and how political situations are structured. Pierson and Skocpol (2000:5) argue that under historical institutionalism, the research community has benefited from sharper and broader explanations, and normative understandings, of the origins, variety, and dynamics of national systems of economic regulation and social provision'.

Pierson and Skocpol (2000:6) also assert that the systematic tracing of the development of social processes can make an important contribution to supporting claims about social causation. This assertion stems from the typical approach adopted within historical institutionalism of a small number of cases, which in turn permits a detailed examination of processes. This avoids reliance on single institutional effects in isolation, as is often found in a rational choice institutionalist approach. The detail 
gained from the analysis can assist with evaluating claims about causality. Skocpol (1992:60) argues that only a genuinely historical analysis can investigate the interaction of social and political transformations, and explore the development of incremental political processes. Pierson and Skocpol (2000:6) suggest that 'without the kind of attentiveness to temporally specified process that is a distinctive hallmark of historical institutionalist scholarship, important outcomes may go unobserved, causal relationships may be misunderstood, and valuable hypotheses may never receive consideration'.

\subsubsection{Limitations of historical institutionalism}

One of the primary criticisms of historical institutionalism is highlighted by a number of proponents of institutional theory (e.g. Peters 1999:68; Rothstein 1996:153) who argue that historical institutionalism struggles to explain the question of institutional change. This criticism is generally agreed upon by proponents of historical institutionalism, and frequently supporters of the method are forthright in their acceptance that institutions do not have this capacity. This is claimed to be particularly relevant when institutions change in unexpected ways, given that the analytical framework is premised on the enduring effects of institutional and policy choices made at the initiation of a structure. Most researchers agree that the approach is better suited to explain the persistence of patterns, rather than explaining how patterns change (e.g. Campbell 1997; Peters 1999).

A further criticism of historical institutionalism comes from Pierson and Skocpol (2000:4), who argue that contributions made to the literature from a historical institutionalist perspective are 'scattered across subfields dealing with different eras or regions of the world'. Accordingly, while theoretical preferences may be similar, there is often not much scope for the sharing of learning between historical institutionalist approaches. Pierson and Skocpol (2000:4) posit that this use of a wide range of topics and research questions may result in an absence of recognition of theoretical commonalities among historical institutionalist approaches. In this thesis, this danger has been addressed through consideration of, and input from, a wide range of research utilising both institutional theory and historical institutionalism in the literature review chapter. 
As with institutional theory, historical institutionalism does not claim that institutional effects can fully explain key decisions that form social policy. Beland (2005:4) argues that a historical institutionalist approach is excellent for explaining how institutions 'create obstacles and opportunities for reform', but it does not adequately explain the policy ideas that influence decisions. However, this may be ameliorated through the inclusion of the historical background of policy formation in the research.

\subsection{Summary}

As with any theoretical framework, it is not expected that institutional theory, and its branch of historical institutionalism, will explain all the nuances of policy change throughout the period researched. However, it is believed that the use of institutional frameworks will provide a sound foundation from which to start analysis and interpretation. Where institutional theories do not explain events, or assist in interpretation, this adds an element of further interest to the research output and contributes to the current literature on institutional theory.

The fundamental concepts of historical institutionalism have a strong link to the topic of this thesis. In particular, the emphasis on a historical approach, the focus on timing and path dependency, together with emphasis on elements such as power dynamics, ideas and the importance of the environment, are all relevant to the thesis. Furthermore, historical institutionalism supports the comparative case study research design.

There is a diverse range of research that utilises the historical institutional perspective. This research has shown that institutional structures play a significant role in influencing the viability of alternative political strategies and, as a consequence, policy development (Pierson 1994:31).

This chapter has outlined details of the theoretical framework used in the thesis. The following chapter, the literature review, explores three sections of the literature: research using historical institutionalism, literature on retirement savings and research on the taxation of retirement savings. 


\section{Chapter 4: Literature Review}

\subsection{Introduction}

The previous chapters have introduced the thesis topic, methodology and theoretical framework. This chapter provides a literature review in three sections. The chapter starts with a synopsis of research using historical institutionalism as a theoretical framework. The second and third sections respectively explore research on retirement savings and the taxation of retirement savings.

\subsection{Theoretical Framework}

The thesis uses historical institutionalism, a branch of institutional theory, as a theoretical framework to analyse the tax treatment of retirement savings in New Zealand and Australia. Justification for the use of institutional theory is outlined in chapter three, together with an in-depth discussion of the concepts, strengths and weaknesses of the approach. This section reviews a selection of the literature that has used institutional theory for analytical purposes. The research examined is primarily comparative with a historical focus, and relates to the topics of process, policy formation, policy variation between countries and tax reform.

The section commences with a review of literature that is predominantly focused on the influence of institutional structure on policy formation. This is followed by an examination of literature that concentrates on policy variations between countries using institutional theory as an analytical framework. The section concludes with a discussion of literature that utilises institutional theory and historical institutionalism for analytical purposes over a wide range of research topics.

\subsubsection{The influence of institutional structure}

The merits of an institutional approach are demonstrated in Steinmo's (1993) seminal comparative study of taxation in Sweden, the United Kingdom and the United States. Steinmo uses an institutional approach to highlight how the preferences, strategies and power of the actors concerned are defined by the institutional context. From this research a model is produced that integrates political and economic institutional 
explanations for variation in tax policies in the three countries investigated. Steinmo argues that the structure of economic institutions (such as labour organisation), together with political institutions, shape the strategic choices of those involved in tax policy formulation. Steinmo claims that differing political and economic institutions (including elected officials, interest group members and bureaucrats) in the three countries present tax policy makers and interest groups with different incentives in relation to tax policy compromises. These institutional contexts may influence the range of policy outcomes seen. Steinmo finds that in Sweden and the United Kingdom, where greater institutional autonomy is present, governments were more successful in restructuring the tax base. Steinmo concludes that institutional autonomy and state capacity improve the prospects of achieving comprehensive tax reform. A similar conclusion was reached by Skocpol (1985:15) in relation to social policy.

Steinmo (1993) investigates how the three countries changed their tax decision making institutions to adapt to growing complexity and argues that the different decision making systems found in each of the countries are rational adaptations of their basic constitutional foundations. Steinmo (1993:7) found that 'the fragmented structure of the American political process stacks the deck against diffuse interests and lends itself to manipulation by highly organized and specific interest groups'. Steinmo argues that a more centralised political system, such as that seen in the United Kingdom, puts political power in the hands of the larger constituencies and prevents the manipulation of public policy by highly specific and non-national interest groups' (Steinmo 1993:7). Steinmo demonstrates that as political rights extended to a wider population base in the three nations, different institutional mechanisms were established to accommodate this change.

Steinmo (1993) found that individuals involved in tax policy development in the three countries wanted similar things; politicians were interested in re-election, bureaucrats wanted to manage stable and efficient tax policy, and interest groups wanted to support the interests of their members. However, how these aspirations were translated into policy preferences was dependent on the 'rules of the game' and the rules of the game 'are written by the institutions through which the game is played' (Steinmo 1993:10). 
Later research undertaken by Steinmo and Tolbert (1998) produces similar results, showing that countries with highly concentrated large unions and national collective bargaining have distinctive spending policy outcomes. Steinmo and Tolbert examine the role of institutional variation in political and economic regimes in shaping taxation policy in OECD democracies. Institutional frameworks are used to show that in countries where business and labour interests are highly organised and integrated into government decision processes, tax policy choices are made with the consent of labour and business interests. A highly organised structure of labour and business interests is suggested to provide a supportive environment for elites to bargain with governmental officials about economic goals and welfare policies. Conversely, where interests are organised in a number of narrow groups that are external to the decision making process, policy makers need to respond to a wider variety of demands and interests. In this latter situation, policy choices tend to have shorter time horizons and policy decisions are made progressively.

Hall's (1992) seminal study of Keynesian and monetary policy in Great Britain investigates a number of institutional dimensions. Hall finds that in institutions such as the Treasury, where routines, rules and decision making procedures existed, procedures acted as filters for communications to outside agencies and affected how ideas were expressed. In addition, the actors within institutions such as the Treasury (which at the time were primarily staffed by career civil servants) had a vested interest and considerable authority over macro-economic policy formation. Hall's research also shows that the organisation of the British trade union movement was particularly relevant to policy development. The trade union was sufficiently powerful to create inflationary pressure, but it was fragmented enough as an organisation to 'render neocorporatist solutions to the problems of unemployment and inflation' (Hall 1992:107). The case used by Hall demonstrates how the trade union institution represented the interests of a social group (i.e. the working class), but equally the social group influenced the expression of the interests.

Hall (1992:91) situates the impact of institutions within a 'broader matrix of competing interests and ideas', showing that institutions interact in a variety of ways. Hall finds that institutions provide incentives for certain types of behaviour, and can contribute to the formation of individual interests within institutions. In addition, Hall 
finds that by organising activity, and the expression of political views from a group perspective, institutions impact on the power with which the interests of that group are expressed.

As with other writers, Hall does not claim that institutions alone produced the changes made to economic policy during the 1970s. The changes seen were the outcome of many complex interactions within a process that was driven by a number of factors including economic conditions and social pressures. The part that institutions played in the process was to influence the direction that the policy formation path adopted. While Hall's research is not comparative, it provides an excellent example of the breadth of research findings that can result from utilising institutional theories in an in-depth historical case study.

A further example of a single case study is that of Radaelli (1999) who uses institutional theory to analyse the tax system in the United States. Radaelli (1999:139) argues that the fragmentation of the American tax system is explained by institutional analysis when looking at the divided political system. Radaelli claims that the system of 'checks and balances' provides multiple points of access to interest groups, creating veto points for those who wish to retain the status quo. Furthermore, Radaelli suggests the Westminster model ${ }^{29}$ of centralised policy making produces a tax policy consistent with these political features. Accordingly, political institutions shape taxation policy through their ability to provide direction in the reform process.

Hansen (1983) also adopts a single case study approach and, like Radaelli, centres the research within the United States. Using rational choice institutional theory, Hansen claims that in the United States a number of institutional constraints affect tax policy making and these constraints should be considered in order to understand tax policy. A 'political incentive' theory of taxation is developed to explain why elected officials want to increase revenues, and how voting rules, an absence of organised opposition and the operation of political institutions are used to enact policies despite resistance. Hansen (1983:15) claims that different characteristics of policies (e.g. visibility,

$29 \quad$ Features of the Westminster model include a unitary form of government, power of Cabinet over Parliament and leadership of the Prime Minister. 
amounts involved, numbers of individuals affected) provide interest groups with different incentives to mobilise to influence the policy.

A further claim from Hansen (1983) is that politicians prefer to avoid both redistributive and zero-sum issues as the conflict between those who benefit and those who lose could lead to political challenge and electoral risk. Hansen builds a model outlining a political and institutional theory of taxation, with the key proposition that political institutions and decision rules can be used to reduce the threat of organised political opposition to the proposed policy. Hansen argues that tax policy often has little to do with economists' input or political theory; rather personalities, expediency and incremental changes explain the tax policy making process. While personalities are certainly relevant in the New Zealand and Australian environments, and incremental changes are seen in the Australian context, the influence of economists in both countries is underplayed in Hansen's model.

Weaver and Rockman (1993a) use institutional theory to consider relationships between political structures and decision making processes. Weaver and Rockman claim that governments made up of a single party holding a minority or slim majority of legislative seats are more likely to be cohesive, as they are usually drawn from a relatively narrow spectrum of opinion on an issue. The party government model, where one party typically holds a majority of legislative seats, is generally seen as especially capable of developing coherent policies and imposing losses on powerful interest groups. Weaver and Rockman (1993a:29) suggest that a government's ability to produce dramatic innovation, and impose losses, will be weaker under a multi-party coalition and this type of arrangement may generate a tendency towards incremental change. A system with a high degree of social and political organisation leads to a stable elite environment, which in turn eases government bargaining with influence groups and facilitates the imposition of losses on some actors.

Weaver and Rockman also find that inherited policy may constrain future policy outcomes and governmental capability. This is associated particularly with expenditure commitments to social functions such as pensions and health care, where extant policy may limit new commitments. Pierson and Weaver (1993) reach a similar finding in their research on loss imposing policy relating to pension schemes in Canada, Germany, Great Britain, Sweden and the United States. Pierson and 
Weaver find that the effects of inherited policy are often stronger than those of political institutions, and may overwhelm the influence of the ParliamentaryPresidential differences. The discussion on path dependency found in both these research articles has particular relevance to the thesis. Path dependency is shown later in the thesis to be an important determinant of the policy outcome for the taxation of retirement savings in both New Zealand and Australia.

Weaver and Rockman (1993b) come to a number of conclusions about the overall influence of political institutional arrangements on government capabilities. Among these conclusions is that institutions do affect governmental capabilities, but their effects are contingent on political and social conditions, and therefore may change over time. Specific institutional arrangements can create both opportunities and risks for individual governmental capabilities (Weaver and Rockman 1993b:446). From their research Weaver and Rockman identify five characteristics that are of particular importance in determining the decision making capability of government: elite cohesion, multiple veto points, elite stability, interest group access and elite autonomy from short-term political pressure. For example, the stability of elites is claimed to be important for ensuring that policies are implemented as intended, and that the policies have some stability over time. During political change, a new political party may attempt a different policy direction.

A more 'traditional' institutional comparison is that of Pierson (1994) who investigates the patterns of welfare state retrenchment in Great Britain and the United States. Pierson's research starts from the premise that two theories have been particularly influential in relation to welfare policy development; one emphasises the power relations within labour movements and the other focuses on the role of institutions. Pierson claims that each is well established as a plausible method of explaining the consequences of many social policy initiatives. However, the power relations perspective does not explain patterns of expenditure reduction in Great Britain and the United States.

Pierson (1994:37) finds that bureaucrats did not have significant roles within the politics of retrenchment; instead, politicians were the principal decision makers, with success reliant on an ability to shape strategies to minimise opposition. Pierson found 
that while bureaucrats play some part in identifying strategies, the choice of policies and the factors determining the likelihood of success, were outside the control of bureaucrats. Pierson (1994:53) also found that the fragmented nature of state provision of pension benefits left political opponents of reform divided and ineffective.

Pierson (1994:57) suggests that evidence supports the claim that standard explanations of patterns of welfare state development, such as political culture or power resources of opponents, did not account for the differences seen in the two countries investigated. Pierson found that the structure of formal institutions made less difference than expected; instead, policy feedback was the vital factor in allowing the policy change to occur.

\subsubsection{Policy variation between countries}

Much of the seminal work using institutional theory and historical institutionalism has occurred in three countries: Great Britain, Sweden and the United States. The majority of the literature reviewed in this section falls into this category; for example, Heclo's (1974) influential research provides a comparative historical account of the long-term development of social policies in Britain and Sweden, and in particular unemployment insurance and retirement assistance. Heclo's research investigates the historical development of income maintenance policies: unemployment insurance, old age pensions and state superannuation. Questions are asked, such as how political forces have influenced the development of modern social policy. Heclo finds that bureaucrats in both countries had more impact on social policy development than political parties or interest groups. Heclo's findings extend to the discovery that bureaucrats had access to the information and administrative expertise to manipulate corrections to social policy that was perceived to have failed.

Steinmo's (1993) aforementioned research into taxation policy in Sweden, the United Kingdom and the United States discusses a number of traditional explanations proposed for policy variation between countries. These include:

- the rational pursuit of short-term self-interest, which Steinmo claims does not appear to explain taxation policy; and 
- the values explanation, where people in different settings have different policy preferences.

From his research findings Steinmo argues that comparative policy research has demonstrated that policy outcomes do not necessarily match the values that are considered to dominate a nation's political culture (Steinmo 1993:5).

Research undertaken by Weir and Skocpol (1985) raises the question of why Sweden and the United States developed similar political responses to the economic crises of the Great Depression, yet resulted in different forms of Keynesian responses. The question of why Great Britain adopted a different approach to the depression than Sweden and the United States is also addressed. The research demonstrates the benefits of a historical institutionalist approach, which emphasises the structural features of the states concerned and the pre-existing components of public policies.

Weir and Skocpol (1985) investigate the influences played by state structures and incumbent policy in the three countries in relation to capacities of interest groups. By taking an in-depth investigation of relationships between states and societies, Weir and Skocpol find that political parties historically outlined their goals to be aligned to existing policies and capacities of the states within which they operated. Furthermore, interest groups were formed, or failed, partially in response to the effects of the policies.

Knudsen and Rothstein (1994) use institutional theory to examine the question of how identical problems are treated differently in two countries with divergent histories: Sweden and Denmark. Knudsen and Rothstein (1994:217) find variations that explain the different approaches to welfare service provision, the primary one being the paternalistic approach of Sweden that imposed greater emphasis on public provision, and a more liberal approach adopted by Denmark that permitted greater introduction of private provision. However, a number of similarities exist in the Scandinavian welfare states, including political features, strong local governments, a tradition of democracy, high welfare ambitions and efficient state administration.

Work by King and Rothstein (1993) uses the early development of British and Swedish labour market institutions to explain the different approaches adopted to the 
unemployment crises in the 1970s. King and Rothstein (1993:149) argue that the way in which institutions were initially established around the turn of the $20^{\text {th }}$ century proved significant for policy choices at a later time. The presence of unique forms of public administration in the labour market made it politically possible to establish an active labour market policy at a later time in Sweden. However, in Britain the absence of a comparable arrangement restricted political attempts to implement a similar active labour market policy. Accordingly, King and Rothstein claim that the structure and capacity of the state is significant for the origin of different types of policy.

An example of research attempting to explain policy variation through institutional frameworks outside of the more 'traditional' countries is that of Tavits (2003). Tavits uses the theoretical frameworks of learning and historical institutionalism to consider what conditions are required for policy transfer from another political system, rather than a country developing its own policy solution. Tavits uses pension reform in Estonia and Latvia to investigate what these conditions might be. The topic and methods adopted by Tavits are similar to those adopted in this thesis. Estonia and Latvia are similar Baltic countries, which adopted different approaches to the reform of their pension systems. Tavits (2003:644) develops a theoretical argument based on transition theories and institutional learning to explain the differences in policy making in transition societies.

Tavits (2003:648) outlines the similar financial and demographic factors in the two countries, including low retirement ages, high contribution to private pension rate, weak links between contributions and benefits paid, and high system dependency rates. Tavits also shows how the three traditionally accepted answers as to why policy transfer was adopted in Latvia (regional diffusion, internal or external determinants and the lesson drawing approach) did not explain why Latvia adopted a different approach to Estonia. Tavits finds that historical institutionalism contributes some explanation of the policy reforms, whereby historical policy choices played an influence on future policy choices, largely through inertia. 


\subsubsection{Research using institutional theory}

Hall $(1986,1992)$ has undertaken a wide range of research using institutional theory. Hall (1986) uses an institutional framework to analyse the political economy of France and the United Kingdom. Hall constructs an institutional analysis of politics, which is claimed to be capable of explaining historical continuities and cross-national variations in policy. This analysis emphasises the institutional relations that bind the components of the state together and form its relations with society. Hall (1986:269) finds that policy making in both France and the United Kingdom reflects the bargaining, which is entered into by producers and the state and is reflected in policy implementation.

Hall (1986) acknowledges the importance of institutions in shaping policy in France and the United Kingdom. Hall argues that to understand the economic policy choices made in France and the United Kingdom, it is necessary to understand their political and policy history. The research finds that choices made during the 1970s and 1980s reflect the long-established patterns of economic policy making in the countries. Hall's work provides a further example of the significance of path dependency in policy making.

Pierson and Weaver (1993) utilise institutional frameworks to analyse situations where losses are imposed in pension policy. Pierson and Weaver (1993:111) argue that policy makers in democratic systems, who suggest policy that will impose losses, must overcome the fear of voter punishment at a later stage. In addition, beyond the initial proposal phase, development and implementation typically requires approval at several further stages (e.g. department or cabinet), and at any of these points the policy may be affected. Pierson and Weaver (1993) find that parliamentary institutions sometimes, but not always, appear to be more capable of imposing losses than the separation of powers system in the United States.

Conclusions outlined by Pierson and Weaver (1993) are that the centralised legislative power and absence of veto points that are found in party government parliamentary systems offer important opportunities to impose losses on the populace. Pierson and Weaver also discuss the proportional representation system, finding that these systems 
vary widely in their ability to impose loss creating policy, with political conditions playing a significant role in determining the level of capability within a government. These factors are both relevant to the thesis due to the presence of party government systems in both New Zealand and Australia.

Hattam (1992) uses institutional theory to investigate political change relating to working class formation in England and the United States during the nineteenth century. Hattam (1992:156) suggests that institutional theory indicates that differences in state structure lead to differences in the labour strategies adopted by these two countries. Furthermore, the particular configurations of institutional power provided very different incentives and constraints for workers, which resulted in labour protests adopting different courses in their development. As with other researchers (e.g. Hall 1992), Hattam finds that the structure of the state cannot solely account for the changing significance of judicial regulation during the time period investigated. Hattam suggests the need to adopt a more relational approach to institutional theory, whereby both institutional factors and the wider social context are considered.

\subsubsection{Research using historical institutionalism}

Historical institutionalism has been utilised in a wide range of economic, political and social policy research. This section provides a selection of the seminal literature using historical institutionalism.

A prominent Australian example, which is particularly relevant to the thesis, is research undertaken by Eccleston (2004). Eccleston uses a historical institutionalist approach to consider the extent to which formal institutional variables influenced the politics of tax reform in Australia. Eccleston considers the formation of new networks in relation to tax policy and the impact such networks had on the direction of Australian tax policy between 1970 and 2003. Eccleston (2004:24) argues that institutional variables have a significant impact on state capacity and policy outcomes and claims that 'the institutional structure of the state not only shapes the decisionmaking authority of executive government, but also has a profound impact on patterns of state-society relations - the so-called institutional basis of relational capacity'. Eccleston also highlights how changing economic conditions acted as a vehicle for the 
national taxation reform debate in Australia, which occurred after 25 years of stable policy. Eccleston (2004:176) concludes that Australia's historically fragmented state structure, liberal political culture and absence of interest group capacity restricted the creation of 'coalitions capable of enhancing the capacity of the state'.

Skocpol's (1979) seminal research using historical institutionalism undertakes a comparative analysis of social revolutions in France, Russia and China. Skocpol concurs with Pierson (1996) when she argues that it is necessary to examine such events in their entirety, rather than trying to isolate individual elements. This claim results from Skocpol's belief that successful social revolutions have a stronger link to the result of different high level structures and historical contexts than failed social revolutions. Skocpol (1979:37) argues that the successful social revolutions that occurred in France, Russia and China demonstrate similar causal patterns, despite a number of other differences. Skocpol concludes that the causes and outcomes of the social revolutions in the three countries investigated could not be repeated in the future due to institutional change (1979:293). Nonetheless the influence of the state is likely to remain a key factor in future revolutions.

Another example of influential research utilising historical institutionalism is Immergut (1992). Immergut considers the central problem within historical institutionalism of explaining change. She approaches this through an analysis of national health insurance politics in France, Sweden and Switzerland, and finds that similar health programs are proposed in the three countries, although the policy results differ. By analysing policy making in terms of correlations between policy inputs (such as demands from interest groups) and policy outputs, Immergut claims that institutional analysis shows why policy inputs and policy outputs may be linked together in different ways in different political systems.

Immergut (1992) concludes that the medical profession had less impact on health policy than was generally believed to be the case, which was caused by opportunities presented by different political systems. Veto points allowed political decisions to be overturned at different stages of the policy process, and permitted interest groups different levels of influence in each country. Accordingly, the policy outcome was heavily influenced by the preferences of interest groups. Barriers that existed in the form of constitutional rules and electoral results served as tools for the use of interest 
groups when they wished to block legislation. In France, opportunities for parliamentary concessions privileged certain groups, such as Catholic unions, doctors and small businessmen (Immergut 1992:82). Conversely, in Sweden, executive decision making tended to privilege the larger producer organisations. This indicated that 'by making some courses of action more difficult and facilitating others, the institutions redefined the political alternatives and changed the array of relevant actions' (Immergut 1992:82).

Research undertaken by Bulmer (1998) in the context of the European Union adopts a historical institutionalist approach to European Union governance. Bulmer examines four different aspects of European Union governance using evidence associated with the launch of the single European market in 1985: systemic change, governance structures, policy evolution, and the role of values and norms. Bulmer (1998:373) claims that historical institutionalism offers a number of insights into the dynamics of the policy process, revealing path dependency and policy solutions that are no longer relevant. Bulmer (1998:382) suggests that these insights can be extended from the single market approach to the whole of the European Union.

Further macro-level research within Europe using a historical institutionalist perspective comes from Pierson (1996) who uses a historical institutional approach to investigate European integration, claiming that the evolution of the arrangements could be considered an 'extraordinary political experiment' (1996:123). Pierson's research focuses on why gaps emerged in member-state control over the evolution of European institutions and public policies. Pierson adopts a historical approach in order to recognise that political development must be understood as a process that unfolds over time. A further link to institutionalism within this research comes from the emphasis placed on the implications of the timing of processes that are embedded within institutions.

Torfing (2001) uses historical institutionalist path dependency arguments to consider welfare reforms in Denmark in the 1980s and 1990s. Torfing (2001:277) finds that political attempts to reform policy often failed, and in the successful cases, the new policy was significantly influenced by the existing policy path. In addition Torfing found that while critical junctures were apparent, these were rare. Situations where 
actors attempted to change policy, implement reform or alter political behaviour frequently created insignificant changes that tended to result in maintenance of the status quo.

An example of a particularly broad historical topic can be seen in Collier and Collier's (1991) research using institutional frameworks to study the relationships between the state and the working class in eight South American countries. The purpose of the research was to discover explanations of change in the relationship between the state and the working class and involved consideration of each country over several decades. Collier and Collier investigate both similarities and contrasts between the countries, with the aim of identifying whether the changes within each country reflect the same causal pattern. Using a critical junctures approach, the research establishes that earlier patterns, where repression tended to be a central feature of the state response to worker organisation, over time moved towards state policies that supported the labour movement.

The recent interest in ideas in historical institutionalism originates from the belief that ideas underpin political behaviours and outcomes. Steinmo (2008b:198) investigates tax reforms in the late $20^{\text {th }}$ and early $21^{\text {st }}$ centuries and suggests that the context from within which policy is made impacts on the context of the future policy making environment. Steinmo (2008b:209), in referring to the tax reforms adopted in the western world from the mid 1980s onwards, suggests that tax policy was the 'leading edge in these new political tides. In short, old policies created new problems. New ideas were introduced to help solve these new problems'.

Perhaps one of the most thought provoking readings on ideas is that of Appel (2000), who utilises institutional theory to explain how mass privatisation benefits were distributed to populations in Eastern Europe. Appel outlines how ideas influenced the design of programs across different countries, challenging existing accounts that primarily focus on the power of individuals and institutions. Appel suggests that a key deficiency of many analyses is that they make no attempt to capture the forces 'shaping how preferences form' (Appel 2000:523), which the concept of ideas may assist with. 
Appel's research on privatisation policies in Eastern Europe has relevance to the thesis; in particular, through its exploration of why the approaches privileged some groups above others. Appel (2000:525) argues that it is necessary to consider ideas in order to address this question and suggests four principal ways in which ideological factors influenced the privatisation policy in the Eastern European countries investigated:

- how ideology helps form policy programs;

- how the ideological context forms power distributions and defines interests;

- how ideas influence validation of policy; and

- the compatibility of policy ideas and ideas within society.

McNamara (1998) explores how and why European Union governments adopted monetary union. McNamara shows that 'political elites have shared a strong ideational consensus concerning the desirability of Economic and Monetary Union, as a way to lock in monetary stability and neoliberal politics' (McNamara: 1998:ix). Among her insights, McNamara finds that the ideas of political and business elites are those that form the policy debates, and 'voters have been only a passive audience' (1998:xii).

Seminal work by Hall (1989) explores the impact of Keynesian ideas across countries, with the aim of explaining 'why an economic theory influences policy in some places and periods, yet not in others'. The focus of ideas in this research emphasises the way in which policies evolve from economic ideas, which enable 'national leaders to chart a course through turbulent economic times' (Hall 1989:361). Hall suggests that ideas can contribute towards an explanation of why it is that some policies are influential in some countries and times, but not in others; thus, Hall argues that ideas should be afforded an explanatory role in analyses of policy making.

What is seen in this brief coverage of a small sample of the literature utilising historical institutionalism for analytical purposes is the broad range of topics and methodologies that historical institutionalism supports. While much of the literature has a social policy focus, historical institutionalism is not limited to this theme, as shown in the above discussion. 


\subsection{Retirement Savings}

While this thesis is interested in the taxation of retirement savings, it is important to situate the research within the wider context of retirement savings. Therefore, this section provides a synopsis of the research undertaken on the topic of retirement saving. As the literature in this area covers an extensive range of topics, it has been necessary to limit the scope of the literature review to the research that is most relevant to the thesis. Accordingly, the literature review has focused on particular themes.

This section commences with a brief review of the literature relating to household saving behaviour in New Zealand and Australia. The current literature on retirement saving in each country is then reviewed. This is followed by a discussion of the literature relating to the policy objectives of retirement saving and the role of the state. The section concludes with a review of the literature that provides a comparative analysis of international approaches to retirement savings and the various reforms adopted by different countries.

\subsubsection{Household saving behaviour}

It is difficult to address the topic of retirement savings without reference to overall savings. At a theoretical level, retirement savings are no different from other forms of savings as they still require individuals to reduce their current consumption to provide for their future consumption. However, it is generally accepted that retirement savings require a longer term deferral of consumption than traditional savings. At a micro-economic level the level of retirement savings will directly impact on a retired individual's standard of living.

Why individuals decide to save or consume has been debated for a considerable period of time. Keynes (1936:107) produced a list of reasons for saving, which includes:

- precaution: to build up a reserve against unforeseen contingencies;

- foresight: to provide for an anticipated future relation between income and the needs of the individual or family that may be different from that which exists in the present; 
- calculation: to enjoy interest and appreciation;

- improvement: to enjoy gradually increasing expenditure;

- independence: to enjoy a sense of independence and a power to do things;

- enterprise: to secure a sufficient amount to carry out speculative or business projects;

- pride: to bequeath a fortune; and

- avarice: to satisfy miserliness (i.e. unreasonable aversion to expenditure).

Keynes (1936:108) also produced a list of reasons why individuals consume:

- enjoyment;

- short-sightedness;

- generosity;

- miscalculation;

- ostentation; and

- extravagance.

Other factors that are likely to impact on savings decisions include the level of state provided support for the elderly and expectations about the future. Tax arrangements may influence saving behaviour; increased taxes may reduce the levels of savings (or consumption) that can be achieved, while a reduction in tax levels may increase the levels of savings (or consumption). Finally, social attitudes may impact on savings. ${ }^{30}$

The reasons why individuals may choose to save or consume may change during their life-cycle and may be a combination of many or all of the above factors. Accordingly, it is unreasonable to expect any one reason will explain saving behaviour, and this contributes to the difficulty associated with policy and planning for retirement saving.

Levels of savings can have macro-economic impacts. From a national perspective, economic welfare is determined by economic growth (Savage 1999:3). As savings are a key source of funds for capital investment, the rate of savings within a society

30 There is some indication in the literature that younger generations have a lower propensity to save than older generations. 
can impact on the ability of an economy to grow. ${ }^{31}$ Household savings in general are seen as important as low savings can result in low investment flows, which may lower real wages and standards of living or alternatively see greater overseas control of the country's capital stock (Fitzgerald and Harper 1992:198). ${ }^{32}$ Furthermore, information about households' saving and borrowing behaviour influences judgements made on the state of a country's economy, while the level and composition of financial savings are important policy issues (Thorp and Ung 2000:17). For the purposes of the thesis, retirement income savings is categorised as a subset of national savings.

Household savings rates in New Zealand were relatively stable over the 1970s and 1980s, but have been declining over the 1990s (Claus and Scobie 2002:7). This decrease in household savings has occurred simultaneously with an increase in household indebtedness, which has risen at a faster rate than in other OECD countries. In addition, New Zealand has a household saving rate that is consistently one of the lowest among OECD countries $^{33}$ and financial asset holdings that are also low compared to OECD countries (Goh, 2005:20). ${ }^{34}$ The economic impacts of this situation are well documented, and include reliance on foreign capital, sensitivity of households to changes in interest rates and, perhaps the most obvious, an inability to meet costs of health, education or retirement without reliance on the state.

31 It has also been argued that higher economic growth, in turn, promotes higher saving rates, as greater levels of saving are achievable with individual wealth increases within a country (Savage 1999:13).

32 It is acknowledged that national saving and individual saving are different concepts. The topic of savings in the economy incorporates household saving as well as business and government saving. The most important measure is national savings (public and private savings), and therefore the savings rate can be significantly influenced by government savings patterns. A number of reviews have pointed to a key problem in New Zealand resulting from low government saving.

33 There are a number of recognised difficulties with cross-country comparisons of savings due to measurement differences, financial market developments, institutional arrangements and societal preferences.

34 For example, IMF country report No. 03/122 finds that New Zealand's average national savings rate is 15.5 per cent, compared to the OECD average of 21 per cent (International Monetary Fund 2003:17). 
Net national savings have varied across OECD countries, ranging from Finland with an average rate of one per cent of GDP to Korea with 21 per cent of GDP (Claus and Scobie 2002:16). Norway has also produced a relatively high rate of national savings at around 12 per cent of GDP. New Zealand is positioned at the lower end with national savings of four per cent of GDP. The declining trend witnessed in New Zealand has occurred in most OECD countries. The net national savings rate in New Zealand, as measured by the conventional flow approach in the national accounts, has been trending downward for the last 30 years (Claus and Scobie 2002:32). Household savings rates as a percentage of household disposable incomes for New Zealand and Australia, together with selected OECD countries, are outlined in Table 4.1. These figures show the decline in household savings among all countries. However, New Zealand is the only country to have negative household savings rates over an extended period. Some suggestion has been made that falling savings ratios can be attributed to the perception of gain in housing wealth (Thorp and Ung (2000:30). However, increases in housing wealth are not peculiar to New Zealand and therefore may only contribute a partial explanation for the downward trend.

Table 4.1: Household Savings Rates in Selected OECD Countries (per cent of household disposable income) ${ }^{35}$

\begin{tabular}{|l|l|l|l|l|}
\hline & $\mathbf{1 9 7 0}-\mathbf{1 9 7 9}$ & $\mathbf{1 9 8 0}-\mathbf{1 9 8 9}$ & $\mathbf{1 9 9 0}-\mathbf{1 9 9 9}$ & $\mathbf{2 0 0 0}-\mathbf{2 0 0 4}$ \\
\hline Australia & $\mathbf{1 4 . 2}$ & $\mathbf{1 1 . 1}$ & $\mathbf{5 . 0}$ & $\mathbf{0 . 1}$ \\
\hline Canada & 12.0 & 15.3 & 9.1 & 3.1 \\
\hline France & 13.2 & 9.5 & 10.0 & 11.2 \\
\hline Germany & 13.1 & 12.8 & 11.6 & 10.4 \\
\hline Netherlands & 4.1 & 14.3 & 13.9 & 10.1 \\
\hline Japan & 23.7 & 16.3 & 12.3 & 6.8 \\
\hline New Zealand & $\mathbf{3 . 6}$ & $\mathbf{2 . 8}$ & $\mathbf{- 1 . 6}$ & $\mathbf{- 6 . 9}$ \\
\hline United States & 9.6 & 9.1 & 5.2 & 1.7 \\
\hline OECD Average & $\mathbf{1 6 . 6}$ & $\mathbf{1 7 . 3}$ & $\mathbf{1 3 . 0}$ & $\mathbf{1 0 . 4}$ \\
\hline
\end{tabular}

The extent to which increased retirement saving will impact on increased overall national saving is reliant on the extent to which saving is new, and not a substitute for

$35 \quad$ Source: Goh (2005:18). 
other saving mechanisms. In addition, overall saving (i.e. including public saving) may reduce to the extent that incentives are provided in the process.

Housing assets account for around 70 per cent of New Zealand households' total assets (Goh 2005:13). This compares with around 65 per cent in Australia, between 50 and 55 per cent in the United Kingdom, Germany and France, and around 37 per cent in the United States (Goh 2005:13). However, when expressed as a percentage of household disposable income, New Zealand's housing wealth is comparable to that of Australia and the United Kingdom.

Goh (2005) suggests that the reasons for the relatively low level of financial asset holdings by New Zealand households are not clear. Measurement issues may account for some of the difference, but are unlikely to be significant. Goh (2005:20) suggests factors such as the absence of a compulsory savings scheme, the absence of tax incentives to promote savings, a preference for investment in property, ${ }^{36}$ risk aversion after the 1987 sharemarket crash, a lack of access to diversified financial investment products and a relatively generous minimum retirement income level may be factors contributing to New Zealand's lower financial asset holdings when compared to other OECD countries. Similarly, the IMF (2003:21) claims that empirical evidence indicates that the government pension and other income support transfers in New Zealand have a significant influence on saving. The IMF (2003:21) suggests that household saving decisions, and the sufficiency of saving, can be seen as being heavily influenced by the expectation that the government will meet its future pension obligations without significant changes in taxation or benefit reduction.

The question of whether New Zealanders are saving sufficiently is far from clear. Commentators such as Claus and Scobie (2002) and the IMF (2003) find little support for the claim that there is a savings problem in New Zealand. The IMF (2003:17)

36 Research does not provide a consistent picture of property investment as a substitute for more traditional retirement saving forms in New Zealand. For example, Bollard, Hodgetts, Briggs and Smith (2006: 23) suggest that there is a 'deep-seated suspicion for financial assets' in New Zealand, resulting in a tendency to invest in property. However, Scobie, Le and Gibson (2007:4) suggest that New Zealanders' investment in property is not dissimilar to other OECD countries. 
claim that the decline in the savings rate of New Zealand households is reasonably well explained by factors such as high public saving, the high government pension and income support transfers to individuals, increased household wealth and improved access to credit.

Research by Scobie, Gibson and Le (2004) examines the issue of saving in New Zealand, with a focus on determining whether New Zealanders are preparing adequately for their retirement. Using a life-cycle approach, ${ }^{37}$ their research suggests that there is not widespread undersaving for retirement in New Zealand. However, findings of this nature reflect the definition of 'adequacy' that is adopted in the research. More recent research by Scobie, Gibson and Le (2005) takes the measure of adequacy of retirement savings as the ability to maintain the level of pre-retirement consumption, based on the assumption that New Zealand Superannuation will be provided.

Among their conclusions, Scobie, Gibson and Le (2005) find evidence that enrolment in a workplace scheme is associated with higher levels of net worth. However, this does not occur for personal schemes. Complementarities, in the form of higher holdings in one scheme associated with higher holdings in other forms of savings, are also found. Explanations provided for this include the recognition effect, which has been widely documented. Both Cagan (1965) and Katona (1965) find a 'recognition effect', which suggests that involvement in any form of retirement savings increases awareness of the need to save for retirement and increases saving through other mechanisms. A further explanation offered is self-selection bias. As with the recognition effect, this has been documented widely and suggests that individuals who enrol in one form of retirement savings scheme are more likely to save than the population as a whole (Hubbard and Skinner 1996:76).

The issues raised by Keynes in 1936 have, more recently, arisen as influencing savings behaviour. For example, Barro (1974:1099) finds an 'intergenerational transfer' or bequest provision where parents and relatives save for the purpose of leaving financial support for their children or extended family. Daldy, Hickey and

$37 \quad$ Life-cycle theory is discussed later in this sub-section. 
O'Neill (1985) find that empirical studies in this area add to confusion on the issue of whether savings can be influenced by social welfare benefits. Daldy, Hickey and O'Neill (1985:30) cite results from a review of empirical studies and find that income transfer programmes reduce annual private savings by between zero and 20 per cent, with the most likely estimate found at the lower end of this range.

A key question for saving policy has been whether government policy can influence the level of saving. Carroll and Summers (1987) investigate this question together with the mechanisms that may affect behaviour. The research is undertaken using the 'exceptionally good natural experiment that has been provided by Canada and the United States of America' over the 35-year period to 1985 (Carroll and Summers 1987:249). As with Australia and New Zealand, the American and Canadian economies are similar, as are their institutional arrangements and geography. Rates of savings in America and Canada were similar for a 25-year period, after which time they diverged dramatically with savings in America reducing and savings in Canada increasing. The research shows that the divergence of the savings rates occurred at a similar time to the introduction of major savings incentives in Canada in the early 1970s. Caroll and Summers (1987) conclude that tax policies can have a significant impact on saving behaviour and the differences in tax structures between the two countries are important factors in explaining the patterns of saving in the two countries.

There are a number of theories of household saving behaviour. The life-cycle theory is the model most frequently used in analysis of household savings behaviour and has been the starting point for most analyses investigating how pensions affect personal saving (Gillion, Turner, Bailey and Latulippe 2000:355). Life-cycle models examine the effect of an individual's decisions over their lifetime (Daldy, Hickey and O'Neill $1985: 24)$. In the life-cycle theory of consumption, households choose how much to save and how much to work over their lifetimes based on present income and expected future income. In its most basic form the life-cycle model implies that households save during their working lives to finance retirement consumption (Hubbard and Skinner 1996:76). The model suggests that households will have high levels of saving at times of high earnings, which will then be 'dis-saved' during periods of lower income, such as retirement. 
Saving patterns will be influenced by factors such as the rate of return on savings, individual preferences over consumption and the time profile of earnings. In terms of the life-cycle model, the provision of a tax incentive to a savings vehicle raises the rate of return for saving through that particular savings mechanism. The life-cycle theory predicts that, in the absence of government intervention, a state's saving or wealth will be determined by the age structure of its population, per capita income and retirement patterns (Gillion, et. al. 2000:355).

Possible explanations for why a decline in household saving rates is seen in some OECD countries, but not in others, are investigated by Hiebert (2006). Hiebert finds that while many countries have similarities insofar as institutional or cultural features are concerned, factors such as capital gains or rapid financial innovation have played some part in the differences in household saving rates; for example, gains in valuation of assets such as housing have been important as a substitute for traditional household saving.

Of the countries studied, Hiebert (2006:1) finds four that have had the most pronounced decline: Australia, Canada, the United Kingdom and the United States. New Zealand is not included in the analysis. In these countries, a reduction in the overall level of savings has corresponded with a rise in wealth and improved access to capital gains in financial and residential markets. Hiebert concludes that gains in wealth in these forms have been used increasingly as a substitute for traditional forms of savings. Hiebert's research demonstrates how the changing nature of saving may be an important factor to take into account when considering levels of national savings.

\subsubsection{Retirement income saving in New Zealand}

When compared to Australia, there is a scarcity of research in some areas relating to retirement income savings in New Zealand. Research has primarily focused on the welfare of retired individuals (e.g. Age Concern 1998; Davey and Gee 2002; Davey and Keeling 2004; Fergusson, Hong, Horwood, Jensen and Travers 2001), the impacts or economics of population ageing (e.g. Bryant, Teasdale, Tobias, Cheung and McHugh 2004; Creedy and Scobie 2002; Davis and Fabling 2002; Guest, Scobie and 
Bryant 2003; Statistics New Zealand 2002; Stephenson and Scobie 2002), or more general savings trends (e.g. Claus and Scobie 2002; Coleman 1998; Office of the Retirement Commissioner 2001). Noticeable gaps exist in relation to areas of policy development, the role of the state in retirement provision and the determinants of saving in New Zealand. ${ }^{38}$ There has also been little robust academic discussion on taxation incentives in New Zealand. ${ }^{39}$

As Savage (1999:15) notes, the evidence that is available in New Zealand 'presents a mixed and incomplete explanation of New Zealand household saving patterns'. Savage cites Clements' (1984) study, which shows inflation has a negative effect on the saving rate as high inflation lowered real interest rates. Clements finds that the savings rate in previous periods has an impact on current savings rates.

Research has been undertaken in New Zealand on the composition and level of retirement savings. As found by the New Zealand Treasury (2007:2), policy analysis on saving in New Zealand is problematic due to (among other factors) an absence of quality data about saving. However, it is generally accepted that there has been a decline in superannuation scheme membership in New Zealand since the late 1980s, although this has stabilised in recent years. ${ }^{40}$ Life insurance companies and superannuation funds comprised over 85 per cent of the long-term savings industry in New Zealand until the 1990s (Thorp and Ung 2000:23). ${ }^{41}$ In New Zealand in 2007

38 Typically the quality and availability of data on saving, and the degree of structural change in New Zealand, are the reasons provided for the absence of research in this area of savings determinants in New Zealand.

The extent of the 'gaps' can be seen when looking at the most recent bibliographic reference of research on New Zealand ageing (New Zealand Institute for Research on Ageing 2005). Of this 50-page document, two and a half pages are devoted to retirement income and one paragraph relates to the taxation of retirement savings. The primary focus is on health, education and aged care.

For the decade between 1995 and 2005 superannuation scheme membership stabilised at around 650,000 members (Insurance and Superannuation Unit Annual Reports, www.med.govt.nz). This has increased substantially since the introduction of KiwiSaver accounts in New Zealand in 2007, which is discussed in greater detail in chapter six.

41 These funds included the Government Superannuation Fund and the National Provident Fund, catering primarily for public sector employees and comprising around half the assets of the 
less than 15 per cent of the labour force were members of occupational superannuation schemes and a significant number who had access to superannuation schemes were not members (Davey 2004:10).

The most frequent commentator on retirement savings in New Zealand is St John (Ashton and St John 1988; St John 1992, 1993, 1994, 1999, 2001, 2003; St John and Heynes 1993; St John and Willmore 2000). St John addresses issues such as equity and the unique approach adopted to retirement savings by New Zealand. New Zealand does feature more frequently in comparative research in relation to retirement savings. This research is discussed in more detail in section 4.3 .5 of this chapter.

\subsubsection{Retirement income saving in Australia}

As noted in section 4.3.2, research on retirement savings in Australia has received wider academic interest than in New Zealand; for example, research by Rothman (2003) examined the extent to which superannuation is a concessional investment opportunity in Australia compared to investing in comparable portfolios outside superannuation funds. Rothman's approach compares investment funds at retirement (after taxes) where an individual invests in a superannuation fund and also where the same amounts of funds are invested outside of superannuation funds (but using the same investment portfolio as used for the superannuation investment).

Rothman (2003:2) finds that for individuals in all tax brackets receiving Superannuation Guarantee employer contributions only, superannuation was a tax preferred investment over a working lifetime of up to 40 years. Rothman extends the analysis to other long-term tax advantaged savings vehicles, such as making additional payments towards a home loan or saving for retirement through investing in an actively managed business. The key factor that determined the outcome in the comparisons was the pre-tax return of the investment relative to the pre-tax return of the superannuation fund. Rothman's analysis showed that in many situations saving

pension industry in the late 1970s (Thorp and Ung 2000:23). The remainder of the industry was comprised of life insurance companies, private managers and large firms with selfmanaged pension schemes. 
through superannuation funds was more tax advantaged than some of the highly tax advantaged alternatives.

Wills and Ross (2002:10) claim that while coverage of superannuation appears high amongst those employed, there are still significant numbers of individuals who have no private superannuation arrangements, primarily those that are unemployed or lowincome earners. Wills and Ross cite research that has found 25 per cent of the preretired Australian population have no private superannuation fund arrangements, including 48 percent of people aged 15 to 24 years of age, 55 per cent of unemployed people and 70 per cent of those not in the labour force, but not retired. In addition, Wills and Ross (2002:11) argue that individuals in Australia are not saving sufficiently to have the standard of living that they expect in retirement.

Edey and Britten-Jones (1990:125) suggest that 'there can be little doubt that concessional treatment of superannuation earnings has led to a shift in the allocation of savings', but the extent to which incentives have increased savings is uncertain. As generally accepted, this depends on the degree of substitutability of superannuation assets for other forms of savings. Edey and Britten-Jones find that in Australia there had been no obvious increase in private savings since 1980, despite the increase in superannuation contributions. They note that when the cost of providing superannuation tax concessions is taken into account (around $\mathrm{A} \$ 3$ billion at the time), that it is possible for national savings to be negative.

Later research has found different results, which is likely to reflect the implementation of the Superannuation Guarantee in Australia. Connolly and Kohler (2004) examine the amount by which increased superannuation saving has been offset through reduced savings in alternate vehicles in Australia. The study was undertaken 17 years after the introduction of award superannuation and accordingly had access to a long time-series of data. Connolly and Kohler (2004:1) find an offset coefficient ${ }^{42}$ of around 38 cents in the dollar, which is dissimilar to those found in other studies. ${ }^{43}$

\footnotetext{
42 The offset coefficient measures how much of the increase in saving through superannuation has been as a result of a decrease in savings in other forms.

$43 \quad$ Refer to section 4.4.2.1 for discussion of these studies.
} 
Conflicting results are found in research by PricewaterhouseCoopers (2005), which examines whether compulsion led to additional total savings in Australia, and finds that compulsory superannuation may have only increased household saving rates by around one and a half per cent above what would have occurred in the absence of the mandatory scheme. Morling and Subbaraman (1995) also investigate the increase in household savings in Australia, and also argue, in contrast with Connolly and Kohler (2004), that there has been no obvious increase in total household savings. This suggests that households have reduced other forms of savings in line with compulsory occupational retirement savings. The results from Morling and Subbaraman's research suggests a significant degree of substitution between superannuation and other forms of saving, of a level of around three-quarters of superannuation savings since 1960. However, the nine-year period between the two research papers may explain the different results found.

A frequent commentator on retirement savings policy in Australia is Bateman (2002, 2005, 2006; Bateman and Piggott 1992, 1997, 1999, 2000, 2001; Bateman, Kingston and Piggott 1994, 2001; Bateman and Kingston 2007). As with St John in New Zealand, Bateman also addresses issues of equity and retirement income strategy in Australia. This research is discussed later in this chapter, and chapters five and eight.

As with New Zealand, there is considerable Australian research focused on national and household saving behaviour. During the 1990s Australia had a gross national saving rate significantly below the OECD average, but, unlike New Zealand, Australia raised national saving over the period (IMF 2003:17). This difference can primarily be linked to public saving. New Zealand raised the level of public saving rate faster and to a greater extent than Australia in the first half of the 1990s. However, while the public saving rate levelled in New Zealand towards the end of the 1990s, it continued to grow in Australia (IMF 2003:17).

\subsubsection{The role of the state}

\subsubsection{Policy objectives}

Payments to individuals according to need are the basis on which the New Zealand and Australian welfare systems have developed. It is generally accepted as socially 
desirable that retired individuals should not face undue hardship in their old age. However, it is also typically considered necessary to elaborate more specific goals for retirement income policy. Over the past 20 years, the broad policy objectives of retirement savings in New Zealand and Australia have diverged. The policy objective in Australia has been clearly stated as ensuring an adequate income for retired Australians 'both now and in the future' (Parliament of the Commonwealth of Australia, 1996). Other, more recent, objectives include enabling Australians to achieve a higher standard of living in retirement than would be possible from reliance on the Age Pension alone.

The policy objective of retirement savings in New Zealand has been articulated as encouraging increased private sector provision for retirement and assisting workers to have a better standard of living in retirement. However, the policy enacted to achieve this objective is significantly more non-interventionist than that adopted in Australia.

What can be seen in New Zealand and Australia is a degree of misalignment between the stated policy objectives and the policy tools utilised to achieve the objectives. It is generally accepted that the policy objectives and policy mechanisms implemented in Australia are both aligned towards income maintenance in retirement, while the policy tools utilised in New Zealand are more likely to lend themselves towards poverty alleviation. As noted by Agulnik (2000:47), earnings related pension schemes, as found in Australia, are designed to protect individuals' living standards in retirement, while flat-rate pensions, as found in New Zealand, have the aim of simply ensuring a universal minimum income standard.

Davey (2004) notes that New Zealanders are 'encouraged' to save for their retirement. However, the level of encouragement in New Zealand does not extend greatly beyond exhortation. All other OECD countries have some or all of the elements of compulsion, tax concessions, favourable tax treatment of private superannuation and encouragement of occupational schemes.

Ashton and St John (1988) discuss the 'bitter political division' in superannuation policy in New Zealand since the early 1970s. This has been well documented in the literature, and generally the numerous policy changes and reversals of policy have led 
to considerable criticism of the various schemes over the period investigated in the thesis. The (United Kingdom) Institute of Chartered Accountants (1999:20) describes the retirement income reform process in New Zealand as 'especially unhappy, protracted and frankly absurd. A full description of all the reforms, proposed reforms, counter-reforms and about turns reads like a rather implausible script for a farce'. While not all commentators are so harsh, the New Zealand system is generally included in studies more for its originality than as any ideal model to be emulated. However, while retirement savings policy has been correctly described as being a 'political football', the policy has found favour with some commentators (e.g. Willmore 2000).

As with New Zealand, the role of the state has been criticised in Australia. Warren (2000:286) writes that there are three goals underlying the government's approach to superannuation in Australia:

1. a level-playing-field approach to taxing all savings;

2. a concern about budget deficits and the need to increase government revenue to fund increased public savings; and

3. a desire to encourage private savings.

The level playing field approach to the taxation of savings has not been achieved in Australia, and there is little indication that this has been a policy objective over the past three decades. When comparing the policy objectives, policy direction and policy tools espoused and implemented in Australia and New Zealand, it could be suggested that the Australian government decision making process was based on different information to that of New Zealand; for example, Robinson (1992) writes that the introduction of 'award' superannuation in Australia was partly the result of recognition that traditional tax incentives had to be supplemented by alternative means if the government's objective of widespread access to superannuation was to be achieved. Considerations taken into account included:

- the acceptance that people prefer to consume now, rather than save for future consumption - and the future is typically discounted too heavily;

- recognition that an 'incentive only' approach to superannuation had not resulted in broad superannuation coverage among the population; and 
- acknowledgement that without compulsion, lower-income earners were unlikely to access the tax concessions for superannuation (Robinson 1992:10). The New Zealand approach, while acknowledging some of the factors mentioned above, has continued on a vastly different policy approach to that of Australia.

\subsubsection{State intervention}

There are numerous potential forms of state intervention in relation to retirement savings, including the regulation of private retirement savings arrangements, compulsory occupational schemes and tax incentives for private retirement savings. The World Bank (1994:6) argues that the key question of the role of the state is not whether the public sector should be involved; instead, it is how the public sector should be involved. However, the World Bank approach is not universally accepted, with a number of commentators questioning the reasonableness of state intervention in retirement income participation. The question of whether there is a rational explanation for compulsory occupational retirement saving schemes has not been widely addressed; rather, the World Bank model has been adopted by most countries with apparently little theoretical foundation for state-mandated schemes.

The World Bank model is a three-pillar model recommending, firstly, a state provided pension; secondly some form of mandatory occupational retirement savings scheme; and, thirdly, voluntary savings through private financial markets. Typically, most OECD countries have these three components within their retirement savings models, although New Zealand and Ireland do not adopt the second pillar. In addition, there is wide variation in the forms in which countries adopt the second pillar. This 'second pillar' is intended to ensure that retired people have an adequate standard of living in retirement, rather than poverty prevention alone, whereas the 'first pillar' is intended to:

- redistribute to the poor;

- augment the income of the old who can no longer work productively;

- protect the elderly from risk by providing an assured benefit;

- protect the elderly against inflation; and

- be a remedy for myopia (World Bank 1994:101). 
The key arguments typically used to defend state involvement in retirement saving include:

- the myopia argument, as few individuals save sufficient funds to continue their lifestyle during employment into retirement (Knox 1992:65); ${ }^{44}$

- the belief that compulsory occupational savings encourages the development of capital markets and facilitates economic growth (St John and Willmore 2000:15);

- insurance market failures, which can be the result of moral hazard behaviour (where individuals have an incentive to consume at the present time in order to be eligible for a means tested benefit in retirement), adverse selection or correlations among individuals making insurance against many risks unavailable (World Bank 1994:5);

- inadequate savings instruments, as capital markets are undeveloped and economic conditions are unstable in many countries;

- the paternalistic argument, where changes in policy may leave an individual with insufficient retirement income (Carmichael and Plowman 1985:131); ${ }^{45}$

- income redistribution, where income earners may have insufficient earnings during their working lives to save sufficient amounts for retirement;

- reduction of government spending on public provision and a higher level of private provision for those most in need (Task Force on Private Provision for Retirement 1992:50);

- access to information, where individuals may be unable to assess their requirements in retirement with a sufficient degree of accuracy, and at the

$44 \quad$ As an alternative to the argument that individuals are myopic, Feldstein (1996) suggests that most households accumulate little or no financial assets, which is rational decision making based on the assumption that state provided benefits will substitute for private wealth accumulation. Conversely, Borsch-Supan (2004:112) argues that there is considerable empirical evidence corroborating the potential for myopia. Mitchell (1998) finds that most Americans save too little to preserve current consumption standards in retirement.

$45 \quad$ Carmichael and Plowman (1985:131) also argue that paternalism can arise from a divergence between an individual's marginal rate of time preference and society's marginal rate of intergenerational preference, where an individual with a strong preference for current consumption may save for a level of retirement income that is below that desired by society. 
point when sufficient information is available to make informed decisions it is too late to make the necessary significant changes to savings levels; and

- willingness to pay, which is the argument that individuals are more willing to pay for a compulsory occupational retirement fund than for a flat-rate or means tested scheme paid out of general taxation.

Many of these points are disputed in the literature; for example, Carmichael and Plowman (1985:130), argue that in the absence of government intervention an individual's desire to avoid poverty in their retirement will provide sufficient incentive to save for retirement. It is also argued that the presence of a 'safety net' may discourage individuals from saving for their own retirement provision. However, the level of savings, or conversely the level of support required, will depend on personal preferences, such as, the willingness to save, together with other potential sources of income (for instance, charitable sources or assistance from families). Similarly, the size of the 'safety net' and the extent to which it is targeted will also have some influence on behaviour.

Arrau and Schmidt-Hebbel (1995:1) suggest that compulsory pension systems are among the 'most multi-dimensional and complex economic arrangements developed by modern societies'. The claim results from the impact retirement systems have on macroeconomic issues, welfare issues, capital and labour markets, and public finance effects. Other researchers (e.g. Savage 1999:12) argue that actuarially fair publicly provided pensions ${ }^{46}$ will have no net effect on individual saving or consumption behaviour, as any premium payments will be offset against expected lifetime income.

From an economic perspective, the rational approach to retirement income system design is to agree on objectives and then establish instruments to achieve these objectives (Barr 2000:30). However, the World Bank focuses initially on policy instruments, without consideration of the concomitant objectives. This method presupposes the policy choices that individual countries will make by providing a prescribed mix of instruments. Conversely, Holzmann and Hinz (2005:3) suggest that a multi-pillar retirement income system design is better placed to manage the multiple

46 That is, those that are funded from taxes and go to an individual account. 
policy objectives likely to exist within the overall issue. However, as the New Zealand system appears to be primarily focused on the one objective of poverty alleviation, with little intent to influence income smoothing, it may be that the noninterventionist approach adopted is the most appropriate. As found by Holzmann and Hinz (2005:4), some systems function effectively with only a universal pension and voluntary savings.

A further issue in relation to compulsory retirement savings schemes is that they may result in individuals saving less than they otherwise may have done, in the belief that the compulsory level of savings is sufficient. Australia has noted the potential for this with the government emphasising that the nine per cent compulsory contributions will provide only a modest income for most savers (James 1998:146). Similarly, mechanisms such as asset tests may result in distortion of savings patterns. This can be seen in Australia, where the assets test does not apply to the family home, thereby encouraging individuals to invest to a greater extent in their individual property than they may otherwise have done.

A further criticism of the New Zealand approach was raised by Ashton and St John (1988) who suggested 20 years ago that a universal retirement benefit alone was not fiscally sustainable in the long-term. Ashton and St John argue that future taxpayers would be unwilling to fund (or politicians would be unwilling to impose) the high taxes that continuation of such a scheme would require. The implementation of the New Zealand Superannuation Fund ${ }^{47}$ has, to some extent, mitigated the issue with an attempt to restore an element of inter-generational equity. Ashton and St John (1988) also suggest that while the level of universal provision in New Zealand appears generous when an international comparison is undertaken, this is only relevant when taken in isolation; for example, in all other OECD countries, the publicly provided pension is only intended to form one component of a multi-tiered system. In New Zealand, the universal pension alone is intended to protect retired individuals from poverty in their retirement.

$47 \quad$ The New Zealand Superannuation Fund introduced an element of pre-funding to the New Zealand Superannuation scheme. This is discussed in greater detail in chapter six. 
Criticisms of Australia's current scheme have also been widespread, albeit typically attracting different forms of commentary; for example, it is generally accepted in Australia that compulsory private retirement savings is likely to result in individuals reducing their savings through other non-compulsory savings vehicles. While presently the offset is well below a full offset, James (1998:148) suggests it is likely to rise significantly over the long term as individual superannuation balances increase.

\subsubsection{Challenges to state intervention}

There are a number of reasons proposed for sole reliance on voluntary provision, including that it:

- provides flexibility and choice for individuals;

- allows individuals to save what is affordable to them;

- promotes competitive financial markets and better savings products;

- may lead to higher rates of economic growth; and

- in the case of New Zealand, accelerates tax revenue growth and makes the state provision more affordable by the government (Task Force on Private Provision for Retirement 1992:12).

Typically, the key disadvantages are that it:

- increases state dependency;

- lowers national savings;

- produces minimal incentive to change behaviour; and

- creates future fiscal risk (Task Force on Private Provision for Retirement 1992:32).

Despite the support for compulsory occupational retirement savings schemes the rationality of the approach has been questioned. St John and Willmore (2000:14), among others (e.g. Agulnik 2000; Willmore 1998) question why a society should care whether a worker has the means to consume above a certain subsistence level during retirement. As noted by the World Bank (1994:5):

when traditional, informal arrangements for subsistence break down in other spheres, they are replaced by formal market arrangements. Why doesn't that happen for old age subsistence? Why do governments everywhere in the 
industrial world and increasingly in developing countries intervene so extensively in this area?

The role of the state in retirement savings provision is also addressed by Willmore (1998) who questions whether the decision should be about the adoption of a public or private pension system. Most research on this topic adopts an economic analysis, but Willmore argues that the decision relates to society's view of the role of the state. Other commentators (e.g. Disney and Johnson 2001:42) argue that a reasonable average standard of living for retired individuals can be achieved by pension systems that are not reliant on significant state expenditure; instead, the private sector can play a key role. Private coverage for superannuation is rising in all countries with the exception of New Zealand (Disney and Johnson 2001:42).

While not entirely discounting the paternalistic arguments, Agulnik (2000:46) finds that only the willingness to pay argument may be reasonable and this is primarily because it provides a political explanation as to why occupational retirement schemes were implemented. None of the arguments raised are found by Agulnik to constitute a sound basis for continuation of the state-supported schemes.

\subsubsection{Comparisons of retirement income savings}

The significant cross-country comparisons of pension provision have generally been undertaken by large organisations such as the IMF (e.g. Barr 2000) and the OECD (e.g. OECD 2005). While recognising the difficulties inherent in comparisons of this nature, the shared experience of pension reform and its impact provides valuable information to policy makers. However, many of the comparative studies on retirement savings are straightforward narratives of the systems in place; for example, Callister (2003) compares the private provision systems in Australia, Canada, Ireland, Germany, the United States and the United Kingdom, noting that all these countries have an average rising age, and similar policy concerns stemming from the economic impacts of an ageing population. As with similar research (e.g. OECD 2005), Callister notes the usual forms of encouragement of private saving for retirement (compulsion, tax incentives, public education and a low level of public retirement support) and discusses the issues associated with each of these forms. The issues around compulsion and tax incentives are those most frequently discussed. 
Research undertaken by the OECD (2005) shows a diversity of pension provision across OECD countries. The research covers public and private arrangements, taking into account differences in the tax treatment of retirement savings. The research starts from the premise that retirement savings policy has two main objectives, which are similar to the Australian policy objectives. Firstly, a redistributive component to assist with poverty alleviation and, secondly, helping workers to maintain living standards during retirement by replacing income from work at an adequate level (OECD 2005:16). As found by the OECD, most countries pursue both goals in their retirement savings policy, but there is a significant variation in the balance of emphasis placed on the two objectives.

One measure used by the OECD to compare levels of pension provision is 'pension wealth'. Pension wealth is the present value of the future stream of pension payments (OECD 2005:17). Pension wealth is considered by the OECD to be the most comprehensive indicator of pension 'promises'. Luxembourg has the highest pension wealth, with workers receiving average wages having pension wealth of 18 times average earnings for men and 22 times for women (due to higher female life expectancy). This is equivalent to US\$587,000 at the time of retirement. The lowest pension wealth for someone who has earned average earnings is found in Ireland (5.4 times), Mexico (4.8 times), New Zealand (5.7 times), the United Kingdom (5.5 times) and the United States (5.5 times) (OECD 2005:63). Australia is 6.7 times, which is also lower than the OECD average of 8.9 times.

All OECD countries have some form of government provided pension for older people. Generally these are asset or income tested. The average minimum retirement benefit across OECD countries is around 29 per cent of average earnings. In New Zealand it is 38 per cent and in Australia it is 23 per cent. In the OECD, only Luxembourg, Portugal and Greece are higher than New Zealand. The OECD (2005) report shows that workers who derive the average level of earnings in the OECD can, on average, expect their post-tax pension to be worth just over 70 per cent of their 
after-tax earnings. New Zealand and Australia both have net replacement rates that are lower than the OECD average, with 41.7 per cent and 56.4 per cent respectively. ${ }^{48}$

Research by Edwards (1995) undertakes an international comparison of the determinants of savings across 36 countries from 1970 to 1992. The research considers why savings ratios have varied across countries. Edwards (1995:i) concludes that state provided social security systems have a negative affect on private savings. In addition, Edwards investigates potential influences on levels of public savings and concludes that public savings tend to be lower in countries with higher political instability.

\subsubsection{Reform approaches}

The many potential options for reform are a frequently researched topic relating to retirement savings. Since the 1980s, most OECD countries have witnessed a variety of both retirement savings and tax reforms. Typically, tax reforms have had efficiency based objectives, leading to simplification of tax policy, elimination of tax loopholes, reduction of marginal tax rates and creation of a broader revenue base. As well as a focus on the three components of efficiency, equity and simplicity, retirement savings reforms have also been concerned with financial pressures on extant systems with forecast ageing populations. Disney and Johnson (2001:41) discuss the similarity that can be found in recent reforms, with a general trend towards increasing the age for receiving a state provided pension while lowering the generosity of the provision. There has been a further trend towards an increased focus on occupational retirement schemes that are either compulsory or tax preferred.

The World Bank has outlined four key concerns with retirement income policy reforms:

1. short-term financing and long-term financial viability;

2. effects on economic growth;

3. adequacy and other distributive issues; and

48 Net replacement rates are individual net pensions relative to individual net earnings, taking into account income taxes and security contributions paid by workers and retired individuals (OECD 2005:52). 
4. political risk and sustainability (Holzmann 1999:2).

The short-term fiscal concern arises from the existence of unfunded or pay-as-you-go schemes that are facing current-period deficits, as recognised by Fox and Palmer (2000). The suggested mechanisms to deal with the demographic trends are either a reduction in the pension rate, an increase in retirement age or increases in taxes. Any increasing of taxes to fund such shortfalls has a potential impact on economic growth. The longer-term fiscal concerns relate to the projected ageing populations, which are forecast throughout the OECD.

Holzmann (1999:4) claims that evidence from both developed and developing countries suggests that poorly designed public pension systems can distort life-cycle savings and work decisions. This in turn can impact on economic output and economic growth. The World Bank has outlined three potential options for reform:

1. reforming the pay-as-you-go system;

2. a move to a compulsory funded system; or

3. a move to a multi-pillar system, where there is a combination of a pay-as-yougo system and funded pensions.

The actual combination adopted will depend on a country's starting conditions and constraints in financing. What can clearly be seen among many reforms is the attempt to shift some of the financial risk of the ageing population away from future generations, to the generation affected (Fox and Palmer 2000:1).

Fox and Palmer (2000) investigate the way that the United Kingdom, Australia and Sweden have increased their retirement savings funding in response to projected ageing populations, through the introduction of individual account systems. The United Kingdom had moved in this direction to some extent during the 1980s, with the option for individuals to 'contract out' of the State Earnings Related Pension Scheme and to join private schemes. Further reforms in the 1990s strengthened this scheme. Australia, as previously outlined, introduced a mandatory occupational scheme. Sweden introduced individual financial accounts, in conjunction with a new pay-as-you-go notional account system. Fox and Palmer (2000) conclude that there are a number of trends emerging in policy direction. These include a tendency for countries to change from the traditional 'pay-as-you-go' schemes for retirement and 
move towards defined contribution schemes and increased privately managed superannuation systems.

Several OECD countries have long established occupational retirement savings schemes that have become the foundation for a mandatory system. Denmark is one of these countries, where both employer and employee are required to contribute, with the contribution based on hours worked, rather than earnings. France has a compulsory occupational retirement scheme that is funded by employer and employee contributions and Switzerland has had compulsory occupational retirement savings since 1985 (Gillion et. al. 2000).

In the United States, Individual Retirement Accounts (IRAs) have been in place since 1974. IRAs provide a tax preferred saving system for employees who do not have pension plans. The primary tax advantage is the ability to defer tax payments on the pension contributions until the funds are withdrawn at retirement (Hubbard and Skinner 1996:74). A further targeted savings program, the '401(k)' ${ }^{49}$ plan has been established since the early 1980s. The 401(k) plans allow tax-deductible contributions, and accumulated interest is not taxed until funds are withdrawn.

In countries where investment income is subject to tax, it tends to be taxed more leniently than ordinary income (Dilnot and Johnson 1993:6). The treatment of lump sum payments from pension funds differs widely. Some countries, such as France, do not allow lump sum payments out of tax-advantaged schemes; other countries, such as Ireland, treat lump sum payments more generously for tax purposes than other payments, while yet other countries tax lump sums in much the same way as other payments. Hong Kong has taken the most extreme measures with tax exemptions for retirement savings at all three possible options, in addition to mandatory contributions of 5 per cent for employees and 5 per cent for employers.

Palme (1990) analyses the development of old-age pensions in 18 OECD countries. Palme (1990:3) finds a wide range of economic, social and institutional factors have

$49401(\mathrm{k})$ plans and Individual Retirement Accounts are voluntary, narrowly targeted, personal savings incentives. They feature preferential tax treatment of contributions and investment earnings, annual contribution limits and penalties for early withdrawals. 
impacted on the welfare arrangements throughout the OECD, including the growth of economic resources, rapid productivity changes, trade union growth, industrial conflicts, the ageing of populations and the industrialisation of production.

\subsection{The Taxation of Retirement Savings}

This section outlines the literature on the taxation of retirement savings. It commences with a broad overview of taxation as it relates to retirement savings. This is followed by an in-depth look at the research relating to tax incentives and savings. To date the primary focus of tax based research relating to savings behaviour has been on the effectiveness of incentives. Accordingly, a key component of the literature review is related to this topic. This discussion is followed by a review of the literature specifically related to the taxation of retirement savings in New Zealand and Australia. There has been significantly more Australian based research on this topic and this is reflected in greater emphasis on Australia in the section.

\subsubsection{Tax treatment of retirement savings}

In theory, any form of taxation introduces distortions into saving behaviour. A primary argument raised in favour of tax support for retirement savings is that retirement savings are more important than other forms of savings. The typical explanations given for this are that individuals may fail to predict their needs in old age, individuals are likely to have difficulty in saving further once retirement age has been reached and increased savings by individuals will reduce reliance on the state in retirement. Furthermore, retirement savings require a long-term commitment not demanded of other savings vehicles.

Bateman, Kingston and Piggott (2001:135) argue that the two most important policy questions in retirement income savings taxation are how preferential the taxation of retirement savings should be and at what point retirement savings should be taxed. The scheme most commonly used is EET $^{50}$ where employers and employees may claim a tax deduction for their contributions to retirement savings funds, and contributions and earnings on the contributions are exempt from taxation until the

50 Refer to section 1.1.1 for explanation of this reference to the taxation of retirement savings. 
funds are paid out on retirement. The primary advantage to taxpayers of this approach is tax deferral and the potential for a lower level of income tax on fund withdrawals (assuming a progressive income tax structure), as typically earnings are lower in retirement than during employment.

The usual tax treatment of non-retirement savings is a TTE approach, which is used in New Zealand for all forms of savings including retirement savings. New Zealand's TTE scheme is focused on treating all forms of saving in a similar way with the aim of achieving tax neutrality. ${ }^{51}$ Retirement savings in Australia are a tax preferred investment. Tax concessions exist in all other OECD countries to encourage saving for retirement and to provide a reward for restricting access to these funds until retirement age. Chapters six and seven, respectively, discuss the New Zealand and Australian retirement income systems in detail.

In addition, most tax systems give preferential treatment to retirement savings or to pension payments themselves. The OECD (2005:36) divides these features into three categories:

1. age based tax allowances and tax credits provided to individuals who are no longer working;

2. tax relief for some or all pension income; and

3. social security contributions that are not levied on pension benefits.

New Zealand has none of these features, while Australia has tax allowances and tax credits.

\subsubsection{The impact of tax incentives}

There has been considerable debate on the issue of tax incentives and retirement savings, particularly over the past two decades as tax incentives have become accepted in almost every developed country. Poterba (2002) argues that how tax impacts on saving decisions is one of the most studied issues in empirical public finance. As well as the desire to understand the effect that taxation has on behaviour,

51 This changed in 2007 with the announcement of a small tax incentive in conjunction with KiwiSaver Accounts. 
the level of interest is also driven from the suggested link between savings, the cost of capital and productive investment in an economy.

Typically, there are a number of arguments that are raised to support the existence of tax incentives in relation to savings. These include:

- an increase in national savings;

- decreased dependency on state provided pensions;

- compensation for income tax on savings;

- changes in behaviour;

- a signal of the importance the government places on having people accept responsibility for their own retirement provision;

- provision of a reward for 'locking-in' savings until retirement;

- improved capital market efficiency;

- encouragement for taxpayers who can provide for their own retirement to do so;

- to enable individuals to save enough to maintain their standard of living in retirement; and

- in the case of New Zealand, to bring New Zealand in line with the rest of the OECD. ${ }^{52}$

The key arguments against the provision of tax incentives include:

- the privileging of some individuals who would have saved in the absence of the tax incentive;

- the potential for tax planning;

- the expense associated with incentives;

- research indicates that high-income earners are those that benefit to the greatest extent from the incentives (e.g. Sinfield 2003);

- saving decisions are best left to individual judgement; and

- the 'locking-in' of retirement savings means that some forms of savings will be favoured above others, thereby distorting industry competition.

52 Adapted from the Task Force on Private Provision for Retirement (1992:34). 
While most countries continue to offer incentives to encourage or to support retirement savings, there is an absence of solid information to verify their effectiveness as a mechanism to increase levels of savings. There is general agreement that high tax rates on savings may act to deter savings, as current consumption is encouraged at the expense of saving and investment (Freebairn, Porter and Walsh 1989:93). However, while lower tax rates may reduce behavioural distortions inherent within the system, it is unlikely to remove them altogether.

\subsubsection{Tax incentives and savings}

Much of the research undertaken in the area of retirement savings relates to the extent to which tax incentives create new savings rather than transfers from other non-tax preferred investments; for example, Attanasio, Banks and Wakefield (2004) consider empirical evidence from the United Kingdom and the United States to examine the extent to which funds in tax advantaged accounts represent new savings. They note that a tax advantage for a savings vehicle is equivalent to a small increase in the rate of return of that asset. This can potentially have two impacts on the decision making of the saver: it might either change the total amount that an individual will save, or it will change the composition of the savings portfolio (Attanasio, Banks and Wakefield 2004:5). Tax incentives are intended to result in a change of the first of these points, but research has established that the second point is also highly relevant. Attanasio, Banks and Wakefield (2004:1) find that only small fractions of the funds should be considered to be 'new' saving, and that the policies are an expensive form of encouraging saving.

Seminal research undertaken by Engen, Gale and Scholz (1996) examines the impact of tax incentives on private and national savings. The authors write of the inherent difficulties in undertaking such research, including:

- the tendency for households that participate in savings plans to have stronger tastes for saving than other households;

- households that have utilised savings incentives have taken on more debt than other households; 
- comparison is restricted by balances in saving incentive accounts being pretax, whereas more conventional savings accounts represent post-tax balances; and

- a lack of consideration that employer contributions to saving incentive plans are part of a total employee compensation package (Engen, Gale and Scholz 1996:1).

The authors find that where savings incentives indicate increased savings, the results can be traced to the various biases outlined above that overstate the effects of saving incentives. When these biases are removed, the positive effect of the incentives on savings is removed.

As with Carroll and Summers (1987), ${ }^{53}$ Jump (1982) investigates the divergence in savings patterns between Canada and the United States since the mid-1970s. In contrast to the findings of Carroll and Summers, when Jump (1982) examines the effect of tax incentives on the rate of savings in Canada, he concludes that the incentive would effectively be a lump sum transfer to middle- and high-income taxpayers, which would not encourage savings for low-income taxpayers. Jump observes that such incentives require the government to set higher tax rates, and accordingly may actually have perverse effects insofar as the incentives have been financed by increased taxes, which are paid by all taxpayers. Moreover, Jump (1982:63) concludes that tax incentives may have contributed more towards a decline in personal saving in Canada, while acknowledging that personal savings did increase over the time period considered. Jump (1982:46) suggests personal savings rates appear to have increased because of distortions of price inflation, rather than as a result of any behavioural change by individuals.

The typical result from the research in this area can be found in a study undertaken by Auerbach and Slemrod (cited in Engen, Gale and Scholz, 1996), which finds a strong effect of tax-based saving incentives on the allocation of saving and assets, but little or no effect on the overall level of saving or wealth accumulation. A further approach to the effectiveness of tax incentives is seen in research undertaken by Borsch-Supan

$\overline{53 \quad \text { Discussed in section 4.3.1. }}$ 
(2004:137). While Borsch-Supan acknowledges that the research does not add significantly to the question of whether tax relief creates additional saving, it does find that tax subsidies strongly increase saving in the specific form that is subsidised. The research highlights the behavioural adjustments that take place, and indicates that tax incentives may be helpful with transition between different schemes. Accordingly, tax incentives may be utilised as a policy tool to influence behaviour.

Research undertaken by Venti and Wise (cited in Jappelli and Pistaferri, 2002) considers whether IRAs and 401(k) plans represent new saving in the United States. They find that contributors to these plans tend to be wealthier and nearer to retirement than non-contributors. Accordingly, it cannot be ruled out that preference among those who contribute to retirement savings plans and those who do not is different, and wealthier individuals contribute to retirement income savings plans because they have a stronger taste for saving than non-contributors. Similarly, Engen, Gale and Scholz (1996) find that households that participate in saving incentive plans prefer saving generally, compared to other households.

Blundell (1996) investigates whether tax-advantaged savings accounts introduced in the United Kingdom in the late 1980s and early 1990s resulted in new savings. Along with other researchers in this area, Blundell finds a significant degree of portfolio substitution across savings accounts, with no more than 15 per cent of Tax Exempt Special Savings Accounts representing new savings. Blundell (1996:109), as with Venti and Wise (cited in Jappelli and Pistaferri 2002) and Engen, Gale and Scholz (1996), also finds that individuals who save in tax preferred savings vehicles are likely to have a greater preference for saving through other mechanisms than other individuals.

Earlier work by Munnell (1982) suggests that people reduce their other saving by 65 cents for each dollar of private pension saving (resulting in a net savings increase of 35 cents). However, Munnell writes that it is impossible to determine whether this net increase is due to favourable tax provisions or to such other features of private plans, such as uncertainty about future benefits, forced saving and induced retirement. Munnell finds that the most useful hypothesis for policy purposes appears to be that 
consumers reduce saving in other forms to compensate for expected future pension provision. While Munnell's study investigates private pension provision, it would appear reasonable to extend the conclusion to state provided pension arrangements, to the extent that they can be expected to exist at the time of retirement.

Seminal research by Feldstein (1996) investigates the impact of the provision of pension payments on private savings. While acknowledging the problems inherent in research of this nature, Feldstein suggests that each extra dollar of state provided pension replaces around 50 cents of private wealth accumulation. Furthermore, social security wealth reduces private saving by nearly 60 per cent. The implications from work of this nature are that state provided pensions cause reductions in private savings and are likely to result in a reduction of real investment income.

Similar research by Katona (1965:6) provides a dissimilar outcome in concluding that pension plans stimulate voluntary saving. The results of Katona's study indicate that coverage by private pension plans discourages saving in other forms where retirement was the primary motivation to save. Cagan (1965:82) also finds that individuals covered by private pension plans save more in other forms than those not covered. As outlined in section 4.3.1, the key explanation provided for these results is the 'recognition effect', which increases an individual's inclination to provide for the future.

More recent research by Antolin, de Serres and de la Maisonneuve (2004) finds that studies have shown strong links between tax incentives and new savings among lowand middle-income earners. Accordingly, incentives are less likely to generate new savings among higher income earners. Antolin, de Serres and de la Maisonneuve (2004:23) write:

The existence of tax-favoured pension arrangements does not seem to be questioned even though these schemes appear to be costly from a public finance point of view. In fact, more and more countries are either introducing them or extending their coverage. A question that arises is whether tax-favoured arrangements can be justified even if they fail to raise private and national saving. 
A further argument for the provision of tax incentives is that they defer the taxation of superannuation benefits to the point of withdrawal. In this case, they can create a substantial fiscal asset at a period where the cost associated with ageing will peak. ${ }^{54}$

As a final demonstration that the debate on the effectiveness of tax incentives remains far from over, Yoo and de Serres (2004) investigate the net tax cost for tax preferred retirement savings plans among OECD countries. The measure is based on the net tax cost per unit (e.g. one dollar) of contribution to the retirement savings scheme. Unsurprisingly, the cost is zero in New Zealand, but ranges between a general minimum of at least 10 cents to a maximum of 40 cents per unit of contribution (in the Czech Republic). Over half of OECD countries incur a cost greater than 20 cents; in Australia it is 29 cents. Yoo and de Serres suggest that these findings provide support for the contention that most OECD governments see the value in providing tax incentives to promote retirement savings.

\subsubsection{The effectiveness of incentives}

There is uncertainty about why savings incentives have not been more effective. Engen, Gale and Scholz (1996:47) suggest that existing incentives are poorly designed, that households have low intertemporal elasticities of substitutions or that people may be uninformed about the need and opportunities for saving.

The absence of certainty in relation to benefits of tax incentives has raised the issue of why tax support for retirement savings is provided at all. One view, raised by Edey and Gower (2000:290) and Ingles (2001:21) is that providing tax concessions when mandatory occupational schemes exist is somewhat wasted, as there is no need to provide an incentive to do what is already compulsory. Knox (1992:54) writes:

throughout this century governments within the developed world have expressed strong support for occupational pension and superannuation schemes through the provision of significant taxation incentives and concessions ... it is so common that one may be considered a heretic for asking why such support exists.

$54 \quad$ For a more detailed discussion of this concept, refer to Antolin, de Serres and de la Maisonneuve (2004). 
Sinfield (2003) also discusses the lack of evidence to support an argument that taxation incentives have a positive effect on either the level of savings within an economy or economic growth. Sinfield writes that a number of organisations have raised doubt about the value of taxation incentives (including the World Bank).

From a different perspective, it is equally difficult to quantify the potential benefits that may accrue to workers from the presence of taxation incentives, as to quantify the cost of the incentives. For an individual, the benefit may be related to marginal tax rates, how long funds are kept within the retirement investment scheme, the rates of return throughout the period the investment is held and the form of withdrawal. However, many of the benefits are not measurable and it may be argued that the social objectives likely to be linked to retirement saving may mean a pure cost/benefit analysis is not appropriate. The New Zealand Treasury (2007:4) has recently adopted a "least-regrets" approach to retirement savings, after 20 years of adopting a unique approach to tax incentive provision. This may not only reflect an absence of support for the historic New Zealand approach, but the acceptance that other factors may also be important.

\subsubsection{Behavioural and equity issues of tax incentives}

Bernheim (2002:1232) suggests that even where the interest elasticity of savings is low and households do not alter their behaviour greatly as a result of tax incentives for saving, it may still be possible to influence saving decisions through tax policy; for example, 'non-neutralities' in the tax system may encourage third-party activities that may impact on the level of personal savings, such as where benefits may accrue to providers of investment products where tax incentives exist. The promotion of these products may increase awareness of the need to save (the recognition effect) and more savings vehicles may be formed. However, the question remains as to whether these savings would be in the form of new savings or substitutions from other savings vehicles.

Research undertaken by Sinfield (2003:5) in the United Kingdom has highlighted the inequity associated with tax incentives. Sinfield finds that at least half of the tax subsidy on contributions goes to the wealthiest ten per cent of taxpayers, with a 
quarter of the tax subsidy going to the top two and a half per cent of taxpayers. The distribution leaves the lowest ten per cent of taxpayers (measured by wealth) with one per cent of the tax benefit. Sinfield (2003:6) puts forward an argument for the potential of a 'dangerous social schism' in the United Kingdom, with the possibility of a number of undesirable outcomes in retirement, such as greater inequalities in living standards after work than in work. Edey and Britten-Jones (1990:125) find similar results in Australia. Using data from the 1984 Household Expenditure Survey, contributions to superannuation funds (and therefore utilisation of tax incentives) were disproportionately provided by high-income earners. The highest income quintile provided 45 per cent of fund contributions, while the top two quintiles combined provided 75 per cent (Edey and Britten Jones 1990:125).

Burman, Gale, Hall and Orszag (2004) find similar results to Sinfield (2003). As a share of income, tax preferred saving incentives provide the most significant benefits to households with an income of between US\$75,000 and US\$500,000, which is approximately the $80^{\text {th }}$ to $99^{\text {th }}$ percentiles of income distribution in the United States (2004:2). Burman et. al. find that in 2004 the top 20 percent of tax filing units by income received 70 per cent of the tax benefits from new contributions to defined contribution plans and almost 60 percent of tax benefits to IRAs (2004:v). The issues raised by Burman et. al. and Sinfield go some way to highlighting the inequity with tax incentives. Burman et. al. (2004:1) find evidence to suggest that high-income and wealth households are more likely to participate in substitution of savings to take advantage of tax preferred accounts, whereas lower-income households are more likely to finance their retirement savings through a reduction in consumption. Accordingly, Burman et. al. (2004: 1) conclude that retirement savings tax incentives targeted at high-income and high-wealth households that are more likely to be accumulating sufficient private savings to maintain their living standards in retirement, while low- and middle-income households are more likely to face difficulty in achieving the same result.

It has been well established that there is no certainty about the impact that tax incentives have on retirement savings specifically or overall levels of savings more generally. Knox (1992) outlines a number of possible effects of superannuation on the level of total savings, including: 
- a decrease in the level of savings (as tax incentives mean that a smaller rate of saving is needed to produce the same retirement benefit);

- no increase in the level of personal or total savings (as individuals substitute from non-tax advantaged savings mechanisms to tax advantaged savings mechanisms without any increase in overall savings, and government savings are reduced through the provision of tax incentives); and

- an increase in the level of savings (as individuals defer consumption and awareness of retirement savings is increased).

Knox concludes that it is reasonable to suggest that there is no straightforward answer to the dilemma of whether tax incentives impact on the levels of savings. In summary, there has been much debate on the effectiveness of tax incentives and their ability to increase retirement income savings. Most studies conclude that tax incentives affect the allocation of household portfolios, but the effect on the amount saved is less clear.

\subsubsection{Taxation of retirement savings in New Zealand}

Research undertaken by Lally and Marsden (2004) examines superannuation funds in New Zealand prior to 1988, at which time generally a tax subsidy existed for individuals who were saving through superannuation funds, as compared to investment in shares or bonds. Lally and Marsden consider the tax situations of two investor types for periods before and after 1988: individuals who own assets directly and investors who receive returns through superannuation funds rather than directly. Investors who received returns through superannuation funds were found to have lower effective tax rates on returns (prior to 1988) due to two incentives; the first was a tax deduction for the contribution made, and the second was the deferral of tax on the returns until the investor's retirement (2004:296). These two factors were found to reduce the effective tax rate considerably.

Lally and Marsden (2004:297) find that when the same investors are compared in the post-1988 period, receipt of dividends via funds, unit trusts or directly is essentially the same. Factors that influence this result are the ability of unit trusts or funds to utilise imputation credits to reduce payable tax and the ability to pass on additional 
imputation credits from tax paid to individual claimants. This results in a New Zealand individual having identical treatment of the fund receipts as if the funds were directly received from the company.

The two key objectives underlying the tax treatment of retirement savings in New Zealand are highlighted by Dilnot and Johnson (1993:18). First is the goal of fiscal neutrality and second is the goal of increasing revenue through the removal of incentives. Dilnot and Johnson discuss the neutrality objective behind New Zealand's position on the taxation of retirement savings. They start from the viewpoint that there are two ways of interpreting fiscal neutrality in relation to saving decisions. Firstly, there is neutrality between consumption and savings, ${ }^{55}$ which is the form conventionally discussed and achieved by the income tax approach towards savings in New Zealand. However, there is also neutrality between present and future consumption. Dilnot and Johnson suggest that individuals generally do not save for the purpose of saving alone; generally, saving is a means for future consumption. Accordingly, in relation to retirement savings, Dilnot and Johnson argue that a more relevant concept of neutrality is not that of consumption and savings, but that of present consumption versus future consumption.

\subsubsection{Taxation of retirement savings in Australia}

The Australian superannuation system has been criticised for the numerous components of its structure; for example, Ingles (2001:6) argues that there is an inherent conflict within the Australian system, where the intent is to encourage saving for retirement, but the presence of a means test discourages saving. The system is frequently criticised for its complexity, particularly in relation to the tax treatment of retirement savings. As Ingles (2001:21) observes, historically the tax on contributions has comprised three different systems, ${ }^{56}$ there have been additional rebates for spouses and low-income earners, investment income has been taxed in two different

$55 \quad$ This is a simplified taxonomy. In reality, additional distortions exist that influence the basis on which such decisions are made, such as taxation and welfare systems, which can bias decision making towards present consumption (Fitzgerald 1996:3).

56 Employer (15 per cent tax), employee (not deductible) and self-employed (up to a limit of A $\$ 3,000$ per annum). 
ways and there were 13 different ways of taxing benefits. Now that superannuation is compulsory, some commentators have suggested that tax concessions are no longer necessary to encourage private provision, particularly when the tax expenditure on superannuation is significant (Bingham and Rothman 2005:2).

Bateman (2002:52) argues that the method of taxation of superannuation in Australia fails to meet the standard criteria of equity, efficiency and simplicity. These claims are repeated by other researchers, such as O'Connell (2003:431) who also concludes that the taxation of superannuation in Australia is 'inequitable, inefficient and overly complex'.

In relation to the simplicity criterion, there is no question that historically the tax treatment of superannuation in Australia has been complex. This complexity has been exacerbated by significant grandfathering of reforms over time. Reference to chapter seven provides more detail on the Australian system. However, it is generally agreed that changes made to the Australian scheme in 2007 have gone some way to reducing the complexity in the system (e.g. Bateman and Kingston 2007).

Bateman (2002:53) argues that the efficiency criterion is not met as the broad design of superannuation taxation is damaging to overall economic efficiency. Bateman claims that the tax on superannuation contributions may inhibit participation in voluntary superannuation arrangements. In addition, the taxation of earnings within retirement savings funds has the potential to affect decisions about asset choice. ${ }^{57}$ Furthermore, as with New Zealand, superannuation fund income is taxed but owneroccupied housing is not, creating the potential for distortion away from retirement savings towards property investment. Again, the 2007 changes have gone some way towards improving the attractiveness of superannuation investment above property investment.

With respect to the criterion of equity, the tax on contributions and fund earnings, which is levied at a flat rate of 15 per cent, is regressive. Some attempts have been made to address this issue with the introduction of a surcharge in 1996, which was

$57 \quad$ For example, assets may be chosen for imputation credits rather than pre-tax rates of return. 
aimed at making the contributions tax on superannuation funds progressive. The surcharge proved to be complex and expensive to administer, and has since been removed.

Atkinson, Creedy and Knox (1999:201) provide research results that show minimal differences in lifetime income in the two tax structures in Australia, namely the EET approach utilised until 1988 and the ttt approach, which replaced that scheme. However, the research findings do show significant differences in the net value of the retirement benefits received, as well as in the timing and size of tax revenue when received by the government.

An empirical study of whether Australia's Superannuation Guarantee was likely to impact on the overall level of savings was undertaken by Fitzgerald and Harper (1992). Fitzgerald and Harper found that over the short- to medium-term the savings offset could amount to 50 per cent, despite the potential for lower-income households spending to be constrained by their income. Fitzgerald and Harper, unlike most researchers, find that compulsion can increase both private and national savings, although the effect in the long run may reduce. Fitzgerald (1996:13) concludes that evidence points towards households increasing their private savings when they have access to tax deferred savings. Fitzgerald also disputes the widely discussed argument that any positive effects on private savings through the existence of incentives is reduced by the cost of tax incentives, and that no overall increase in national savings are found. Fitzgerald argues that this point is misconstrued and that, as the vehicles in the United States (on which the majority of this research is founded) are tax deferral vehicles, with no concession in the tax rates applying to withdrawals, it is not clear that when viewed in an appropriate longer-term time frame there is necessarily any offset in public saving.

Freebairn, Porter and Walsh (1989:106) argue that a fundamental problem with the taxation arrangements in Australia is the different tax bases that are applied to measure the taxable funds of different savings and investment options. Freebairn, Porter and Walsh outline a number of different tax base options in order to assess the relative methods of alternative tax bases in achieving effective change to the tax system. Overall, they recommend a strategy of a shift to an income tax method for 
the taxation of savings and investment, arguing that this step would remove existing distortions, although the revenue base of this method would reduce.

\subsection{Summary}

A number of the studies signal the importance of path dependency in historical policy research. The exploration of literature on institutional theory clearly indicates that the use of institutional frameworks does not limit the potential outcome of the research. Some of the research results points to a strong fit with the literature, while other researchers, such as Pierson (1994), find results that do not concur with what may be expected from a traditional institutional approach. With either result, a potentially valuable contribution to the existing body of knowledge is created.

This section also includes a, necessarily, succinct exploration of a selection of the literature on the taxation of retirement savings. While many researchers from a wide range of disciplines have investigated the topic, it is apparent that there is still a broad range of perspectives on aspects of the topic, from the effectiveness of tax incentives through to the role of the state in retirement savings. The lack of concurrence between researchers on the various areas of retirement savings indicates the inherent difficulty with research of this nature and demonstrates the potential for further research of both a qualitative and quantitative nature. Hence, one of the contributions from the thesis is to investigate the institutional, and other, frameworks that help to explain the different approaches to the taxation of retirement savings in New Zealand and Australia. As outlined in section 1.2, and validated by the absence of literature on the topic, the thesis considers how and why New Zealand and Australian governments adopted different solutions to the taxation of retirement savings; how well institutional frameworks explain these different approaches; the extent to which New Zealand and Australian governments enacted taxation policy that privileged certain groups above others; and how institutional structures combined with other factors to impact on policy development for the taxation of retirement savings.

The following chapter, chapter five, explores the institutional arrangements that existed in New Zealand and Australia during the 1982 to 1992 period. This is 
followed by two chapters outlining the key historical events that have structured retirement savings policy in New Zealand and Australia. 


\section{Chapter 5: Institutional Arrangements}

\subsection{Introduction}

This chapter provides an introduction to the institutional arrangements that have influenced retirement savings taxation policy in New Zealand and Australia. The discussion in this chapter is based on secondary source data. Primary source data is used for analysis in chapters eight to eleven.

Chapter five is divided into two sections representing New Zealand and Australian institutional arrangements, respectively. The sections are separated into various institutional groupings, such as political institutions, employer organisations and interest groups.

The policy development process allows for a number of opportunities for interested groups to potentially influence policy formation. Ministers obtain policy advice from a variety of sources, including government departments, consultants, political advisers and individual experts (Shaw 2003:149). Further influence may come from senior public sector employees who provide expert advice to government, political parties that play a key role in determining issues for discussion, interest groups that may lobby to influence policy changes, and individuals and corporations that hold power and may have the opportunity to influence policy development (Collins 1977:23).

The rationale for investigating institutions is based on the premise that many observed patterns of interaction are 'based on shared perceptions among a group of individuals of proper and improper behaviour in particular situations' (Crawford 1995:583). Policy advice or interest group influence is not value free. Institutions influence individual behaviour through the defined rules and policies that direct the pattern of actions taken by each individual. Hence, the directions adopted and preferences espoused are likely to reflect the priorities and preferences of the institutions involved, together with the individuals in positions of power within the institutions. 


\subsection{Institutional Arrangements: New Zealand}

A number of institutions have the potential to influence policy direction in $\mathrm{New}$ Zealand. These include the state and its political institutions, structured organisations representing large groups of individuals and industry bodies acting for their members. However, a number of factors, including the prevailing environment, power dynamics and alignment of philosophies will impact on the extent to which such groups can 'make their voices heard' and influence the policy outcomes.

\subsubsection{Political institutions}

While it is generally accepted that elected governments hold power in liberal democracies such as New Zealand and Australia, reference in the thesis is often made to 'the state'. The state is defined by Bell and Head (1994:3) as:

a collective institutional term, useful in forms of analysis that see public policy outputs as resulting not just from the actions of government, but also from a wider pattern of activity and institutional dynamics within the state, particularly the role of key departments and independent statutory authorities.

Accordingly, reference to 'the state' refers to the broader political influences within public institutions.

The state, with its considerable influence on society, has access to a significant amount of society's resources. Accordingly, the state and those that represent the state have numerous opportunities to influence policy development. It is generally accepted within institutional theory that the institutional arrangements of the state will influence individual officials' preferences. Furthermore, institutional arrangements play a key role in deciding the extent to which state preferences are translated into public policy. Nordlinger (1987:360) suggests that institutions provide officials with opportunities to 'transform, neutralise, and overcome societal opposition'.

For most of the $20^{\text {th }}$ century the political institutions within New Zealand were representative of New Zealand's history as a former British colony (Weaver 2002:2). New Zealand has a unicameral legislature (the House of Representatives) and, prior to 1996, a first-past-the-post election system. ${ }^{58}$ New Zealand does not have an upper

$58 \quad$ Until 1950, a second chamber (the Legislative Council) existed. 
house to act as a check on the House of Representatives. Furthermore, unlike Australia, there are no state governments.

For most of the period through to 1996, the single-member electoral system in New Zealand produced two large parties, where one party often won a majority of seats in the legislature with a minority of the popular vote (Weaver 2002:5). Smaller parties ended up with very few, if any, seats. This system had the potential to provide considerable power to the ruling government. Cabinet ministers, who exercised the executive powers of the Crown, could generally expect to receive the support of their own party majority in the lower house. In addition, there is no judicial review of the content of legislation passed in Parliament. The structure 'combined to make New Zealand governments arguably more powerful than governments in any other Westminster democracy' (Mulgan 2004:63).

From 1996, the New Zealand electoral system changed from a 'first-past-the-post' voting system to a Mixed Member Proportional (MMP) system. The MMP system significantly reduced the potential for a party to have a parliamentary majority with which to promote or enforce its own programmes.

The question of where the balance of power sits in relation to the provision of advice to ministers is raised by Mulgan (2004). Mulgan (2004:159) questions whether it is with the public servants or politicians, arguing that 'constitutional and democratic principle requires that authority should lie with the elected politician, the minister...in reality, however, effective political power may be in the hands of the permanent bureaucracy'.

The New Zealand Treasury is an important institution in this comparative case study. Boston (1992:194) claims that no government department in New Zealand has exerted more influence on public policy from the mid-1980s than the New Zealand Treasury. The Treasury is the government's primary adviser on economic and financial matters, and while it is relatively small it influences almost every area of public policy. All government department policy proposals that have financial implications require Treasury consultation. 
Towards the end of the 1980s the committee structure of Cabinet was changed with its influence shifted to a policy committee with the Treasury as its chief source of advice (Bollard 1994:90). Thus, Treasury holds a privileged position within the government decision making structure. This position is advanced by factors that include the high Cabinet rank traditionally held by the Minister of Finance, the absence of other rival departments, the skills of Treasury employees and a wide ambit to comment on departmental proposals. Other central agencies, such as the Department of Prime Minister and Cabinet and the State Services Commission 'provide no match for the Treasury except in certain specific policy areas, such as the machinery of government and public sector management' (Boston 1992:209).

A particularly relevant factor for the thesis is the ability of the Treasury to set the theoretical framework within which policy developments are assessed. ${ }^{59}$ Boston (1992:205) argues 'by so doing the Treasury is able to define the central questions for analysis, exclude certain issues from consideration and reject policy solutions which do not conform to the accepted wisdom'. This ability impacts on departments and interest groups outside the Treasury. Boston (1992:206) also suggests that clearly any policy analysts, either in another department or outside the public service, who reject the prevailing Treasury orthodoxy are at a major disadvantage'.

The struggle for power between Treasury officials and ministers was particularly pronounced during the time that Prime Minister Muldoon held the Finance Minister portfolio (1975 - 1984). During this time, the Treasury had been frustrated by ministers that took little, if any, of its advice in relation to economic management (McKinnon 2003:324), but this was to change with the election of the fourth Labour government in 1984. As noted by McKinnon (2003:274):

the conflict of the early 1980s was not only a matter of individuals with new ideas gaining influence - it was also an episode in the more than centurylong history of minister-official relations, and an episode in the generationold contest over who should guide economic management - Treasury experts or the politicians.

59 The framework within which the Treasury worked up until the mid-1970s was Keynesian based economics. This changed to a neo-classical/monetarist approach after the election of the Labour government in 1984. McKinnon $(2003: 274)$ claims that the 'paradigm shift' towards market based economics had 'pre-1980 roots in the Treasury'. 
Boston (1992:195) suggests that the Treasury was the leading advocate of many of the radical reforms undertaken in New Zealand since 1984, with ministers no longer directing bureaucrats to produce specified outcomes. However, in more recent years, the New Zealand Treasury's privileged position in relation to input into tax policy development has been diluted. The Inland Revenue Department is now the principal force behind tax policy development and policy drafting. A key impact from this change is frequent changes to tax policy due to operational level difficulties in policy implementation. Difficulties with policy implementation are a common reason for changes in tax policy in New Zealand. However, the Treasury's dominant role in relation to economic advice remains.

In New Zealand's transition from the heavily regulated economy to the de-regulated economy of the mid-1980s, a number of authors (e.g. Bollard 1994:90; Boston 1992:202) suggest that the Treasury was heavily influenced by theoretical developments such as public choice theory, agency theory and transaction-cost analysis, all of which tend towards right-wing policy conclusions. Traditionally, Treasury officials have accepted the theoretical framework of the department, with Boston (1992:204) observing 'opponents of the Treasury line tend to leave, or more likely, find themselves socialised into greater conformity with departmental thinking. It is not a place in which Marxists or even social democrats would find much sympathy'. This extended to debate in the wider community, with Bollard (1994:91) claiming that 'the Treasury's ideas were not much debated with the economics profession outside the department. The department held a coherent internal position and was impatient with dissenting views'.

Government structures can be considered to be a function of the individual personalities within them. As found in institutional theory, the influence of individuals and institutions is multi-directional. Thus when looking at government processes, decision making and outcomes, it is necessary to take into account the individual personalities that exist within the structure. While some perspectives may assume individuals will act in a self-interested manner, it is also assumed that some element of party ideology and policy goals, as well as norms of behaviour within the central political organisation, will influence individual behaviour (McLeay 1995:3). There are numerous secondary source references to the influence of individual 
personalities within the Treasury. Many of these individuals have been interviewed as part of the data collection process for the thesis; these findings are outlined in chapters eight to eleven. What is apparent is a significant change in the historical relationship between Treasury officials and ministers after 1984. As suggested by McKinnon (2003:313) 'the Treasury became the principal initiator; to know what governments would do, one read the Treasury's briefing papers, not party programmes'.

\subsubsection{Trade union arrangements}

Trade unions have historically been a significant mass institution in New Zealand (Bramble and Heal 1997:119). New Zealand was an early adopter of trade unionism with the introduction of the Industrial Conciliation and Arbitration Act in 1894. This Act recognised trade unions and provided negotiation rights for internal groups and employers. Thus, New Zealand developed a strong trade union movement during the first half of the $20^{\text {th }}$ century (Castles, Gerritsen and Vowles 1996:4).

The key actor in New Zealand labour organisations is the New Zealand Council of Trade Unions (CTU), which combines both private and public sector unions. ${ }^{60}$ While it has been claimed that the CTU has taken an active role on pension issues (and a former CTU Secretary served on several government pension advisory bodies during the 1990s (Weaver 2002:13)), unions in New Zealand have faced a number of different threats to their existence over the past 35 years. Accordingly, issues relating to superannuation have not always taken a high priority.

New Zealand had compulsory unionism from 1936 to 1961, followed by periods of voluntary unionism, voluntary collectivism and restoration of voluntary unionism. The outcome of these various changes has resulted in a union structure that tends to be focused on arbitration of disputes and to be based on occupation rather than industry or class (Campbell and Kirk (1983:28). While trade union membership has fallen in recent times, traditionally it has been high. In 1987, 63 per cent of wage and salary earners were union members (Vowles 1992:348). Certain events in New

60 The current CTU structure originated in 1987 with the amalgamation of the Federation of Labour and the Combined State Unions. 
Zealand, such as the introduction of the Labour Relations Act 1987 and the Employment Contracts Act 1991, resulted in reduced powers for trade unions with a move towards voluntary unionism, enterprise bargaining, the elimination of national awards and the removal of the traditional bargaining role of unions. The drop in union membership that followed these legislative changes was significant, with a decrease in membership from around 600,000 to 362,000 in the period from May 1991 to December 1995. Membership has been around 350,000 since the mid-1990s in New Zealand (Street 2003:381); approximately 16 per cent of the work force in 2007. Similarly, the requirement of the Labour Relations Act 1987 for unions to have a minimum membership of 1,000 individuals saw a reduction in the number of unions, with approximately half of unions ceasing to operate in the years between 1986 and 1989.

The success of the Australian trade unions in gaining access to political influence and power can be contrasted with the New Zealand result. Unlike the Australian Council of Trade Unions, the CTU in New Zealand had little success in its attempt to introduce negotiated policy. Generally, it has been accepted that the influence of institutions such as the New Zealand Business Roundtable and the New Zealand Treasury thwarted efforts of the CTU to play a role in policy development and decision making. This position is captured by Bramble and Heal (1997:135) who claim that 'in effect, the CTU leadership had nothing to sell that the government and employers did not feel they could take by virtue of the industrial climate and their perception of the CTU's inability to discipline its affiliates'.

\subsubsection{Interest groups}

Interest groups can be thought of as organised groups representing to government the views of those who share a common interest (Mulgan 2004:208). The thesis investigates interest groups that have had an involvement with retirement savings and the taxation of retirement savings policy. Political theory suggests that interest group pressure is an:

inevitable and healthy part of a democratic political system ... elected governments want to retain the support of voters and will therefore have an incentive not to alienate sections of the voting public who express strong views on certain issues ... governments may also need the active support and 
cooperation of certain groups ... on whom they depend to implement their programmes successfully. ${ }^{61}$

Mulgan (1989:121) claims that the pressures leading to the establishment of interest groups are the same in all areas of the government: each side needs the other. Government needs the cooperation of those likely to be affected by political decisions, while interest groups seek to influence government in their decision making role. Other theories, such as pluralism, suggest that interest groups exist due to an inability of society to take into account of the needs of all members. Accordingly, interest groups evolve to moderate power imbalances.

\subsubsection{The elderly}

As a body, the elderly population in New Zealand are sizeable and potentially well placed to influence policy decisions. Research has shown that individuals aged over 65 years of age are the group most likely to vote (Levine and Roberts 1993:232). As noted by Weaver (2002:13):

interest group politics in New Zealand has probably been less important to pension policymaking than purely electoral politics. Unlike seniors in many other countries, there has been surprising volatility in voting by the elderly in New Zealand in recent years, fuelled in large part by conflict over pensions in particular perceptions by seniors that the incumbent government had or was likely to cut their pensions.

Levine and Roberts also note the pattern of voting that has occurred among the over 65 population since 1975 when the National Party implemented universal superannuation, observing that from 1975 to 1993 the Labour Party has not gained more than 36 per cent support from this age group (1993:233). A further trend became apparent towards the end of the 1990s with support from the retired community for the New Zealand First Party, which had promoted policies that found favour with the elderly population.

It has been suggested that the generous National Superannuation provision in the late 1970s was designed to capture votes of interest groups. As noted by Weaver (2002:11), the existence of a universal pension in New Zealand ensures that any

$61 \quad$ Mulgan (2004:210). 
policy changes expected to result in reductions to retirement spending are likely to raise significant and unified opposition from retired individuals.

The most well-known group representing the older population is Grey Power, a lobby group promoting the welfare of individuals aged over 50 years of age. Grey Power was formed as a small Auckland-based lobby group called the New Zealand Superannuitants Association in 1985. Their purpose at the time was to 'fight the imposition of the superannuation income tax surcharge, ${ }^{62}$ Grey Power frequently issues press releases critical of government cutbacks associated with elderly citizens, superannuation being the highest profile issue (Weaver 2002:12).

Another organisation representing the elderly is Age Concern, a not-for-profit organisation, which has objectives relating to promoting the quality of life and wellbeing of older people. ${ }^{63}$ Age Concern is a federation of local Age Concern Councils that provide information and services in most cities and major provincial towns around New Zealand. ${ }^{64}$ Age Concern does not have the same political influence as Grey Power, although historically it has added to the debate on superannuation provision.

While interest groups representing the elderly have the potential to form a powerful, militant group, there is little indication that they have done so in relation to many areas of retirement savings policy. This is likely to reflect the focus of such groups on two primary areas of policy: the universal pension and the surcharge. Thus, issues such as the taxation of retirement savings have not been a topic that these groups have confronted to any significant extent.

\footnotetext{
62 Source: Grey Power NZ Federation Inc April 32006 Newsletter Board Bulletin 2, www.greypower.co.nz viewed May 2006. established in a number of New Zealand cities. These groups acted as coordinating bodies for groups concerned about the elderly. 


\subsubsection{The Retirement Commission}

The Retirement Commission, was established in 1995 as 'an autonomous crown entity that helps New Zealanders prepare financially for their retirement' ${ }^{65}$ While the Retirement Commission supports research in relation to issues around retirement, it has a primary focus on educating individuals to 'understand retirement income policies and the benefits of supplementing New Zealand Superannuation ... with their own savings, ${ }^{6} 6$

As with groups representing the elderly, the Retirement Commission has had little input into the policy process. The organisation appears more focused on promoting the need for retirement savings, than attempting to influence policy issues.

\subsubsection{Business organisations}

Business organisations are often credited with structural power. Typically, it is agreed that there is a component of interdependence between Governments and business organisations, often leading to mutually beneficial outcomes from policy decisions. It is generally accepted that businesses play a key role in society, which raises the question of the level of power businesses and business organisations may possess in influencing policy outcomes.

The key business organisations in New Zealand include the Manufacturers' Federation, Federated Farmers and the New Zealand Employers Federation. In addition, the New Zealand Chamber of Commerce and Industry has local affiliations of trade associations. Business groups in New Zealand are often advantaged over trade union representation due to a superior public image. Vowles (1992:354) suggests 'the public image of unions is rarely presented in such a favourable light, and the unions themselves have been partly responsible for this'.

The New Zealand Employers' Federation has historically produced a superannuation scheme that small employers could adopt, although this was not widely utilised.

\footnotetext{
65 Source: Retirement Commission www.retirement.org.nz, viewed May 2006.

66 Ibid.
}


Generally, employer organisations have been supportive of employer subsidised retirement schemes, but have been opposed to any concept of compulsion.

An organisation in New Zealand with the ability and influence to impact on policy development is the New Zealand Business Roundtable (NZBR). The NZBR is a group of about 30 chief executives of major New Zealand companies (Mulgan 1989:123). Membership of the NZBR is by invitation only, and a number of NZBR members 'individually and collectively have ready access to ministers and government officials' (Mulgan 1989:124). Vowles (1992:355) describes the NZBR as 'probably the most powerful and influential group in New Zealand outside the Cabinet and Treasury'.

As the New Zealand government adopted less formal channels for consultation, the opportunities increased 'for powerful groups and individuals to exercise informal influence directly on ministers and government officials' (Mulgan 1989:124). Groups such as the NZBR have been strong proponents and supporters of the economic policies adopted in New Zealand in the mid- to late-1980s, such as reduced government intervention in retirement savings. As was to become the norm in New Zealand, business group preferences that were aligned with pro-market philosophies, such as those of the NZBR, were privileged in the decision making process. Dissenting opinions were infrequently heard.

\subsubsection{The financial sector}

For most of the $20^{\text {th }}$ century there were two key superannuation fund participants: the Government Superannuation Fund and the National Provident Fund. The Government Superannuation Fund provided superannuation for government employees and for a considerable period of time it included a significant proportion of New Zealand's workforce. 
The National Provident Fund was established in $1910^{67}$ and provided superannuation for the employees of local authorities, other approved bodies and the general public. Until the mid-1980s the majority of the National Provident Fund investments constituted government and local authority securities, and Government Superannuation Fund investments were placed in government stock. Following the liberalisation of the financial markets in the mid-1980s, financial services groups, life insurance companies and banks began to develop the managed funds industry, focusing on unit trusts and superannuation funds.

The peak industry group in New Zealand, the Life Offices' Association, made significant attempts to influence the direction of retirement savings policy in the late 1980s. The Life Offices’ Association representative, Boyd Klap, was frequently cited in the media opposing the removal of tax incentives for retirement savings. The claims of the Life Offices' Association, together with other life insurance and superannuation fund organisations, had minimal influence on the policy direction; their views were seen as self-interested and not representing the changing economic conditions.

\subsubsection{Individuals}

A few key actors played a significant role in forming retirement savings taxation policy that is found today in New Zealand. The first of these is Roger Douglas, who was the key player in the reform movements in the post-1984 period. Roger Douglas was the Minister of Finance in the Labour government after the 1984 election. ${ }^{68} \mathrm{He}$ was heavily influenced by new economic thinking and the Treasury philosophy of the time. Two other individuals who should be mentioned in the same context are David

67 The initial intent of the National Provident Fund was to provide state subsidised pensions to low-income earners. Large government subsidies were available to individuals who joined the scheme. The National Provident Fund was comprehensively restructured in 1990 and closed to new members in 1991. The National Provident Fund is now used to describe a group of 14 superannuation schemes and the Global Asset Trust that holds the investment assets on behalf of those schemes.

68 Roger Douglas was the Minister of Finance from 1984 to 1988 and is responsible for some of the most radical changes in New Zealand's economic history. 
Caygill and Richard Prebble, the two associate ministers of finance. As described by Bollard (1994:89) 'the ministers proved to be a most effective trio.' The important influence of individuals is discussed in detail in chapters nine and ten.

\subsubsection{Summary}

When the fourth Labour government took office in 1984, the power of lobby groups had become a key obstacle to economic and social progress (Jesson 1992:372). Roger Douglas is quoted by Jesson (1992:372) as commenting in 1991: 'blunting their power was the real role of the Economic Summit of that year. Having forced them into a commitment to put New Zealand first, we used the 1984 budget to hit the privileges of all the interest groups at once'. Mulgan (1989:122) concurs with this analysis, and suggests that since the election of the Labour Party in 1984, the traditional links between policy makers and various interest groups were weakened.

Levine and Roberts (1993) argue that prior to the mid-1980s New Zealand was a country 'bedevilled by pressure groups', but on deregulation of the economy there was considerably reduced scope for 'protectionist policies or subsidy schemes, and interest groups found it difficult to protect the special position of their members' (Levine and Roberts 1993:244). Some groups, such as farmers and manufacturers, which historically had been politically influential, had considerably less involvement in policy development after 1984 (Mulgan 1989:122). The most influential institution was the New Zealand Treasury. The New Zealand Treasury was privileged in its association with Roger Douglas, with its political power and influence and with the political acceptance of its broad economic frameworks for policy formation.

\subsection{Institutional Arrangements: Australia}

The institutional structures in Australia played a key role in implementing the superannuation arrangements that are in place today. The principal changes to superannuation that occurred in Australia in the mid-1980s were driven by the trade unions, who viewed compulsory work-based superannuation as a mechanism to provide additional benefits to its members. However, as with New Zealand, there are other interest groups that influenced, or attempted to influence, policy development in 
Australia. The key interest groups that influenced the formation of retirement savings and retirement savings taxation policy are outlined in this section.

\subsubsection{Political institutions}

In Australia, as in New Zealand, the state can be seen as a 'complex set of interacting institutions' (Bell and Head 1994:3). In Australia, the power and authority of 'the state' is described by Bell and Head as 'fragmented, and the formal authority that governments have in determining public policy is often not the same as real control' (Bell and Head 1994:4). Bell and Head (1994) claim that an elected government may struggle to implement certain policy reforms where there is opposition from organised interest groups, or where there is insufficient control over the 'state apparatus', suggesting that 'the government's policy and administrative capacities are constrained by bureaucratic routines, the priorities of bureaucratic elites,...judicial independence, and the state's ability to raise revenue through taxation or borrowing' (Bell and Head 1994:4). ${ }^{69}$

As in New Zealand, the election of the Labor government in 1983 was the catalyst for a significant change in the direction of economic management in Australia. The Australian Labor Party (ALP) was instrumental in the implementation of mandatory workplace superannuation. This was achieved through the Prices and Incomes Accord, which was reached between the government and the trade union movement and allowed the Labor government to maintain a degree of control over the labour market, while at the same time permitting unions to have some involvement in government policy (Brosnan, Burgess and Rea 1991:3).

Six Accords were agreed between 1983 and $1991 .^{70}$ The Accords were intended to:

69 In Australia, the states are responsible for service provision in education, welfare, transport, health and public housing. The Commonwealth has national responsibility for defence and external affairs, overseas trade and investment, immigration, customs and excise, income tax, social security and public sector borrowing (Bell and Head 1994:5). wage system with wage indexation, provisions to prevent non-wage incomes rising faster than wages, tax reform, intervention in industry to improve economic performance and job 
bring a measure of control over the economy and to ensure that economic recovery was not jeopardised by wage breakouts, with militant unions driving up inflation by winning large salary increases which would flow through to the rest of the work-force, irrespective of the economy's ability to absorb them. $^{71}$

The principal factor in the 'Accord Mark II' agreement in 1986 was the agreement to increase employee remuneration at a rate of six per cent, to keep up with inflation, but for half of this to take the form of a three per cent employer contribution to a superannuation fund.

The Australian Treasury was split into two departments in 1976, with economic matters remaining within the domain of the Treasury, but with financial management falling to a new Department of Finance. Like the New Zealand Treasury, the Australian Treasury was seen as privileged and powerful, being like-minded, welleducated elite. Also, similarly to New Zealand, public servants in key economic portfolios such as the Treasury formed part of an 'economic rationalist deluge that had flooded out from Australian universities to ultimately dominate Canberra' (Patmore and Coates 2005:10).

The Australian Treasury established itself in a key position due to the wide ambit of government activities with which it was involved (Whitwell 1986: 20). It is generally agreed that the Treasury is a key actor in determining policy direction and governmental decision making, but, unlike New Zealand, the Australian Treasury did not have the same level of autonomy in the area of policy advice. In contrast with the New Zealand Treasury, a number of other departments have influence over economic policy formation other than the Australian Treasury, such as the Department of Finance and the Department of Prime Minister and Cabinet. However, in criticism that is comparable to that seen in New Zealand, Whitwell (1986:15) suggests that the Australian Treasury presents a single line of advice to ministers, claiming that the department has a reputation for giving the advice it considers to be correct, regardless of the known policy preferences of ministers and, indeed, sometimes

\footnotetext{
creation, a universal health insurance scheme and the repeal of anti-union legislation (Patmore and Coates 2005:13). 
sticking to those views long after an alternative strategy has been adopted by a government'.

\subsubsection{Trade union arrangements}

Trade unions in Australia have historically been linked to the Labor Party; described as a 'collective parent' within a relationship that 'varied from proud cooperation to bitter recriminations throughout the $20^{\text {th }}$ Century. ${ }^{72}$ The trade union movement has not agreed with all Labor Party policies, but the two organisations have maintained an integral link throughout the 1982 - 1992 period.

At the end of the 1970s, trade unions in Australia underwent a significant structural and ideological transformation (Olsberg 1997:75). There was a move away from a focus on work conditions and wages, towards broader environmental and social concerns. Unions were restructured to become more corporate, with economic, political and industrial relations influences becoming more prevalent. Historically, trade unions have been powerful institutions in Australia. In 1986, more than 49 per cent of the total workforce were union members (Plowman 1989:2), although union membership has declined from about 2.5 million people in 1986 to 1.8 million in 2006 , or about 20 per cent of employees. ${ }^{73}$

Trade unions have supported the provision of superannuation as a benefit to members since the end of the 1970s. In addition, trade unions began operating their own superannuation schemes. Bateman and Piggott (1997:19) observe that:

the entry of the trade union movement to the area was especially significant as it represented a fundamental change in direction away from the conventional employer sponsored and controlled superannuation model towards trade union-initiated and often industry-wide schemes.

While it is frequently claimed that the trade unions in Australia had a significant influence in the implementation of the compulsory occupational scheme now in place there, it is also argued that the success was in no small measure related to the political,

\footnotetext{
72 Business Review Weekly, 18 December 1987, How Trade Unionism Became an Institution, p77.

73 Australian Bureau of Statistics (2006b).
} 
social and economic developments in Australia over this period (e.g. Olsberg 1997:74). In 1983, the Hawke government's accord encouraged union interest in superannuation. $^{74}$ The Accord Mark II agreement was the result of intense negotiations between the Australian Council of Trade Unions (ACTU) and the Australian Chamber of Commerce and Industry. Clarke (1992:343) argues that the structure of the various Accords 'not only secured a broad consensus over wages policy but they made the ACTU a virtual partner with the government in establishing the structure of economic policy in general'.

The Accord philosophy encapsulated what was known at the time as 'strategic unionism'. This was a commitment by the unions to forego workplace industrial action, in return for access to political power (Bramble and Heal 1997:134). This meant that unions could enter into negotiations with the aim of improving standards of living at a broader level. An element that is frequently cited as being of strategic importance in the success of the Accord was the reciprocity inherent in the arrangements.

The relationship between the Labor Party and the ACTU is credited as being a crucial component in the evolution of retirement savings policy. Donn (1983:329) claims that 'all of the ACTU's principal officers have played a large role in ALP affairs. Most have held various offices in the party and all have been involved behind the scenes'. A number of individuals are frequently cited as being key players in the reforms of the time, including economists Simon Crean, Bill Kelty and Greg Sword. ${ }^{75}$ The significant involvement of trade unions in economic developments and public policy formation during these two decades is often attributed to the close relationship between Bill Kelty (as the ACTU General Secretary) and Treasurer Paul Keating. As noted by Olsberg (1997:99):

the campaign for superannuation owed much to informal networks and friendly relationships among some key players, who used superannuation benefits as a trade-off to sustain union commitment to wage restraint and

74 Refer to chapter seven for discussion on the Prices and Incomes Accord.

75 Simon Crean became president of the ACTU and a Labour government minister. Bill Kelty became General Secretary of the ACTU. Greg Sword, of the Federated Storemen and Packers Union, was a significant actor in the development of the reformed retirement income system. 
hence the sanctity of the Accord. The need to protect the Accord strongly affected the direction of superannuation outcomes.

In addition, individuals had direct access to key Labor ministers. There appears to be agreement that union leaders obtained a high degree of political power at the federal level during the late 1980s and 1990s, despite declining union membership (Olsberg 1997:76; Patmore and Coates 2005:13). One explanation for this was that union control of industry-wide superannuation funds provided increased power and influence of the trade unions.

\subsubsection{Interest groups}

Olsberg (1997:79) cites a 'widely publicised national survey in mid-1978' that reported that 80 per cent of employees considered superannuation to be their most important fringe benefit. An equal number supported union involvement and action in relation to the issue. Accordingly, it would be expected that there would be a significant number and variety of interest groups on the topic of retirement savings and its taxation in Australia.

\subsubsection{The elderly}

Australia has an Office for the Aged, with a primary function of 'fostering consultation with older people so that their views and concerns can be made known to government' (Levine and Roberts 1993:247). There are few other organisations of a significant size for the elderly.

Similarly to New Zealand, Australia also has an increasing cohort of individuals aged over 65 years, who form a potentially strong political group. Also like New Zealand, the elderly in Australia are seen as a group that were organised and potentially well placed to influence policy. However, there is little evidence that organised groups informed the policy direction of the time. This may be, at least in part, because most decisions made did not adversely impact on the existing retired population. 


\subsubsection{Employer groups}

Until the late 1970s, there were three national associations that were the key representatives of business in Australia. These were the Australian Council of Employers' Federations, the Associated Chambers of Manufactures of Australia and the Associated Chambers of Commerce of Australia (Matthews 1994:198). A number of sector-based organisations also existed, such as the Metal Trades Industry Association and the Australian Mining Industry Council.

The major employer groups in Australia during the 1980s were the Confederation of Australian Industry (CAI), the Australian Chamber of Commerce and the National Farmers' Federation, although Olsberg (1997:109) claims that none of these were strong enough to gain direct employer representation in the Accord process. In addition, the absence of a coherent organisational approach limited their opportunity to influence policy direction. Dabscheck (1989:27) similarly suggests that employers played a relatively minor role and had limited input into policy decisions that were being made in relation to both wage and superannuation provision.

The CAI was the representative body of the major employer groups in Australia and was the key employer group involved in the legal challenge to the trade union claims that superannuation benefits should be included as a condition of employment. The claim made by the CAI was based on whether the Conciliation and Arbitration Commission had the jurisdiction to rule on claims that were not of an industrial nature. The High Court ruled against the employers in 1986, from which time superannuation could be considered within the award-based employment issues.

Employer groups initially opposed union claims for employer-funded superannuation. Olsberg (1997:107) claims that 'they saw it as a union ploy to get extra benefits outside agreed wage controls and a weakening of managerial prerogative'. Employer groups also voiced concern about the power that would be vested with union groups if they were to retain control of what were likely to be significant amounts within superannuation funds. 
In representing the CAI, Nolan ${ }^{76}$ (1986:52) writes 'let me make it clear that the CAI has no opposition, in principle, to the concept of superannuation'. However, Nolan expresses a number of concerns of the CAI over what was perceived to be the intention of the ACTU to undertake a continuing campaign seeking, through industrial pressures, to force employers to participate in new levels of superannuation'. These concerns included:

- the potential for trade unions to be shifting the obligation of superannuation from society to employers;

- the involvement of unions in management and administration of superannuation scheme funds; ${ }^{77}$

- a 'high degree of probability that aggregate savings might fall significantly below levels that would otherwise have been reached' (Nolan 1986:61); ${ }^{78}$

- firms will be worse off as they will have to accommodate the increase in costs for providing superannuation benefits; and

- firms will be forced to reduce their labour force, due to the increased costs of labour, and may be forced into retrenchments, reduced levels of investment and increased prices.

This is then extended by Nolan to a macro-economic perspective, where the economy will be less competitive, markets will be lost, imports will be increased and the rate of economic growth will decline.

Matthews (1994:203) claims that the CAI was always hampered by organisational problems. Reasons for this included that it was never fully representative, as a number of key sectors were not included in its membership (such as the Australian Mining Industry Council, the Australian Chamber of Commerce and the Australian Finance Council) and that it did not allow large corporations to be members of the group in their own right. This limited the ability of many key business individuals to be actively involved in the CAI's operations. When combined with financial difficulties, the influence of the CAI was diminished and it merged with the

76 David Nolan was the Director of the CAI's Industrial Council.

77 Nolan (1986) claims that unions will not invest in specific areas or regions because of political or industrial considerations, which will result in an inefficient allocation of capital.

78 The basis for this claim results from the potential for increased costs for employers resulting in reduced investment by employers. 
Australian Chamber of Commerce in 1992 to form the Australian Chamber of Commerce and Industry.

The Business Council of Australia (BCA) was a group whose influence was potentially greater than that of the CAI during the 1980s. The BCA is similar to the NZBR in New Zealand, with a membership of around 80 invited chief-executives of the largest business organisations in Australia. However, notwithstanding that the BCA were influential in other areas of tax reform, the BCA had little influence in retirement savings taxation policy, particularly in relation to the implementation of the Superannuation Guarantee.

\subsubsection{The financial sector}

Life offices were supportive of trade union claims for superannuation provision for all workers, primarily due to the expectation that the life insurance industry would share in the benefits from the expansion of superannuation (Rafter 1986:247). The AMP Society led the drive to partner with unions in industry funds, and by the second half of the 1980s, all major insurance companies had some involvement in union, industrywide funds (Olsberg 1997:112). However, Olsberg (1997:111) suggests that support for employer-based superannuation from the insurance companies was unexpected. Olsberg's claim is primarily ideological, where Australia's insurance industry had historically been conservative and economic liberalist.

\subsubsection{Individuals}

A number of individuals deserve separate mention in relation to the taxation of retirement savings and compulsory superannuation in Australia, including Prime Minister Bob Hawke and Treasurer Paul Keating, together with trade union officials, such as Bill Kelty. The influence of Paul Keating is particularly clear, and is discussed in greater detail in later chapters.

Much has been written about the relationship between union members and the government, and in particular the consensus-seeking approach to the policy process; for example, 'Keating and Kelty further agreed that the government would support an 
ACTU sponsored three per cent increase for productivity which employers would pay not through wages but as occupational superannuation benefits during the 1986-88 period' (Kelly 1994:206). The importance of these relationships will also be discussed in later chapters.

\subsubsection{Summary}

Overall, the implementation of the compulsory work-based superannuation schemes in Australia was supported by the majority of key institutional actors. The few initial dissenting players soon appeared to comply, although in some cases it was tacit compliance only. A number of factors appeared to contribute to the acceptance of the scheme, including the link to productivity gains and the long periods over which the scheme was to be fully implemented.

\subsection{Summary}

The benefit of utilising New Zealand and Australia for comparison purposes can be seen when looking at the institutional arrangements in each country. As found by Peetz (1998:157), for much of the period since the middle of the $20^{\text {th }}$ century, New Zealand and Australia had comparable political and institutional arrangements. These included long periods of conservative rule from 1949, Labour governments elected for a short period in the early 1970s and for a longer period in the 1980s. In addition, the major economic reforms that occurred from the mid-1980s were not dissimilar in both countries. It was after this time that the New Zealand and Australian policy directions in relation to the taxation of retirement savings began to diverge.

Key differences in institutional structures include the unitary state and unicameral parliament in New Zealand and the federal system and bicameral parliament in Australia. As noted by Janiewski and Morris (2005:3), the federal structure adopted by Australia requires more 'complex coalition-building to achieve electoral success and slows down radical and rapid structural change'. The New Zealand system, until the adoption of MMP in 1996, allowed for greater power to sit at the parliamentary and executive levels, and for changes to pass quickly through the 
system. With New Zealand being a unitary state, the government has historically had greater control over policy development and implementation.

In Australia the close relationships between the ACTU and the Labor government led to the development of the Accord to facilitate policy development in the mid-1980s, whereas in New Zealand policy formation was strongly influenced by market based economic policies. The political aim of the Australian Accord was to allow the Labor government to maintain a degree of control over the labour market, while at the same time allowing unions to have some involvement in government policy. This allowed both the political system and labour market institutions to evolve to 'cope with the problems within the context of the traditional policy framework' (Brosnan, Burgess and Rea 1991:1).

New Zealand and Australia both experienced similar patterns of diminishing attention provided to many interest groups from the early 1980s. Vowles (1992:356) notes that the nature of relations between interest groups and government in Australia changed significantly during the 1980s: 'lobbying and bargaining strategies focusing on particular business interests became increasingly counterproductive, particularly when those interests were perceived as standing in the way of change'.

As also noted by Vowles (1992:343), it is no longer expected that the state will be a neutral or passive organisation. In addition, interest groups are not merely influencing the state, as their structure and interactions are determined by historically formed policy frameworks. Furthermore, as explained in the introduction to this chapter, it is expected that institutions will represent the beliefs and values of their individual members, as much as individuals will be influenced by the position of their institutions. These issues in relation to institutions, institutional influence, and individuals within institutions are explored in greater detail in chapter nine.

The following two chapters outline the historical development of retirement savings taxation policy in New Zealand and Australia, respectively. To allow environmental and historical factors to be taken into account, policy changes since the early 1900s are discussed, with a more detailed focus on the 35-year period from 1972 to 2007. 


\section{Chapter 6: The History of Retirement Savings Taxation in New}

\section{Zealand}

\subsection{Introduction}

The previous chapter examined the key institutional arrangements involved in retirement savings policy in New Zealand and Australia. A number of these institutions feature in this and the following chapter, as a brief history of the tax treatment of retirement savings in each country is detailed. This chapter outlines the background to the key policy changes in New Zealand in 1988 together with some of the amendments to retirement savings policy subsequent to 1988. The objective is to provide the reader with an understanding of the antecedents to New Zealand's current arrangements for the taxation of retirement savings, and to provide a contextual review for the analysis that follows in chapters eight to eleven.

The chapter starts with a brief historical review of the development of retirement savings, and taxation thereof, in New Zealand since 1898. The period from 1972 through to 2007 is discussed in more detail, with a particular focus on the events between 1982 and 1992, as decisions made in this period played a significant role in establishing future retirement savings policy in New Zealand.

While the thesis is primarily interested in the taxation of retirement savings, it is necessary to locate this topic within the broader environment of retirement savings policy. Thus, the history encompasses elements of broader social and economic policy, together with the specific taxation amendments. A table outlining the key events in New Zealand's retirement savings policy history is provided in Appendix 6.1.

\subsubsection{Background: Prior to 1972}

Many government employees in New Zealand had access to state superannuation from the mid-1850s. This is attributed to New Zealand's colonial heritage. It is generally accepted that New Zealand (and Australia) at the start of the $20^{\text {th }}$ century, and for some years after, were ahead of much of the world in many aspects of social policy (Castles 1985:17). In New Zealand, together with other Commonwealth countries, social policy reforms relating to retirement, employment and health were 
enacted in the years between the turn of the century and the Second World War. However, New Zealand was unusual as one of few countries to provide a noncontributory state pension.

The seminal legislation that put New Zealand at the forefront of international social policy was the Old Age Pension Act 1898. The key significance of this legislation is that 'it marked the recognition of the principle of state responsibility for the relief of individual poverty within the community, and the tentative beginning of social security as we know it today' (Booth 1977:74). The Old Age Pension Act 1898 provided a modest pension of around one-third of a working-man's wage (Preston, 2001:10). Entitlement to the pension was strictly limited. To qualify an individual needed to meet criteria of age (65 years), residence (25 years), moral qualifications ('sober and reputable living' (Whyte 2004:126)) and have limited assets. Only around one-third of the population aged over 65 qualified for the pension, and targeting measures meant that most Māori received less than the full rate. Furthermore, until 1936 individuals of Asian nationality were excluded. ${ }^{79}$

Historically, life offices did not pay company tax, as they were viewed as existing for the mutual benefit of members, rather than profit-making enterprises. Instead, life offices paid personal income tax on behalf of policyholders, under the 'trustee concept' ${ }^{80}$ The tax basis for life offices from 1930 through to the early 1980s was the present value of surpluses allocated to policyholders, plus dividends allocated to shareholders.

After the implementation of the targeted old age pension, successive governments looked for ways to encourage people to provide for their own retirement, rather than relying on state funded pensions. The National Provident Fund was established in

79 Early funding of old age pensions came from indirect taxes such as customs duties, as the majority of New Zealanders paid no income taxes during their working lives (Thomson 1991:30).

New Zealand Treasury memo to the Deputy Minister of Finance, 7 October 1981. New Zealand Archives reference AALR, 873, W5427, 1898, 76/13/6 Part 1. The trustee concept adopts the view that the tax paid should equal the amount that would be paid if it was possible for policy holders to be taxed directly on the income portion of fund benefits. 
1910 and a tax exemption was extended to superannuation contributions (and payments to the insurance fund of a friendly society) in $1915 .{ }^{81}$ Both life insurance premiums and superannuation fund contributions were exempt from personal income tax, subject to a maximum exemption amount. This exemption had been in place since income tax was first introduced in 1892 and was intended to encourage selfreliance in retirement. ${ }^{82}$

The 40 years between the Old Age Pension Act 1898 Act and its successor, the Social Security Act 1938, did not result in any significant changes to the old age pension. There were four further Old Age Pension Acts, which were subject to ten amending acts, but these amendments were primarily enacted to increase the level of benefits and to change the asset or residence requirements (Booth 1977:75).

A key event in New Zealand's social welfare policy was the introduction of the Social Security Act 1938, which introduced a dual publicly-provided pension system. Individuals of retirement age, who had been resident in New Zealand for 20 years, could choose between an age benefit payable at age 60, which was not taxed, but was subject to an income test, and a superannuation benefit payable from the age of 65 , which was not income tested, but was taxable. Individuals who did not qualify for the means tested age benefit received the universal superannuation benefit.

In the period after the Second World War, there was considerable difference in the levels of social welfare provision fare in New Zealand and Australia. New Zealand had 'become one of the world's leading spenders on social security provision, devoting 9.7 per cent of GNP to such schemes in 1949 - more than twice the percentage in Australia' (Castles 1985:28). This generous provision was initially not problematic as New Zealand enjoyed a high standard of living until the 1960s. Demand for agricultural products was high, unemployment was low and the social security system in New Zealand was available to groups viewed as likely to be facing hardship. However, towards the end of the 1960s there was some interest in the level

$81 \quad$ New Zealand Treasury memo to the Deputy Minister of Finance, 7 October 1981. New Zealand Archives reference AALR, 873, W5427, 1898, 76/13/6 Part 1. The exemption was introduced in the Finance Act 1915.

82 Ibid. 
of efficacy of the social security system; in 1946 the age benefit for a married couple had been 63 per cent of gross average weekly earnings, but by 1970 this had reduced to 48 per cent (Lacy 1994:8).

The next decade was to see New Zealand fall in its ranking against other OECD countries as a result of numerous factors including the oil crisis, global restructuring, the impact of the United Kingdom entering into the European Community and the European Community's Common Agricultural Policy (Stephens 2003:2). These factors, in conjunction with New Zealand's economic policies were to result in high inflation, low economic growth and high unemployment.

\subsubsection{2 - 1982}

After the Labour Party election victory of 1972, the then Minister of Finance, Bill Rowling, introduced a White Paper on the New Zealand Superannuation Scheme (NZSS). The New Zealand Superannuation Corporation Bill was introduced into parliament a short time later. After public hearings during May 1974, the scheme was introduced in April 1975. ${ }^{83}$ Every employee aged between 17 and 65 was required to belong to either the NZSS or an approved private scheme. The minimum level of contributions was four per cent of earnings, with a five-year phasing in period. Employers were obliged to at least match employee contributions.

The objectives of the scheme were to ensure that all employees had access to superannuation schemes, as only about 30 per cent of the work force was covered by superannuation at the time (Cameron and Nicholl 1975:3) and that the superannuation benefits were portable. ${ }^{84}$ Self-employed individuals were not required to participate and instead were given tax incentives to encourage voluntary participation. At the

83 This is despite 192 submissions, none of which was fully supportive of the Bill (Lacy 1994:12).

84 As well as the provision of superannuation coverage to the wider workforce, the NZSS was also seen to have the potential to impact positively in a number of areas of the financial system including the size of financial institutions, interest rates, portfolio adjustment effects (with substitution between financial assets and institutions), international capital flows and the domestic capital market (Cameron and Nicholl 1975:34). 
same time, the universal superannuation benefit remained (payable at 65 years of age and adjusted for cost of living increases).

The New Zealand Superannuation Corporation Bill creates a critical juncture in New Zealand for a number of reasons. Perhaps most significant is that it was the first time in 40 years that retirement savings had been a key policy focus. In addition, it is claimed that in the absence of the Bill, the National Party would not have produced any alternative retirement savings policy. ${ }^{85}$ While the National Party was campaigning on a plan to remove the NZSS, promotion of an alternate was also required. The National Party's policy for retirement savings was announced in June 1975 by Robert Muldoon, the then Leader of the Opposition. ${ }^{86}$ As found by Palmer (1977:9):

It resembled nothing so much as the policy devised by the Parliamentary Select Committee of 1938 chaired by Mr A H Nordmeyer, as he then was. National had adopted Labour's 1938 policy, a policy which there had not been enough money to implement in 1938. National's policy was six pages in length and of breath-taking simplicity.

However, the National Party scheme was expensive. The proposed scheme was expected to increase spending on welfare benefits by 35.6 per cent (Palmer 1977:10).

Superannuation was a key issue in the 1975 election. The National Party criticism of the compulsory Labour Party scheme, together with the proposal of an alternative generous non-contributory scheme, are credited as critical factors leading to the landslide National Party election victory in 1975.

National Superannuation was introduced in 1977. National Superannuation was a benefit available to those aged 60 years or over who satisfied a residence test. It was payable at 70 per cent of the gross average ordinary-time wage from February 1977.

85 For example, Lacy (1994:20) writes that 'the area had been ignored by National during its many years in office and there was no indication in 1972, or until Labour produced its scheme, that anyone in the National Party was contemplating any alternative'.

86 These changes are typically acknowledged to result from the Royal Commission of Inquiry on Social Security (1972) in New Zealand, which suggested that the elderly population was facing significantly reduced standards of living. 
Two key differences existed between National Superannuation and the scheme that had operated for the previous four decades: the taxation of all individuals receiving the payment and the linking of National Superannuation to a percentage of the gross average wage, rather than the same amount as income tested benefits. National Superannuation was now financed out of ordinary government revenue on a pay-asyou-go basis. ${ }^{87}$

Robert Muldoon, as Prime Minister and Minister of Finance, was the key protagonist of National Superannuation, and even when economic conditions deteriorated he was to continue support for the generous provision in the face of strong advice to the contrary. ${ }^{88}$ By 1981 New Zealand's spending on superannuation provision had become significantly more than other OECD countries' at 17.3 per cent of government spending, compared to around 11 per cent of government spending in Australia and Britain (McClure 1998:194).

Until the 1980s, the debate relating to superannuation primarily focused on the cost of provision. ${ }^{89}$ Missing from the discussion was an analysis of the role of the state in provision of retirement savings. It was assumed that the state, in its paternalistic role, would continue to provide for retired individuals.

A key report of this period was produced by the New Zealand Planning Council in 1979: The Welfare State? Social Policy in the 1980s. While the report addressed wider social policy issues, it also covered the topic of superannuation. The review concluded that it was necessary to reduce National Superannuation payments to

$87 \quad$ Under the Social Security Act 1938, a Social Security Fund was established in New Zealand. This was funded from a social security income tax that was initially at a rate of five per cent. This tax was incorporated into the general income tax system in 1968.

88 A number of government departments were critical of National Superannuation. The Department of Social Welfare called it 'an undue burden ... the worst mistake ever made' (McClure 1998:194). Belich (2001:398), in his New Zealand history, refers to it as 'staggeringly reckless'.

89 During the introduction of National Superannuation, Prime Minister Muldoon had stated that it would not require any taxation increases. There was just one reduction of National Superannuation during this period; in 1979, the pension was effectively reduced with a change in the linking of the amount to the net (rather than the gross) average weekly wage. 
contain the growth of public expenditure. The Planning Council was one of the first groups to identify issues associated with paying superannuation to individuals who may not need it, and who may also still be in full-time employment.

It was also during this period that policy objectives were revisited. The Planning Council reviewed the social security policy options that were presented in the Royal Commission of Inquiry into Social Security in 1972 (also known as the McCarthy Commission). The McCarthy Commission offered four possible objectives:

(a) to maintain life and health, i.e. to have access to the essentials of life (subsistence);

(b) to belong and participate, i.e. to meet and mix with other New Zealanders as a full member of the community (belonging);

(c) to be equal in economic well-being, i.e. to have substantially the same standard of living as all other New Zealanders (equality);

(d) to have continuity of economic status, i.e. to maintain the same individual standard of living as that enjoyed in the past (continuity).

The Royal Commission chose option (b) and recommended a benefit that was 80 per cent of the wage of a builder's labourer, which was seen as providing support for the objective of 'belonging'. The discussion on the other options found (a) inadequate, (c) not reflecting widely held values in New Zealand, and (d) as not the role of the community. Reference to 'belonging and participation' remains at the present time in government documents relating to retirement savings.

In 1981 the New Zealand government announced the establishment of a Task Force on Tax Reform (Task Force on Tax Reform 1982)..$^{90}$ The terms of reference of this Task Force were:

- to undertake a thorough and systematic review of all aspects of central government taxation;

- to draw on what is already known and established about taxation in New Zealand and overseas; and

- report on options for a reformed tax system for New Zealand.

90 Also known as the McCaw Review. 
At the time the Task Force was established in 1981, personal contributions to superannuation funds were tax deductible for both individuals (up to a limit of $\mathrm{NZ} \$ 800$ if in an employer-subsidised scheme or $\mathrm{NZ} \$ 1,000$ if no subsidy was provided) and employers (up to a ceiling of NZ\$700 per employee for a lump sum benefit or ten per cent of the amount of an employee's wages or salary for a pension benefit). Earnings of the funds were not taxed and lump sum superannuation was not taxed on withdrawal. Pension superannuation funds were taxed as part of personal income on withdrawal, although in many cases pensions were converted in some part to a lump sum on retirement and thus avoided tax. ${ }^{91}$ Using the generally accepted classification of taxation of retirement savings, this scheme fell within the EEt category.

The Task Force report discusses the concept of neutrality among different forms of saving. The Task Force concluded that superannuation funds should be treated as an agent of the policy holder and therefore liable for income tax on investment income at the marginal income tax rate of the policy holder. In addition, to achieve greater consistency with other forms of savings, and to minimise revenue loss, removal of the exemption from taxation on fund withdrawal was the preferred option.

A Caucus Committee subsequently examined these issues in 1982 and recommended that the income of superannuation funds (and building societies and life offices) should be taxed. A further recommendation was that exemption limits for superannuation contributions should be increased above the prevailing levels. A third change that emanated from the Caucus Committee recommendations was the removal of the then NZ\$700 limit on employer contributions to lump sum schemes. This was replaced with a maximum employer contribution of 10 per cent of employee salaries. Thus, in 1982 fund earnings for lump sum superannuation schemes became taxable at 33 per cent. This was expected to generate additional revenue of approximately NZ\$75 million per annum. ${ }^{92}$ Pension payment fund earnings remained tax exempt.

$91 \quad$ For example, up to 25 per cent of a pension entitlement was permitted to be paid as a lump sum. Exemptions, such as for permanent emigration or permanent incapacity, also allowed benefits to be paid in a lump sum form.

92 Memo from the Caucus Committee to the Minister of Finance, 11 June 1982. New Zealand Archives reference AALR, 873, W4446, 632, 76/2/54, Part 1. 


\subsubsection{3 - 1987}

By the 1980s, New Zealand was facing a serious economic crisis with low growth and high inflation. In 1984 the Labour Party came to power after nine years of National government. This period was to be the start of significant economic reform in New Zealand; reform which is widely accepted as taking New Zealand from one of the most regulated countries in the OECD to the most deregulated. In addition, significant reform of the taxation system was implemented during this period.

New taxes in the form of a Fringe Benefits Tax (in 1984) and a Goods and Services Tax (in 1986) were implemented. These new taxes were intended to increase the fairness of the tax system, and reduce the penalties on innovation and work which flowed from an over concentration on income tax as the main source of revenue' (New Zealand Government 1986:6).

In the 1984 Budget some of the personal tax exemptions for life insurance premiums and superannuation contributions were removed. ${ }^{93}$ These were for life insurance, personal lump sum superannuation schemes and non-subsidised employee lump sum superannuation schemes entered into after the night of the Budget. It may be interpreted that this step was the first move towards a more neutral tax treatment of long-term savings. Indeed, this was signalled by the announcement of a review of superannuation and life insurance, which would involve consultation with industry participants. While this move bought the tax treatment of life insurance policies and personal lump sum superannuation schemes closer to a TTE income tax treatment, investment earnings were not taxed at the marginal rate of the member, but at the standard rate of 33 per cent. This was punitive for lower marginal tax rate taxpayers

$93 \quad$ From 8 November 1984, contributions to employer subsidised superannuation funds (both pension and lump sum) were deductible up to NZ\$1,200 per annum. Contributions to personal pension schemes and non-employer subsidised employee pension schemes were deductible up to NZ\$1,400 per annum. Contributions to personal lump sum schemes and nonemployer subsidised employee lump sum schemes were not deductible. Investment income of superannuation funds for lump sum policies (personal, employer subsidised or non employer subsidised) were subject to tax at 33 per cent from 1 April 1985. Investment income of superannuation funds for pension policies was tax exempt. Benefits from lump sum schemes were tax exempt and benefits from pension schemes were generally taxable. 
and concessional for those on higher marginal tax rates. Employee lump sum schemes remained under the ETE system for employer contributions, with investment earnings also taxed at the standard rate of 33 per cent. Personal and employee pension superannuation schemes continued under the existing EET system. Estimated costs of tax concessions for superannuation at this time was NZ\$440 million. ${ }^{94}$

Two strategic Treasury documents established the direction of reform into the future. These documents were Economic Management (New Zealand Treasury 1984) and Government Management (New Zealand Treasury 1987). Economic Management introduced the major economic issues facing the incoming government. It was also one of the first documents to highlight the need for tax policy to follow certain criteria, including economic efficiency and equity (New Zealand Treasury 1984:211). The narrow tax base, a lack of efficiency and equity, and tax expenditures ${ }^{95}$ were raised as potential problems within the tax system. This document provided an insight into the direction that reforms were likely to take, stating:

While there is little wrong in principle with the concept of tax expenditure, many of them are in practice a poor method of delivering assistance, and because they are not highly visible, they are barely controlled. It is desirable to review many of the measures and expose them to greater ongoing scrutiny. ${ }^{96}$

Another policy initiative from this time is the 'superannuation surcharge'. In the campaign for the 1984 election the Labour Party had promised that National Superannuation, as it was then, would not be changed. However, within the economic climate, this promise became untenable and a 'surcharge' on other earnings was implemented. The surcharge took the form of an increased income tax rate on earnings over and above National Superannuation. The surcharge was very unpopular, viewed as inequitable and resulted in a proliferation of tax avoidance mechanisms. What the surcharge also appeared to do was create an environment among interest groups representing interests of the elderly that focused on issues

$94 \quad$ Memo from the New Zealand Treasury to the Minister of Finance, 23 October 1985. New Zealand Archives reference AALR, 873, W4446, 632, 76/2/54, Part 2.

95 Tax expenditure is the general term for special assistance provided to certain types of taxpayer. These were identified in Economic Management as having an annual cost of NZ\$1.5 billion.

$96 \quad$ New Zealand Treasury (1984:17). 
relating to the surcharge; this appeared to dilute the debate on issues such as tax incentives, which were perhaps more relevant to future retiring populations than those currently retired.

Government Management (the briefing to the incoming government in 1987) identified some of the important objectives of National Superannuation. These were highlighted as being a basic standard of living, retention of dignity and facilitating participation in society. However, the document also noted that it does not follow that protection of these values requires that all people over a certain age should receive a universal payment. The values underlying such a payment, in particular “honouring age”, seem to have little firm basis' (New Zealand Treasury 1987:173).

Retirement savings issues raised in Government Management include:

- the large intergenerational transfer of income from current taxpayers to those aged over $60 ;{ }^{97}$

- the 'modest form of targeting' that the National Superannuitant surcharge was adopting; ${ }^{98}$

- the high average personal tax rate that was required to fund National Superannuation; ${ }^{99}$

- erosion of the tax base and efficiency losses through the provision of tax incentives for retirement savings; and

- the increasing cost of National Superannuation.

These points led to a number of conclusions, including that an improved form of targeting assistance to the elderly was necessary, such as increasing the age of eligibility or introducing income or asset testing. The document's arguments were

97 Estimated at a gross cost of over NZ\$3.9 billion in 1987/88 (New Zealand Treasury 1987:173).

98 At the time the surcharge added a tax rate of 18 cents in the dollar (for married couples) to incomes of NZ $\$ 13,000$ or more, and recouped approximately four per cent of the gross cost of National Superannuation (New Zealand Treasury 1987:173).

99 Estimated at over eight per cent, assuming that the scheme was entirely funded from personal income tax (New Zealand Treasury 1987:173). 
supported by economic theory, with frequent reference to reduction of efficiency costs and improvement of intergenerational equity.

In 1987, employer contributions to lump sum schemes remained deductible up to a maximum 10 per cent of member payroll. This created the potential for tax planning by allowing employers to contribute at low rates for the majority of members, and high rates for selected high income earning members. This abuse was noted by the Government Actuary in 1987 as 'not large, but is growing'. 100

The most significant change of this period occurred in December 1987 when the government announced a number of proposals in relation to the way superannuation scheme savings were to be taxed. The key changes were:

- contributions to superannuation schemes would be from taxed income;

- income earned within superannuation schemes would be taxed at a rate approximating the marginal tax rate of fund members; and

- funds from superannuation schemes would be free of tax on withdrawal.

Using the taxation classification, this moved the tax treatment of retirement savings to TTE, the same as that of a bank deposit. The aim was a 'level playing field' for investment, but a strong link was made between the removal of superannuation incentives and the introduction of lower personal tax rates. In addition, removal of the tax concessions was seen to improve equity within the tax system. ${ }^{101}$ These tax changes to superannuation, and the introduction of a TTE scheme, were intended to move these forms of savings on to the same basis as other savings vehicles, thereby removing their privileged tax position. The changes also reduced the tax revenue foregone in relation to tax concessions provided. ${ }^{102}$

100 Memo from the Government Actuary to the Secretary to the Treasury, 13 February 1987. New Zealand Archives reference AALR, 873, W5427, 1828, 76/2/54, Part 3.

101 Tax incentives in relation to superannuation and life insurance were viewed as 'to a large extent, captured by a section of society which is predominantly made up of male middle-aged professionals belonging to high-income socio-economic groups' (New Zealand Government 1987:3). about 2.5 cents per dollar for all taxpayers, after making superannuation benefits non-taxable. 
The changes to contributions to superannuation schemes were two-fold. Firstly, individuals could no longer claim a personal tax exemption on contributions to superannuation funds. Secondly, the 10 per cent limit on deductibility of employers' contributions to superannuation schemes was removed. The introduction of a fringe benefit tax on employer superannuation contributions was also announced, although this was later amended to a withholding tax from 1 April 1989.

After the announcements made in the December 1987 Economic Statement, a Consultative Document on Superannuation and Life Insurance (the Consultative Document) was issued by the New Zealand government in March 1988 for the purposes of discussing the changes announced and outlining details of the implementation of the new scheme. The Consultative Document observed that the changes were the final stage in a process that commenced in 1982 with the partial removal of tax incentives for lump sum superannuation schemes.

The Consultative Document raises the familiar arguments against tax concessions, ${ }^{103}$ claiming that 'arguments for retaining tax preferences - the desirability of encouraging savings and the desirability of encouraging private, as opposed to public, provision for retirement - do not, in the end, stand up to close analysis' (New Zealand Government 1988:1). The Consultative Document acknowledges both the important role that superannuation funds have for savings and investment purposes, but concludes that tax concessions for superannuation and life insurance are 'inequitable and incur high economic costs' and 'any of the supposed benefits which the concessions provide in terms of increased incentives to save and higher retirement incomes are better met by more direct policies' (1988:81).

After the publication of the Consultative Document, the government called for public submissions on matters relating to the implementation and operation of the proposed measures. A Consultative Committee was charged with receiving these public submissions and reporting to the Minister of Finance. The ambit of the Consultative

103 Including that tax concessions were expensive in terms of tax revenue lost, tax incentives create distortions in investment behaviour and labour markets, they create opportunities for abuse of the system, require tight regulatory control and favour high-income earners. 
Committee on Superannuation, Life Insurance and Related Areas (the Consultative Committee) did not extend to an analysis of the potential strengths or weaknesses within the changes suggested by the government. However, the Consultative Committee did step outside its terms of reference on occasion; for example, reporting that 'we would be failing in our duty, however, if we did not report to the Minister that the overwhelming majority of submissions received were very strongly opposed to the policy which Government has announced in this area' (Consultative Committee on Superannuation, Life Insurance and Related Areas 1988:3).

The Consultative Committee suggested modification of the scheme proposed by the government, which would effectively result in an ETT regime. The Consultative Committee argued that this approach was not concessionary as, under certain assumptions, it was the same as the proposed TTE regime. The ETT scheme was thought to have a less disruptive impact on superannuation schemes and overall levels of savings. ${ }^{104}$

The findings of the Consultative Committee were 'noted' by the government. However, the future of the taxation of retirement savings was sealed when the Minister of Finance announced that in view of the ... need for an early decision to enable superannuation funds to plan for the future, it has been decided not to proceed with further consideration of the modified taxation regime outlined in the Committee's report'. ${ }^{105}$

The Royal Commission on Social Policy ${ }^{106}$ was published in 1988. This report investigated a number of areas of social policy, including support for the elderly and the role of the state in providing retirement incomes. The review emphasised individual responsibility for self-provision for retirement, while still accepting that the state is required to perform some role in the form of income assistance to those in need (Royal Commission on Social Policy 1988:620). The report acknowledges the

$104 \quad$ Refer to section 1.1.1 for explanation of these taxing regimes.

105 Statement by the Minister of Finance, Hon R O Douglas, Release of the Report on Superannuation, 26 July 1988. 
'traditional' arguments in support of tax incentives. ${ }^{107}$ The report concludes that there is insufficient evidence to recommend the re-implementation of taxation incentives for retirement savings and advocates the status quo, i.e. the continuation of a universal superannuation scheme, despite finding that:

while we are not convinced that a return to preferential tax treatment is justified, we are also not persuaded that individuals in all socio-economic groups currently have a realistic opportunity to save enough during their working lives to provide even a small income for themselves and their dependants after retirement. ${ }^{108}$

\subsubsection{8 - 1992}

The election of the National Party in 1990 saw a number of proposed cuts to superannuation, as part of an overall reduction in welfare spending. Contrary to election pledges, ${ }^{109}$ these included 'freezing' the pension for three years, increasing the age of eligibility to 65 and replacing the surcharge ${ }^{110}$ with a regime that clawed back even greater amounts of superannuation. ${ }^{111}$ The considerable unpopularity of these proposals saw their withdrawal in 1991, although the increase in age of eligibility remained and the surcharge was replaced with a more rigorous income test.

The Task Force on Private Provision for Retirement (the Task Force) ${ }^{112}$ was appointed by the National government in October 1991 to report on policy options to

107 For example, that individuals will be unable or unwilling to provide for their own retirement in the absence of incentives or employer supported provision, and the potential beneficial impact of increased long-term savings on economic growth and investment. Royal Commission on Social Policy (1988:643).

109 The National Party campaigned on the slogan of a "Decent Society", implying that they would reverse Labour's welfare charges and offset the increase in income inequality (Stephens 2003:7).

110 Introduced by the Labour government in 1985. While not the same as an income test, the outcome of the surcharge was similar to an income test.

111 The proposals would have reduced superannuation payments for individuals aged under 70 at a rate of NZ\$0.90 cents in the dollar for all income above NZ\$4,160 per year. Individuals would lose all superannuation benefits at incomes of $\mathrm{NZ} \$ 17,279$ for a single person or NZ\$23,740 for a married couple. Under the previous scheme, a couple could have other income of NZ $\$ 71,000$ before the entire superannuation provision was lost. 
encourage self-reliance in retirement. In addition to this key objective a number of broad principles were provided by the government, including promotion of intergenerational equity, promotion of economic efficiency in resource allocation and promotion of fiscal sustainability. A number of specific areas were reported on, including:

- the tax treatment of private superannuation, superannuation schemes and longterm investments;

- compulsory contributions to private superannuation schemes;

- the interface between private superannuation savings and state provided retirement income provision;

- regulations for private superannuation; and

- policies or regulations that may impede savings.

The Task Force produced an interim report in 1991 and a final report in 1992. As was to become the pattern for the future, the Task Force did not make any major policy reform suggestions, although it did provide three 'model' options for retirement savings. ${ }^{113}$ The Task Force reiterated the need to increase savings and to support long-term savings, but concluded that neither of these two issues provided a strong argument in support of tax incentives. Overall, the Final Report of the Task Force (1992:11) recommended:

- improvement of voluntary private provision;

- integration of voluntary private provision with National Superannuation, which would continue to be paid on an income tested basis;

- implementation of six-yearly reviews; and

- improvement of public understanding of retirement provision issues.

The evolution of a New Zealand 'Accord' arose from the Task Force. The Todd Task Force emphasised the need for inter-party consensus on pension policy. The governing National Party, the Labour Party and the Alliance Party signed an accord in August 1993, which outlined some specific policy details relating to retirement issues.

113 The three options were a voluntary 'neutral' option based on the existing tax regime for savings, an incentive option based on tax concessions and a funded compulsory option requiring contributions from employees and the self-employed. 
These included linking New Zealand Superannuation (as it was now known) to a band of 65 to 72.5 per cent of the after-tax average weekly wage, continuation of a surcharge in some form, continuation of the increase in age of eligibility to 65 years and no compulsion for retirement savings.

Although the Accord was criticised for having insufficient 'power' (for example, there were no sanctions for non-compliance), it was to be reasonably successful for the period that it existed. However, there were factors that limited its effectiveness. The key one is likely to have been that not all political parties signed the agreement and, in particular, the New Zealand First Party did not. New Zealand First policies were aligned with many of the interests of the retired population and, accordingly, had considerable support from this part of the population.

\subsubsection{3 - 2005}

The 1996 election campaign resulted in all major political parties, except the National Party, withdrawing from the Accord. ${ }^{114}$ The 1996 election resulted in a National and New Zealand First Party coalition government, which was to have particular implications for superannuation policy. New Zealand First had campaigned on a platform of elimination of the superannuation surcharge, higher pension benefits and the implementation of a compulsory work-based scheme. Elimination of the surcharge was part of the coalition agreement and was subsequently carried out.

The coalition agreement between the National Party and New Zealand First outlined the intent to introduce a compulsory savings scheme on 1 July 1998, if approved under a referendum. The proposed scheme was to have contribution rates of three per cent, starting in 1998/1999, increasing to a maximum level of eight per cent in $2002 / 2003$, with the intention of assisting each income earner to save NZ\$120,000 before retirement. Individuals who did not achieve this amount by retirement would

114 While no longer used, the Accord still exists and a number of the reforms implemented through the Accord remain, including the establishment of the Office of the Retirement Commissioner, the provision for regular Periodic Report Group reviews on public and private provision of retirement income and the band for superannuation provision set at $65-72.5$ per cent of net wages. 
have their savings supplemented by the government, thereby ensuring that payments received would be at least at the same level as New Zealand Superannuation.

The aim was that the two schemes (the proposed Retirement Savings Scheme and the current New Zealand Superannuation) would co-exist until New Zealand Superannuation was eventually fully phased out. However, when the compulsory scheme was taken to a referendum it was soundly defeated with nearly 92 per cent of voters rejecting it. ${ }^{115}$ This was despite the clause in the coalition agreement that stated, subject to the availability of adequate government surpluses, there would be an 'equitable programme of tax cuts to broadly match the increase in the compulsory superannuation contribution rates' (New Zealand National Party and New Zealand First Coalition Agreement 1996:54).

A plethora of government instigated reports was produced in this period from organisations such as the Periodic Report Group (PRG), the Savings Product Working Group (SPWG) and the Treasury. The $\mathrm{PRG}^{116}$ produced two reports in 1997, the Interim Report, which presents most of the findings, and the Final Report, which addresses outstanding issues (Periodic Report Group 1997a, 1997b). Along with many of its predecessors, the 1997 Retirement Income Reports find the extant system of retirement income in New Zealand 'flexible enough to deal with the changes we will face over the next 50 years and that New Zealand is better able to adjust to those changes than many other countries' (Periodic Report Group 1997a:4).

The next report to enter into significant discussion on potential tax incentive schemes for New Zealand was the New Zealand Treasury report Savings Incentive Options, Consultation and Analysis, produced in 2001. The officials consulted widely and received responses from a number of interest groups, including Business New Zealand, the Council of Trade Unions, the Insurance and Superannuation Industry and the Office of the Retirement Commissioner. The report discussed three tax incentive

115 The proposed scheme had significant opposition from a number of areas, including two-thirds of National Party cabinet ministers, the major opposition parties, trade unions, the Employer's Federation and Grey Power (Weaver 2002:23).

116 The PRG was an independent group, including the Retirement Commissioner and independent consultants. 
designs (tTE, TET and TEt). After significant analysis, the conclusion was that none of these schemes would meet all of the objectives of savings incentives. The report concludes that if the government did wish to proceed with tax incentives for private savings, a tTE system using rebates and subject to an upper limit on contributions was the preferred scheme.

The Treasury report acknowledges the serious equity issues that are related to implementation of savings incentives, noting that a savings incentive is 'largely a tax break for the top 10 - 20 per cent of income earners' and that roughly 70 per cent of the cost of an incentive would be directed at the top 20 per cent of households by income (New Zealand Treasury 2001:8). In addition, over 50 per cent of the cost would be directed at the top 10 per cent of households by income. The report also acknowledges the likelihood that higher income households are more likely to respond to tax incentives. As with its predecessors, the report concludes that (among the options considered) the extant TTE regime provides the best treatment.

As with the 1997 report, the 2003 PRG Retirement Income Report found few problems within the extant system of voluntary private provision for retirement savings combined with a state provided pension. While acknowledging that 'there is no room for complacency about the current system's ability to provide for future cohorts' (Periodic Report Group 2003:8), there is little in the way of recommendations that would indicate any action was necessary to ameliorate the situation. The report legitimises this stance through the observation that submissions to the report did not reflect a strong interest in departing from the current voluntary model (Periodic Report Group 2003:8). However, the report appears to contradict itself with the observation that submissions to the report were divided between favouring and opposing tax incentives (Periodic Report Group 2003:77).

The PRG 2003 report introduces the concept of promoting occupational savings schemes to encourage retirement savings. At the time of this report, less than 15 per cent of the labour force were members of registered occupational superannuation schemes. While some attempt is made to explain why New Zealand has considerably 
lower membership than other countries in occupational superannuation schemes, ${ }^{117}$ the absence of government support for this approach is not addressed. Furthermore, despite increased media activity promoting retirement savings, the level of occupational superannuation participation was to remain around this level until the introduction of KiwiSaver accounts in 2007.

The PRG 2003 report is another example of a review that supports the government position on tax neutrality. The authors choose not to enter into the debate about tax incentives, instead referring to the topic as 'well worn' and making the broad statement that 'the costs of tax incentives outweigh the benefits' (Periodic Report Group 2003:80). Given that the topic had received little attention since the previous report six years earlier, an update on research and other international approaches would appear to have been warranted.

The New Zealand Superannuation Fund was introduced in 2001. The New Zealand Superannuation Fund is intended to partially fund the future cost of New Zealand Superannuation. The aim of the New Zealand Superannuation Fund is to introduce a 'smoothed pay-as-you-go' approach to New Zealand Superannuation, which takes contributions from budget surpluses to 2025, after which time the fund will be drawn on to help fund the future costs of superannuation. ${ }^{118}$

The SPWG emanated from recommendations in the 2003 PRG report. It was established in May 2004 with the central objective of providing advice to the government on design and implementation issues associated with the delivery of a generic, occupational savings scheme. The SPWG report does not recommend any

117 For example, the large number of small firms, shifts towards a total remuneration environment and the high cost of providing occupational superannuation products to employers and employees. Demographic changes are the key factor in determining the need for the New Zealand Superannuation Fund. In the 2002/03 period, New Zealand Superannuation accounted for 57 per cent of core benefit expenditure (NZ\$4.8 billion) or around four per cent of GDP (Davey 2004:1). Demographic projections forecast New Zealand Superannuation expenditure to remain around this level until approximately 2012, at which point the numbers of people claiming superannuation are projected to increase, rising to nine per cent of GDP around 2050 . 
significant changes to the extant retirement income arrangements, although it does suggest the introduction of an automatic enrolment scheme when commencing new employment. This scheme (named KiwiSaver), which was accepted by the government and implemented in July 2007, requires an individual to 'opt-out' of the scheme if he or she does not wish to participate.

The SPWG was required to 'provide advice to the government on the detailed design and implementation issues' relating to occupational superannuation (Savings Product Working Group 2004:3). The working group was also required to comment on the taxation of savings and to identify where the tax system may discourage occupational retirement savings. However, minimal discussion was made in this area. The key recommendations, with the exception of the automatic enrolment scheme, differed little from previous reports, and included greater education and streamlined regulation to include the removal of some of the disincentives currently associated with portfolio investments.

The focus on education is surprising, given that the report acknowledges that international evidence suggests that education does not generate significant increases in participation in retirement savings schemes. The report acknowledges the New Zealand approach is heavily reliant on individual responsibility for saving decisions. However, the working group does not attempt to enter into debate on the likely consequences if decisions are made that do not leave an individual in an optimum financial position at the point of retirement.

\subsubsection{Tax treatment of retirement savings}

In 2006, the tax treatment of retirement savings remained unchanged from 1988. Contributions to superannuation funds were made from taxed income, superannuation funds paid tax at 33 per cent on their earnings and fund withdrawals were exempt from tax. The treatment of retirement savings was generally the same as for any other form of savings. While the potential for salary sacrifice existed, the implementation 
of a five per cent fund withdrawal tax (introduced in 2000) largely removed any benefit gained via this avenue. ${ }^{119}$

\subsubsection{Changes}

Prior to 2007, New Zealand Treasury working papers (while not strictly purporting to represent a Treasury viewpoint) have argued that, while levels of savings in New Zealand appear low, there was no strong case for any form of intervention. However, in May 2007 a Treasury position paper outlines the need to adopt a 'least-regrets approach' to policies for savings in the absence of good quality data on which to base decisions, and 'the possibility that individuals are basing saving decisions on longrun expectations that could turn out to be mistaken' (New Zealand Treasury 2007:4). The New Zealand Treasury also makes reference to behavioural economics, recognising the presence of less rational behaviours such as procrastination.

The initial introduction of KiwiSaver accounts in July 2007 began an important change in New Zealand retirement savings policy. KiwiSaver is an automatic enrolment occupational retirement savings scheme, which is activated when an individual commences new employment. While it is not compulsory, the onus is on the taxpayer to 'opt out' of the scheme if he or she does not wish to remain as a member. A NZ\$1,000 contribution to each new KiwiSaver account is made by the government, together with some annual fee subsidisation. In some cases, after a minimum contribution period, the fund may be used as a deposit towards a first home purchase. A ‘contribution holiday' may be taken after one year of participation.

A subsequent indication of a significant policy direction change was the 2006 announcement of an exemption from Specified Superannuation Contribution Withholding Tax (SSCWT) ${ }^{120}$ for employer contributions to KiwiSaver schemes or other complying funds. The tax exemption is for the lower of the amount of the

\footnotetext{
119 Salary sacrifice arrangements were beneficial to individuals paying the top marginal income rate of 39 per cent.

SSCWT is the tax on monetary contributions paid by an employer to an employee's superannuation fund. In the Income Tax Act 2007, it is renamed the Employer Superannuation Contribution Tax.
} 
employee's contribution or four per cent of the employee's gross salary or wages. Further changes announced in the May 2007 Budget indicate that retirement income policy in New Zealand is about to start a new chapter. With effect from 1 July 2007, employees and self-employed individuals who are part of the KiwiSaver scheme will qualify for a tax credit of up to NZ\$1,040 per annum for their KiwiSaver contributions.

In addition, and perhaps the most significant change in retirement savings policy in the last two decades, from 1 April 2008 a compulsory matching employer contribution will commence. This will be phased in over a four-year period, starting at one per cent of a KiwiSaver contributing employee's gross income in 2008 and increasing to four per cent by 2011. Employer contributions also qualify for a matching tax credit up to $\$ 20$ per week, which is made available to the employer to offset the contribution cost. The cost of these proposals is forecast to be NZ\$680 million in the 2008/2009 income year, assuming a 50 per cent adoption rate. ${ }^{121}$

\subsection{Summary}

Over the 30-year period since implementation of the previous short lived compulsory scheme, the landscape has again changed in relation to retirement savings policy with the introduction of tax incentives and compulsory employer co-contributions in 2007/2008. If it is assumed that participation in occupational superannuation and increased national savings are desirable, the change is long overdue and appears to signal the demise of the non-interventionist approach to retirement savings in New Zealand.

Superannuation schemes in New Zealand number approximately 20 per cent of what they were in 1990. Furthermore, superannuation funds have grown at rates that are significantly lower than Australia (and other OECD countries). Participation rates are particularly low when compared among OECD countries, although these are increasing quickly with the introduction of KiwiSaver accounts. The current New Zealand retirement savings policy appears to place substantial weight on inertia to

121 The uptake of KiwiSaver accounts was 673,942 in June 2008. This represents around 30 per cent of the workforce. 
maintain participation in KiwiSaver vehicles after the initial mandatory one-year contribution period ends. However, employer and government subsidies are likely to provide sufficient financial incentives to ensure continued participation.

The following chapter provides a history of the key changes to the taxation of superannuation and superannuation policy in Australia over the 35 years since 1972. 


\section{Appendix 6.1: Primary Events in New Zealand Retirement Savings \\ History ${ }^{122}$}

\begin{tabular}{|c|c|}
\hline Date & Event \\
\hline 1898 & Old Age Pension introduced. \\
\hline 1910 & National Provident Fund established. \\
\hline 1915 & Tax concessions for private superannuation provided for in the Finance Act 1915. \\
\hline 1916 & Concessions introduced for investment earnings of superannuation funds. \\
\hline 1921 & Employer contributions to superannuation funds qualified for tax concessions. \\
\hline 1938 & $\begin{array}{l}\text { Social Security Act } 1938 \text { introduced the dual publicly provided pension system. } \\
\text { Superannuation funded through social security tax. }\end{array}$ \\
\hline 1975 & $\begin{array}{l}\text { Introduction of a compulsory contributory retirement savings scheme. } \\
\text { Pensions taxed as EET; lump sum withdrawals taxed as EEE. }\end{array}$ \\
\hline 1977 & $\begin{array}{l}\text { Withdrawal of compulsory contributory retirement savings scheme. } \\
\text { Universal superannuation scheme known as National Superannuation introduced. } \\
\text { Superannuation now financed from ordinary government revenue. }\end{array}$ \\
\hline 1979 & Rates revised to reflect a net rather than gross relationship with average wages. \\
\hline 1982 & Lump sum investment income taxable as ETE. \\
\hline 1984 & Tax review announced. \\
\hline 1985 & National Superannuation surcharge introduced (announced in 1984). \\
\hline 1988 & $\begin{array}{l}\text { Removal of all tax concessions associated with retirement savings. } \\
\text { Superannuation funds required to pay standard company tax rate. }\end{array}$ \\
\hline 1989 & $\begin{array}{l}\text { National Superannuation no longer linked to } 80 \text { per cent of average wage levels; } \\
\text { rates changed to increase by the lower of price and wage movements within a } \\
\text { band of } 65-72.5 \text { per cent of net average wages. }\end{array}$ \\
\hline 1990 & National Superannuation renamed Guaranteed Retirement Income. \\
\hline 1991 & $\begin{array}{l}\text { Guaranteed Retirement Income renamed National Superannuation. } \\
\text { Changes to qualifying age gradually introduced to reach } 65 \text { by April } 2001 .\end{array}$ \\
\hline 1993 & $\begin{array}{l}\text { Multi-party accord on retirement income policies agreed by several parliamentary } \\
\text { parties. Formalised by the Retirement Income Act } 1993 \text {. } \\
\text { National Superannuation renamed New Zealand Superannuation. }\end{array}$ \\
\hline 1994 & $\begin{array}{l}\text { Transitional Retirement Benefit introduced for those affected by the increase in } \\
\text { qualifying age. }\end{array}$ \\
\hline 1997 & $\begin{array}{l}\text { Referendum held on the introduction of a compulsory retirement savings scheme; } \\
92 \text { per cent voted against the initiative. }\end{array}$ \\
\hline 1998 & $\begin{array}{l}\text { Surcharge abolished and minimum level of superannuation payment reduced to } 60 \\
\text { per cent of net average weekly earnings. }\end{array}$ \\
\hline 2000 & $\begin{array}{l}\text { Minimum level of superannuation payment restored to } 65 \text { per cent of average net } \\
\text { weekly earnings. }\end{array}$ \\
\hline 2001 & $\begin{array}{l}\text { New Zealand Superannuation Act } 2001 \text { passed, which established the New } \\
\text { Zealand Superannuation Fund. }\end{array}$ \\
\hline 2004 & $\begin{array}{l}\text { State Sector Retirement Savings Scheme introduced: a scheme for public sector } \\
\text { employees, which benefits from employer co-contributions of up to six per cent of } \\
\text { gross earnings. }\end{array}$ \\
\hline 2007 & $\begin{array}{l}\text { KiwiSaver initiative introduced, which provides tax incentives for employees and } \\
\text { employers, and compulsory employer co-contributions. }\end{array}$ \\
\hline
\end{tabular}

122 Adapted from the Ministry of Social Development (2003); Preston (2001); St John (1999); and the Task Force on Private Provision for Retirement (1992). 


\section{Chapter 7: The History of Retirement Savings Taxation in Australia}

\subsection{Introduction}

This chapter, together with chapters five and six, establishes the background for the analysis that follows in chapters eight to eleven. The chapter outlines the key changes to retirement savings policy in Australia from 1972 through to 2007. A synopsis of these changes is provided in Appendix 7.1. No attempt is made in this chapter to cover all the reforms in depth, as these are numerous and complex. ${ }^{123}$ Furthermore, the complexity inherent in the Australian system, primarily resulting from attempts to reform retirement income policy through the taxation system, has resulted in a system with significant 'grandfathering' arrangements. Instead, the critical junctures are outlined in detail and the period from 1982 to 1992 forms the key period of focus.

While the primary period of interest in the research is the most recent 35 years, events since the late 1800 s are briefly outlined to situate recent history within the wider historical context. The chapter also introduces the broader environmental factors that played a part in constraining or supporting the direction of superannuation policy over the 35 years investigated.

While the term 'political football' is frequently attributed to New Zealand's retirement income policy, a brief look at the history of Australia's retirement income policy indicates it has also not been immune to countless reforms over the past 35 years. However, after the significant removal of tax concessions in 1988, New Zealand changes may be categorised as primarily 'tinkering' with the level of targeting and the level of provision. Meanwhile, the changes in Australia have resulted in a complex set of arrangements, particularly in relation to the taxation of, and taxation concessions associated with, superannuation. The Australian reforms have resulted in a vastly different approach to the tax treatment of retirement savings than that adopted in New Zealand.

Taxation and superannuation in Australia are inextricably intertwined; it is difficult to discuss one without the other. The future of superannuation schemes has always been

123 For a comprehensive account of the historical development of superannuation in Australia, see Dixon (1981), Kewley (1980) or the National Superannuation Committee of Inquiry (1974). 
heavily dependent on government taxation policy. This is partly because the Commonwealth of Australia has no express power to make laws on superannuation; accordingly, it has relied on its power to tax under the constitution to pursue retirement income policy (Senate Select Committee on Superannuation 1998:4). Secondly, enforcement of the regulations in the Income Tax Assessment Act 1936 was historically linked to tax concessions; superannuation funds that did not meet the regulatory requirements did not receive the concessions.

While retirement savings is now compulsory in Australia, considerable emphasis has also been placed on the tax system to encourage retirement savings. The relationship between tax incentives and retirement savings is an important economic issue. As superannuation has been a tax preferred arrangement in Australia for many years, the tax arrangements associated with superannuation have been used to influence both economic policy and social policy; for example, to decrease reliance on overseas borrowing and to impact on individual saving behaviour.

\subsubsection{Background: Prior to 1972}

Along with New Zealand, Australia was considered a land of opportunity during the $19^{\text {th }}$ century. Rapid social and economic progress commenced in the mid-1800s. High wages and low unemployment ensued, with few social problems, such as destitution. Again, similarly to New Zealand, towards the end of the $19^{\text {th }}$ century economic conditions deteriorated and unemployment, combined with an ageing population, became a social issue.

The late 1800s saw an increase in demand for poverty relief, attributed to population ageing and the depression, which began in the early 1890s. These changes placed pressure on the extant arrangements for poverty relief, such as voluntary charitable organisations. This resulted in movement towards an old-age pension in Australia at the end of the 1890s. As with other similar social developments at this time, ${ }^{124}$ the

124 The introduction of insurance or pension schemes had already occurred in a number of countries, including Germany (1882), Denmark (1891), Belgium (1892) and, as outlined in chapter six, New Zealand in 1898. Only the schemes of Denmark and New Zealand were non-contributory. 
objectives of the initial schemes were to supplement the assistance provided by families and voluntary charitable organisations in such a way that would not 'discourage thrift and self-reliance', and to provide this assistance at a level that was acceptable to the community (Dixon 1983:20).

The states of New South Wales, Victoria and Queensland all implemented state provided old-age pensions between 1900 and 1908. ${ }^{125}$ All these schemes continued to operate until the introduction of the Invalid and Old Age Pensions Act 1908 and the subsequent implementation of the Commonwealth scheme in July 1909. ${ }^{126}$ As in New Zealand, the scheme was viewed as providing assistance to the 'deserving poor', but stopped short of accepting full responsibility for elderly individuals. Between its implementation in 1909 and 1940, the Invalid and Old Age Pensions Act 1908 was amended on twenty occasions (Kewley 1980:17). However, these changes were not significant and primarily related to changes in the pension rate.

Encouragement for occupational superannuation first occurred in 1915 when legislation was passed to permit employers to deduct superannuation contributions against assessable income (Senate Select Committee on Superannuation 1992:10). However, little significant change was to occur in either state provision or the treatment of voluntary retirement savings for around 70 years. Despite this apparent lack of activity, a number of unsuccessful attempts to introduce radical new measures to superannuation were made. ${ }^{127}$

The Australian state provided pension scheme has always carried a number of eligibility requirements. In 1908, an applicant had to satisfy tests relating to age, income and assets, race and nationality, residence, morality and domicile (Dixon

\footnotetext{
125 This was a non-contributory, flat rate payment, which was means and asset tested.

126 While the 1898 Federal Convention had decided that pension provision was the responsibility of the federal government, it was seven years after Federation that the Commonwealth found a way of financing pensions (Dixon 1981:67). to change the status quo, concern from Friendly Societies that a nationally provided scheme would encroach on the services that they provided or because of the outbreak of World War II, at which time defence spending became a priority.
} 
1977:106). While these eligibility requirements relaxed over time, it was over 50 years before some of the less equitable components were removed. ${ }^{128}$ Furthermore, the age of eligibility was set above the average life expectancy until after the Second World War, which ensured a low adoption rate (Olsberg 1997:51). In addition, a strict residency requirement of 20 years existed until 1962. Relaxation of the rules resulted in an increase in coverage from 32 per cent in 1920 to 60 per cent by 1970, peaking at almost 78 per cent in 1978 (Senate Select Committee on Superannuation 1992:5). Changes to the means test, imposing stricter requirements, have subsequently seen this level of coverage decline.

Until the 1970s, the Australian pension was granted on the basis of need. Until 1960, an income test and a property test existed, although these had been significantly liberalised since 1908 (Dixon 1981:69). The means tests on income and property were merged into one test in 1960. A 'tapered means test' was introduced in 1969, which resulted in a 50 per cent withdrawal rate, rather than 100 per cent. A further change occurred in 1973 when the means test was abolished for those aged over 75 years, and in 1975 this was extended to those aged 70 to 74 years. These last two changes were made by the Whitlam Labor government, while the Fraser Liberal coalition government elected in 1975 replaced the means test with an income test and introduced price indexation of the state provided pension. ${ }^{129}$

In 1972, the Whitlam Labor government was elected on a platform that promised an extension of social democracy in Australia, including significant changes to social welfare and, in particular, the old-age pension (Olsberg 1997:55). The age pension was increased to 25 per cent of gross average weekly earnings and the government sought to increase equity in employee access to employer supported occupational superannuation benefits. The first national survey of superannuation coverage in 1974 showed that the occupational superannuation system was highly inequitable.

\footnotetext{
128 Aborigines did not become eligible for the old-age pension until 1942, and then had to meet criteria of character, intelligence and development (Olsberg 1997:51). These discriminations continued until 1960.

The Hawke government subsequently reinstated the income test for those aged over 70 years in 1978. This change resulted in government revenue savings of $\$ 170$ million, but impacted adversely on around 89,300 pensioners (Gruen 1985:6).
} 
Only 32 per cent of the workforce was covered by superannuation, 36 per cent were male employees and 15 per cent were female (Olsberg 1997:68). In addition, 24 per cent of people in the private sector had occupational superannuation coverage, compared with 58 per cent in the public sector.

The investment income of Life Office superannuation had been tax exempt since 1961 (Rafter 1986:232). However, in order to be eligible for this tax exemption superannuation funds and life offices had to comply with what became known as the $30 / 20$ rule, where 30 per cent of assets were required to be invested in government securities, with at least 20 per cent invested in Commonwealth securities. The objective of this policy was to reverse the decline of investment in government securities. Abolition of the 30/20 rule was announced in 1984, although recommendations for it to be removed had been made for over a decade. ${ }^{130}$

A number of reports informed the debate over the next few years, including the Taxation Review Committee (1975), the National Superannuation Committee of Inquiry $(1974,1976,1977)$, the Committee of Inquiry into the Australian Financial System (1981) and the Commonwealth Task Force on Occupational Superannuation (1983). A number of these are discussed in greater detail in the following sections.

\subsubsection{2 - 1982}

From the mid-1970s to the early 1980s, Australia's economy performed poorly with high unemployment and inflation. The mid-1970s saw the age pension used as a political bargaining tool, with both major parties making election promises to gain the support of the increasingly powerful group of retired voters. However, promises of increased payments for old age pensions came at a time of weakening economic conditions and there was considerable pressure to cut spending on the old-age pension as part of public spending reductions. Unlike New Zealand, at the end of the 1970s eligibility criteria for the old-age pension were tightened.

130 For example, the Asprey Report (Taxation Review Committee 1975) considered that compliance with the $30 / 20$ rule should not be a condition for tax exemption on investment income. 
The outcomes of two reviews completed in this period were to influence the future direction of superannuation. The first review was the National Superannuation Committee of Inquiry in June 1973, widely known as the Hancock Committee. The broad terms of reference of the inquiry were to examine and report on proposals for national superannuation schemes. However, a prior directive was issued by the government to abolish the means test for those aged over 65 years and to increase progressively the basic rate of pension to 25 per cent of average weekly earnings. Only the second of these was achieved.

The Hancock Committee produced a two-part report comprising an interim report in June 1974 and a final report in $1976 .^{131}$ The report recommends a combination of universal and compulsory contributory, earnings related pensions. The primary claim was that a contributory scheme would increase government revenue and thus allow an increase in the overall level of income support available to the elderly. In addition, the existing arrangements were not seen as an efficient mechanism for providing retirement incomes to low- and middle-income earners. ${ }^{132}$

The scheme suggested by the Hancock Committee was a compulsory contributory scheme of five per cent of income. This would provide a universal pension payable from general revenue, combined with an earnings related pension linked to contributions. The scheme was eventually rejected by the Coalition government in $1979^{133}$ for a number of reasons, including that a compulsory scheme contradicted the government's position that individuals should be free to adopt the form of retirement savings that best suited them. In addition, the provision of a universal benefit was not

131 The Hancock Committee's final report was also in two parts. The first part was A National Superannuation Scheme for Australia, Parliamentary Paper No 155 of 1976, presented in Parliament on 3 June 1976. The second part was Occupational Superannuation in Australia, Parliamentary Paper No 70 of 1977, presented in Parliament on 30 March 1977. A minority dissenting report recommended continuation of the existing flat-rate noncontributory scheme.

133 Press statement by the Treasurer (the Hon John Howard), 12 July 1979, Press Release No 68. The press statement noted that a national superannuation scheme would 'be an additional tax on personal income. The levy proposed by the majority involved a five per cent surcharge on that part of the income above 30 per cent of average weekly earnings. Such a surcharge would impose a very heavy burden on middle and lower income earners'. 
aligned with the government's view of targeting social assistance to those most in need.

The profile of occupational superannuation in Australia was permanently raised in the late 1970s. The significant incident that achieved this change was industrial action undertaken by Woolworth's employees ${ }^{134}$ in 1979. Among the benefits requested in the negotiations with employers was membership of the company retirement fund (Committee for Economic Development of Australia 1981:4). At the same time, during the 1979 Australian Council of Trade Unions (ACTU) Congress, the ACTU launched occupational superannuation fund scheme that would provide for all members. From this time, union involvement in occupational superannuation became more widespread.

Prior to 1982, tax concessions for superannuation were extremely generous. Employer and employee superannuation contributions to funds were tax exempt. Voluntary contributions to retirement savings funds were generally deductible. Tax exemptions existed for fund earnings and only five per cent of lump sum benefits were included as assessable income. ${ }^{135}$ Payments received in the form of a pension were assessable income. This is representative of the EET scheme, which is common in OECD countries today (although lump sum payments were effectively EEE). However, despite this generosity, superannuation coverage for the general work force remained low until the 1980s.

The second influential review of this time was the 1981 Committee of Inquiry into the Australian Financial System (also known as the Campbell Committee). The Campbell Committee report covered a wide range of issues within the Australian financial system, including the tax treatment of superannuation. The report found that the tax treatment of superannuation resulted in a significant departure from tax neutrality and suggested an alternative that would improve the neutrality and equity of the superannuation system. Committee proposals included adoption of an income tax

\footnotetext{
134 Woolworth's employees were members of the Storemen and Packers Union.

135 The principle of assessing only five per cent of a lump sum has existed since income tax was first levied by the Australian Government in 1915. The Asprey Committee suggests that the choice of the figure of five per cent was purely arbitrary (Palmer and Gould 1975:5).
} 
approach where funds are taxed annually net of operating expenses at a rate that is representative of the weighted average of the marginal rates of members. The Committee also argued that a tax concession should be provided for contributions made by employees and self-employed individuals to superannuation funds, rather than through tax concessions to the funds themselves, in order to achieve government objectives of encouraging retirement saving. While the report received wide publicity and generated considerable discussion, few changes were made to the taxation of retirement savings as a result of the inquiry.

For the purposes of completeness, it is necessary to mention a third report of this period: the Taxation Review Committee: Full Report (Taxation Review Committee 1975). This report (more commonly known as the Asprey Report) is notable for a number of reasons. It was the first time a broad review of the taxation system in Australia had occurred since the 1930s. Secondly, the report noted a concern for the future of the tax system. Thirdly, it was significant due to the focus on fairness, which could be found in much of the discussion. The Asprey Report outlined deficiencies in the prevailing system for the taxation of superannuation and life insurance and provided two possible options: retention of the majority of the existing system with minor amendments to obvious anomalies or making fundamental changes to the system. The report did not express a preference for either option. Elements from both options appear to have been adopted at various times in the years ahead.

\subsubsection{3 - 1987}

Australia faced deteriorating economic conditions during the early and late 1980s. The Hawke government, which replaced the Fraser government in 1983, devalued the Australian dollar, deregulated the currency and the financial sector, reduced tariffs and advised the public that the country's financial situation was to result in broken election promises (Clarke 1992:340). A period of considerable reform in social and economic policy was to follow.

The 1983 National Economic Summit conference produced general agreement among participants (key business, trade union, community and government groups) to support centralised wage fixing. However, specific agreement on wage determination 
could not be reached and it was decided that the Arbitration Commission would decide these matters. This approach was also to have consequences for occupational superannuation in Australia.

Historically, the superannuation system was frequently manipulated and tended to attract those who wanted tax preferred savings for short-term investments (Wills and Ross 2002:5). The absence of preservation regulations facilitated this manipulation. It was estimated that between 25 and 33 per cent of the sums saved through occupational superannuation were paid to those aged less than 55 years (Gruen 1985:i). One of the key concerns with the tax treatment of superannuation in the early 1980s was the proliferation of tax minimisation arrangements and that the tax treatment of lump sums discouraged the taking of pensions and annuities. This encouraged the practice of 'double-dipping', where individuals would take a lump sum prior to retirement, which if appropriately 'consumed' would ensure qualification for the state provided pension. In addition, when workers changed employment, there was no restriction on 'cashing in' the almost tax-free superannuation benefits.

In response to these problems, and in an attempt to preserve at least some funds for the purposes of retirement, on 1 July 1983 the Hawke government increased tax on lump sum payments from five per cent of the payment to the full amount, subject to a maximum marginal rate of 30 per cent. These new arrangements applied to funds accumulated after 1 July 1983. Contributions by employees and the self-employed after 1 July 1983 that did not attract a tax deduction (known as undeducted contributions) were tax exempt. The amended tax arrangements for lump sum payments were expected to yield revenue savings of around $\mathrm{A} \$ 15$ million in the first year, peaking at around $\mathrm{A} \$ 50$ million in eight years (Parliament of the Commonwealth of Australia 1983:20).

As an incentive to preserve benefits for genuine retirement purposes, the 30 per cent tax on the first $\mathrm{A} \$ 55,000$ of the post 30 June 1983 component was reduced to 15 per cent if taken after the age of 55 years. The legislation also provided tax relief where funds were rolled over into approved superannuation funds and not accessed until after the age of 55 years. 
A key document of this era was the draft white paper, Reform of the Australian Tax System (Parliament of the Commonwealth of Australia 1985). While the document does not specifically discuss superannuation or retirement savings, it outlines the intended direction that tax reform would adopt. Nine principles were outlined, including:

- no increase in the overall tax burden;

- increased elimination of tax avoidance and evasion;

- a simpler system;

- a fairer tax system; and

- widespread community support (Parliament of the Commonwealth of Australia 1985:2).

While efficiency was not explicitly included in the principles, it was discussed from the perspective of requiring taxes to be neutral in their effect on decisions to work, save and invest.

A significant development in relation to both industrial relations and superannuation during the Hawke era was the Accord between trade unions and the government. ${ }^{136}$ The Accord outlined the broad goals for management of Australia's economy and represented the positions of the Labor Party and the ACTU on how these goals would be met. The Accord provided for greater government consultation and facilitated involvement by the trade unions. Six variations on the Accord between 1983 and 1991 were to dominate the Hawke era. ${ }^{137}$

136 The formal title is the Statement of Accord by the Australian Labor Party and the Australian Council of Trade Unions Regarding Economic Policy. The Accord was endorsed by a special conference of all unions affiliated to the ACTU in February 1983. The Accord was intended to encourage economic growth, reduce unemployment and lower inflation. Singleton (1990:1) writes that 'the basis of the policy was agreement by the ACTU, the peak union body, to accept full wage indexation and centralized wage-fixing. In return the Hawke government would provide compensatory tax cuts, improvements to social security benefits and a range of supporting policies that would satisfy other union objectives'.

137 The Accords outlined the structure for the national wage setting process, together with the amounts awarded for wage increases. 
A key component of the Accord was the inclusion of occupational superannuation in the process. As noted by Olsberg (1997:80):

the Accord represented a commitment by unions to wage restraint in return for a number of social wage improvements. Union leaders who were closely involved in negotiations over the Accord were also the strongest exponents of superannuation claims, and demands for a national superannuation scheme were included in the first Accord.

It was not until December 1985 that the Labor government confirmed the introduction of occupational superannuation under the centralised wage system, with the Accord Mark II, as it became known. Government agreement was achieved through deferment of the ACTU productivity claim ${ }^{138}$ until 1986 in return for government support of full indexation at the second National Wage Case in 1985 (Plowman and Weaven 1989:9). In addition, the ACTU agreed to a discount of two per cent of the consumer price index for indexation purposes, with the trade-off being that the wage discount would be offset with tax cuts and government support for the superannuation claim. The Accord Mark II determined that a three percent increase in productivity would be distributed to workers in the form of company superannuation. The government was to establish guidelines in regard to preservation, vesting ${ }^{139}$ and security, and tax concessions were provisional on meeting these guidelines. However, the National Wage Case decision applied only to federal awards, so employees covered by state awards or those who had no award coverage were not covered by the decision.

The Conciliation and Arbitration Commission ${ }^{140}$ agreed to the superannuation agreement between the trade unions and the government in 1985, with

138 Typically, the benefits of increased productivity are shared between wages, profits and customers. Under the wage claims, the wages element of increased productivity is effectively replaced by superannuation savings. including employer contributions and accrued interest, when changing employment. The Commonwealth Court of Conciliation and Arbitration was established in 1904 to facilitate in issues of disputes and wage rates, and remained largely unchanged over the next 85 years. The Court's resolutions were legally binding (Whiteford 2004:88). 
implementation in July $1986 .{ }^{141}$ It was envisaged that the three per cent occupational superannuation contribution would be the only general addition to employers' wage costs over the two-year period from 1 July 1986 to 1 July 1988, apart from indexation increases.

An influential report of this period was Government Support of Retirement Incomes in Australia (Department of Social Security 1984). This report made a number of suggestions for retirement income reform, including greater income support for the aged, greater support of the 'income maintenance' policy objective and reducing the cost of retirement income support.

In March 1987, the National Wage Bench announced a two-tier wage structure, granting all Australian workers an $\mathrm{A} \$ 10$ per week wage increase, with an additional four per cent increase. In addition, it guaranteed superannuation coverage of three per cent for the majority of the workforce, which was intended to establish the superannuation 'safety net' promised by the federal government in the September 1985 Accord Mark II. Superannuation benefits were introduced in two 1.5 per cent steps over the next two years, with the aim of having all, or at least 80 - 90 per cent, of Australians covered by federal awards of at least three per cent of earnings by January 1989.

Tax concessions remained generous when compared to other OECD countries at this time. The cost of superannuation tax concessions were estimated for the 1985-86 financial year at $\mathrm{A} \$ 3.1$ billion. $^{142}$

141 In 1986, the issue arose of whether superannuation was an industrial matter for the purposes of the Conciliation and Arbitration Act 1904. The decision in the High Court of Australia on 5 May 1986 determined that superannuation was sufficiently connected to an employment relationship to be an industrial matter that was capable of being the subject of an interstate industrial dispute under the Act (Smith 1987:1). 


\subsubsection{8 - 1992}

Following the historical trend of regular reviews of retirement income policy, another report was published early in the 1988 to 1992 period, Towards a National Retirement Incomes Policy (Department of Social Security 1988), more widely known as the Cass Report. In response to this report, a Task Force was established, which received more than 300 written submissions. The report highlighted a number of elements within Australia's retirement income policy that needed to be addressed, including the adequacy of the income provision arrangements, taxation and integration of the public and private provision. A key point made in the issues paper was that the then minimum income of just below 25 per cent of average weekly earnings was barely adequate. The review concluded that the retirement income system should aim to redistribute income to lower-income households. This led to an increase in some benefits, but also to a higher degree of targeting for social security payments in general (Wiseman 1996:302).

As in New Zealand, Australia was also to experience significant tax changes to retirement savings in 1988. The May 1988 Economic Statement (Parliament of the Commonwealth of Australia 1988a) announced that instead of applying tax of 15 or 30 per cent on final benefits, ${ }^{143}$ funds would pay 15 per cent tax on employer contributions, while the tax on end benefits would be reduced by the same rate. This was to achieve a 'bringing forward of the taxing time' as the tax at the benefits stage was reduced by the tax already paid by the fund, without changing the level of benefits available (O'Connell 2003:432). By allowing earlier tax collection, the cost of the superannuation arrangements would reduce, but, theoretically, without impacting on the incentive to save. Accordingly, the new tax rates on lump sums were reduced to zero on the first $\mathrm{A} \$ 60,000$ (a concessionary indexation from the previous $A \$ 55,000$ threshold) and 15 per cent on the remainder. In addition, pensions or annuities paid from taxed funds received a 15 per cent rebate. For lump sums withdrawn earlier, the entire lump sum was taxed at a rate of 20 per cent (reduced from 30 per cent).

143 That is, 15 per cent on the first $\mathrm{A} \$ 55,000$ and 30 per cent on any excess, or 30 per cent for the whole component if taken as a lump sum before the age of 55, relating to employment after 1 July 1983. 
These new arrangements were intended to move towards a more standard income tax treatment of saving. However, taxes on lump sums remained when they were taken prior to retirement in order to provide an incentive to preserve superannuation savings. Retirement savings taxation was intended to be 'radically yet sympathetically changed, putting it on a more logical long term basis without reducing lump sum and pension entitlements'. ${ }^{144}$

A further change announced was the introduction of a 15 per cent tax on superannuation fund earnings. The purpose of this was to bring superannuation funds within the imputation system for company taxation, from which they were previously excluded. It was seen that the exclusion from imputation had the potential to discourage superannuation fund investment in Australian firms and also to encourage tax minimisation schemes. As noted in the 1988 Economic Statement (Parliament of the Commonwealth of Australia 1988b:6):

in practice, this 15 per cent tax will be zero or a very low amount because:

- only capital gains accruing after 1 July 1988 will be taxed (when assets are sold) and the inflation component of capital gains will be exempt from tax; [and]

- dividends received from taxpaying Australian companies will carry imputation credits for company tax by these companies; these credits will not only eliminate tax on the dividend, but because the company tax is much higher than 15 per cent, excess company tax credits will reduce tax on other superannuation fund income.

Considerable emphasis was placed on the fact that the changes would not result in an increased overall level of tax.

Other, more minor, changes included tightening the maximum benefit limits ${ }^{145}$ and the reintroduction of graduated Reasonable Benefit Limits (RBLs) to discourage the conversion of salary into tax advantaged occupational superannuation schemes providing benefits 'in excess of reasonable retirement income requirements' (Parliament of the Commonwealth of Australia 1988b:16). The new scales were a multiple of final average salary calculated on tax-deductible or employer funded

\footnotetext{
144 Hansard, House of Representatives, Volume 161, 25 May 1988, p. 3013. Economic Measures: Ministerial Statement, the Hon P J Keating (Treasurer, ALP). 
contributions only (i.e. they excluded employee contributions that are not tax deductible).

In 1991, the Australian industrial court (the Industrial Relations Commission) rejected an application for a further three per cent productivity award superannuation increase, even though this application was supported by the government and the trade union movement. This was to have been paid as part of the Accord Mark VI. ${ }^{146}$ The government response was to introduce the Superannuation Guarantee Charge Act 1992 and the Superannuation Guarantee (Administration) Act 1992. These Acts introduced the three key components of Australian's retirement income policy that remain today:

- $\quad$ compulsory occupational superannuation;

- $\quad$ voluntary superannuation contributions; and

- $\quad$ the provision of a state age pension and social security benefits.

At the time of announcing the Superannuation Guarantee Levy (SGL), the government argued that along with projected demographic pressures, experience indicated that tax incentives in isolation had failed to result in an adequate uptake and growth (O'Connell 1995:263). The SGL was intended to assist in expansion of superannuation to those employees not covered under award superannuation arrangements as well as providing an efficient method to encourage employers to comply with their obligation to provide occupational superannuation to employees. ${ }^{147}$

The Superannuation Guarantee Charge Act 1992 imposed a non tax-deductible levy on employers who did not comply with the mandatory superannuation contributions for employees. The Superannuation Guarantee Levy (the Superannuation Guarantee)

146 The Accord Mark VI wage agreement included a commitment to doubling superannuation contributions to six per cent by 1993. The Industrial Relations Commission rejected the Accord Mark VI in April 1991.

147 The Senate Select Committee on Superannuation Report Safeguarding Super reports that out of 2,880,000 private sector employees covered by awards, approximately 2,050,000 were actually receiving award superannuation (Senate Select Committee on Superannuation 1992:13). 
started at three per cent of employee earnings on 1 July $1992,{ }^{148}$ and gradually increased to nine per cent by 1 July 2002. It remains at nine per cent today and over 90 per cent of Australian workers have superannuation coverage. ${ }^{149}$

At the time these arrangements were proposed, a further amendment was part of the 'package'. This was the proposal that compulsory employee contributions would be made to a level of three per cent, financed primarily through tax cuts. The federal government announced in 1997 that this proposal would not proceed.

Taxation changes made in 1992 primarily related to member contributions by individuals who received no employer financed superannuation contributions and the self-employed. These individuals in 1992 were permitted to deduct contributions of up to $\mathrm{A} \$ 3,000$ plus 75 per cent of the excess of contributions over $\mathrm{A} \$ 3,000$ up to certain age based funding limits. It was acknowledged that the introduction of the Superannuation Guarantee would result in a loss of this entitlement as more employers provided occupational arrangements for employees. Therefore, from 1 July 1992 the tax concessions for contributions made by supported employees were replaced by an income tested rebate of ten per cent for the first $A \$ 1,000$ of contributions for low-income earners.

\subsubsection{3 - 2005}

In 1994, changes were made to deductible superannuation fund contributions that could be claimed by an employer. These were limited by age with three levels of deductible contributions. These limits were (per employee per annum) A $\$ 9,000$ for those aged under 35 years, $\mathrm{A} \$ 25,000$ for those aged 35 to 49 and $A \$ 62,000$ for those aged over 50. However, in an organisation with at least 10 employees, contributions could be based on an average level of $\mathrm{A} \$ 25,000$ per employee regardless of age. This was known as the 'standard contribution limit'. A particular problem associated with

148 Initially, the proposal was five per cent of earnings for employers with payrolls above $\$ 500,000$ per annum and three per cent for other employers. This was subsequently reduced to three per cent for all employers.

149 Certain exemptions apply, for example, for employees less than 18 years, very low-income earners and non-residents. 
this approach was the absence of any requirement for the contribution to be pro-rated among employees. This had the potential to result in a small number of employees being allocated significant deductible contributions. In addition, from 1 July 1994, RBLs changed from being expressed as a multiple of highest average salary to fixed dollar limits.

In 1994, a 15 per cent rebate was introduced for all rebateable pensions and annuities (regardless of their commencement date) and to the whole of the taxable amount. The rebate was payable after age 55 and was intended to increase the attractiveness of pensions and annuities over lump sum Eligible Termination Payments (ETPs). ${ }^{150}$

An additional tax surcharge of 15 per cent was introduced in 1996 for superannuation contributions by high-income individuals. ${ }^{151}$ While the surcharge increased the complexity of the arrangements, the overall aim was to improve the equity of the superannuation system due to the high presence of salary sacrifice arrangements (Gray, Cerche and Nolan 1996:7). ${ }^{152}$ Known as the Superannuation Surcharge, this was reduced by 1.5 per cent in each of the years from 2002 to 2005 , before being removed in 2005.

Other changes in 1996-97 include:

- removal of the standard contribution limits (leaving age based contributions in effect);

- allowing individuals aged over 65 years to continue to make superannuation contributions up to the age of 70years, provided certain employment criteria were met;

An eligible termination payment is a lump sum payment, usually made from a superannuation fund. They may be rolled over into an Approved Deposit Fund on receipt (usually retirement or change of employment).

151 When introduced this impacted on individuals earning above A \$73,220 per annum.

152 While the 30 per cent tax on contributions was still less than the top marginal tax rate at the time of 48.7 per cent, as income earned on contributions was also taxed at 15 per cent, the total tax could amount to close to the top marginal tax rate. In addition, as contributions could still only be made within the age based contribution limits the scope for salary sacrifice arrangements was reduced.
} 
- the introduction of retirement savings accounts;

- capital gains tax relief for small business owners, where a capital gains tax exemption could be claimed when a small business was sold and the proceeds were used for retirement. The exemption was available for a maximum gain of $\mathrm{A} \$ 500,000$ under certain circumstances;

- a new savings rebate; ${ }^{153}$ and

- $\quad$ an ability to opt out of the superannuation guarantee. ${ }^{154}$

In 1999, rules were introduced relating to access to superannuation funds. These 'preservation rules' required certain contributions to be preserved until retirement on or after attaining the preservation age (O'Connell 2003:432). The issue of preservation of retirement savings was one that had been widely debated for over 15 years.

From 1 July 2002, the low-income earners superannuation rebate was replaced with a more generous government superannuation co-contribution of up to $\mathrm{A} \$ 1,000$. The maximum co-contribution applied to those earning less than $A \$ 20,000$ and reduced for those earning between $A \$ 20,000$ and $A \$ 32,500$. Further changes occurred for low-income earners with the introduction of a new government contribution scheme on 1 July 2004. With this system the government provides $\mathrm{A} \$ 1.50$ for each $\mathrm{A} \$ 1.00$ invested into a superannuation fund by individuals earning below A $\$ 28,000$. These initiatives were aimed at encouraging greater superannuation saving.

\subsubsection{Tax treatment of retirement savings}

In 2006, the cost to the Australian government of tax concessions for retirement savings was valued at $\mathrm{A} \$ 15.9$ billion (Australian Treasury 2006:1). Details of the tax treatment of retirement savings as at 2006 are outlined in this section. Contributions

153 A tax rebate was available for personal superannuation contributions made from post-tax income up to a maximum level of $\mathrm{A} \$ 3,000$. For low- and middle-income earners making personal superannuation contributions, the first $\mathrm{A} \$ 1,000$ of contributions would attract both the savings rebate and the existing ten per cent rebate available to individuals earning up to $\mathrm{A} \$ 31,000$.

For employees earning between $\mathrm{A} \$ 450$ and $\mathrm{A} \$ 900$ a month. 
are treated differently according to whether they are sourced from employees, employers or the self-employed, and whether they are for funded or non-funded schemes. Up to age based contribution limits, contributions paid by an employer to a fund are tax deductible to the employer, and do not form part of the taxable income of the employee.

Self-employed individuals are entitled to tax deductions for part of their fund payments. Contributions tax is paid on deductible contributions at the same rates as employer contributions.

Contributions made directly by employees to superannuation funds (called 'undeducted contributions') are made from taxed income. These contributions are exempt from the ETP, while earnings from these contributions are taxed at the normal rate and are subject to the ETP.

Investment earnings of superannuation funds are taxed at the concessionary rate of 15 per cent. Capital gains for investments held longer than one year are taxed at a concessional rate of two-thirds of the nominal 10 per cent rate. In addition, the form of income will influence the tax treatment. As funds consist of both contributions and investment earnings, each of these elements is treated differently. Contributions that have received tax concessions in the hands of the contributor (either employer or employee) are taxed, but those paid out of untaxed income are exempt.

Superannuation benefits from funds may be withdrawn as a lump sum, a retirement income stream or a combination of the two. The tax treatment depends on whether recipients are over 55 years of age and whether the benefits are taken as a pension or lump sum benefit. Benefits taken as lump sums are subject to the ETP. ETPs are divided into six components, only some of which are taxed concessionally. If part of the payout is used to purchase an annuity or pension income stream, that part does not form part of an ETP. 
Benefits are taxed at normal rates on withdrawal, but may be subject to a 15 per cent rebate. ${ }^{155}$ The tax treatment is the same for contributions made through the Superannuation Guarantee and for voluntary contributions to private superannuation funds.

A RBL exists for the amount of concessionally taxed superannuation benefits an individual may receive over his or her lifetime. The pension RBL is available on the condition that at least 50 per cent of the benefits received are taken in the form of a pension or annuity. Benefits paid in excess of the RBL do not receive preferential tax treatment.

\subsubsection{Amendments}

Significant changes to the taxation of superannuation benefits were announced in the 2006 federal budget. A key aim of the changes was to simplify the system and it is generally accepted that these changes have, after many years, gone some way towards achieving this (e.g. Bateman and Kingston 2007). The key beneficiaries are individuals withdrawing benefits from taxed superannuation funds after the age of 60 years. These benefits are now tax free, regardless of whether they are in the form of a lump sum or a pension. Benefits paid to persons aged over 60 years from an untaxed fund are taxed at 15 per cent on the first $\mathrm{A} \$ 700,000$. Benefits above this level are taxed at the top marginal rate.

In addition, the abolition of RBLs was announced and the age-based contribution limits were amended to one level regardless of age. Furthermore, the self-employed benefit from fully deductible contributions and the ability to participate in the government co-contribution. The 15 per cent tax on contributions and fund earnings is not changed. However, personal superannuation contributions (undeducted contributions) that are not tax deductible are capped at $\$ 150,000$ per annum while deductible contributions are capped at $\$ 50,000$ per annum (such as employer contributions). ${ }^{156}$ These changes apply from 1 July $2007 .{ }^{157}$

155 The rebate is also subject to a RBL.

156 Concessional contributions over $\mathrm{A} \$ 50,000$ will be taxed at 31.5 per cent. Amounts over the non-concessional contribution limit of A $\$ 150,000$ will be taxed at the rate of 46.5 per cent. 


\subsection{Summary}

What can be seen over this period is a change in direction from a focus on adequacy of income in retirement and targeting of provision to a focus on ensuring that those who could provide for themselves in retirement were encouraged to do so. In addition, there is emphasis placed on equity, as compared to the focus on efficiency that is more prevalent in New Zealand.

The changes made to the taxation of superannuation in 1983 and 1988 in Australia are likely to have improved the neutrality and equity within the system, although it remained far from a 'level playing field'. The 1988 May Statement (Parliament of the Commonwealth of Australia 1988b) changes went some way towards reducing the disparity between the tax treatments of different savings vehicles, although neutrality was not achieved, nor, it would appear, was intended.

The 2006 proposals provide a clear indication that the Australian government is taking seriously the policy objective of encouraging and supporting individuals to maintain a standard of living in retirement not dissimilar to that of their working situation. The policy objective of these changes is 'to assist and encourage people to achieve a higher standard of living in retirement than would be possible from the age pension alone' (Australian Treasury 2006:1).

Participation in superannuation funds is now greater than 90 per cent among Australian workers. Australia now has significant levels of funds invested in

157 A further incentive to encourage retirement is the halving of the pension assets test taper rate to $A \$ 1.50$ per fortnight for every $A \$ 1,000$ of assets above the asset test free limit (currently $\mathrm{A} \$ 157,000$ for a single person or $\mathrm{A} \$ 223,000$ for a couple). The previous scheme (where a person loses $\mathrm{A} \$ 3$ of pension per fortnight for every $\mathrm{A} \$ 1,000$ of assets above the assets test free limit) was seen as punitive, as retired individuals needed to achieve a return of at least 7.8 per cent on their additional savings to overcome the effect of a reduction in their age pension (The Australian Treasury 2006:7). An income test remains. This is A $\$ 124$ per fortnight for a single person or A $\$ 220$ for a couple. Income above this level reduces the government pension by 40 cents in the dollar for a single person or 20 cents in the dollar for a couple. 
superannuation funds, with managed funds now in excess of $A \$ 1.3$ trillion since the 2006 changes. ${ }^{158}$

Chapters eight to eleven provide an in-depth analysis of the rationale behind New Zealand's historically unique approach to the taxation of retirement savings. The discussion is structured around the four key dimensions that emerged from the literature review and the data collection process in the thesis. The first of these chapters, chapter eight, outlines the environmental factors that are relevant in the 1982 to 1992 period.

158 The transition arrangements to the 2006/2007 amendments allowed for individuals to make up to $\$ 1$ million of post-tax contributions between May 2006 and June 2007. This was intended to allow people who were intending to make a large contribution under the extant rules to do so. 


\section{Appendix 7.1: Primary Events in Australian Retirement Savings History ${ }^{159}$}

\begin{tabular}{|c|c|}
\hline Date & Event \\
\hline 1908 & Age pension introduced. \\
\hline 1913 & Conservative parties proposed contributory national superannuation. \\
\hline 1915 & $\begin{array}{l}\text { Introduction of superannuation tax concessions - tax exemption for } \\
\text { superannuation fund income, tax deductibility of superannuation } \\
\text { contributions. }\end{array}$ \\
\hline 1922 & Commonwealth employee's superannuation fund established. \\
\hline 1928 & $\begin{array}{l}\text { Conservative government introduced National Insurance Bill, which } \\
\text { provided for a national superannuation scheme. }\end{array}$ \\
\hline 1936 & Introduction of tax concessions for lump sum amounts. \\
\hline 1945 & Social services contribution introduced. \\
\hline 1950 & Social services contribution merged with personal tax system. \\
\hline 1969 & $\begin{array}{l}\text { Means test amended so that only half the amount was deducted, known as } \\
\text { the 'tapered means test'. }\end{array}$ \\
\hline 1973 & $\begin{array}{l}\text { Means test abolished for persons aged over } 75 . \\
\text { National Superannuation Committee of Inquiry established. }\end{array}$ \\
\hline 1975 & Means test abolished for persons aged $70-74$ \\
\hline 1976 & $\begin{array}{l}\text { Means test abolished for all retired individuals and replaced with an } \\
\text { income test. }\end{array}$ \\
\hline 1978 & Reintroduction of assets test for individuals aged over 70 years. \\
\hline 1983 & $\begin{array}{l}\text { Accord (Mark I) finalised. } \\
\text { Reduction of tax concessions for lump sums. Increased tax deductibility } \\
\text { for superannuation contributions by employees without superannuation } \\
\text { cover and the self-employed. }\end{array}$ \\
\hline 1984 & $\begin{array}{l}\text { Rollover funds established. } \\
30 / 20 \text { rule abolished. }\end{array}$ \\
\hline 1985 & $\begin{array}{l}\text { Assets test reintroduced for all retired individuals. } \\
\text { Accord Mark II finalised. }\end{array}$ \\
\hline 1986 & $\begin{array}{l}3 \text { per cent Productivity Award Superannuation endorsed by Conciliation } \\
\text { and Arbitration Commission. }\end{array}$ \\
\hline 1988 & $\begin{array}{l}\text { Major reform of superannuation taxation; } 15 \text { per cent tax on } \\
\text { superannuation fund income, reduction of taxes on lump sums, } \\
\text { introduction of } 15 \text { per cent rebate on annuity and pension income, } \\
\text { increase in tax deductibility for the self-employed and uncovered workers } \\
\text { and introduction of RBL scales. }\end{array}$ \\
\hline 1990 & $\begin{array}{l}\text { Age pension income and asset tests amended. } \\
\text { Introduction of tax rebates for low coverage employees. }\end{array}$ \\
\hline 1991 & $\begin{array}{l}\text { Industrial Relations Commission rejects further three per cent } \\
\text { productivity award superannuation. } \\
\text { Government announces introduction of nine per cent Superannuation } \\
\text { Guarantee. }\end{array}$ \\
\hline 1992 & $\begin{array}{l}\text { Superannuation Guarantee commences. Tax rebate for superannuation } \\
\text { contributions extended to all employees but reduced in amount. }\end{array}$ \\
\hline
\end{tabular}




\begin{tabular}{|l|l|}
\hline 1994 & $\begin{array}{l}\text { Age determined employer contribution limits introduced. } \\
\text { RBLs changed to fixed dollar amounts. }\end{array}$ \\
\hline 1996 & $\begin{array}{l}\text { Changes to the tax treatment of superannuation contributions for high- } \\
\text { income earners. }\end{array}$ \\
\hline 1997 & Retirement Saving Accounts established. \\
\hline 2002 & $\begin{array}{l}\text { Replacement of low-income earners rebate with government } \\
\text { superannuation co-contribution. }\end{array}$ \\
\hline 2004 & Introduction of a more generous government co-contribution scheme. \\
\hline 2005 & Superannuation surcharge removed. \\
\hline 2006 & Significant reform to the taxation of retirement savings announced. \\
\hline 2007 & $\begin{array}{l}\text { Changes to the taxation of retirement savings, including removal of } \\
\text { RBLs, tax exemption on fund withdrawals after the age of } 60 \text { and a } \\
\text { standard contribution limit regardless of age. }\end{array}$ \\
\hline
\end{tabular}




\section{Chapter 8: The Environment}

\subsection{Introduction}

The previous chapters outline the methodology and theoretical framework used in the thesis and provides a synopsis of the historical context within which this research is situated. This chapter commences the analysis using primary source data and institutional theory to address the question of why Australia and New Zealand adopted dissimilar policy approaches in response to a similar policy 'problem'.

Chapter eight and the following three chapters are structured to represent the four key themes that emerge from the data collected from interviews, and primary and secondary source documents. This chapter commences with a study of the environment. This is important both to provide a contextual background for the analysis and to establish the importance of the environment as an influence on the policy direction. The following chapters focus on institutional influences, power and ideas, respectively. ${ }^{160}$

The analysis is structured so as to isolate and emphasise the importance of each of these concepts. However, it is not intended to privilege any of these factors individually. Rather, the four dimensions combine to provide a set of complementary variables, which ultimately merge to provide an understanding of the policy development outcomes that occurred.

The objective of this chapter is to highlight important details of the context within which this case study is situated and to acknowledge the different attitudes in New Zealand and Australia to some of the key variables, such as forecast ageing populations. As mentioned in chapter two, an interpretive approach is used in this analysis. An interpretive approach allows the data to 'speak for itself'. Accordingly,

160 It is noted that these factors are similar to those suggested by Simeon (1976) when recommending that the study of policy making needs to go beyond the investigation of bureaucracy and public administration. Simeon suggests that the factors that influence the alternatives considered by decision makers are the environment, the formal institutional structures, ideas (including the values in society), the distribution of power and the policy process for decision making. 
considerable use is made of interview quotes and primary source documents throughout this and the following three chapters. The appendix outlines the interview respondents' affiliation with the research topic.

It is important to situate the research within the environment that it occurred. This is, at least in part, because policy making occurs within a framework that is representative of the direction of a country at a particular time. In New Zealand, this framework was a neo-liberal focus on reducing state involvement in the economy. In Australia, the framework was not dissimilar, but with a stronger focus on social justice from policy reforms.

While the research is situated within the 1972 to 2007 period, the analysis focuses on the 1982 to 1992 period. This decade was selected as it is the time period where many of the arrangements that remain in retirement savings policy at the present time were introduced. This decade is also relevant because at its start New Zealand and Australia had very similar approaches to the taxation of retirement savings. However, by the end of the ten years their approaches were significantly different. This decade also encompasses two of the key events in the history of retirement savings policy: the removal of all tax incentives for retirement savings in New Zealand in 1988; and, the introduction of compulsory occupational superannuation in Australia through the Accord process in the mid-1980s and subsequently confirmed with the Superannuation Guarantee in 1992.

It is also important to test the suggestion of the environmental impact through the use of institutional theory. An important concept of historical institutionalism is consideration of the historical events that have influenced policy making. The argument is made within this theory that historical influences will continue to play a key enabling role into the future and will impact on future policy choices. As noted by Krasner (1984:240), once a policy has been implemented, it cannot be removed retrospectively, ultimately influencing future developments. Thus, it is expected that historical policy developments will maintain some influence in policy direction. Furthermore, policies of any nature are not created in a vacuum; numerous factors contribute to eventual outcomes and historical institutionalism emphasises the importance of the context within which these debates occur. 
At the start of the 35-year time period investigated, New Zealand and Australia had similar approaches to the taxation of retirement savings. Both countries provided generous tax incentives for retirement savings that privileged lump sum payments above pension streams and contributed to tax planning schemes. In the early 1980s, both countries made changes to tax incentives to improve the attractiveness of pensions over lump sum payments. From the mid-1980s, clear differences in direction can be seen, with Australia increasing the level of involvement of the state in retirement savings policy and New Zealand reducing state interest in encouraging retirement savings.

There were two primary environmental factors driving the retirement savings policy in each country, the projected demographic changes and the serious economic situations facing both New Zealand and Australia. These dimensions are explored in more detail in the following sections.

\subsection{Demographic Issues}

\begin{tabular}{|c|c|}
\hline New Zealand ${ }^{161}$ & Australia $^{162}$ \\
\hline $\begin{array}{l}\text { Contrary to scaremongering by } \\
\text { politicians and superannuation } \\
\text { companies, New Zealand's } \\
\text { population is not ageing faster than } \\
\text { most nor is there any immediate } \\
\text { age-dependency crisis. }\end{array}$ & $\begin{array}{l}\text { The Government is convinced that } \\
\text { it would be reckless and } \\
\text { irresponsible not to respond now to } \\
\text { the demographic imperative of an } \\
\text { ageing Australia. }\end{array}$ \\
\hline
\end{tabular}

Both New Zealand and Australia had forecast ageing populations. However, the Australian commentary was significantly stronger in suggesting that demographic changes may adversely impact on the sustainability of extant retirement savings policy. In New Zealand, the projected demographic changes were given little attention in the period from 1982 to 1992 . In Australia, demographic issues had been widely discussed from the late 1970s and were used to justify the need for incentives and compulsion. From the early 1980s, annual reviews were prepared on Australia's

\footnotetext{
161 Task Force on Private Provision for Retirement, Reported in the National Business Review, 21 August 1992, Super taskforce puts off evil day for government, p11. 
demographic trends ${ }^{163}$ and it was acknowledged that 'persons in the older age groups are also of particular interest to policy makers, ${ }^{164}$ with the number of people aged 65 years and over expected to increase by two-thirds within 20 years. Respondent 31 commented that demographic issues in Australia 'did have an influence on the thinking about the Superannuation Guarantee. Again it was contextual. It didn't drive the policy development, but it was a very important part of the contextual framework from which the Superannuation Guarantee emerged'.

Demographic projections and old-age dependency ratios ${ }^{165}$ for selected OECD countries are outlined in Table 8.1. The changing relationship of the 'working' population to the 'retired' population is seen in this table. Over the 45-year period from 2005 to 2050, most countries will face a reduction from around three and a half 'working' people for every 'retired' individual to around one and a half. This reduction, of over fifty per cent in almost every country, is the result of both increased numbers of people aged over 65 years and decreased numbers of people in the 15 to 64 age group. The table shows similar demographic projections over the next 45 years in both Australia and New Zealand.

Table 8.1: Projected Population Distributions and Old-Age Dependency Ratios of Selected OECD Countries ${ }^{166}$

\begin{tabular}{|l|c|c|c|c|c|c|c|l|}
\hline & \multicolumn{9}{|c|}{2005} & $\mathbf{2 0 5 0}$ \\
\hline & $\mathbf{0 - 1 4}$ & $\mathbf{1 5 - 6 4}$ & $\mathbf{6 5}+$ & Ratio & $\mathbf{0 - 1 4}$ & $\mathbf{1 5 - 6 4}$ & $\mathbf{6 5}+$ & Ratio \\
\hline & $\%$ & $\%$ & $\%$ & & $\%$ & $\%$ & $\%$ & \\
\hline Australia & $\mathbf{1 9 . 6}$ & $\mathbf{6 2 . 6}$ & $\mathbf{1 7 . 8}$ & $\mathbf{3 . 5}$ & $\mathbf{1 5 . 1}$ & $\mathbf{5 3 . 2}$ & $\mathbf{3 1 . 7}$ & $\mathbf{1 . 7}$ \\
\hline Canada & 17.6 & 64.5 & 17.9 & 3.6 & 15.7 & 52.4 & 31.8 & 1.6 \\
\hline Hong Kong & 14.4 & 70.2 & 15.4 & 4.6 & 12.4 & 48.8 & 38.7 & 1.3 \\
\hline Italy & 14.0 & 60.4 & 25.6 & 2.4 & 13.1 & 45.5 & 41.3 & 1.1 \\
\hline Japan & 14.0 & 59.7 & 26.3 & 2.3 & 13.4 & 44.9 & 41.7 & 1.1 \\
\hline Netherlands & 18.2 & 62.6 & 19.2 & 3.3 & 15.6 & 53.1 & 31.3 & 1.7 \\
\hline New Zealand & $\mathbf{2 1 . 3}$ & $\mathbf{6 1 . 9}$ & $\mathbf{1 6 . 7}$ & $\mathbf{3 . 7}$ & $\mathbf{1 6 . 0}$ & $\mathbf{5 3 . 9}$ & $\mathbf{3 0 . 0}$ & $\mathbf{1 . 8}$ \\
\hline United Kingdom & 17.9 & 60.9 & 21.2 & 2.9 & 16.4 & 54.2 & 29.4 & 1.8 \\
\hline
\end{tabular}

163 Review of Australia's Demographic Trends, prepared annually by the Department of Immigration and Ethnic Affairs. 1981 Publication, Parliamentary Paper No 94/1981. 1982 Review of Australia's Demographic Trends, p4.

165 The old-age dependency ratio is the population aged 15-64 divided by the dependent elderly population (those aged 65 and over). Australian Bureau of Statistics (2006c). 
Australian policy makers were concerned about demographic issues, despite the fact that Australia's demographic profile was quite favourable when compared to many other OECD countries, ${ }^{167}$ partially due to effective and targeted immigration policies. The focus on potential issues associated with the demographic changes increased over time. The Social Security Review Towards a National Retirement Incomes Policy (Department of Social Security 1988:6) recommended that 'there are a number of policy directions which should be pursued now to minimise problems that this [ageing of the population] may cause'. By 1991, Treasurer John Kerin suggested that 'self provision for retirement must become a foundation of Australia's retirement incomes policy: ensuring such self-provision is a key function of the Superannuation Guarantee'. ${ }^{168}$

Statements of this nature are not seen in New Zealand. While there is discussion reflecting an apparent awareness of the forecast demographic changes (for example, the increasing costs of National Superannuation are noted in Government Management (New Zealand Treasury 1987:175)), there is an absence of debate and analysis on the projections and extant retirement income policy during the 1982 1992 period. The demographic changes in New Zealand were typically used to justify the status quo, rather than emphasising the need for policy changes, as in Australia, for example, New Zealand media reported that 'largely as a result of the government's gradual lifting of the entitlement age for National Superannuation from 60 to 65, the government can afford to pay the state pension without any additional burden on taxpayers until 2010' ${ }^{169}$ The Task Force concluded that there was time for a voluntary option to reduce the fiscal risks caused by projected demographic changes.

Some explanation for these different perspectives may be found in the different policy objectives in the two countries. Retirement savings policy objectives in Australia are long-standing and clear. Two objectives are paramount: firstly, to ensure that all

167 Submission No 29 to Senate Standing Committee on Community Affairs by the Social Welfare Policy Secretariat, Feb 1984.

168 Kerin (1991:15).

169 National Business Review, 21 August 1992, Super taskforce puts off evil day for government, p11. 
Australians have an adequate and secure income in retirement; and, secondly to encourage those in the workforce to save for their retirement to obtain a higher standard of living. The objectives are generally reiterated in the introductions of government publications in relation to retirement savings and there can be no confusion over the role of the government. The objectives of retirement income policy in Australia are infrequently challenged, as they are generally supported by most interest groups.

The policy objective for retirement savings in New Zealand has been expressed as encouraging increased private sector provision for retirement and assisting workers to have a better standard of living in retirement. ${ }^{170}$ However, the policy enacted to achieve this objective has adopted a significantly more non-interventionist approach to that seen throughout the rest of the OECD. If policy objectives were attempting to achieve aims beyond poverty alleviation, it would be expected that a greater degree of state involvement in retirement income savings would be seen.

\subsection{The Economic Situation}

New Zealand's reforms were always more radical than Australia's because your position was more desperate than Australia's in my view. ${ }^{171}$

Australia and New Zealand both faced serious adverse economic conditions during the 1980s. Both countries adopted economic liberalisation and restructuring, public sector reform, deregulation of the financial sector, tax reform and reductions in industry assistance. Stephens (1989:65) gives some idea of the magnitude of the changes in New Zealand when writing that the reforms:

include an extensive process of market liberalisation and deregulation, especially in the financial, agricultural and transport sectors. The exchange rate has been devalued and floated; export incentives and supplementary minimum prices to farmers have been abolished; import licenses have been opened up to tender; the average level of tariffs has been reduced; stateowned enterprises have been corporatised and given commercial objectives; and attempts have been made to reduce the size of the government sector as well as to fully monetarise the budget deficit.

\footnotetext{
$170 \quad$ New Zealand Treasury documents, e.g. Scobie, Gibson and Le (2004).

$171 \quad$ Respondent 24.
} 
Many interview participants acknowledged the difficult economic environment of the time. The situation is encapsulated by New Zealand Respondent 12:

It's a very interesting thing ... you know when you have a little house made of cards in front of you and you pull one card out, something's likely to start to fall all over the place. One of the amazing things about dismantling fortress New Zealand after 1984 was that it closely resembled a card house and when you pulled something away all sorts of other things required attention. The challenge for the government was constantly to do the dismantling process in the right order, but speed was essential because everything was collapsing and collapsing quickly.

There appears to be a general agreement that New Zealand was in a worse economic situation than Australia in the early to mid-1980s. It is not intended to imply that Australia did not also have a difficult economic environment. As mentioned by Australian Respondent 31, 'it's not that things didn't need to be done; they certainly did need to be done here. But the economic circumstances were not nearly as bad as in New Zealand'.

In New Zealand, the removal of the tax concessions for retirement savings is often framed within the context of the overall reforms of that period. A number of similar comments were received from interview participants such as 'the way we approach retirement savings had much less to do with specific issues about retirement savings and much more to do with the approach we were undertaking generally to do with the tax system ${ }^{172}$ and 'it is hard to think about this issue outside the context of a wider set of regulations in the financial sector, on the one hand, and national economic development priorities on the other'. ${ }^{173}$ Similarly, New Zealand Respondent 15 commented:

It was entirely consistent with that time. The ... era was an era when all of the tax incentives and tax concessions were stripped out of the legislation. It was recognised that they had got totally out of control - they were creating massive distortions in the economy and were producing quite perverse benefits.

In both New Zealand and Australia, there was an emphasis on economic stabilisation, trying to reduce inflation, reduction of government deficits and opening up the economy to competition. This resulted in an environment where tax revenues had to

\footnotetext{
$172 \quad$ Respondent 10.

173 Respondent 13.
} 
increase faster than expenditures. In New Zealand, this was achieved by removal of many of the industry subsidies. As commented by Respondent 8:

The other aspect [of the reforms] was to reduce the levels of government assistance to various industries and activities in the belief that government assistance could affect the direction in which resources went. ... A good part of the industry assistance was in fact created and delivered through the tax system, so a lot of the activities were removing incentives and concessions in the tax system - aimed at bringing the tax system to the point where it had less direct influence on this activity, relative to that activity. More neutrality was the terminology.

Respondent 8 continued to say 'some activities would get less assistance than otherwise. The superannuation/savings area became a big part of that'.

\subsection{Raising Revenue}

\begin{tabular}{|l|l|}
\hline \multicolumn{1}{|c|}{ New Zealand ${ }^{174}$} & \multicolumn{1}{|c|}{ Australia $^{175}$} \\
\hline Under TTE it got the revenue up & The whole driver was just to get \\
front... [otherwise] the government & extra revenue on a timing basis. \\
could not have gone ahead with & That was the message from \\
their tax cuts, which is all this was & Treasury; go and find a billion \\
about: tax cuts. The entire package & dollars of revenue somehow and \\
was about the personal rates. & come back with options. \\
\hline
\end{tabular}

In 1988, both countries were looking to either reduce government expenditure or increase government revenues. However, there were different reasons for needing increased revenue or decreased expenditure in each country. ${ }^{176}$ Part of the New Zealand reforms of the mid-1980s was a proposed 'flat-tax'. ${ }^{177}$ This was to be funded by removing the tax incentives on life insurance and superannuation. ${ }^{178}$ Respondent 3 advised:

Well, it [removal of tax incentives for retirement saving] actually was to pay for a flat rate of tax of 23 per cent ... by withdrawing all the up-front deductions for superannuation contributions, which is by far the largest amount. Although in present value terms TTE and ETT might be equivalent

\footnotetext{
$174 \quad$ Respondent 3.

175 Respondent 33.

176 Revenue foregone in 1988 as a result of the concessions was estimated at NZ\$660 million (New Zealand Government 1988). In Australia, this was estimated at A \$3.1 billion in 1988 (Sydney Morning Herald, 13 January 1988, Super Concessions Cost \$3BN, p30). For political reasons, the introduction of the 'flat-tax' in New Zealand did not occur.

178 It is interesting to note that the cost of National Superannuation provision was not challenged at this time. National Superannuation in New Zealand was costing around \$3.5 billion.
} 
under certain scenarios, in ETT the government lost revenue in the immediate term and gained revenue, supposedly, in the long term.

In Australia, revenue was increased by the 'bringing forward' of the tax revenue in 1988 and taxing superannuation fund earnings. Respondent 33 advised that revenue concerns were driving the changes to tax incentives in 1988, advising 'it was: go and find revenue - it wasn't go and find a way of ensuring that imputation works better for people'. So while the issue in Australia was framed as addressing the exclusion of superannuation funds from receiving tax credits under the dividend imputation system, ${ }^{179}$ this was also a convenient trade-off for additional revenue collection. Despite this, it was reported in the media that 'an important reason for taxing superannuation funds is not to raise revenue but to remove distortions in the tax system' ${ }^{180}$ This is, at least partly, likely to have some foundation as superannuation funds had no incentive to invest in company shares yielding franked (carrying imputation credits) dividends, as the funds were excluded from the dividend imputation system.

\subsection{The Prices and Incomes Accord}

There was no point thinking about, or dreaming up, policies that were going to, in any way, challenge the legitimacy of that agreement between the government and the trade union movement. ${ }^{181}$

The Australian context is not fairly represented in the absence of some discussion on the need for wage restraint in Australia or the presence of the Prices and Incomes Accord. As noted by Respondent 32:

The main original motivation, for the government anyway, going along with the union interests in superannuation was that it was a way of providing improvements, or perceived improvements, for union members and taking the pressure off the ACTU while the ACTU was trying to restrain wages and doing it in a way which would not boost inflation. So it was really pretty clear in its original motivation as a way of helping the ACTU to deliver perceived benefits to its members to compensate for the wage restraint that it was cooperating with the government in achieving.

179 The dividend imputation system is designed to eliminate classical double taxation of corporate income in the hands of both the company and its shareholders. 
Australian industrial relations has historically been more centralised than in New Zealand and had a greater focus on industry. Australia has a history of formal wage setting with judicial arbitration. Under the Labor government, centralised wage fixing became a tool of macro-economic policy, and the unions and government negotiated wage moderation in exchange for increases in the 'social wage'. Thus, a three per cent increase, justified on productivity grounds, was given in the form of a contribution to a superannuation fund. As noted by Respondent 18, in Australia:

There was a strong view among economists and in particular the
government's most influential economic advisers in the Treasury that this
system had locked in wages in real terms at levels that were very damaging
to prospects of reducing unemployment, which in those days was quite high
and the view in Treasury economist circles was that some sort of circuit
breaker was needed to stop this - wages feed into prices - feed back into
wages-cycle.

The Prices and Incomes Accord was intended to break this cycle with superannuation taking the place of a wage increase. Effectively this was to be a form of 'deferred income'.

While no arrangement such as the Prices and Incomes Accord existed in New Zealand, a legislative change did permit superannuation to become part of wage negotiations. With the introduction of the Labour Relations Act 1987 in New Zealand, any factors impacting on employer/employee relationships could be placed on the negotiating agenda. It was only after this time that superannuation may have been an item in employment contracts.

\subsection{National Superannuation}

Why would you bother to try to get super for people that might be moving on to a pension that was better than their wages were? ${ }^{182}$

Another key difference between New Zealand and Australia was the provision of state superannuation. In New Zealand this had been at generous levels (a maximum of 80 per cent and a minimum of 60 per cent of gross average weekly earnings) over the decade before 1988. The importance of this is noted by Australian Respondent 31 who comments:

$182 \quad$ Respondent 5. 
The context was quite different. In the first place New Zealand had this National Superannuation as it was called. Had we had that, we probably would have removed all the tax concessions for superannuation too. We probably would have; I mean why would you run two hugely expensive models? It was very important, as I said earlier, that part of the context here was that our age pension system, on a cross-country comparison, is not a particularly generous one. And it's heavily means tested. So that context is very different.

By providing a generous universal pension, much of the argument that was raised in Australia around concepts of equity was diluted in New Zealand; there was no possibility of the creation of a cohort of elderly individuals living in poverty.

National Superannuation provides a good example of the path dependency argument that historical policy decisions can constrain policy options into the future. National Superannuation has been provided at generous levels for 30 years in New Zealand and has become embedded into the New Zealand culture. Even in the face of projected significant increases in the cost of funding National Superannuation, no political party is prepared to challenge it. ${ }^{183}$

\subsection{National Savings}

\begin{tabular}{|l|l|}
\hline \multicolumn{1}{|c|}{ New Zealand ${ }^{184}$} & \multicolumn{1}{|c|}{ Australia } \\
\hline From an economic perspective & But that's where it came from; \\
there is nothing inherently good (or & really a general concern with \\
bad) about savings, any more than & national saving, concern that \\
there is anything inherently bad (or & private savings were too low and \\
good) about consumption. & $\begin{array}{l}\text { something had to be done to } \\
\text { increase private savings. }\end{array}$ \\
\hline
\end{tabular}

An area where New Zealand and Australia adopted very different approaches was in their respective attitudes towards national savings. One of the primary arguments in Australia in relation to retirement savings policy was the perceived need to increase levels of saving. Rather, in New Zealand three contrasting arguments dominated in relation to savings: firstly, that New Zealand did not need higher levels of savings;

\footnotetext{
183 The Sunday Star Times, 23 December 2007, Super Sensitive, pC6, quotes the Finance Minister and the Leader of the Opposition vehemently denying contemplation of any changes to the National Superannuation scheme.

$184 \quad$ New Zealand Government (1988:77).

$185 \quad$ Respondent 31.
} 
secondly, that the introduction of a neutral scheme of taxation may increase savings (as the trade-off for tax incentive removal was lower personal income tax rates); and, thirdly, that the presence of international capital markets removed any imperative to improve national savings.

It had been previously acknowledged in the early 1970s that savings in New Zealand were insufficient. In July 1972, it was observed that 'one of the messages spelled out by the first National Development Conference, and subsequently proved by the effective limitation of internal investment was that our savings were insufficient for the country to develop at what is considered a desirable rate. ${ }^{186}$ Despite this claim, New Zealand agencies disputed the existence of a 'savings problem'; for example, a 1982 Treasury report suggests:

It is doubtful whether a lack of savings has been a significant problem in New Zealand in recent years; rather, the problem has been more one of efficiency with which the existing level of savings has been used and it would seem that this position could be improved by promoting greater competition among financial institutions through reducing special assistance to a particular sector of the capital market. ${ }^{187}$

A number of New Zealand interview participants remarked that one explanation for why New Zealand did not focus on increased national savings was the perspective that increased savings were not necessary due to the existence of international capital markets. Respondent 9 commented that 'talking to David Caygill as Associate Minister [of Finance], he made it very clear to me that capital formation (one aspect of pension policy) was not important, because we can borrow offshore'. Furthermore, Respondent 14 advised:

Treasury has long taken the view that savings, or lack of savings, is not a constraint on New Zealand growth ... the world capital market is huge and we can access that capital market easily. We are regarded as a good risk and therefore we don't need to artificially stimulate, as they would see it, domestic savings in the sense of departing from what is the way we tax every other form of savings in the TTE form.

\footnotetext{
186 Address to the Association of Superannuation Funds of New Zealand, Wellington, 31 July 1972, by W E Rowling MP. 
Some extreme claims were made from the industry, such as 'the only source of longterm finance in the private sector is life insurance and superannuation'. ${ }^{188}$ Other industry participants raised more balanced arguments, including that 'the continuation of a sizeable pool of long term funds is necessary for the process of capital formation in New Zealand and for future economic development'. ${ }^{189}$ This argument was countered by Treasury claims that other financial institutions can provide long-term finance through marketable securities, and if demand for long-term savings exceeded supply then interest rates would adjust to ensure that the problem was solved. ${ }^{190}$

A number of individual submissions to both the Caucus Committee on Taxation of Life Offices and Building Societies (the Caucus Committee) in 1982 and the Consultative Committee on Superannuation, Life Insurance and Related Areas (the Consultative Committee) in 1988 argued that tax concessions were necessary to persuade individuals to invest in long-term savings. As might be expected, this argument was raised by a number of industry participants (e.g. submissions to the Caucus Committee by the Government Life Insurance Office, the Association of Superannuation Funds of New Zealand, the New Zealand Bankers' Association, AMP Society ${ }^{191}$ and National Mutual Life Society ${ }^{192}$ ). However, the argument was also supported by a number of other organisations and individuals (e.g. submissions to the Caucus Committee by the New Zealand Society of Accountants and the Consumers Institute, ${ }^{193}$ and submissions to the Consultative Committee by the National Provident Fund ${ }^{194}$ and the New Zealand Chamber of Commerce, ${ }^{195}$ among others). Comments

188 Life Offices Association of New Zealand Inc to R Muldoon, 16 April 1982. New Zealand Archives reference AALR, 873, W4446, 632, Record 76/2/54 Part 1. Government Life Insurance Office submission to the Caucus Committee on Taxation of Life Offices and Building Societies, 1982. New Zealand Archives reference AALR, 873, W4446, 632, Record 76/2/54 Part 1. New Zealand Treasury Report T76/3/6/1, May 1982. New Zealand Archives reference AALR, 873, W5427, 1898, Record 76/13/6 Part 4. New Zealand Archives reference AALR, 873, W4446, 632, Record 76/2/54 Part 1. Correspondence from National Mutual Life Society, August 1985. New Zealand Archives reference AALR, 873, W4446, 632, Record 76/2/54 Part 2. New Zealand Archives reference AALR, 873, W4446, 632, Record 76/2/54, Part 1. Submission No 215, April 1988. New Zealand Archives Reference AALR, 873, W5427, 1829, Record 76/2/54/2 Part 1B. 
such as the following from the AMP Society to David Caygill in May 1985 are representative of much of the communication in the 1984 to 1988 period:

It is clear to us that without some encouragement and discipline, the majority of people will be unable to make financial sacrifices over the long term in order to achieve a reasonable retirement income, such are the very real domestic financial pressures which occur during working years. ${ }^{196}$

Moreover, the Consultative Committee also did not accept the government arguments that the level of savings in New Zealand was satisfactory, noting:

We find great difficulty, however, accepting that, at this particular stage in New Zealand's history, we can be indifferent to the level of savings. By most objective assessments, New Zealand's net overseas indebtedness has now risen close to the point where it imposes significant constraints on future economic growth. That net overseas indebtedness reflects, of course, simply the accumulation of many years of deficit in the current account of the nation's balance of payments, reflecting in turn our long-standing propensity to spend more than we produce as a nation - that is, a long-standing propensity to save too little. ${ }^{197}$

While New Zealand maintained a position of not needing to improve its levels of savings, Australia was clearly concerned about increasing the level of national savings. Respondent 31 commented:

There was another bit of context that is important here as well. That is the concern - I guess it was a preoccupation that Australian economic policy had with national savings. This really came out of Paul Keating's 'banana republic' statement. ... What he managed to do was to set up a fear of international debt and in particular a fear of the current account deficit. ... Anyway, he used it very powerfully to argue that the budget deficit needed to be got under control. But subsequently, towards the end of the 1980s, it was being used as an argument for increasing national savings; not just public saving, but private saving.

There was considerable discussion on the potential impact that the proposed policies were likely to have on national savings in Australia. The Superannuation Guarantee proposal, in particular, generated significant debate, with a wide range of perspectives

195 Submission No 157, April 1988. New Zealand Archives Reference AALR, 873, W5427, 1829, Record 76/2/54/2 Part 1B.

196 Correspondence from the AMP Society, June 1985. New Zealand Archives reference AALR, 873, W4446, 632, Record 76/2/54/1 Part 1. 
and potential outcomes suggested. Most suggested that the Superannuation Guarantee would have beneficial impacts on the level of national savings, despite much of the existing literature suggesting that the substitution effect would mean that not all savings within the new scheme would be new savings. Projections estimated that the Superannuation Guarantee would increase saving in the form of private superannuation by about two per cent of GDP within 15 years. ${ }^{198}$

\subsection{Summary}

\begin{tabular}{|l|l|}
\hline \multicolumn{1}{|c|}{ New Zealand } & \multicolumn{1}{|c|}{ Australia $^{200}$} \\
\hline $\begin{array}{l}\text { Nobody was being singled out and } \\
\text { picked on - everybody was being }\end{array}$ & $\begin{array}{l}\text { Our system is a progressive set of } \\
\text { changes. It suited everybody's } \\
\text { picked on. And it was abundantly } \\
\text { clear that the government meant } \\
\text { business. }\end{array}$ \\
\hline
\end{tabular}

At the time of the election of Labour governments in both countries there was a view that existing policy arrangements for retirement savings were not effective. The New Zealand approach to reforming the taxation of retirement savings in the 1980s was quite deliberate; it was a systematic removal of privileges that had built up over time. The Australian approach involved greater consultation and negotiation, in particular with the trade union movement. As illustrated throughout this chapter, these approaches were facilitated by a number of environmental factors.

Investigation of the environment highlights the enabling and constraining factors in the two countries. Historical institutionalism supports investigation of contextual factors and provides some insights into the reasons why these directions were pursued. Exploration of the environment also highlights the privileging of arguments of the time; for example, the emphasis on the demographic changes in Australia and the economic crisis in New Zealand.

Where institutional theory is useful in this chapter is in highlighting the constraining effects of the environment in the Australian context and the enabling effects of a

198 Submission SG 47, to the Senate Select Committee on Superannuation by the Australian Treasury, 1992.

199 Respondent 12.

$200 \quad$ Respondent 20. 
similar environment in New Zealand. In Australia, environmental factors, such as the changing demographic situation and a perceived need to increase national savings, were used to support the implementation of the Superannuation Guarantee, while the need for increased revenue provided the impetus for the tax changes in the late 1980s. In New Zealand, the serious economic situation was the catalyst for many of the reforms of the time, but the economic crisis also provided validation of many of the changes made during the 1980s. In relation to the removal of tax incentives, these merely formed part of the wider reforms of the time, but also proved to be particularly valuable in providing the means to reduce income tax rates, which assisted with maintenance of credibility for individual actors and institutions.

Considerable emphasis was placed on the seriousness of the economic situation, which assisted in persuading individuals that the innovative reform was essential. Similarly in Australia, the constraints on both policy options and policy implementation that existed, together with the need to negotiate, be cognisant of the 'social wage' and involve the industry in decision making, resulted in outcomes that were less extreme than those of New Zealand. Thus, the emphasis placed on the environment by historical institutionalism contributes towards an explanation of why the two countries adopted the particular policy solutions witnessed.

A fundamental factor that must be acknowledged is the different approaches to the broad topic of retirement savings that were adopted by the respective governments. The Australian government deliberately targeted savings and, as such, policies were intended to influence the levels of savings. New Zealand's position was intended to introduce a more neutral tax treatment of savings vehicles and policies were implemented to achieve this result. That the New Zealand government wanted people to make savings decisions that were not driven off the tax system was clearly a very different objective to that of the Australian government.

There can be no doubt that the changes in both countries were a combination of factors, all relevant to the particular environment. However, while environmental factors highlight some of the situation-specific factors from within which this comparative case study emerges, they do not allow for a detailed analysis of the policy process. It is necessary to investigate other factors in order to provide a fully 
researched argument. Thus, the following three chapters consider the institutional frameworks, the power dynamics and the prevailing ideologies, to assist in producing meaningful conclusions about the policy development processes in each country. 


\section{Chapter 9: Institutions}

\subsection{Introduction}

Institutional theorists argue that institutions provide the context in which decisions are made, thereby shaping the potential range of policy options. The argument is that individual capacity is empowered or constrained by the institutions from within which individual actors operate. However, it is also important to acknowledge that political institutions are not neutral environments; they are comprised of individuals with interests and world views that are likely to be aligned in a particular direction. Thus, institutions, through individual actors, are ultimately a vehicle for certain types of activity, while providing constraints on the forms this activity will adopt.

This chapter analyses the key institutions involved in the case study, including the trade union movement in Australia, government and government departments, interest groups, individuals and individual relationships in both countries. It also considers the role of interest groups and employer organisations in both countries.

\subsection{The State}

\begin{tabular}{|l|l|}
\hline \multicolumn{1}{|c|}{ New Zealand ${ }^{201}$} & \multicolumn{1}{|c|}{ Australia $^{202}$} \\
\hline There are insufficient efficiency or & Occupational superannuation is a \\
equity grounds to justify the present & key element in the Government's \\
preferential treatment of super- & retirement income policy of \\
annuation and life insurance. & encouraging retirement provision \\
& by employees during their working \\
& lives. \\
\hline
\end{tabular}

Governments have to balance conflicting priorities to achieve a policy mix that is both workable and, at least to some extent, acceptable to the populace. It is at the governmental level that perhaps the most distinctive differences in policy approach were pursued in the two countries.

Institutional theory generally supports the suggestion that institutions adapt to a changing environment through a learning process. ${ }^{203}$ This is apparent in both the New

\footnotetext{
$201 \quad$ New Zealand Treasury (1987:300).

202 Senate Select Committee on Superannuation (1992:2).
} 
Zealand and Australian contexts. In Australia, this can be seen in the adoption of a corporatist approach from the early 1980s; with subsequent reforms under the Labor government based on negotiation and consensus, and at a significantly slower pace than those seen in New Zealand. Respondent 19 observed that 'Bob Hawke is the apostle of consensus really - so hence the summits and bringing people together and so on'. Both New Zealand and Australia had Economic Summits in the early 1980s in an attempt to generate a cohesive approach to broader economic reform. However, New Zealand did not attempt the same degree of consultative reform that occurred in Australia.

By 1988, the contrasting position in the two countries in relation to the role of the state in retirement savings is evident. The trend in Australia was for greater state involvement, while in New Zealand it was for minimal state involvement, with the exception of National Superannuation. In Australia, the government clearly supported both the extension of occupational superannuation and tax incentives to encourage saving. The May 1988 Economic Statement in Australia notes that it is ' $a$ fundamental objective of the Government that every employee is entitled to superannuation cover' (1988:1). This view strengthened as the time of the Superannuation Guarantee neared with Senator Sherry suggesting:

In terms of the complaints of some welfare groups, I would have to say that, frankly, they are misguided and lack a vision of what, potentially and catastrophically, could occur in terms of the current old age pension if we do not tackle this issue now and if we do not provide substantial levels of selffunding for those who can afford it. Thirty to 40 years hence, I would predict that, if we do not have the substantial levels of compulsory superannuation that are provided for in the legislation, the current old age pension will be reduced by future governments. ${ }^{204}$

203 It is acknowledged that there is an ongoing debate within institutional theory on the rationality of social learning. This is captured by Hall (1993:276), who suggests that it: is presented in 'only the sketchiest of terms'; it emphasises the role of ideas in policymaking without developing an image of the way ideas fit into the policy process; and it is treated as confirming the autonomy of the state, whereas it may be a process influenced by 'societal developments rather than one that takes place largely inside the state itself'.

Superannuation Guarantee (Administration) Bill 1992, Superannuation Guarantee Charge Bill 1992, Superannuation Guarantee (Consequential Amendments) Bill 1992, Superannuation Legislation (Consequential Amendments and Transitional Provisions) Bill 1992. Senate Hansard Volume 153, 18 June 1991, pg 3909, Senator S Sherry (ALP). 
Meanwhile, in New Zealand the government claimed: 'if the Government wished to continue to assist private provision for retirement, superannuation and life insurance concessions would be a poorly targeted and cost-ineffective way of achieving that goal' (New Zealand Treasury 1987:300).

With the removal of incentives in New Zealand, the involvement of the state in private retirement savings was minimal. As will be seen throughout this and subsequent chapters, there was significant disagreement with the New Zealand approach, particularly in relation to the impact the New Zealand changes would potentially have on future reliance on National Superannuation. Many of the submissions to both the Caucus Committee on Taxation of Life Offices and Building Societies (the Caucus Committee) in 1982 and the Consultative Committee on Superannuation, Life Insurance and Related Areas (the Consultative Committee) in 1988 suggested that the state had a role to play in encouraging self-provision in retirement. The following submission from ACL Corporation Limited to the Consultative Committee is typical of communication of the time:

To abdicate responsibility because there are strong private incentives is to ignore the underlying social pressures and reasons as to why there are strong private incentives. These incentives include self-reliance, independence from reliance on the State, financial freedom. These incentives decrease reliance and dependence on State welfare, and should therefore be encouraged. Surely no one would advocate that dependence on the State should be encouraged? ${ }^{205}$

A similar argument was raised in the Australian context, although the claim was supported by the government. In the 1990-91 National Wage Case, the government, in support of the ACTU's claim for a further round of award contributions, noted that 'the key to providing better income for the growing number of old people in the future is to increase savings now. Improved access to superannuation is the best way of achieving this' ${ }^{206}$

205 Submission No 200 to the Consultative Committee by ACL Corporation Limited, 8 April 1988. ACL Corporation Limited owned Australasia Commercial Life Insurance Co Ltd and New Zealand Superannuation Corporation Limited. 
It is worthwhile making an observation about the impact of the Opposition in Australia during the implementation of the Superannuation Guarantee. While the Liberal Party resisted the Superannuation Guarantee arrangements, the apparent lack of cohesion between the coalition parties may have been a factor in their inability to curb the passing of the legislation. ${ }^{207}$

Even the media appeared to support the Superannuation Guarantee proposal, reporting:

Opposition, of course, is entitled to proclaim an alternative policy and some elements of the Fightback superannuation package, particularly in terms of achieving tax neutrality, are commendable. But it is difficult to see on what the coalition bases its apparent belief that compulsion is not required if a target of universal superannuation (or retirement income) coverage of the workforce is to be achieved. ${ }^{208}$

The state in Australia managed to achieve a strong degree of support for the Superannuation Guarantee proposals. The debate that may have been problematic in relation to the changes to tax incentives in 1988 was ameliorated through the tradeoffs that were made; the bringing forward of the tax on final benefits, under certain assumptions, produced a neutral result and the taxing of superannuation fund earnings was relieved to a significant extent through inclusion in the imputation system. The trade-offs in the New Zealand context were less apparent, although it is clear that, in the absence of the removal of the tax incentives, a reduction in the personal tax rates would not have been possible.

207 Of interest is the input of two individuals into this situation. One was Cheryl Kernot, the Australian Democrat Senator for Queensland and the other was Liberal Party MP David Connolly. Both individually supported the Superannuation Guarantee, and it was in no small part due to the influence of Cheryl Kernot that the Superannuation Guarantee Levy Bill was passed. Cheryl Kernot was in a powerful position in the Senate, as without the support of the Democrats (who held the balance of power in the Senate), the government's policy would not have been implemented. Australian Financial Review, 29 November 1991, Super is no political football, p18. 


\subsection{The Treasury}

\begin{tabular}{|l|l|}
\hline \multicolumn{1}{|c|}{ New Zealand ${ }^{209}$} & \multicolumn{1}{|c|}{ Australia $^{210}$} \\
\hline $\begin{array}{l}\text { It is important to see Treasury and } \\
\text { the Ministers as in a symbiotic } \\
\text { relationship. }\end{array}$ & $\begin{array}{l}\text { There was no real gap between the } \\
\text { department and the Minister on } \\
\text { this. There were no real gaps on } \\
\text { most things actually, but on this } \\
\text { there was certainly no gap. }\end{array}$ \\
\hline
\end{tabular}

Historical institutionalism, together with other political theories, suggests that individuals within institutions are enabled (and constrained) by the political structures within which they operate. It is apparent in the New Zealand context that the interests of the individuals within the New Zealand Treasury were aligned with those of the institution and the New Zealand Treasury was strongly linked to government capability.

Historical institutionalism suggests that individuals within key government departments have considerable influence in the policy process. This is, in part, due to the expertise present within an institution, but also because of the role of individual actors in policy advice provision. Although it is less apparent from the literature, there was also considerable alignment in the position of the Australian Treasury and the Treasurer in relation to tax incentives. However, the Australian Treasury had little input into the Superannuation Guarantee proposal.

Government department officials in New Zealand, and in particular those within the New Zealand Treasury, had considerable autonomy at the time in providing policy advice. They were also in a position to know what potential policy proposals were likely to be agreeable to the government and other interest groups, and they were also well-placed to advise which policy alternatives were likely to achieve greater success. Respondent 6 captures the time, commenting:

I can't remember any formal process. I just remember that Treasury, if you like, had a fairly economically rational way of approaching things ... and at the same time as industry policy was shifting towards removing the protection of various forms of industry and creating a more competitive level playing field by removing tariffs on imports and removing subsidies to farmers and exports - so there was general pressure from the Treasury which

\footnotetext{
$209 \quad$ Respondent 10.

$210 \quad$ Respondent 31.
} 
was taken up more or less by different political masters at the time to reduce the favours.

In Australia, the Labor government policy was aligned with the direction of the trade unions; whereas the direction of the New Zealand Labour government was aligned with the thinking of the New Zealand Treasury. New Zealand Respondent 14 reported that:

Treasury was strongly committed to TTE and I think the Minister of Finance was strongly committed to TTE, quite separately to Treasury. Often the Minister of Finance reflects what Treasury says, but Roger Douglas definitely had a mind of his own. I think on this particular issue he agreed with Treasury quite clearly.

Historical institutionalism suggests that the 'rules' within an institution represent individual perspectives and philosophies. In turn, this helps to limit divergences of opinion and individual behaviour that does not comply with the 'rules' of the institution. The New Zealand Treasury in the 1980s reflects this suggestion, with the engagement of like-minded individuals within an organisation that was suggested to provide a 'single-stream' of policy advice at the time. Meanwhile, the Australian Treasury was more cognisant of wider input and preference, which limited potential policy options.

\subsection{Trade Unions}

Experience has shown that simply providing "incentives" rather than
compulsion will not lead to an increase in the spread of superannuation
coverage. The pre-1983 taxation arrangements were very generous - no
tax on contributions or superannuation fund earnings and virtually no tax
on benefits - yet only $39 \%$ of employees received any employer provided
superannuation support. Very few workers earning less than average
weekly earnings had superannuation. 211

Trade union interest in superannuation can be traced back many years. It has been suggested (e.g. Olsberg 1997:75) that Australian trade union involvement in superannuation was encouraged by changes to the industrial relations systems. This was the result of the centralised national wage indexation in 1975, which resulted in trade union compliance with award indexation guidelines and, as a result, a high

\footnotetext{
211 Submission SG 29 to the Senate Select Committee on Superannuation, by the Australian Council of Trade Unions, 1992.
} 
element of wage restraint. Accordingly, unions moved towards seeking other benefits, such as reduced working hours and superannuation benefits. Some early success was seen in relation to this approach, but with limited scope (such as in the Pulp and Paper Industry and the Storemen and Packers Union). ${ }^{212}$ However, it was another decade before occupational superannuation was viewed as a legitimate area of interest for unions in looking after the welfare of their members.

From the late 1970s, the ACTU argued that an adequate standard of living in retirement was an economic right of all workers. However, in the absence of implementation of a national superannuation scheme, it was agreed that unions should either collectively or individually develop superannuation cover. By the mid-1980s, occupational superannuation had become part of the overall package of improvements for workers, in line with ACTU policy and the Prices and Incomes Accord.

The primary arguments supporting ACTU involvement in superannuation were:

- inequity - workers in Australia were not equal in regard to occupational superannuation provision:

- 40 per cent of the workforce had employer sponsorship of their retirement; ${ }^{213}$

- 24 per cent of working women were involved in superannuation;

- $9.6 \%$ of employees earning up to $\mathrm{A} \$ 280$ per week $(47.3 \%$ of the workforce) had superannuation coverage;

- 70.2 per cent of employees earning in excess of A $\$ 440$ per week (16.6 per cent of the workforce) had superannuation coverage;

- 66 per cent of employees in the public sector had superannuation while only 36 per cent of private sector employees had coverage; and

- demographic issues associated with an ageing population (ACTU 1985).

Institutional theory suggests that institutions can adapt to changing environments through a learning process. The concept of punctuated equilibrium assists with $212 \quad$ Respondent 30.

213 Most schemes in the public and private sector had restrictive requirements in relation to length of service, combined with low rates of return, resulting in only 15 per cent or less of the workforce actually benefiting from employer superannuation contributions (Weaven 1989:18). 
explaining such institutional change. Punctuated equilibrium suggests that institutions will change function at certain critical junctures, in response to a changing environment, allowing institutions to take advantage of opportunities that may arise. This can be seen in the Australian context where the trade union movement adapted to the changing economic environment, in particular in relation to labour arrangements, with the inclusion of occupational superannuation in national wage negotiations. A further area where unions adapted to the changing environment is in relation to industry funds. As noted by Respondent 31, 'it gave the ACTU a future for one thing and gave trade unions a future'. Unions appeared to recognise the future potential power of superannuation funds and were keen to be involved in their administration and management.

Labour interests in Australia are highly organised. Institutional theory suggests that policy decisions are made with the involvement of such influential groups, creating an environment for elites from the trade union movement to be actively involved in negotiations in relation to many areas of social and broader economic policies. However, it is also important to be cognisant of the role of the trade union; that is, to represent workers. Ultimately, workers also have the ability to influence the position of the trade union movement on certain issues. Thus, if continued support was desired, the position of union elites needed to represent the preferences of the workers.

As well as being influential with the implementation of compulsory occupational superannuation in the mid-1980s (and later with the Superannuation Guarantee), the trade unions were also influential in the tax changes in the late 1980s; for example, in relation to bringing forward the tax on final benefits and the introduction of tax on superannuation fund earnings. As noted in the media, 'most regard superannuation retirement benefits as sacrosanct from further government intervention and there are strong community fears that the average worker could be disadvantaged'. ${ }^{214}$ Actions included 15 major unions forming a new grouping in opposition to the proposed changes, with the argument that 'any move to tax super funds would reduce the benefits available to workers on their retirement, and would negate much of the

214 Australian Financial Review, 6 May 1988, Opposition Mounts to Super Tax Changes, p1. 
progress of recent campaigns to provide national retirement coverage' ${ }^{215}$ In addition, threats were made by unions that financial support for the Labor Party would be withdrawn if new taxes on superannuation were introduced. ${ }^{216}$ However, the inclusion of superannuation funds within the imputation scheme appeared to resolve much of the conflict without significant industrial action.

From the late 1980s, it was clear that the trade union movement had adopted a committed position in relation to superannuation cover. The 1989 National Retirement Incomes Policy suggests:

The Trade Union movement will continue to develop superannuation as a supplement to pension entitlements. Genuine superannuation coverage should be available as a right for all workers. ... The ACTU will continue to seek such extended superannuation cover by promoting multi-employer schemes which provide full vesting, portability, and preservation of benefits, and by seeking to increase over time the level of employer contributions to such schemes as well as encouraging employee contributions (ACTU 1989:9).

By the time the Superannuation Guarantee proposals became public, the ACTU was forceful in its support for the scheme, both via the media and directly to the Senate Select Committee on Superannuation. The information in Tables 9.1 and 9.2, showing the significant increase in employees with occupational superannuation, was provided by the ACTU to demonstrate that compulsion was proving to be more successful than the historic system based on incentives.

The ACTU argued that, despite generous tax incentives for retirement savings, less than 40 per cent of employees received employer support. Furthermore, significant disparities existed in gender and industry levels of support. ACTU support was based on the objective of increasing retirement incomes.

\footnotetext{
$215 \quad$ Ibid.

216 For example, the Municipal and Shire Council Employees' Union, a 40,000 member organisation. Sun Herald, 22 May 1988, Union Warns Hawke: Don't Tax Super, p1.
} 
Table 9.1: Superannuation Coverage by Industry and Sector ${ }^{217}$

\begin{tabular}{|l|c|c|}
\hline \multicolumn{2}{|c|}{ Proportion of Total Number of Employees (\%) } \\
\hline Industry & August 1985 & July 1991 \\
\hline Communication & 85.3 & 91.7 \\
\hline Electricity, Gas Water & 76.6 & 94.4 \\
\hline Public admin and defence & 72 & 89.9 \\
\hline Mining & 70.3 & 88.4 \\
\hline Transport \& Storage & 49 & 79.1 \\
\hline Finance & 41.9 & 72.2 \\
\hline Manufacturing & 41.6 & 80 \\
\hline Community Services & 39.4 & 76.8 \\
\hline Construction & 31.6 & 61.2 \\
\hline Wholesale \& Retail trade & 22.6 & 62.8 \\
\hline Agriculture & 15.4 & 51.9 \\
\hline Recreation & 12.6 & 47.1 \\
\hline Public Sector & 61.7 & 86.3 \\
\hline Private Sector & 29.45 & 66.7 \\
\hline Total & $\mathbf{3 9 . 5}$ & $\mathbf{7 2 . 2}$ \\
\hline
\end{tabular}

Table 9.2: Superannuation Coverage by Gender ${ }^{218}$

\begin{tabular}{|l|c|c|}
\hline \multicolumn{3}{|c|}{ Proportion of Total Number of Employees (\%) } \\
\hline Gender & August 1985 & July 1991 \\
\hline Males & 50.0 & 84.4 \\
\hline Females & 24.0 & 71.8 \\
\hline Total & $\mathbf{3 9 . 5}$ & $\mathbf{7 8 . 0}$ \\
\hline
\end{tabular}

The trade union movement in Australia illustrates another concept of historical institutionalism, the importance of historical influences. Historical institutionalism suggests that influences that played a part when institutions are formed continue to play a role in that institution into the future. The trade union movement in Australia had historically been a participant in wage negotiation and the inclusion of superannuation in these negotiations appears to have been a natural progression as the nature of the trade union movement changed in response to a different environment.

Perhaps the key link in the Australian context is the positive relationship between the trade union movement and the state. This was manifested in the Prices and Incomes Accord, which was the first significant step in the introduction of compulsory

\footnotetext{
217 Submission SG 29 to the Senate Select Committee on Superannuation, by the Australian Council of Trade Unions, 1992. 
occupational superannuation. The Accord demonstrated the ability for a successful alliance to exist between the government and the unions, supported by a common ideology focusing on equity and social justice. Furthermore, the Accord facilitated a mutually beneficial approach to economic reform, which was to give it legitimacy and credibility within a broad environment.

The absence of discussion on New Zealand trade unions in this section is evident. The trade union movement in New Zealand did not attempt to influence policy for the taxation of retirement savings, and the minor role that it played was in relation to the maintenance of National Superannuation.

\subsection{Individuals and Relationships}

\begin{tabular}{|l|l|}
\hline \multicolumn{1}{|c|}{ New Zealand ${ }^{219}$} & \multicolumn{1}{|c|}{ Australia 220} \\
\hline I think he [Roger Douglas] deserves & He [Paul Keating] was absolutely \\
an extraordinary amount of credit & committed to the process - one of \\
for what happened, and he led the & his key priorities was continuation \\
specific charge. & of the superannuation reforms. \\
\hline
\end{tabular}

Historical institutionalism encourages investigation of relations between institutions and individuals within institutions. As noted in chapter three, relationships can play a key role in forming policy outcomes. In both countries at the governmental level, as might be expected, it was the Finance Minister/Treasurer who was to drive the respective changes to superannuation policy. However, this was not just from a figurehead perspective, but also as an actively involved actor in the policy process.

In January 1985, the key players in the national centralised wage decision were the then Treasurer, Paul Keating and the Secretary of the ACTU, Bill Kelty. The personal relations and historical affiliations between the trade unions and the Labor government have been well documented. ${ }^{221}$ As a former president of the ACTU,

$219 \quad$ Respondent 10.

$220 \quad$ Respondent 21.

221 For example, Olsberg (1997:101) claims that the 'close personal relationship between ACTU Secretary Bill Kelty and the then Prime Minister Paul Keating was ... central to Keating's continuing support for industry-wide superannuation'. Similarly, Singleton (1990:183) suggests that the 'close, friendly and cooperative association between the key players, Crean, Kelty, Keating and Hawke, has made the task of negotiating much easier'. 
Prime Minister Hawke's approach to unions reflected his institutional knowledge of the trade union process. However, as noted by Respondent 17, in Australia it is 'important to realise that Keating drove the process - not Hawke'.222 The commitment of Paul Keating to occupational superannuation was frequently raised during interviews.

The most influential individual in the New Zealand context was the Finance Minister, Roger Douglas. When asked the key drivers of the changes to the taxation of retirement savings in New Zealand, individuals often suggested that it was Roger Douglas. Respondent 10's comments are representative of those received; 'to the extent that there is a primary actor, it was Roger'.

In Australia, key individuals within institutions such as the unions were also important in driving the process. In particular, individuals within the unions pursued these changes on an equity platform. As noted by Respondent 17: 'some people ... were important - this was where the equity argument came in - blue collar versus white collar - social reform in general'.

While individuals are important in this analysis, it is perhaps more the combinations of individuals that provided the ability to achieve unique outcomes. These relationships played a significant role in both the successful introduction of compulsory occupational superannuation and the relatively smooth adoption of the key changes to the taxation of superannuation in 1988. Perhaps the best example of such a relationship was in Australia where the Hawke/Keating/Kelty arrangement provided unprecedented union access to decision making in government. However, in New Zealand the key relationship was between Roger Douglas and the New Zealand Treasury, rather than specific individuals. This absence of historical links between individuals and New Zealand institutions, such as unions, may have been a contributing factor to the more resolute approach seen in New Zealand. Respondent 25 advised 'the notion that Hawke would turn on the union movement was just inconceivable'. This degree of apparent loyalty was not evident in the New Zealand context.

222 It is noted that the Prime Minister, Bob Hawke, was the driving force behind the Accord. 


\subsection{Interest Groups and the Industry}

\begin{tabular}{|l|l|}
\hline \multicolumn{1}{|c|}{ New Zealand ${ }^{223}$} & \multicolumn{1}{|c|}{ Australia $^{224}$} \\
\hline What they were really telling us was & They really were interested in \\
- we don't like what you are doing & protecting their own little patch, \\
to us because it injures our morals. & where they could. \\
Well, we do understand that ...but & \multicolumn{2}{|}{ that didn't make it right. It } & \\
certainly didn't provide an & \\
intellectually based defence. & \\
\hline
\end{tabular}

Political theory suggests that interest groups may not have significant influence on policy outcomes. However, where influence might be seen is in the detail of the policy. This may partially be due to the evident perspectives that interest groups represent; the predictable responses of such groups may assist in policy development, with likely disagreements managed in advance. Indeed, it has been suggested (e.g. Peters 1991:13) that significant negative interest group responses may mean that an ineffective policy process has occurred. This process was apparent in the New Zealand context with archival documents indicating anticipation, and preparation for, negative feedback from the proposed changes. ${ }^{225}$

Hall (1986:232) adopts a different approach, suggesting that policy is formed in response to pressure from interest groups. However, in both Australia and New Zealand many interest groups were not organised to allow for effective input. The primary organisation in Australia to criticise government policy on the taxation of superannuation was the peak council of the community and welfare sector; the Australian Council of Social Services (ACOSS). ACOSS was also the group that appeared to be given the most attention, although this was often through the media rather than at governmental level.

\footnotetext{
$223 \quad$ Respondent 11.

$224 \quad$ Respondent 28.

225 Anticipated arguments included the discouragement for self-provision for retirement, increased state dependency, decreasing overall savings and the importance of the need for long-term investment. Correspondence from the New Zealand Treasury to the Minister of Finance, 14 September 1984. New Zealand Archives AALR, 873, W5427, 1898, Record 76/13/6, Part 5.
} 
The ACOSS arguments were based on equity grounds, namely that the concessions tended to benefit higher-income earners and resulted in spending cuts on the most needy. ${ }^{226}$ ACOSS supported the taxation of investment earnings of superannuation funds, but also called for the removal of employer tax exemptions above a certain limit. ACOSS was the interest group that was most vocal in opposition to the Superannuation Guarantee, consistently suggesting:

The extension of superannuation coverage to low income earners will not of itself reduce the inequity of the system. The Superannuation Guarantee Levy will, in effect, require low income earners to forego wage increases and to make their own contributions directly, in return for very limited or nonexistent retirement income benefits. ${ }^{227}$

It has been suggested (e.g. Weaver 2002:12) that New Zealand has well organised interest groups representing the interests of the elderly. However, these interest groups were perhaps not the most effective agents to argue on the issue of tax incentives. Groups such as Age Concern in New Zealand represented individuals who were already retired; therefore, issues such as tax incentives were less relevant as opportunities to take advantage of these had typically passed. Issues relating to the New Zealand National Superannuation surcharge were occupying greater resources of interest groups representing the elderly during the 1980s. Furthermore, interest groups, such as Age Concern were also opposed to compulsory private provision, although more from a concern that broader private provision would reduce public provision; for example, the Age Concern position is reflected in the following submission comments: 'Age Concern does not support the introduction of a compulsory contributory scheme, despite its superficial attractiveness' ${ }^{228}$

It is typically expected that interest groups will promote the interests of their stakeholders. Institutional theory suggests that institutions will respond to challenges with familiar responses before investigating alternatives that may be less aligned with the values of the institution. However, the theory also indicates that institutions adapt to their environment through a learning process. This can be seen with interest groups

226 Sydney Morning Herald, 18 April 1987, Problems persist as ACOSS seeks to shake the last great tax shelter, p22.

227 Submission SG 23 to the Senate Select Committee on Superannuation, 1992, by ACOSS.

228 Submission to the Task Force on Private Provision for Retirement by Age Concern, May 1992. New Zealand Treasury Library, access via Official Information Act. 
in Australia, where there was considerable consensus that compulsory occupational superannuation was a necessary and constructive step towards improving retirement savings.

By the time of the Task Force on Private Provision for Retirement in 1991, when Australia's policy direction was clear, New Zealand continued to argue that it was not necessary to have greater state involvement in retirement saving. Somewhat surprisingly, even some of the life insurance companies did not support the decision, with comments received such as 'MFL is generally opposed to compulsory contributions to private superannuation ${ }^{229}$ and:

$A M P$ recognises that a compulsory scheme is almost universal within the OECD countries and suspects that, in the longer term, this will be New Zealand's position too. However, there are significant dangers for the economy in seeking to introduce such a scheme in the current environment which has minimal wage growth and lacks central wage bargaining. ${ }^{230}$

There is little indication that interest groups influenced policy direction in 1988. It might be expected that interest groups representing the elderly and the life insurance industry would support occupational superannuation, particularly at the time that Australia adopted this policy, but this did not occur; the New Zealand environment did not ever appear to place significant emphasis on compulsion as a policy option. This may, in part, result from a lack of power of many of the New Zealand interest groups. This dimension is explored in greater detail in chapter ten.

Conversely, and less surprisingly, the larger life insurance and superannuation institutions in Australia supported the superannuation policies. These institutions also argued that compulsion was the most suitable option for Australia's future. However, the benefit for the superannuation industry was apparent:

The two major superannuation industry bodies, the Life Insurance Federation of Australia and the Association of Superannuation Funds of Australia, in recent years have been involved in a love-hate relationship with the Federal Government. As successive changes and reforms are introduced, LIFA and ASFA find themselves hating the complexities (and the additional 
costs) - but loving the elevation of superannuation to a preferred government policy for retirement savings. ${ }^{231}$

Many interest groups and individuals argued for retention of the tax incentives on moral or social grounds. These were arguments that were not going to find favour in the New Zealand context. They were likely to find greater acceptance in the Australian context, where there was a stronger focus on equitable outcomes. While there was a range of interest groups attempting to influence policy in both countries, with the exception of the trade union movement in Australia, most interest groups were unable to activate sufficient disciplined approaches within their institution to form a consistent and coherent argument to support their position.

\subsection{Employer Groups}

\begin{tabular}{|l|l|}
\hline \multicolumn{1}{|c|}{ New Zealand ${ }^{232}$} & \multicolumn{1}{|c|}{ Australia $^{233}$} \\
\hline $\begin{array}{l}\text { The role of the employer is largely } \\
\text { ignored. }\end{array}$ & $\begin{array}{l}\text { Officials are aware they will have } \\
\text { to consult carefully with key } \\
\text { business groups to neutralise } \\
\text { opposition. }\end{array}$ \\
\hline
\end{tabular}

In contrast with the influence of the trade union movement, employer organisations in Australia were less organised than labour organisations. This was reflected in their inability to influence the policy direction in the case study investigated, despite considerable opposition to the Superannuation Guarantee proposal. In New Zealand, employer groups (and trade unions) were also not highly organised, nor were they integrated into the government decision process.

In New Zealand in 1988, a number of submissions were received from business organisations that adopted a paternalistic approach towards the provision of retirement savings. These responses would frequently include a veiled threat that the removal of tax incentives would result in employers no longer supporting occupational superannuation. There was also the view that individuals did not make their own

231 Australian Financial Review, 28 October 1991, Convincing Australians to invest in the long term, p100.

232 Submission No 11 to the Consultative Committee on Superannuation from Knight Alexander Stenhouse, 1988. Australian Financial Review, 10 November 1987, Super industry to fight govt on tax, p5. 
decisions about whether and how much to save for their retirement: employers did. The submission from Knight Alexander Stenhouse is typical of many employer responses:

The reality is that most decisions about superannuation are made by employers. Left to themselves, many employees would make no provision for their retirement, and those who do seldom have any real idea of how much capital must be accumulated to provide a reasonable income in retirement. ${ }^{234}$

Opposition in the mid-1980s to occupational superannuation in Australia was seen through major employer groups such as the Confederation of Australian Industry (CAI), the Business Council of Australia (BCA) and the major metal employer association (the Metal Trades Industry Association). The initial absence of employer support can be seen in the case brought by the CAI to determine the issue of superannuation within productivity claims. A primary argument, which was to continue over the years ahead, was that organisations were not in a position to afford additional expenditure in relation to labour costs. The CAI argued the Superannuation Guarantee would produce adverse affects on employment, job creation, economic activity and international competitiveness.

Although much of the reported dialogue from employer groups indicated a general aversion to the provision of superannuation, there is some indication of a willingness among employers to provide superannuation coverage for employees. Nolan (1985:30) representing the CAI, claimed that the CAI supported occupational superannuation as a matter of principle, 'but only in accordance with the capacity and circumstances applying in individual companies in which such super schemes may be implemented'. On the question of occupational superannuation, Nolan claimed:

The CAI does not support the contention that productivity is available for distribution... [and] the CAI does not believe that should be utilised in the form of increased benefits to wage earners. If real long-term economic progress is to be achieved, the CAI believes that any productivity gains should be applied to increased business investment and to the creation of new employment opportunities. ${ }^{235}$

\footnotetext{
234 Submission No 11 to the Consultative Committee on Superannuation from Knight Alexander Stenhouse, 1988.

$235 \quad$ Nolan (1985:30).
} 
The BCA, in a submission to the Senate Select Committee on Superannuation, argued that there was a degree of consensus across the industry and throughout employer groups that compulsory payment was necessary. ${ }^{236}$ The Committee reported that most of the oral submissions were in favour of compulsion, with contribution levels of between nine and 12 per cent of income. ${ }^{237}$ This level of contribution would provide between 40 and 50 per cent of final salary upon retirement after 40 years.

The Australian Small Business Association argued that a compulsory levy of three per cent of salary could increase the rate of small business failure and/or lead to a reduction in employment in small businesses; a sector responsible for over 60 per cent of private sector employment. The state and territory governments were taking a similar stand, along with other organisations. More surprisingly, Aged Care Australia, an organisation representing charitable service providers, also did not support the Superannuation Guarantee, for the same reason. Perhaps for similar reasons to New Zealand, groups representing the elderly were more concerned with issues relating to those currently retired and the needs of their own institution, rather than those who were working.

\subsection{Summary}

\begin{tabular}{|c|c|}
\hline New Zealand ${ }^{238}$ & Australia $^{239}$ \\
\hline $\begin{array}{l}\text { The extreme view that Muldoon had } \\
\text { was replaced by the extreme view } \\
\text { that Douglas had. They were just } \\
\text { extreme ... they had nobody to } \\
\text { balance it out. ... When you are } \\
\text { Minister of Finance, you have the } \\
\text { power. I think that's our problem - } \\
\text { partly. So they get the power and } \\
\text { don't listen to other points of view. }\end{array}$ & $\begin{array}{l}\text { One of the differences between } \\
\text { Australia and New Zealand is that } \\
\text { they have very different trade union } \\
\text { movements, and in Australia at that } \\
\text { time there is very strong ACTU } \\
\text { leadership. So you have a whole } \\
\text { series of Accords ... Government } \\
\text { was then described as very much a } \\
\text { corporatist government, and I think } \\
\text { that simply meant that there was a } \\
\text { tendency to consult - but consult } \\
\text { within this kind of Accord style } \\
\text { framework. }\end{array}$ \\
\hline
\end{tabular}

\footnotetext{
236 Senate Select Committee on Superannuation (1992:25).

$237 \quad$ Ibid.

238 Respondent 9.

239 Respondent 19.
} 
An institutional analysis suggests that the key focus of policy development should be the influence of institutions on behaviour. What this analysis highlights is the broad influence that institutions have had in both the Australian and New Zealand environments. In particular, as also found by Steinmo (2008a:161), the analysis indicates that 'institutional structures had profound effects on shaping political strategies, outcomes and, ultimately, political preferences'.

There has been considerable debate on the impact of institutions on the policy process. At one level, the influence is self-evident; policy is driven and implemented by the state. However, as found by other researchers, the structure of the state in isolation does not explain the policy changes investigated in the thesis. Individuals within institutions clearly are a force, particularly when they have strong links to the governing institutions. What can be seen in this case study is powerful individuals (Paul Keating in Australia and Roger Douglas in New Zealand), who have provided either ideas, or support for ideas, which have been acceptable to the majority either through trade-offs or a willingness to negotiate.

Eccleston (2004) highlights the potential for political relationships to influence the state's ability to negotiate for particular outcomes. Similarly, Immergut (1992) finds it necessary to explain how state institutions influenced both who was included in policy making and 'the rules of the game' in order to explain how policy outcomes varied. Perhaps this is best seen in this case study in relation to the privileging of the trade union movement in the Australian context. The alignment of the trade unions and the government, together with the existence of established relationships and powerful actors in influential positions, resulted in an arrangement where dissenting voices were infrequently heard. This was also clearly seen in the Consultative Committee process in 1988 in New Zealand. Interview respondents advised that the committee structure was deliberately formed with like-minded 'economic rationalists' likely to provide an outcome that was acceptable to government. Submissions that were not aligned with government thinking were afforded little weight or credibility. Ultimately, even the recommendations of the Consultative Committee were dismissed in favour of the path that the New Zealand Treasury had been pursuing for a number of years. 
The importance of the mutual agreement of the ACTU and the government on this policy issue in Australia cannot be understated. The ACTU was reliant on government support to pursue the policy through the appropriate channels, while the government was reliant on the ACTU to sell the policy to its members.

As noted in chapter three, the level of influence of interest groups is, in part, facilitated by the recognition of government; inevitably some interest groups are privileged above others. The Australian context clearly demonstrates the greater power that existed in the trade union movement, through the Accord agreement and through the personal relationships that were in place. Conversely, in New Zealand, in keeping with the 'level playing field' approach, no interest groups, employer groups or industry groups were privileged.

That institutions influence individual actors is apparent. Institutions can control the levels of information of individuals and privilege certain views above others. They are also likely to have an inherent ideology, which may not be dissimilar to the actor's own world view. It may be argued that individuals create their ideas and objectives separately from the institutions from within which they operate. However, individuals select to become part of an institution. Therefore, it could be suggested that actors self-select into institutions or organisations with which they identify. Thus, rather than arguing that institutions influence individuals or individuals influence institutions, it is more likely that institutions reinforce existing norms and ideologies. This argument may have had greater relevance in the 1980s when employment mobility was less common and there were fewer opportunities for individuals with dissenting opinions to challenge the prevailing philosophy.

It is difficult to have a historical institutionalist analysis in the absence of a discussion on path dependency. As noted in chapter three, path dependency is the broad argument that historical events will influence policy decisions into the future; in other words, historic policy decisions may constrain possible future policy options. While it may appear that path dependency has greater relevance in the Australian context, with grandfathering of tax concessions and the presence of the superannuation guarantee, it is still highly relevant in the New Zealand context, as noted in the following comments from New Zealand Respondent 3: 
It's very hard to change those vested interests in the status quo. They are enormous and very hard to change. Particularly if you are playing around with people's retirement - you need to be very careful. Frankly in this area, the only way to do anything is with very big and bold measures - the partial measures end up with marginal losers here and there - as retirement is affected - and uncertainty. It's politically not sustainable.

Path dependency can also be seen in the continuation of universal superannuation in New Zealand. Since the introduction of National Superannuation in 1977, this scheme has become entrenched to the extent that no political party has been willing to suggest a significantly less generous scheme. However, the presence of National Superannuation has generated a strong platform from which governments can argue that there is no need to provide greater assistance, as the objective of "poverty alleviation' is effectively resolved.

The institutional concept of punctuated equilibrium is also of relevance in relation to institutional change in the Australian context. The change of focus among the trade union movement from a focus on wage negotiation to inclusion of broader factors, such as superannuation, was evident in the late 1970s and early 1980s. Prior to this time, unions had concentrated on more traditional wage policy, whereas subsequent to this time, a broader 'social wage' was considered. Thus, the concept of punctuated equilibrium contributes towards an explanation of the adaptation of the trade union movement to the changing environment, in order to ensure its continued significance to its members.

Reference to institutional theory suggests that interest groups may play a part in influencing the direction that a particular policy will follow. This research indicates that interest group influence was negligible in both countries, with the exception of the ACTU in Australia. However, to some extent this needs to be referenced to other factors. The impact of institutions has a strong link to the environment as both the social and economic environment create opportunities for policy reform. It is also necessary to take into account dimensions such as power balances in order to fully understand the dynamics that are involved in the policy formation process.

Institutional theory suggests that certain policy characteristics, such as the financial implications or the numbers of actors potentially affected by policy changes, may 
impact on the incentives to attempt to influence the policy. In the case of Australia, the potential for greater power within the trade union movement may have been a strong catalyst for support of occupational superannuation. The trade union movement in Australia, together with the life insurance industry, were the two institutions that were likely to derive the greatest gain from the introduction of compulsory superannuation. In relation to the tax incentive changes in Australia, these were unlikely to have either significant financial impacts or broader economic influences, contributing to an explanation of the apparent absence of strong interest in the issue by many institutions. In the New Zealand context, it may be argued that while significant numbers of individuals were affected by the removal of tax incentives for retirement savings, the majority benefited from reduced personal income tax rates, thus providing an effective trade-off for the policy. This trade-off also provided validation for why there was little discussion on future possible changes; any state support for retirement savings was likely to result in higher personal income taxes.

Eccleston's (2004) examination of tax reforms in Australia finds that the institutional structures restricted implementation of tax reform that was not aligned with broader public opinion. $^{240}$ Interview respondents in New Zealand did not suggest that institutional structures constrained implementation of reforms, despite an absence of broad public support; instead, institutional interactions combined to produce strong coalitions in support of a particular direction. Similar alliances could be seen in the Australian context, but the consensus seeking approach appeared to moderate public opposition in this case study.

An indication from the analysis over the past two chapters is that historical institutionalism may be more useful for examination of broader tax reform, rather than at a more detailed policy level. The theory provided greater utility as a framework for analysis of the environment in chapter eight. However, the analysis in this chapter, while supported by historical institutionalism, provides few significant

$240 \quad$ Eccleston (2004:74) finds institutional constraints on the capacity of the state were the key factor limiting tax reform in the late 1970s through to the mid-1980s. 
insights into the case study beyond that which might arise from a purely narrative approach.

It is also tentatively suggested at this point that the utility of historical institutionalism may be determined by the level of detail both required from the research and investigated in the research process. This comparative case study has adopted an indepth investigation of the processes of the time, taking into account individual primary source documents and input from actors of the time. Analysis over the last two chapters has found historical institutionalism effective as a framework at the highest level for structuring the interpretation, but less useful for assisting with explanation of the detail of the case study; for example, institutional theory facilitates in highlighting important contextual factors and institutional relationships, such as how the institutional arrangements of the New Zealand Treasury and the trade union movement in Australia legitimised their respective influence on the policy process. Historical institutionalism also facilitated with highlighting the four explanatory variables as outlined over chapters eight to eleven. Perhaps if the research output was to conclude at a higher level, such as the level of institutions, then institutional theory would be of greater service. However, this research analyses policy development at a detailed level, which appears to challenge the utility of historical institutionalism. It may be that the key analytical components of historical institutionalism, such as path dependency, do not provide for sufficient focus on the critically important detailed interactions found in this comparative case study; instead, the components provide greater utility for analysis of the policy 'process' in the more traditional sense, that is, at a higher level.

The potential for certain options to be successfully implemented in each country was certainly either facilitated or constrained by the extant institutional arrangements. However, institutions alone do not offer an informed understanding of the reasons why New Zealand and Australia adopted such different policy responses to similar policy problems. It may be that in the context of this analysis, institutions are best thought of as what Hall (1992:109) terms 'critical mediating variables'; that is, they do not replace other concepts (such as power and ideas), but they can influence these concepts or potentially limit their outcomes. The two dimensions of power and ideas are explored in chapters ten and eleven respectively. 


\section{Chapter 10: Power}

\subsection{Introduction}

Chapters eight and nine introduced the environmental factors and institutional arrangements that are relevant in the analysis of this comparative case study. This chapter explores the third dimension: power. Power is a significant theme within historical institutionalism. Both institutional structures and power dynamics contribute to determining those interests that will be heard in the policy process. Furthermore, the existence or absence of power can impact on resource allocation which, in turn, can privilege one institution over another.

This chapter examines the impact of individual and institutional power in the policy formation process and the extent to which power arrangements allowed interested groups to influence the policy direction. The chapter starts with consideration of power within the two most influential institutions: the trade union movement and the Treasury. It then investigates the power of two key individuals, Roger Douglas and Paul Keating, before examining the relationships between the institutions and these individuals and how they influenced the power dynamics in this case study. The chapter also investigates the extent to which the concerns of other interest groups, such as employer organisations and the life insurance and superannuation industry, were considered in the decision making process. Finally, the chapter considers some of the outcomes of these unique power arrangements.

It is not the place of this thesis to enter into a discussion on the possible theoretical approaches to power. However, it is important to acknowledge the dimension of power that forms the basis for the discussion in this chapter. The concept of power in this research is not the elitist model, which suggests power is concentrated within a few institutions or individuals who will use this to their own advantage. While the elitist model suggests that there are 'those at the top with power and the "mass" without power' (Parsons 1995:248), the democratic environments of New Zealand and Australia and the presence of interest groups allow for a broader power base. Power, in this context, refers to the power of individual actors within institutions, and institutions that have the ability to influence policy direction. 
It is important to acknowledge firstly the structural factors in both countries that impacted on the power arrangements. The power within the New Zealand environment was, at least in part, facilitated by the unitary state and unicameral parliamentary structure. As observed by Australian Respondent 31 'in those days if the government wanted to do something they could do it, in New Zealand'. However, in Australia, the federal state and bicameral parliamentary structure may have limited the potential options that could be followed. ${ }^{241}$ Australian Respondent 31 advised that:

Quite apart from the Accord between the Labor government and the trade union movement - so that meant a negotiation - you had the Senate in which the government certainly did not have control. ... So you could not crash through with radical deregulatory economic policy programs in Australia; certainly not as easily as you could in New Zealand.

With Australia's bicameral system of government and the presence of an upper house to act as a further point of scrutiny for policy proposals made by the government in the House of Representatives, the potential existed for the Senate to delay decision making and the implementation of new legislation. These institutional arrangements resulted in different abilities to implement policy changes in the two countries.

In addition, New Zealand had a first-past-the-post voting system until 1996, which facilitated rapid changes and the introduction of radical policy. Conversely, the bicameral structure in Australia resulted in a slower pace of reform. As noted by Respondent 27 'everything in Australia was like a pale shadow of ... New Zealand'. However, the more critical economic situation was not necessarily seen as a constraining factor with Respondent 27 stating 'I think the main thing in New Zealand was a bigger crisis and therefore more political scope to do something and then a totally different political environment - very few checks and balances'.

241 In addition, as mentioned in chapter seven, Australia had a different constitutional framework, which limited the possible options for retirement income policy reform. 


\subsection{Unions}

\begin{tabular}{|l|l|}
\hline \multicolumn{1}{|c|}{ New Zealand ${ }^{242}$} & \multicolumn{2}{|c|}{ Australia ${ }^{243}$} \\
\hline The principal focus, although not & $\begin{array}{l}\text { Super was the one that we } \\
\text { the unanimous focus of unions, } \\
\text { understood also could funda- } \\
\text { became protecting New Zealand } \\
\text { Superannuation. }\end{array}$ \\
\hline
\end{tabular}

Institutional theory suggests that institutions that are supportive of the government's direction are likely to have greater involvement in the policy process. This can be seen in the Australian context, with the inclusion of the trade union movement not only in retirement savings policy, but also in broader economic and social policy. The influence of the unions in the environment of the time was explained by Respondent 24:

The unions were powerful in the past; so it depends what time period you are talking about. If we are in the ' 82 to '92 period, there is no doubt at all that they were very influential. More than just influential, they were centrally engaged in the conduct of economic policy with the Hawke/Keating government, because of the Prices and Incomes Accord, ... and it was through the Accord that the government would negotiate things like wage settlements, tax scales and superannuation. All of these things were negotiated all the way through that decade with the ACTU. They were not policy on high from government; they were always developed with the ACTU.

... There was a real social partnership between government and unions.

The unions had been interested in including superannuation as a negotiating tool for their members for many years. Historically, it was viewed as the privilege of whitecollar and management workers. When discussing the origin of occupational superannuation funds, Respondent 20 described the union position as raising what 'were really fundamental class issues in a sense; control and whose money was it'.

It was reported that the Australian Council of Trade Unions (ACTU) was strongly opposed to the federal government's proposals to tax lump sum superannuation payments in $1983 .^{244}$ Industrial action was threatened as a result of the proposed changes, with the Miners' Federation threatening a campaign of action by mining unions unless changes were made to the tax thresholds on lump sum superannuation

\footnotetext{
$242 \quad$ Respondent 5.

$243 \quad$ Respondent 20.

244 Australian Financial Review, 27 June 1983, Unions, employers to seek tax offsets, p7. The CAI was also opposed to this proposal.
} 
payments. ${ }^{245}$ While significant changes were not made as a result of the opposition, grandfathering of existing arrangements mitigated some of the resistance.

In an apparent change of position, there was greater acceptance by the unions of the changes to the taxation of retirement savings in the late $1980 \mathrm{~s}$, with an acknowledgement by the unions that the tax concessions were generous. This, acceptance was at least partially due to the composition of the union association; as noted by Respondent 20: 'we were not unhappy because at the time our people weren't getting big lump sums anyway'. Thus, union interest was diminished as union members were not among those gaining greatest advantage from substantial tax preferred lump sum payments.

At one level, the field of retirement savings policy appeared to be a coordinated and consensus seeking approach between the government and the unions. However, there is some indication that the trade unions were the key actors in driving elements of the scheme. A number of interview participants suggested that this was the case; for example, in relation to the Superannuation Guarantee, Respondent 20 advised:

You don't have the government saying we are going to make a decision; you have a government saying we are prepared to support a wage increase, if it's applied to superannuation. What I'm saying to you is behind closed doors it was the trade union movement saying - we want you to support it on this basis only - so we can argue that we are prepared to accept it.

Another crucial factor in this environment was the cohesive approach of the unions. This approach was less apparent in New Zealand, with Respondent 16 noting in relation to the New Zealand unions that 'they weren't totally united'. This cohesive approach, combined with the ability to effectively organise activity, appeared to increase the power of the Australian unions. Australian Respondent 20 suggested:

I think we all had the same social view of the world and how it was and where we should go. And it was a big issue. Super was a big issue ... because we were also talking about ownership - and ownership meant that the trade union movement and ordinary working people would have a stake in making decisions about where future investment capital would go and how it would be employed.

Similarly Australian Respondent 30 commented:

$245 \quad$ Australian Financial Review, 3 August 1983, Miners' Federation promises Government a fight over super tax, p7. 
Certainly the ACTU was united. There was no question about that. I had an incredibly supportive environment in the ACTU and we had a lot of people around us who were wanting to support the campaign: that was true. So from our point of view, it was very united. A lot of the unions were in a mood to accept a bit of leadership on that issue at least. I think they felt it was a bit outside their normal territory - so they were very happy to have a bit of central coordination and to do things in that way.

A factor that may have resulted in New Zealand trade unions adopting a different approach from their Australian counterparts was the potential threat to New Zealand Superannuation. New Zealand Respondent 5 advised: 'of course the hot issue of the time was the surcharge - and the "you lied to us, you said you wouldn't change National Super" - so in the superannuation row there was so much focus on that really'. Respondent 5 also advised that while New Zealand unions:

had influence on some areas of policy making... superannuation was outside of that core area. It was seen as being fiscal policy - and they didn't have influence with Douglas. ... Those that had super thought that they could keep it - and they probably could. Those that didn't have it didn't have the mechanisms to try to have influence.

Similarly, New Zealand Respondent 3 commented:

The trade unions, strangely enough were not involved at all here. We didn't talk to them - partly because superannuation in New Zealand, particularly at that time, was something that was not available to trade union members. It was for the bosses. There were exceptions ... but the trade union movement wasn't interested much, or involved much.

Very different approaches can be seen in the trade union movements in the two countries. In Australia, the trade unions had a position at the negotiating table with the government and were actively pursuing policy to ensure their members had access to the privileges that management employees were provided with. In New Zealand, the trade unions appeared less interested in extending the breadth of their industrial relationship. The Australian situation is captured by Respondent 30 who commented:

Union power is absolutely enshrined by a system that said; you are part of the system - there is arbitration - there is social intervention in the public interest for those who have not had things sorted out by collective bargaining and relative power (bargaining power).

Institutional theory suggests that structures within policy making institutions can impact on the degree of power that actors will have in the policy development process. In Australia, the power of the trade union movement was, to some extent, a reflection of historical power and existing relationships with influential individuals. 
This can be seen with the privileging of the Australian trade union movement in relation to the issue of retirement savings and the taxation of retirement savings. In New Zealand, the absence of power was both a historical component and a structural weakness. The union movement in New Zealand was less cohesive, lacking a strong peak body as in Australia, which contributed to the disjointed and less influential approach to the policy direction than was seen in Australia.

\subsection{The Treasury}

\begin{tabular}{|l|l|}
\hline \multicolumn{1}{|c|}{ New Zealand ${ }^{246}$} & \multicolumn{1}{|c|}{ Australia 247} \\
\hline The essential difference is that the & We had very good access to \\
New Zealand Treasury was & Treasury during that period, but \\
authorised, not formally perhaps & they were largely by-passed in all \\
but at least informally authorised, & this, certainly in terms of Treasury \\
by the New Zealand government to & policy - it was seen as just such a \\
be the principal policy adviser on a & huge macro political deal really, \\
whole range of areas that were & which it was. It was crucial to \\
right outside the competence of a & getting the ACTU on side about \\
Treasury in most places, in most & wage restraint and then protecting \\
countries, in most times. & the ACTU from the ire of their \\
& members for providing that wage \\
& restraint. \\
\hline
\end{tabular}

Historical institutionalism suggests that power is unevenly distributed across interest groups. Perhaps this is most clearly seen in the case of the New Zealand Treasury. The Australian Treasury was a significantly reduced actor in the Australian context at this time when compared to their New Zealand counterparts. This is captured in the following comments on the Australian Treasury by Respondent 31: 'it was not as powerful as the New Zealand Treasury was. It hadn't been given quite the same licence by government to effectively determine policy so broadly across government'.

This perspective on the perceived power of the New Zealand Treasury was common in Australia and supported by the media:

The rise of the free market philosophy has as much to do with economists as it has with economics. In particular, it is tied to a small group of economists in New Zealand Treasury whose work has greatly influenced this country's decision to abandon decades of industry protection and government intervention. It is about the lack of departmental opposition to the advice offered by Treasury to the Government, a scarcity of competing advice from

\footnotetext{
$246 \quad$ Respondent 31.

$247 \quad$ Respondent 32.
} 
other sources, and Treasury's relationship with two strong ministers of finance. $^{248}$

One outcome of the power structure in New Zealand was that it facilitated imposition of policy with little meaningful consultation. Perhaps the best example is in relation to the decision to remove tax incentives; archival documents indicate this decision was made some years prior to its announcement and long before the consultative process commenced. The consultation and committee procedures therefore seemed to exist only for the purposes of appearance, rather than substance. This suggestion is supported by both archival records and interviews in New Zealand, such as the New Zealand Treasury Budget Report No 12, which notes that:

At a meeting with Treasury officials on 30 January 1986, you indicated broad agreement that the objective of the current reviews of superannuation and life insurance should be to achieve, at the end of an appropriate transitional path, a taxed/taxed/exempt regime for all superannuation and life insurance. In essence this involves removing all existing taxation concessions for superannuation and life insurance. ${ }^{249}$

It also appears that the lack of consultation prior to the announcement of the Consultative Committee on Superannuation, Life Insurance and Related Areas (the Consultative Committee) originated from a Treasury recommendation. As noted in Treasury Budget Report No 2:

A constructive dialogue on the issues involved is not likely to eventuate until the benefits of the reform are seen to be tangible. Experience here and overseas suggests that publication of such a document is likely to galvanise opposition to reform in the absence of a very clear and firm public policy statement which establishes the Government's end-point and the parameters for any consultations. ${ }^{250}$

Some months later, a further New Zealand Treasury document was issued noting: 'the Minister agreed that the desirable end-point was a neutral income tax regime for superannuation and life insurance. The Minister was convinced that this should be done on both efficiency and equity grounds ${ }^{, 251}$ That the Treasury concurred with this

248 Australian Financial Review, 4 December 1991, Why NZ toes a single line in economics, p12.

249 Budget Report No 12, 27 March 1986. New Zealand Archives reference AALR, 873, W4446, 631, Record 76/2/22 Part 1.

Budget Report No 2, 4 December 1985. New Zealand Archives reference AALR, 873, W4446, 631, Record 76/2/22 Part 1.

251 Internal New Zealand Treasury correspondence, 11 April 1986. New Zealand Archives reference AALR, 873, W4446, 631, Record 76/2/22 Part 1. However, there is evidence that 
view was also apparent, taking the position that 'our conclusion is that tax preferences for superannuation and life insurance cannot be justified on economic, social or other grounds. We support a tax reform programme, which would remove the preferential tax status of superannuation funds and life offices...' ${ }^{252}$

Very different levels of input and influence can be seen in the Australian context. At the outset, the Australian Treasury did not support compulsory occupational superannuation. However, Respondent 31 advised that they quickly adapted to the idea:

Even before then, before the Superannuation Guarantee, there had been quite a significant increase in the occupational coverage of superannuation. But, this was the next step and, as I say, Treasury was initially not terribly supportive of it. Maybe, at best you could probably say they were a little ambivalent about it; but, quickly became converts. I don't know at what point you would say the Treasury became strong supporters of the Superannuation Guarantee, but it wouldn't have been that long after Keating came up with the idea. Anyway, it didn't originate here - that's for sure. There was a bit of resistance - I guess philosophical resistance to the concept of compelling employers to make this sort of provision on behalf of their employees. It sounded a bit like centralised wage fixing, which both we and the Treasurer were moving well away from.

Conversely, the New Zealand Treasury appeared unlikely to be persuaded of the potential benefits of compulsory superannuation; for example, New Zealand Respondent 16 noted that in relation to compulsory occupational superannuation:

There were one or two who started to talk about it, but it was not really anything that was driven and it was not something that Treasury was asked to work on, or wanted to work on probably. A lot of them are not in favour of compulsory super.

As with the trade union movement in Australia, the New Zealand Treasury was highly influential in the policy development for retirement savings and retirement savings taxation over this period. While the relationship between the government and the trade unions in Australia was clearly mutually beneficial, the power of the New

other options were considered. Cabinet Memo CM 85/4/13, February 1985, sets out major options for reducing expenditure on National Superannuation. These options include reducing the rates of payment, restricting eligibility or introducing a contributory scheme to supplement taxpayer funded income-support arrangements. New Zealand Archives reference AALR, 873, W5427, 882, Record 52/479/15, Part 6. 
Zealand Treasury appeared to result from an alignment with the prevailing government philosophy.

\subsection{Roger Douglas and Paul Keating}

\begin{tabular}{|c|c|}
\hline New Zealand ${ }^{253}$ & Australia $^{254}$ \\
\hline $\begin{array}{l}\text { The Minister, Roger Douglas, } \\
\text { basically wanted to control the } \\
\text { process and to be fair I didn't think } \\
\text { he had a lot of time to do a lot of } \\
\text { change, so he didn't want to be } \\
\text { mucked around with bureaucratic } \\
\text { nonsense. }\end{array}$ & $\begin{array}{l}\text { So, on a lot of the big policy issues } \\
\text { in the 1980s, Treasury's power } \\
\text { rested on Keating's personal power } \\
\text { and influence in the Cabinet. If he } \\
\text { wasn't interested in the topic, it } \\
\text { didn't happen. No matter how } \\
\text { energetic we were, or the Treasury } \\
\text { people were, no matter how } \\
\text { vigorously they fought something, } \\
\text { no matter how passionately they felt } \\
\text { about something - it wasn't going } \\
\text { to happen. }\end{array}$ \\
\hline
\end{tabular}

As noted by Steinmo, Thelen and Longstreth (1992:10), a focus on institutional features provides 'the theoretical bridge between "men who make history" and the “circumstances" under which they are able to do so'. The power of individual actors in this case study is critical. The most influential individual in the New Zealand context was Roger Douglas; there can be no question that without his support the New Zealand policy direction would not have been adopted at that time.

The power of Roger Douglas (and the New Zealand Treasury) can be seen in the Consultative Committee process. It was suggested during interviews that individuals on the committee were selected based on known perspectives and there was some expectation of what the outcome of the committee process was going to be. On this issue New Zealand Respondent 3 advised:

The committee's membership is not decided on a random basis. You are careful who you appoint and you don't appoint people violently opposed to your government policy to a committee like that. The three of us were the majority of the committee the government could rely on. Not because there was any deal done - but because the minister was confident that we would be sympathetic to the policy.

\footnotetext{
$253 \quad$ Respondent 8.

$254 \quad$ Respondent 31.
} 
However, the Consultative Committee did reach the point in their analysis where they suggested that there may be a case for retaining separate tax treatment for superannuation and life insurance, but this option was dismissed by Roger Douglas. New Zealand Respondent 11 advised that when the Consultative Committee suggested to the Minister of Finance that the committee was:

not at all convinced that TTE was the right model for a structured savings regime and because we had, all of us, a very good personal relationship with Roger Douglas, we went to him and said that we were minded to recommended the alternative... and after what we thought were pretty thoughtful exchanges, Roger said that he was not at all persuaded that we were right about that and we were going to stick with TTE.

Respondent 11 continued:

We said - fine - we will produce the report in two parts on the basis that we know what you are going to say, so we will do our best in respect of TTE and so we wrote the report in two parts, knowing perfectly well before it was even presented to him which part was more important. And I think we drafted the legislation at that point, on the basis that we knew what the answer was.

Although not apparent from documentation of the time, it is likely that the preference for a TTE scheme over the suggested ETT alternative was due to financial imperatives. The selection of a TTE regime ensured immediate fiscal benefits from the changes.

The influence of Roger Douglas, together with the New Zealand Treasury, is also seen in the political management of the Consultative Committee process, which was specifically aimed at implementation and transitional issues, rather than encouraging debate on the issue of tax incentives. As commented by Respondent 3:

Our job was not to assess or relitigate the underlying policy - it was to assess submissions on how to implement that policy. So we were not to write a report on actually saying - removing superannuation tax concessions was a bad idea. But, in fact I think ... we were all economic rationalists - and were convinced that it should go. The arguments for concessions per se were less than convincing, but it really wasn't the mandate of the committee. Although a committee that was strongly opposed to it may have been problematic - but we all thought that they should go.

The Consultative Committee process in New Zealand in 1988 was highly politically influenced, reflecting the preferences of elites, both in the New Zealand Treasury and the government. The process effectively undermined the potential for dissenting 
views to be accepted, both through the terms of reference and through the selection of consultative committee members. ${ }^{255}$ Many submissions to the Consultative Committee commented on the absence of meaningful consultation, despite previous government statements that there would be public consultation on the issue. A submission by Geoff Rashbrooke, Fellow of the Institute of Actuaries, captures the feeling of many of the submissions:

Submissions ... seemed a waste of time; if it is a matter of making some halfbaked ideological stance work (or rather minimise the damage ensuing from it being put into effect) then the Government should be getting paid professional advice, not making a pretence at consultation when the basic decisions have already been made. ${ }^{256}$

In Australia, the primary actor supporting the Superannuation Guarantee was Paul Keating. His relationship with the trade unions is widely recognised and he was wellpositioned to influence policy direction. Respondent 31 commented:

The Superannuation Guarantee, the concept of making superannuation compulsory, was not driven by the Treasury department. Not at all. In fact, in the early days, the view of the Treasury department probably was that -I know it was - that this was not a desirable step. It was something that Keating had decided upon; influenced in part by the union movement, it's true - influenced in part by their desire to see superannuation spread right throughout the work force.

Interview participants commented on the power of the Australian Treasurer and the potential for policy suggestions to be unsuccessful if they were not aligned with his thinking. In the Australian context, Respondent 31 commented:

Here the Treasury was very powerful, but its power rested on the strength of the partnership - and it really was a partnership - the partnership with Keating. If Keating wasn't convinced of something, and he could not be convinced of the merits of something ... more than that, if he could not be relied upon to carry the case, to carry the argument in Cabinet, then it wouldn't have mattered how passionately the Treasury people felt about it it just wasn't going to happen.

255 However, it is noted that consultation of any form was a significant change in the policy process in New Zealand. Under the previous Muldoon-led National government, consultation in relation to tax policy development was unusual. 
Interview respondents also commented on the resolve of Treasurer Keating to increase equity by extending superannuation cover to a broader group of workers. Respondent 25, when discussing Paul Keating, commented:

He wasn't up there saying I believe in free market ideology, which maybe Roger Douglas did. You'd never find Paul Keating going to the HR Nicholls Society or the Centre for Independent Studies - no. He's not that - he used the market to achieve what he considered to be an economic system which would be more responsive and deliver more benefits to ordinary Australians. And where it wouldn't do that, he had absolutely no compunction in overriding it. And in the area where he felt it wouldn't do that, because of our institutional structures and because of the way he thought the system worked, was here in superannuation and retirement incomes.

Perhaps one of the key insights facilitated by historical institutionalism, which is not supported by other forms of institutional theory, such as rational choice, is that actions of individuals may not always be self-interested. This can clearly be seen in both the New Zealand and Australian situations, where the decisions made were intended to be in the public interest, rather than for political gain. It was suggested by interview respondents that neither Roger Douglas nor Paul Keating appeared to have this motivation and were not 'sold on staying in power as politicians had generally been and they decided, well, we've got to do something about this and we've got to do it drastically' ${ }^{257}$ Respondent 8 , when discussing the individuals involved in the policy direction in New Zealand, stated 'I don't think they were worried about writing history or staying in power really. They were very highly motivated about doing important things - the key players were'.

The ability to proceed with the actions necessary to implement the policy proposals necessitated a degree of power; that Roger Douglas and Paul Keating had sufficient power to do so in this context is evident. However, this analysis is not intended to imply that these two actors had autonomous power in relation to the taxation of retirement savings and retirement savings policy more generally. Constraints on the potential options existed at a number of points, particularly in Australia in the 1980s.

$257 \quad$ Respondent 29. 


\subsection{Partnerships}

\begin{tabular}{|l|l|}
\hline \multicolumn{1}{|c|}{ New Zealand ${ }^{258}$} & \multicolumn{1}{|c|}{ Australia $^{259}$} \\
\hline $\begin{array}{l}\text { Treasury believed in it on efficiency } \\
\text { grounds ... but it would never have } \\
\text { got anywhere without ministerial } \\
\text { support ... nothing wuch led by the ACTU } \\
\text { happened without both. }\end{array}$ & \\
\hline
\end{tabular}

Perhaps even more important than the individual actors in this case study are the relationships that were fostered through the time period analysed. A component of historical institutionalism is the suggestion that institutions shape political interactions, which in turn play a key role in policy development. Thus, it is important to consider these relationships in conjunction with the influence of the individual actor.

The relationship between Paul Keating as Treasurer (and Bob Hawke as Prime Minister) and the trade union movement in Australia is well documented. In particular, the relationship between Bill Kelty of the ACTU ${ }^{260}$ and Treasurer Keating is well known. It has been suggested that a significant contributing factor to the power of the unions was the relationship between Bill Kelty as ACTU Secretary and Paul Keating; for example, Olsberg (1997:101) claims that 'there was widespread acknowledgement that one-to-one negotiations between Kelty and Keating determined the direction of policy-making'. The importance of this relationship was also highlighted in a number of interviews.

The relationship between Roger Douglas (as Finance Minister) and the New Zealand Treasury is also well established. This relationship was fundamental to the success of the implementation of the retirement savings policy; the institutional arrangements facilitated implementation of the policy that was largely favoured by a small group of individuals. However, the approach was assisted by the 'package' approach that was adopted to the broad tax reform of the period. This approach may also be viewed as a

\footnotetext{
$258 \quad$ Respondent 3.

$259 \quad$ Respondent 20.

260 Bill Kelty is quoted in the media as having a 'strong personal commitment to improving conditions for low-paid workers' (Australian Financial Review, 26 April 1991, Govt may legislate to implement super, $\mathrm{p} 1)$.
} 
series of trade-offs, although it was never specifically referred to as this by interview respondents. As noted by New Zealand Respondent 6:

In the case of superannuation, there was no way you were going to persuade anybody that removing tax privileges for saving was good policy - so the chances are the consultation didn't get anywhere and the argument was well if we remove this, then we can have lower tax rates in general, which benefited everybody. ... But that, particularly in the Roger Douglas days, was what he was saying: 'do a lot and do it quickly - because if everybody is screaming then nobody can claim that they are being relatively hard done by'. And there is something in that from the point of view of political agenda and getting it through, but ultimately it is sound policy.

A significant factor in the success of the New Zealand arrangements was that both the Treasury and the Finance Minister were aligned in their thinking. As noted by New Zealand Respondent 29:

I would say that the politicians during the period you are dealing with were the people with the power to make radical change. The Treasury wouldn't have got away with what happened if they hadn't had a government like the Lange/Douglas government; that is quite fundamental - it couldn't have happened without that.

The extent of negotiation in Australia is seen in the following interview comments. Despite the media reports, which suggested union opposition to the 1988 tax changes, Australian Respondent 30 contended that support by the trade unions was provided with the understanding that government support would continue for occupational superannuation:

It is true that we then had to engage ... so when Keating started dancing around with the numbers, we obviously had to decide whether we would oppose what he was doing on tax or support it. We actually supported it, but I suppose it's a way of give and take on where he was going, and overall support for the system and all of that. ... It was more or less neutral in the longer run I suppose; so we were able to say - well we're not going to campaign against that if what we want is the government to continue to support the spread of superannuation and to come to an ultimate position on universal super.

There is also some indication that occupational superannuation continued to be driven by the trade unions, despite the external appearance that it was government driven. Australian Respondent 20 advised that while there was a combination of factors that led into the process, the united union and government approach was important, commenting:

Not to underestimate the fact that there were visionaries within the government who supported our view, but it really depended on the union movement negotiating. Because only the union movement could agree to 
aggregate wage outcomes; only the union movement could say that we agree to this process - so they had to drive it and they were the fundamental part of it. As I say - the social partnership. It couldn't be done without the social partnership.

As well as this view of a social partnership, the 'shared vision' of those in positions of influence was a crucial dimension in the policy process. As advised by Respondent 30:

The ACTU was at the height of its power. The 80s was really, with Kelty coming to the Secretaryship and Hawke (his former boss) as Prime Minister, and Keating, who took a shine to the ACTU; so that was a pretty helpful environment. You could actually talk to people and expect them to at least share your vision a bit. I think that was absolutely important. But, as I said too, because the issue was such a great thing to campaign on, you could bring allies on side. If it was a different issue, you wouldn't have got the same interesting and active and energetic people to say let's get on board.

What can be seen from the discussion above is the unique coalitions formed in each country, combining intellectual and human resources to support very different policy proposals. In New Zealand, the Treasury proved to be a strong partner for Roger Douglas's economically rational approach, while in Australia the trade unions found a sympathetic and powerful ally in Paul Keating.

\subsection{The Industry}

\begin{tabular}{|l|l|}
\hline \multicolumn{1}{|c|}{ New Zealand ${ }^{261}$} & \multicolumn{1}{|c|}{ Australia $^{262}$} \\
\hline I had meetings with Treasury where & Well all the life offices were pretty \\
I very strongly said - look this is & interested. They had a lot of \\
what we should do, and this is a & existing superannuation business, \\
way we could go and they were not & which potentially was going to be at \\
prepared to listen. There was never & risk, so I think initially it was - hey \\
any change of direction. & $\begin{array}{l}\text { this is a new significant market } \\
\text { growing, let's try to position } \\
\text { ourselves to get part of the new } \\
\text { market. }\end{array}$ \\
\hline
\end{tabular}

The life insurance and superannuation industry in New Zealand had little influence over policy direction. While submissions were made, both to the Caucus Committee on Taxation of Life Offices and Building Societies in 1982 and to the Consultative Committee in 1988, they appeared to carry little persuasive power, as noted by New Zealand Respondent 11:

\begin{tabular}{ll}
\hline 261 & Respondent 9. \\
262 & Respondent 33.
\end{tabular}


I've got no doubt that in relation particularly to the largely life institutions, saving industry generally - they really believed what they were saying. They did. But we could not get an articulated view as to why tax subsidies to what was quite a small group of people was in the public interest.

Arguments typically raised by the industry in New Zealand were that the removal of tax incentives would result in closure of significant numbers of superannuation schemes. Positions, such as that of the Association of Superannuation Funds of New Zealand, were typical of the time:

The Government should therefore be aware that any added tax burden without significant relaxation of deductions may well result in many funds terminating their activities. The resulting impact on the individual members would inevitably lead to adding to other social and political pressures. ${ }^{263}$

However, there was some suggestion that the life insurance and superannuation industry did not form a significantly powerfully lobby group in relation to the removal of tax incentives in New Zealand. Respondent 3 suggested that:

The finance industry is torn anyway because they really did like Roger Douglas for other reasons (he deregulated the financial industry and so forth). That blunted their opposition - they weren't going to bring him down. A lot of things came together to make what would otherwise seem impossible, politically work.

A similar position can be seen in the following comments from Respondent 13:

You didn't worry much about managing industries in the mid-1980s. The other thing to keep in mind was that the support for this highly regulated financial sector vanished - even the old lobbyists who made their careers out of it, abandoned ship in the end. The crisis in the mid-80s was such that there really wasn't a fight; it just went and the industry lobbying groups closed down. ... I don't recall it being much of a fight at all. Nobody was able to mount an argument that it had a proper public policy purpose. They still haven't.

The difference in relationships between the government and the unions, and the government and the industry in Australia is evident in the absence of consultation in relation to the changes to the taxation of retirement savings. When asked about the level of input or consultation with the life insurance industry on the tax changes, Australian Respondent 33 advised there had been none: 'not at all. It was done totally confidentially within Treasury'. This was expanded by Australian Respondent 31 who advised that:

263 Submission to the Caucus Committee on Tax Reform, 1982. New Zealand Archives reference AALR, 873, W4446, 632, Record 76/2/54, Part 1. 
In 1988, when the biggest changes were made to superannuation; the night before the statement was issued, Keating called in, in this building, the Chief Executive of AMP and the Chief Executive of National Mutual - one after the other. And he told them what he was going to announce the next day. That was the first they knew of it - and it was the only time he spoke to them about it. So it's not that they were not involved, but that was the extent of their involvement.

The argument that was most frequently raised in relation to increased occupational superannuation was the concern that the introduction of occupational superannuation would see a significant rise in industry funds, which would then act as a device for the trade union movement to produce financial institutions to fund the Labor Party. As noted by Australian Respondent 19, there was the thinking that if you could get funds that were essentially controlled by unions or the friends of unions, then it potentially represented power'. This view was encapsulated by Australian Respondent 20:

Ownership meant that the trade union movement and ordinary working people would have a stake in making decisions about where future investment capital would go and how it would be employed ... I'd have people saying I'm from the mafia and I'm going to use the money to finance strikes - and we're all criminals, and we'll shoot through with the money. This was the sort of campaign that was being run.

The media, to some extent, assisted with this perspective, reporting in 1989 that 'the Budget's superannuation changes, which are expected to inject about $\$ 40$ billion annually into the sharemarket by 1995, will give life offices unprecedented power - in some cases de facto management of our lazier companies ${ }^{, 264}$ and:

The Treasurer, Mr Keating, has urged the trade union movement to use the billions of dollars generated by superannuation over the next 20 years to increase its own industrial clout. Mr Keating told Congress delegates that the development of union-run superannuation funds would give the union movement "institutional muscle" to supplement its already substantial industrial strength. He suggested that the additional clout could prove a potent weapon against conservative administrations intent on eroding the power of the union movement. ${ }^{265}$

Respondent 32 commented, in relation to unions and industry funds:

I think they realised at the time how much economic power it would give the union movement to have large superannuation funds at their, I won't say at their disposal because they don't directly control them - the industry funds ... but it does give the union movement much greater general economic power to have that role with the funds. 
As might be expected from the different positions adopted in each country, different responses were received to the proposals from the life insurance and superannuation industry in each country. In New Zealand, the industry had little influence on the policy process. Similarly, the industry in Australia also had little power; this is perhaps best demonstrated by the manner in which they were advised of the tax changes in 1988. In both countries, the groups appeared to be unwilling or unable to challenge the issue in a united manner, or through effective channels, which might have increased their power base.

\subsection{Interest Groups and Employer Organisations}

\begin{tabular}{|l|l|}
\hline \multicolumn{1}{|c|}{ New Zealand } & \multicolumn{1}{|c|}{ Australia } \\
\hline This was a government that said to & We were closely involved in it - \\
interest groups - go away, all you & protesting all the way and \\
want is assistance and we're not & encountered very virulent criticism \\
open for business. That business is & from the ACTU. \\
how we got ourselves into a terrible & \\
muddle. We were unusually & \\
unreceptive to special interests. & \\
\hline
\end{tabular}

It is apparent that, in the decade investigated, interest groups had little influence on policy in relation to retirement savings and retirement savings taxation in either country. In the New Zealand context, Respondent 8 commented:

I didn't meet too many pressure groups in my time at all. The Minister dealt with some of them and met with them sometimes, but if you were just sort of complaining because you were adversely affected you didn't get far in those days.

The seriousness of the economic situation in New Zealand again came to light in the context of the influence of interest groups. Respondent 12 commented that all interest groups were affected:

They were very loud and very noisy, but change moved on at such a pace... that quite frequently what was the issue of the Public Service Association yesterday had been overtaken by another issue today and - the government's over there tomorrow. So, staging a major fight back by any of the interest groups against change became almost impossible.

\footnotetext{
$266 \quad$ Respondent 10.

267 Respondent 32.
} 
In a similar manner to industry groups, a number of employers suggested in the mid1980s that removal of deductibility of the company contributions for tax purposes would result in companies reassessing the viability of their occupational pension plans. A number of organisations suggested that any increased costs would be passed on to members, benefits would be reduced or schemes would be discontinued. ${ }^{268} 269$ This possibility was not addressed in government or New Zealand Treasury documentation.

The apparent lack of interest group influence on policy development was unchanged throughout the decade investigated. Respondent 15 commented on the Task Force on Private Provision consultation process in 1992:

We certainly picked up comments and observations along the way, but the process itself was not a hugely important part of it - not as it had been, for example, with GST where we had very substantial submissions and the legislation was changed quite radically in many ways to reflect those submissions.

In Australia, interest groups were having a similar level of influence, although they were more involved in the process, if not the outcome, than their New Zealand counterparts. The fact that the elderly population was becoming more militant in their approach to retirement policy was notable in Australia. As reported in the Australian media:

The political trends of grey power mean the aged have clout and their organisers are becoming significant political figures. The greying of Australia has presented the Federal Government with a major dilemma how to design a Budget strategy that will meet the rising aspirations of the aged, neutralise their growing political militancy and satisfy the other conflicting demands on Federal funds, such as tax cuts for the general community. The heart of the dilemma is that the old are becoming more

For example, correspondence to Associate Minister of Finance David Caygill from Westpac in May 1985, from Brierley Investments in June 1985, from Shell New Zealand in July 1985, from Sonata Laboratories in October 1985 and correspondence from the Association of Superannuation Funds of New Zealand to Finance Minister Roger Douglas in July 1985. New Zealand Archives reference AALR, 873, W4446, 632, Record 76/2/54 Part 8. wound up during 1988 (compared with 300 in 1987). Life Offices' Association of New Zealand survey reported in the New Zealand Herald, 2 March 1989, Many super schemes falling by wayside, p1. 
numerous, more vocal and better organised. They are rapidly becoming, if they are not already, an important political force on a new level. ${ }^{270}$

These acknowledgements of the potential power of organised elderly voters may have contributed to the absence of proposed radical reforms to retirement savings policy in Australia.

This was not a difficulty seen in New Zealand, although the same issues with the ageing population existed. The key organisation representing the elderly in New Zealand was Grey Power. The Consultative Committee observed that 'some 22 per cent of all voters are currently entitled to National Superannuation and any reduction in that benefit is therefore liable to trigger a significant political backlash' (Consultative Committee on Superannuation, Life Insurance and Related Areas 1988:12). However, the proposed changes were to the tax incentives, and had a greater impact on the current working population; they had little impact on retired individuals who were already receiving pensions or superannuation. Grey Power was most notable for its protests against the surcharge on superannuation, introduced by the Labour government in 1984. As noted by Respondent 3:

Grey Power or Age Concern - or whatever those groups were - were mainly focused on the surtax - and the interests of pensioners. The big issue was the public service pension. But they got a windfall gain - not vast amounts, but they used to get a taxable pension and now they got a tax-free pension reduced by less than the tax that they paid - so they got an increase. So they weren't complaining.

As in New Zealand, employer groups in Australia did not protest loudly at the introduction of Award Superannuation in the mid-1980s or the tax changes in Australia in the late 1980s. As noted by Australian Respondent 18 'from the point of view of employers, three per cent as wages or three per cent as super - what's the difference'. However, this position was to change over the next three years. With the announcement of the Superannuation Guarantee, debates commenced in Australia as to which 'group' would be absorbing the increased costs associated with the Superannuation Guarantee: employers or employees. Threats were made of potential

$270 \quad$ Australian Financial Review, 4 June 1982, The politics of grey power, p27. 
job losses of up to 100,000 positions. ${ }^{271}$ Another view of the employer perspective was provided by Respondent 22:

The only people who were reticent about it were the small business operators because the system required employee contributions and employer contributions and the employers didn't mount a fairly big campaign; I mean they would say that about everything that ever happens. Employers oppose every national wage case practically - so it was a script.

While there appeared to be little power and influence among New Zealand employer organisations, the ability of the Australian employer organisations to unite on issues was apparent. It was reported in the Australian media that:

Australia's biggest industry and business groups have formed a powerful coalition to counter the ACTU's influence on the Hawke Government. The "Big Seven" aim to present a united front at the next national wage case in September. They want to ensure a "responsible" wages outcome linked with productivity improvements. They also want greater freedom for enterprises to negotiate wage deals under certified agreements and will oppose the proposed three per cent superannuation increase unless it comes out of workers' wages. The coalition of industry groups ... represents a major new element in the federal political equation and reflects business's worsening relations with the Hawke Government. ${ }^{272}$

Despite this apparent ability to form a united front on the issue, employer organisations were unable to make significant changes to the proposed policy. ${ }^{273}$

271 Submission 15 to the Senate Select Committee on Superannuation 1992 from the CAI, quoting Australian Treasury estimates.

272 The 'big seven' referred to are the BCA, the CAI, the Australian Mining Industry Council, the National Farmers' Federation, the Australian Chamber of Commerce, the Metal Trades Industry Association and the Australian Chamber of Manufactures'. Reported in the Sun Herald, 24 June 1990, 'Big Seven' warn Hawke, p3.

Some small concessions were made, such as the compromise on the issue of the tax-free threshold, with an agreement to tax the first A\$50,000 of lump sum superannuation payments at 15 per cent for people retiring over the age of 55. Australian Financial Review, 8 August 1983, Super tax pullback, p1. 


\subsection{Summary}

\begin{tabular}{|c|c|}
\hline New Zealand ${ }^{274}$ & Australia $^{275}$ \\
\hline $\begin{array}{l}\text { It was quite a different society to } \\
\text { what we have now. We didn't really } \\
\text { consult with people much - we just } \\
\text { announced things. }\end{array}$ & $\begin{array}{l}\text { There was ... a certain amount of } \\
\text { opposition, but it was opposition } \\
\text { that the Labor government felt quite } \\
\text { able to ignore. }\end{array}$ \\
\hline
\end{tabular}

In both the New Zealand and Australian contexts, there was little effective opposition to the policy changes in the 1982 to 1992 period. It is not intended to imply that opposition did not exist; rather the power structures in place left those with dissenting opinions from the prevailing ideas with little opportunity to influence the policy direction. As noted in the New Zealand context, 'lobby groups have lost their power under a government which, devoted to an ideal of levelling the economic playing field and giving no favours to any particular industries or regions, simply refuses to listen to them ${ }^{, 276}$ and:

More significantly for the future of the country, the success lies in the fact that there has been no effective opposition to Rogernomics, from the left of the labour party, from the wets of the National Party, from the trade union movement, from industry lobby groups, or anywhere else. ${ }^{277}$

There is clear evidence in both countries of the privileging of certain institutions above others in this comparative case study. In relation to the taxation of retirement savings in New Zealand, interest groups were not supportive of the direction of the government and had little impact on the outcome. In Australia, interest groups that were aligned with the government direction had their voices heard; interest groups that were not, such as employer organisations or the life insurance and superannuation industry, had little influence on the policy outcome.

As mentioned in chapter three, Skocpol (1992) suggests that policy success may be linked to an alignment between government institutions and the organisational capacities of interest groups wishing to influence policy. This is evident in the Australian context, where the highly organised trade union movement had greater

\footnotetext{
$274 \quad$ Respondent 3.

275 Respondent 18.

276 Australian Financial Review, 13 August 1987, Kiwis infatuated by TINA [There Is No Alternative], p10. 
influence on the policy process than any other group. Other interest groups did not display similar levels of cohesiveness or have an agreed world view from which to pursue their preferences.

Historical institutionalism suggests that individuals are limited by the boundaries of the institution from within which they operate. However, the boundaries of the key institutions in this analysis did not appear to limit the influence of individuals, rather they facilitated the powerful coalitions that were formed. That the New Zealand Treasury had significant power and influence on this element of policy is clear. Similarly, that the trade union movement in Australia had considerable influence with government is also evident. It is necessary to highlight the privileged position afforded to these two institutions. Other institutions that may have been powerful in other policy areas had little influence on the topic of retirement savings and taxation, at least partially because their position was not supportive of the government.

An important difference in the New Zealand context was that politicians and bureaucrats had successfully convinced the population of the need for radical reform. Furthermore, certain individuals had widespread community support, as noted by Respondent 8: 'the Douglas period was exceptional in the sense that there was a general view in the community that what Douglas was doing was good...'. This convergence in elite opinion and mass opinion was a key factor in legitimising the power arrangements in the New Zealand context.

The issue of potential conflict was confronted by the dilution of interest group power. A number of comments were received that the New Zealand approach was designed so that there were shared benefits and losses. Workers received cuts in personal tax rates, companies received tax rate reductions and pensioners also received windfall gains. Therefore, while concessions were being removed from industries and individuals, those most likely to be financially worse off from the removal of the tax incentives in New Zealand were those who were taking the greatest advantage of the system. This was suggested by Respondent 3 to be the 'everyone's a winner' approach:

That bought in the money up front, but also because we made everybody's pension schemes tax free and let the funds adjust (gave the power to adjust the pensions) - we gave windfall gains to pensioners. And therefore we 
suddenly had a support block for it - which was the pensioners. And the government got money and it had a support block for the change. Politically that worked. No one ever thought of doing it before - it was quite outrageous.

The 'package' approach to reform implementation in the 1980s proved to be effective on a number of counts. Perhaps the most significant was in the way it tempered the input of pressure groups to the debate. As found by New Zealand Respondent 16 when discussing the trade unions:

A lot of them, particularly those who were close to the Labour Party were bitterly opposed to a lot of what we were doing, so they tended to be our biggest critics. On the other hand, they couldn't fight us on all fronts, so to some extent at least, they had to choose where they would take the battle on; so GST, more than anything else, became a focal point for their annoyance, if you like.

In expectation of resistance to the suggested reforms, the New Zealand government had prepared strategies to counter arguments against the proposed direction. Conversely, the Australian approach was to galvanise support from institutions likely to gain from the proposals, and to use this to offset the small amount of opposition that did eventuate.

Similar levels of manoeuvring potential public resistance can be seen in Australia. There is some indication that the tax changes initially proposed in 1988 were likely to have been less accepted by the population. Australian Respondent 33 advised that 'the original plan was to have a 20 per cent tax rather than 15 per cent - and not to reduce the tax at the end'. When asked why this option was not implemented, Respondent 33 replied:

The political saleability - that would have then been criticised by everyone outside the government because it would have been a reduction in everyone's benefits. Whereas the approach they ended up with - the 15 per cent bring forward - with a 15 per cent reduction at the end means they were able to run the line that the changes weren't going to detrimentally affect any individual, it was really just a timing issue, whereas the original proposal would have adversely affected every individual.

In the New Zealand context, the New Zealand Treasury as an institution was privileged above other interest groups. As noted by interview participants, in New Zealand all interest groups were losing concessions and benefits equally, thus, placing them on similar levels. 
In many ways, the Australian approach suited the agendas of many of the different actors of the time. It suited the trade union movement's aim to assist in increasing standards of living in retirement and ensuring that individuals received some form of increase in their remuneration package; it suited the government's agenda to control wage inflation and increase national savings; and it suited the ideology of key actors of the time. As captured by Australian Respondent 30, 'it was hard fought and for a long time there were battles. But I think the simple answer is that the time had come for that issue. It was the right conjunction of circumstances'.

The power arrangements in both countries were facilitated by a combination of environmental and institutional factors (as outlined in chapters eight and nine). However, a further variable also advanced the power dynamics in both countries: the prevailing ideas. This dimension is discussed in the next chapter. 


\section{Chapter 11: Ideas}

\subsection{Introduction}

The previous three chapters have analysed the concepts of the environment, institutions and power respectively. The fourth, and final, dimension explored in this comparative case study is that of ideas. The concept of ideas is important within the context of this topic. ${ }^{278}$ While there was some dissention among interview participants as to the extent that the superannuation reforms were driven by any form of ideology, there is evidence that ideology framed many of the discussions of the time. Both similarities and differences can be seen in the prevailing ideologies in each country.

This chapter focuses on the two primary ideological concepts that were raised in each country: equity and efficiency. However, the chapter also investigates the influence of institutions in relation to the prevalent ideas and the policy objectives which resulted from this ideology in each country.

The concept of ideas is one that has had infrequent application within the historical institutional literature. ${ }^{279}$ This is not intended to indicate that historical institutionalism does not support the concept of ideas influencing policy making, but it has been suggested that historical institutionalism downplays the influence of ideas on policy making (e.g. Beland 2005). While other researchers place more emphasis on ideas (e.g. Eccleston (2007) who finds that economically grounded ideas may

278 Ideas and ideology are used interchangeably in this chapter. It is acknowledged that use of the term 'ideology' is somewhat controversial, with 'ideas' representing a more neutral implication. Reference to ideology in the thesis refers to a set of ideas or beliefs held by an individual or an institution, rather than a specific political theory. Perhaps this is best captured by Appel (2000:527), who writes 'ideology here does not imply a Marxian false consciousness but refers simply to a belief system with nothing pejorative intended'. Appel (2000:530) also refers to the 'ideological context' as 'simply a linguistic shortcut for the sum of ideas held by members of the elite and mass groups that find expression in both the political discourse and formal institutional mechanisms'. 
influence policy direction), Beland argues that historical institutionalism cannot highlight the policy ideas that influence legislative decisions. However, the adoption of a broad institutional perspective, as in this thesis, suggests that ideas are included within the broad definition of institutions, in a similar manner to the inclusion of rules and routines. Furthermore, ideas evolve from an institutional context. While historical and environmental factors may shape the evolution of ideas, they will be moulded by what is acceptable within a particular institutional environment.

Hall (1992) observed the importance of ideas in policy making, and in particular in shaping policy. Most institutions have an underlying ideology, which facilitates a 'sense making' environment for individual actors. An institutional ideology is formed from established rules and common practices, which in turn provide a framework for how institutional ideas are expressed. It is expected that institutions, such as the trade union movement, will have a strong ideology shaping their policy preferences. However, ideology is also important within state institutions and broader interest groups, facilitating a coherent institutional perspective on policy matters. Institutional theory suggests that individual actors will have some affiliation to the ideology of the institution, which in turn provides meaning for the institutional position.

An ideology oriented approach in isolation is unlikely to provide a satisfactory explanation to this case study; instead, it allows investigation of the high-level framework from which ideas are privileged. What an ideologically focused approach can also do is capture some of the interactions between variables that a focus on institutions alone may obscure.

In the time period investigated, New Zealand was following market based economic ideas. Australia was also adopting a pro-market approach, but to a lesser extent than New Zealand, particularly in relation to retirement savings policy. This balance is seen in comments from interview participants, such as that of Respondent 25 who suggested that Treasurer Keating's 'support for the market was only ever as a means to an end, and if it didn't serve that end then he wouldn't support it' and Respondent 24, who commented that in Australia 'it was sort of economic rationalism light, I would call it, compared to yours [New Zealand], which was economic rationalism heavy'. 


\subsection{Equity}

\begin{tabular}{|l|l|}
\hline New Zealand ${ }^{280}$ & \multicolumn{1}{|c|}{ Australia 281} \\
\hline Equity was never given huge & Most people didn't have access to \\
emphasis ... under my regime, & superannuation ... So there was a \\
because in effect most of the equity & view that the Treasury would have \\
considerations are pretty narrow. & shared in the early 1980s that the \\
They tend to focus on the immediate & tax concessions for superannuation \\
effect - winners and losers - no & were inequitable. \\
dynamics. And basically most of & \\
the economic concepts of equity are & \\
pretty superficial. There is no real & \\
depth. If somebody says - this isn't & \\
fair - usually it means that they & \\
didn't like it or they were adversely & \\
affected by it. & \\
\hline
\end{tabular}

Before commencing an analysis of equity, it may be helpful to outline the concept of equity that is used in the research. As observed by Holmes (2001:14), the success or failure of tax systems is linked to perceptions of equity. Typically with taxation, the concepts of horizontal and vertical equity are used. However, the concept of equity in this analysis extends to a broader 'social justice' approach; the fair distribution of advantages, disadvantages, rights and opportunities within society. The equity referred to in the research is not intended to imply an equal distribution of advantages, instead fair access to such advantages and opportunities.

The Australian reforms to the taxation of retirement savings and more general retirement savings policy throughout the 35-year period investigated had an underlying theme of equity. While greater equity was not always achieved through the changes made, it was a common thread and generated considerable debate over the 1982 to 1992 period.

\subsubsection{Equity in Australia}

There has been no shortage of historical commentary on the perceived unfairness of Australian retirement income policies. Two primary arguments have been raised in support of a focus on equity in the Australian context: access to occupational superannuation and access to tax concessions.

\begin{tabular}{ll}
\hline 280 & Respondent 8. \\
281 & Respondent 31.
\end{tabular}




\subsubsection{Access to superannuation}

The Asprey report in $1975^{282}$ was among the first reports to recognise the potential inequity in retirement savings arrangements in Australia. The report suggested that while the Australian government encourages the provision and growth of occupational superannuation through tax support for all who wish to participate, only about 35 per cent of the labour force benefit from the assistance. Furthermore, the report acknowledged that within this 35 per cent, those receiving the greatest benefit were high-income earners. A similar argument was to dominate in Australia for the next 15 years. Respondent 28 stated:

By 1981 I was knocking on the door of the Prime Minister and saying; look really, this is an area of policy that is severely under covered. We have 25 per cent of the work force in various forms of long-term retirement savings. Most of those are public servants or relatively senior executives and the vast majority - as I say, 75 per cent of the work force had no coverage at all; so about 25 per cent had some level of coverage. I saw this as not being in the interest of the nation.

By 1988, these statistics were not significantly improved, despite the implementation of Award superannuation in 1986:

The statistics show that it is the people in the most highly-paid professions who overwhelmingly benefit from superannuation. According to the statistics, three-quarters of male managers, administrators and professionals get superannuation cover but only 30 per cent of labourers and related workers get superannuation cover. ... The statistics also show that 70 per cent of people who earn more than $\$ 520$ a week get superannuation cover but that only 30 per cent of people who earn less than $\$ 440$ get superannuation cover. $^{283}$

\subsubsection{Access to concessions}

In relation to tax incentives and equity, two main arguments were raised. The first argument regarded the design of the system, where it was generally accepted that tax concessions were of greater value to high-income earners than low-income earners. This argument was that tax concessions accrued to wealthy individuals with sufficient income or assets to maintain their desired standard of living in retirement without the provision of such incentives. This argument was extended to incorporate the cost of

\footnotetext{
282 Taxation Review Committee (1975).

House of Representatives Hansard, 23 March 1988, Volume 160, p1221, Mr L Price (ALP).
} 
the tax incentives, which would reduce overall social welfare spending, impacting most significantly on low-income earners.

The second issue was the potential for manipulation of the system. As well as 'double-dipping', there was potential for creative interpretation of the rules, as found by Dr Ronald Mendelsohn: 'the cunning and resourceful can find many ways of gaining both long and short term special advantages from any form of government tax relief'. ${ }^{284}$ Furthermore, as noted by Treasurer Keating the presence of tax incentives alone was ineffective:

On the revenue side, the $\$ 2$ billion or so of assistance for occupational superannuation goes mostly to people who are neither needy nor poor and largely fails to achieve one of its principal objectives - the promotion of more effective self-provision in retirement. This is because benefits are principally being taken in the form of lump sums rather than pensions. The present tax provisions also facilitate tax avoidance arrangements under which an employee's pay is deferred so as to be taken in a lump sum termination payment at the end of his or her employment in a particular job. ${ }^{285}$

A further claim of inequity within the Australian scheme was in relation to intergenerational equity and the financing of retirement savings arrangements in Australia. Professor Keith Hancock raised the concern of inter-generational equity with the present generation financing the retirement of past workers. ${ }^{286}$ Dr Ronald Mendelsohn also raised this concern:

One generation is expected to support the previous workers, in return for an implied promise by a future working group. Of course certain expectations are built into this system. The current generation expects at least as good a treatment as it has meted out to its parents. Trouble can arise when, as at present, the next generation proves to be much larger in numbers than expected, or when prosperity declines, and with it society's capacity to maintain the living standards of the aged. ${ }^{287}$

284 Submission No 20 to the Senate Standing Committee on Community Affairs, February 1984. Dr Mendelsohn was an academic based at the Centre for Research on Federal Financial Relations, at the Australian National University, Canberra. House of Representatives Hansard, 19 May 1983, Volume 131, p805. Ministerial Statement by Mr Keating, Treasurer (ALP).

Submission No 18 to the Senate Standing Committee on Community Affairs, March 1984. Professor Hancock was Chairman of the National Superannuation Committee of Inquiry, which commenced in 1973. 
Equity concerns also contributed to the debate in Australia when the proposal was raised to tax superannuation fund earnings in 1988; again, the arguments were raised about high-income earners benefiting more than low-income earners. It was suggested that the arrangements became more inequitable for low-income earners:

Treasury proposed and the Government accepted the May 1988 action that made this situation even worse - a flat 15 per cent tax on all superannuation fund contributions and income. Now that the bottom marginal rate of tax (in the range of income from $\$ 5,100$ to $\$ 17,650$ ) has been reduced to $22.25 \mathrm{per}$ cent, the tax advantage from superannuation savings for lowest-income Australians is now negligible - only 7.25 per cent of income. This small incentive is, in many cases, eaten up by the overheads and administration charges of many superannuation funds. ${ }^{288}$

Such equity discussions have remained throughout the time period investigated in this thesis. Towards the end of the decade analysed, a similar argument was raised by the Australian Council of Social Services (ACOSS) in a submission to the Senate Select Committee on Superannuation in relation to the amount of government support that should be provided for retirement savings. ${ }^{289}$ ACOSS argued that government support should be based on need, and if people wish to save in order to maintain an above-average lifestyle retirement, it is not the Government's responsibility to subsidise this'. ACOSS argued for greater targeting of retirement savings incentives, suggesting that higher levels of benefits should go to those who would not otherwise be able to save for their retirement.

Partly as a result of these concerns, the concept of occupational superannuation developed, which was seen to potentially create a more equitable system for lowincome earners, both by extending access to occupational superannuation and reducing inequities inherent in the previous arrangements. ${ }^{290}$ Australian Respondent 31 advised:

Initially the equity concern was that all of the tax concessions were going to those who were in privileged employment positions, effectively. But, as occupational superannuation was being developed the idea that progressively the entire workforce would be in a position where they could benefit from higher retirement incomes - that became quite a powerful idea.

288 Sydney Morning Herald, 22 April 1989, Keating's task: save the savers to rescue the economy, p43.

289 Senate Select Committee on Superannuation, Super Guarantee Bills (1992:65).

290 Submission SG 29 to the Senate Select Committee on Superannuation, 1992, by the ACTU. 
The philosophies driving the policy direction were representative of the theme of various reviews of the time, such as the Cass Report, ${ }^{291}$ which highlighted four key concerns with retirement policy, all of which had equity components. Australian Respondent 21 observed that with the Cass Report 'adequacy and equity [were] one of the, if not the, key criterion ... of all our reports'.

\subsubsection{Equity in New Zealand}

It would not be a fair representation of the New Zealand situation to suggest that either the New Zealand Treasury or the politicians did not have a concern for equity. However, it is reasonable to suggest that the debate on equity adopted a significantly different form from that of Australia. As observed by New Zealand Respondent 8:
I don't know whether it comes through - but the emphasis on nearly all these policies was efficiency and we did a little bit on equity when we needed to - and particularly on the personal side - or GST - the big things. But the little micro policies - you just generally assume that there are a whole lot of changes taking place in the economy - some go this way and some go that way and they wash out.

Despite this view that equity did not play a fundamental role in the policy development, the presence of equity arguments could be seen, although these were framed differently than those in Australia. Frequently, equity arguments in New Zealand were described in the language of economic efficiency; for example, 'equity concerns are further likely to arise if the problems of bounded rationality and information costs do not impact evenly on the population' (New Zealand Treasury 1987:31).

A number of Treasury documents entered into broad discussion on equity criteria. A New Zealand Treasury Report in 1986 outlines some principles summarising a recommended approach to equity:

- efficiency-improving tax reform or policy change benefits the community as a whole by increasing the level of national income;

- such reforms produce wealth gains and losses to some individuals as a direct result of the change in relative prices which are necessary to improve resource allocation and thus increase national welfare;

- any initial losses imposed on particular individuals may be offset over time by the benefits of the policy changes; 
- not compensating losers may be the fairest approach. Losers from one tax or other policy change are likely to benefit from other changes which impose losses on other sections of society. "Rough justice" may therefore prevail if no compensation is provided in any case. $^{292}$

As in Australia, it was claimed that tax incentives were of greatest benefit to the wealthy. The Life Offices' Association in New Zealand disagreed with this assertion. It was argued that 72.3 per cent of those in employee superannuation schemes run by the two biggest companies (AMP and National Mutual) were earning less than NZ\$30,000 per annum and those who earned more than NZ\$40,000 per year made up 12 per cent of the total. ${ }^{293}$ The data supporting these claims that superannuation was not the preserve of 'middle-aged professionals' is outlined in Table 11.1. ${ }^{294}$

Table 11.1: 1988 Salary Distribution of AMP and National Mutual Superannuation Scheme Members ${ }^{295}$

\begin{tabular}{|c|c|c|}
\hline Salary (NZ\$) & Number of members & $\begin{array}{c}\% \text { of total number } \\
\text { of members }\end{array}$ \\
\hline$<15,000$ & 4,399 & 10.3 \\
\hline $15,000-20,000$ & 11,315 & 26.5 \\
\hline $20,000-25,000$ & 8,730 & 20.5 \\
\hline $25,000-30,000$ & 6,395 & 15.0 \\
\hline $30,000-35,000$ & 4,162 & 9.8 \\
\hline $35,000-40,000$ & 2,739 & 6.4 \\
\hline $40,000-50,000$ & 2,793 & 6.5 \\
\hline $50,000+$ & 2,141 & 5.0 \\
\hline Total & 42,664 & 100 \\
\hline
\end{tabular}

\footnotetext{
292 New Zealand Treasury Budget Report No 12, 27 March 1986. New Zealand Archives reference AALR, 873, W4446, 631, Record 76/2/22, Part 1. New Zealand Herald, 11 August 1989, Stability plea of retirement savings, p5. In addition, many submissions to the Consultative Committee on Superannuation, Life Insurance and Related Areas provided data to support the view that lower-income earners were the key beneficiaries of the incentives; for example, Carter Holt Harvey advised that 85 per cent of members earned less than NZ\$33,000 per annum. Submission No 87. New Zealand Archives reference AALR, 873, W5427, Box 1829, Record 76/2/54/2, Part 1B. 
Arguments were put forward by the life insurance and superannuation industry in both countries that a large number of low-income people saved through tax preferred superannuation funds. While this was correct, the focus on the number of superannuation fund members distorted the perspective. A focus on the total value of concessions received (as outlined in Table 11.2) provided a more balanced view demonstrating, for example, that less than half of the benefits were claimed by individuals earning less than NZ\$30,000 per annum. This was commented on by New Zealand Respondent 8: 'I remember there was a standard Treasury view that if you looked at who got the benefits from those things, it was the people on higher incomes. So that strengthened our efficiency arguments'.

Table 11.2 Distribution of Superannuation Tax Benefits Received from the Superannuation Contribution Personal Exemption ${ }^{296}$

\begin{tabular}{|l|l|l|}
\multicolumn{1}{|c|}{$\begin{array}{c}\text { Assessable Income Band } \\
\text { (NZ\$) }\end{array}$} & \multicolumn{1}{c|}{$\begin{array}{c}\text { Average } \\
\text { benefit (NZ\$) }\end{array}$} \\
\hline$<5000$ & 119 & 0.4 \\
\hline $5,000-9,500$ & 109 & 0.5 \\
\hline $9,500-14,000$ & 206 & 2.2 \\
\hline $14,000-16,000$ & 233 & 2.3 \\
\hline $16,000-18,000$ & 274 & 4.6 \\
\hline $18,000-20,000$ & 289 & 5.0 \\
\hline $20,000-22,000$ & 292 & 6.4 \\
\hline $22,000-25,000$ & 316 & 9.3 \\
\hline $25,000-30,000$ & 379 & 17.6 \\
\hline $30,000-40,000$ & 527 & 33.6 \\
\hline $40,000-50,000$ & 596 & 13.1 \\
\hline $50,000+$ & 594 & 5.0 \\
\hline
\end{tabular}

Equity issues were also raised in relation to tax concession funding. Robin Oliver, in an address to the Institute of Policy Studies in June 1988, commented that by providing taxation concessions of about $\$ 800$ million per annum, New Zealand governments have been spending this amount of money each year to subsidise the

296 New Zealand Treasury Budget Report No 60, 1986/87 financial year. New Zealand Archives reference AALR, 873, W4446, 631, Record 76/2/22, Part 1. 
minority of the population which has undertaken this form of savings' ${ }^{297}$ This argument supported the need to, on the one hand, create an appearance that the reforms had an equity focus and, on the other, to reduce government expenditure. ${ }^{298}$

Equity arguments continued to be used throughout this decade to support a 'level playing field' for savings in New Zealand. In 1991, the Treasury argued against the adoption of other possible methods of taxation, which would have introduced a tax concession, for a number of reasons including that they would only benefit a minority and that they would benefit high-income earners most. ${ }^{299}$

While equity concerns did not appear to be a primary driver of policy in the New Zealand context, there is evidence of the concept of equity shaping some of the New Zealand debates. However, this form of equity was not the 'social justice' view seen in Australia; instead, the concern was that equitable arrangements were aligned with efficiency priorities and outcomes.

\subsection{Neutrality}

\subsubsection{Neutrality in New Zealand}

\begin{tabular}{|l|l|}
\hline \multicolumn{1}{|c|}{ New Zealand ${ }^{300}$} & \multicolumn{1}{|c|}{ Australia $^{301}$} \\
\hline$[\mathrm{B}]$ ecause there had been so many & There was never the almost \\
tax breaks and all those sorts of & evangelistic fervour for neutrality \\
things during the Muldoon period, & of taxation - that was never the \\
that were obviously distorting the & case. \\
economy, that the mood during that & \\
period ('84 and '87 in particular) & \\
was to get ...the level playing field. & \\
\hline
\end{tabular}

297 Robin Oliver of McLeod Lojkine Associates, in an address to the Institute of Policy Studies, 17 June 1988. New Zealand Archives reference AALR, 873, W5427, 1828, Record 76/2/54, part 4A. are aware of the priority you have given to achieving large fiscal savings next year'. New Zealand Archives reference AALR, 873, W5427, 882, Record 52/479/15 Part 8. AALR, 873, W5427, 1829, Record 76/2/54, Part 6. 
Neutrality is one of the most important dimensions in analysing the events of the New Zealand situation. A number of references were made to the market based approach adopted to retirement savings policy and economic policy more generally in New Zealand, both by New Zealand and Australian commentators, interview respondents and in the literature. Government documents clearly outline the economic perspective:

A system in which more individuals are expected to provide for their own needs in retirement would reduce efficiency costs by allowing marginal tax rates to fall and would be likely to promote greater intergenerational equity as each individual would be in a position to make the personal trade-off between present and future consumption. ${ }^{302}$

The 'undesirable economic consequences' of tax concessions for superannuation were also made clear: distortion of savings behaviour, providing a competitive advantage for superannuation funds, distortion of investment patterns and creating the ability to enter into tax planning arrangements (New Zealand Treasury 1987:299).

The extent to which the New Zealand approach was theoretically driven was frequently mentioned. Australian Respondent 23 advised:

New Zealand took a lot more, I guess, theoretically pure approach to this than Australia did. My recollection is that in New Zealand, almost overnight, you had this level playing field, just getting rid of any tax concessions. In Australia ... a lot of changes happened in the 80s. The view was to level the playing field, but not to the same extent as in New Zealand. So some of the tax concessions we had were just watered down; we didn't completely get rid of them. I don't think there was any view that we should get rid of tax concessions for retirement savings at all.

This highlights one of the differences between the two countries; Australia was not opposed to the retention of tax incentives in the pursuit of social objectives, whereas New Zealand became opposed to almost any form of incentive. Even the proponents of neutrality, such as Ian Harper, an Australian academic who was bought to New Zealand to help market the idea, were not as ideologically determined as the New Zealand Treasury. Ian Harper's widely cited paper in support of the removal of tax incentives claims 'one may, of course, wish to argue that some departure from neutrality is warranted in the case of superannuation on broad social grounds, in particular, the value to society of subsidising individual provision for retirement and

$302 \quad$ New Zealand Treasury (1987:175). 
the associated saving activity, ${ }^{303}$ However, the pure ideology was difficult to dislodge. New Zealand Respondent 6 suggested that 'those ideas ... if they ever had any economic currency they were completely dismissed by rational and modern economic analysis. We were about removing privileges within the tax system'.

The following comments were received from Respondent 25, who had presented a paper to the New Zealand Treasury on the topic of neutrality within retirement savings:

I think I was always careful in saying that this isn't necessarily what ought to be done. ... But the impression I had was that the New Zealand Treasury had already decided that was what it wanted to do, and it was, firstly looking for an answer to the technical problem, which I think my work supplied, or helped them to think through and then secondly looking for some sort of endorsement. But that second part was always probably stretching it a little bit.

... I wasn't actually saying this is what you ought to do. What I was pointing out was that the taxation arrangements for life insurance and superannuation were favourable, towards life insurance and superannuation here; and that favourable treatment did produce a non-neutrality; and to eliminate that nonneutrality, you would do x. ... I don't believe anyway, or even if it's asserted there, it's certainly not defended, that that's what you ought to do.

\subsubsection{The development of ideas in New Zealand}

Appel (2000:528) finds that ideology determines how policies are designed, suggesting that 'in many respects it is intuitive that economic ideas embedded in economic theory influence economic policy-making'.

The move towards the government focus on efficiency could be seen developing in the late 1970s, well before the election of the fourth Labour government in 1984, which was also to support this approach:

The existence of the exemption still gives life insurance policies a considerable advantage over other forms of saving. Ideally the tax system should not favour any one type of savings instrument as this may not result in the funds involved being channelled into the most productive use. The presumption is that a free market allocation is more likely to do so. ${ }^{304}$

\footnotetext{
$303 \quad$ Harper (1985).

304 Correspondence from the New Zealand Treasury to the Minister of Finance in May 1980.

New Zealand Archives reference AALR, 873, W5427, 1898, Record 76/13/6, Part 1.
} 
The position was also made clear in the following statement:

The introduction of the National Superannuation scheme has lessened the need for the Government to subsidise private forms of saving for retirement. ... Those who can afford to spend in excess of $\$ 800$ per annum during their working careers to supplement this retirement income will probably do so irrespective of the tax incentive and, in any case, are not those who are in most need of assistance through the tax system. It is considered that any further tax concessions should be directed through rebates only to those with a more demonstrable need. ${ }^{305}$

However, correspondence from the New Zealand Treasury in October 1981 suggests a different position from that which is apparent a year or two later: 'a principle of neutrality does not of itself require that all forms of saving receive the same tax treatment, ${ }^{306}$ indicating the presence of a different perspective at this time. The same document notes:

In an economic system free from market distortions, neutrality of the tax system is coincident with equity within it and naturally leads to efficiency within the capital market. In such a system, market price signals (including interest rates) ensure that the optimum level of savings, channelled through the various financial institutions, find their way into the most productive projects. To the extent that there are market distortions, some lack of neutrality may be desirable to restore equity and efficiency.

It was around 1982 that the issue of neutrality started to be pursued more actively. In 1982, a Treasury Report claims: 'it is desirable that the tax system be as neutral as possible between different activities including between the variety of financial instruments and institutions available in the capital market, ${ }^{307}$ This Treasury Report also claims:

We have previously expressed the view that it is difficult to justify the existing level of assistance provided to the life insurance and superannuation industry through tax concessions (an estimated \$436 million in revenue forgone in 1980/81) and that a more neutral scheme would be highly desirable. ${ }^{308}$

However, the Treasury did provide options to the government, including in 1982:

\footnotetext{
305 Correspondence from the New Zealand Treasury to the Minister of Finance in May 1980. New Zealand Archives reference AALR, 873, W5427, 1898, Record 76/13/6, Part 1. 1981. New Zealand Archives reference AALR, 873, W5427, 1898, Record 76/13/6, Part 1. Treasury Report T76/3/6/1, May 1982. New Zealand Archives reference AALR, 873, W5427, 1898, Record 76/13/6, Part 4. 
If the government considered it desirable on social or other grounds to give special encouragement to this particular form of savings then this could be done by way of a limited tax rebate on pensions/contributions. ... Alternatively, government assistance could be provided directly from the Budget and this be open to greater scrutiny and subject to regular review. However, in view of other assistance provided to the aged, we doubt whether such action would be appropriate. ${ }^{309}$

The Report of the Task Force on Tax Reform in 1982 reported that there is 'considerable merit in the argument that the treatment of savings should be neutral and should not discriminate strongly in favour of one avenue of savings against another' (Task Force on Tax Reform 1982:243). However, the Caucus Committee findings subsequent to this report found that fiscal neutrality was desirable, but 'planned divergences from neutrality might be desirable for a number of reasons including ... to encourage some particular activity or form of organisation'. 310 Arguments such as these were not found after the election of the Labour government in 1984.

The views of the New Zealand Treasury are unchanged throughout the 1980s, although the arguments perhaps became stronger with the election of a like-minded Labour government in $1984 ;^{311}$ for example, internal Treasury correspondence in September 1985 states 'there is no reason why the Government should encourage and subsidise saving for retirement any more than precautionary saving for illness, unemployment (or indeed someone's saving for a consumer item such as a new video)'. ${ }^{312}$ This view indicates the prevailing ideas of the time and appeared to carry much influence in the policy process.

It also started to become more apparent in the mid-1980s that neutrality was becoming a serious consideration of the government, rather than just a Treasury

\footnotetext{
309 Treasury Report T76/3/6/1 May 1982. New Zealand Archives reference AALR, 873, W5427, Box 1898, Record 76/13/6, Part 4.

310 Correspondence from the Caucus Committee to the Minister of Finance, 11 June 1982. New Zealand Archives reference AALR, 873, W4446, 632, Record 76/2/54, Part 1.

$311 \quad$ Hale (2002:59) notes that ideas for major policy change have limited influence in the absence of support from authoritative political figures. 
concept. In a speech in October 1985, David Caygill, Associate Minister of Finance, stated:

As government we have been reviewing all areas of our expenditure. We have required all government programmes to meet the requirements I have outlined earlier: fairness and efficiency. In this way we can channel the limited resources available into those areas of highest priority. I suggest there is every reason to subject tax concessions for life insurance and super to these requirements, ${ }^{313}$

Secondary source documents from the late 1980s outline clearly the government's approach to the taxation of retirement savings. The Consultative Document on Superannuation and Life Insurance (New Zealand Government 1988:78) suggests that privileges for retirement savings are not necessary to encourage private provision for retirement as 'there are strong private incentives to provide an acceptable standard of living during one's retirement'. This argument was not one that was raised in Australia.

Other key arguments were that the provision of tax incentives would reduce reliance on the state. The Consultative Committee on Superannuation, Life Insurance and Related Areas (the Consultative Committee) argued that a mechanism to reduce the cost of National Superannuation would be to provide a tax concession clearly defined, targeted and limited ... constructed so as to ensure that those concessions were at least fully offset by savings to the state retirement income scheme of the future' (Consultative Committee on Superannuation, Life Insurance and Related Areas 1988:16). This was viewed by the Committee as being 'neutral' and therefore consistent with the overall tax reforms. However, as noted in chapter ten, suggestions of the Consultative Committee that did not fit within the theoretically determined parameters of neutrality did not find favour with the government.

Not all actors were convinced of the appeal of a level playing field. A number of submissions to the Consultative Committee suggested that neutral treatment was not desirable for retirement savings. The Feltex International Ltd submission suggests that:

313 Address by the Hon David Caygill, Associate Minister of Finance, to the Conference of the Association of Superannuation Funds of New Zealand, 3 October 1985. New Zealand Archives reference AALR, 873, W4446, 632, Record 76/2/54, Part 2 
In the cold, hard world of economic theorists "superannuation, life insurance and bank deposits" may be the same but for the average employee a company superannuation scheme provides him/her with a sense of belonging and for some the only opportunity of providing for retirement. ${ }^{314}$

The National Provident Fund (NPF) was also concerned about the absence of neutrality from a more global perspective, writing:

The consistency of treatment by these other major countries is not coincidental and reflects both the awareness by these countries of the benefits of encouraging long-term contractual savings for retirement and their concerns about arbitrary changes to long term contractual arrangements. As far as NPF can determine, no major economic or social objectives are achieved by New Zealand being different to other international equivalents other than supposed tax neutrality which does not seem to be achieved. ${ }^{315}$

Even the Consultative Committee (1988:22) report acknowledges that:

It is still true that, even with no means test on state-provided retirement income, there would be little incentive for many people to contribute new funds to a super scheme, or indeed even maintain existing funds in a super scheme. With a means test applying to state-provided retirement income, in the form of the National Super surcharge, there is a positive disincentive to remain within a super scheme.

Institutional theorists (e.g. Appel 2000:529) suggest that economic ideas can shape policy 'by virtue of their acceptance among technical experts' in specific areas. This is, perhaps, most clearly seen in the New Zealand Treasury, which retained an unchanged position from the late 1980s into the early 1990s, with communication reflecting views held almost a decade earlier:

As well as probably being ineffective, savings incentives impose a variety of economic costs by distorting the composition of savings, and by potentially distorting investment patterns and work/leisure choices. They require extensive regulatory regimes and inevitably give rise to avoidance opportunities. $^{316}$

314 Submission 109 to the Consultative Committee on Superannuation by Feltex International, April 1988. New Zealand Archives reference AALR, 873, W5427, 1829, Record 76/2/54/2 Part 1B.

315 Submission No 215 to the Consultative Committee, by the National Provident Fund, April 1988. New Zealand Archives reference AALR, 873, W5427, 1829, Record 76/2/54/2, Part $1 \mathrm{~B}$. 
As well as the focus on a level playing field, there is some indication that the measures in New Zealand were also beneficial from a financial perspective. There has been much written on the proposed flat tax, and it was suggested by interviewees that the superannuation tax changes were intended to fund the flat tax. The changes certainly facilitated decreased personal income tax rates. It was suggested by Australian Respondent 24 that:

Technically what New Zealand did was it went for a neutral income tax. Now a neutral income tax isn't necessarily good economics; it might be better to have a neutral expenditure tax, which is very technically better economics, but New Zealand went for a neutral income tax for two reasons. One is that they thought it was good policy in itself. But the other is that they needed the money. It's actually quite good for having a broad tax base and getting your fiscal position sound; so it did that.

Other financial issues were raised; in particular, the potential for extant arrangements to generate an inefficient investment market, due to unproductive investment allocation. However, in Australia the Life Insurance Federation of Australia was arguing that tax concessions were necessary to ensure the superannuation and life insurance industry received sufficient funds to encourage a healthy capital market:

A secondary but important function of superannuation is the economic one of assembling long term investment money. Superannuation funds and life offices provide the major source of uncommitted long term capital for Australian ownership and development. ${ }^{317}$

The arguments about capital market efficiency were supported by the New Zealand Treasury and Treasury advisers. In September 1985, Treasury correspondence suggests that 'long-term savings are not required for long-term investment. One of an intermediary's functions is to enable a flow of short-term savings to be invested longterm' $^{, 318}$ and 'the value to society of long-term savings will, in a deregulated financial market, be reflected in relative long-term expected real interest rates'. 319

This element of the debate led into a discussion of whether retirement savings were different, and hence deserving of different treatment, to other forms of savings. One

\footnotetext{
317 Submission No 26 to the Senate Standing Committee on Community Affairs, March 1984, by the Life Insurance Federation of Australia. Internal New Zealand Treasury correspondence, September 1985. New Zealand Archives reference AALR, 873, W5427, 1898, Record 76/13/6, part 6. 
argument proposed was that long-term savings were no different from a set of shortterm savings and therefore were not deserving of any special treatment. In Australia, it was typically claimed that 'retirement savings are different', whereas in New Zealand the claim tended to be that 'retirement savings are no different from other forms of savings'. Interview respondents in New Zealand primarily concurred with the concept that retirement savings were not different, with Respondent 8 commenting 'in terms of savings, to me there is nothing special about retirement. People save for all sorts of purposes, why should we treat retirement in a particular way'. Respondent 9 disagreed with this sentiment, arguing:

I remember having discussions with economists who would say that longterm savings were only a series of short-term savings. And, of course, that's nonsense. My own view is that it was nonsense because short-term savings get spent again - and they won't be there at 65. They will go into a new car and a holiday and whatever. So - philosophically - I always felt that there was a difference between short-term savings and long-term savings.

The Consultative Committee submissions typically agreed with Respondent 9. A number of submissions argued that retirement savings are different from other forms of savings; for example, Ciba Geigy New Zealand claimed:

The current changes do not recognise that savings for retirement are different from savings for such items as a car or a deposit for a house. These require savings over a relatively short period of time and the sums involved are readily comprehensible and calculable. ${ }^{320}$

The New Zealand Treasury accepted that superannuation did have some differences to other forms of saving, but insufficient differences to justify preferred tax treatment. Treasury correspondence acknowledges:

The point is not whether a difference exists but whether the difference is material. There are many forms of saving all of which have their own characteristics. ... The mere fact that one form of saving varies in certain respects from another does not justify differences in tax treatment. An additional point here is that in the less regulated and more competitive financial market we have now entered, differences between different financial institutions are breaking down. ${ }^{321}$

\footnotetext{
320 Submission 95 to the Consultative Committee on Superannuation by Ciba Geigy New Zealand Limited, March 1988. New Zealand Archives reference AALR, 873, W5427, 1829, Record 76/2/54/2 Part 1A.

321 Internal New Zealand Treasury correspondence, September 1985. New Zealand Archvies reference AALR, 873, W4446, 632, Record 76/2/54, Part 2.
} 
A common theme that occurs in the New Zealand environment is the lack of evidence to establish that tax incentives achieve the objective of increasing saving. A number of individuals commented that they were not averse to tax incentives; rather, it was the lack of evidence of their success that became a limiting factor. Respondent 13 commented that 'I never put my foot down on Treasury advice, and said we definitely won't. But I kept asking the question - prove it to me.' The lack of 'evidence' to support the provision of tax incentives was mentioned by many individuals. Respondent 10 commented:

Often there is not a whole lot of science to this, when people say tax incentives for retirement savings lift the savings rate, they might be right, but it's hard to prove, or they might just be doing something which shifts the form of savings from one to another, without adding to the total.

Perhaps one of the key points in relation to the ideology in New Zealand was that New Zealand implemented a system that was more theoretically focused than any other OECD country. In support of the proposals, reference was made to several theoretical studies, one of which was written by Respondent 25 who advised:

I tried to tell them; I said-look guys this is a theoretical study and I'm a bit nervous about you simply importing all these ideas into the legislation and then saying, well there you go, there's the new law. And in particular while it does establish ... neutrality amongst different sorts of savings, clearly it doesn't establish neutrality between the treatment of leisure and work and the treatment of housing. ... I wasn't asking the question as to whether if you made this system neutral within that domain, whether that was going to promote tax efficiency and tax neutrality right across the public revenue spectrum. I just wasn't asking that question. They said - well we're not interested in that.

The argument is made here that the prevailing ideas within the New Zealand Treasury, supported by government thinking of the time, provided a force that did not allow for serious consideration of alternate proposals. Instead, claims made for the retention of tax incentives were dismissed with rational economic arguments.

\subsubsection{Neutrality in Australia}

As with the dimension of equity, the concept of neutrality attracted vastly different treatment in Australia than in New Zealand. The topic of neutrality had been discussed in Australia since the early 1970s, but the focus on economic efficiency did not have the same level of dominance and support as in New Zealand and appeared to be balanced with a wider social perspective. One of the first significant discussions 
was that included in the Asprey Report (Taxation Review Committee 1975), which recommended that there should be special provisions within the income tax to correct the bias that is created against saving. The Asprey Report found that superannuation was deserving of tax assistance, because of the long-term savings that it is intended to encourage.

Professor Keith Hancock ${ }^{322}$ was among the first to question the neutrality approach:

One is that life is full of hazards and that, in a world of completely free choice, people in their old age would find themselves inadvertently with inadequate means of supporting themselves. Another is that people do not know how long they will live; this constitutes a case for the pooling of some of our income to ensure that long-livers are provided for. A third reason is that Governments have somewhat superior means of protecting people against long-term changes in the value of money. ... Beyond all of these considerations, there is undoubtedly an element of paternalism. Our society is concerned for people to be able to live in dignity and is not prepared to dismiss the hardships of the aged as of no community concern purely because the people in hardship should have made better provision for themselves.

Historically there has been, and remains today, considerable departure from neutrality in the Australian arrangements for the taxation of superannuation. The absence of neutrality in the early 1980s was noted in the Final Report of the Campbell Committee, in particular relating to the taxation of employer's contributions, the effective tax deferral through the tax-exempt status of most funds, the privileging of lump sums over pensions and the lack of uniform tax treatment between funds. ${ }^{323}$ Furthermore, the concern about inefficiency in resource allocation was developed over the 1980s. Australian Respondent 31 noted:

It probably, though, wasn't until the second half of the 1980s that we started, in this place (in the Treasury), to worry about the implications that this tax preference for superannuation might be having on the efficiency of investment allocation. We started to get more worried about it the more popular superannuation became.

The possibility of a market failure in the area of retirement savings was raised in Australia; this was not discussed in New Zealand. Cheryl Kernot commented that in Australia:

The overwhelming evidence was in favour of compulsion. However one looks at it, for some reason there has been a market failure in Australia. I think the reason is a combination of both political and cultural factors. As a nation we

\footnotetext{
$322 \quad$ Submission No 18 to the Senate Standing Committee on Community Affairs, March 1984.

323 The Committee of Inquiry into the Australian Financial System (1981:244).
} 
have failed to save. We do not take provision for ourselves in the long term future seriously. ${ }^{324}$

Support for this position could also be found in commentary from the Senate that voluntary saving in Australia had been shown not to work. Senator Sherry suggests:

People will simply not - the overseas experience shows this - voluntarily save adequate levels of income for their pension retirement. ... If that is the theory, why were more Australians not saving for their superannuation prior to 1983 when we had one of the lowest tax regimes and the most favourable tax treatment - less than 5 per cent? Why were they not saving then? The simple answer is that voluntarism does not work. ${ }^{325}$

While some of the debates were similar in the Australian context, they produced different policy solutions. In Australia, the suggestion that tax incentives did not work was a factor that contributed to the introduction of a compulsory scheme; in New Zealand, the same suggestion resulted in removal of the incentives.

\subsubsection{Institutions and neutrality}

The power of the New Zealand Treasury was discussed in chapter ten. What is also significant in the analysis is the prevailing ideas within the New Zealand Treasury. It has frequently been suggested that the New Zealand Treasury in the 1980s was made up of extremely capable individuals with similar perspectives. Ex-Prime Minister David Lange is quoted in 1991 commenting on the Treasury's influence:

The Treasury is a formidable group of like-minded individuals. They have a distinctive culture. They are dedicated. They are hard-working. They are fortified by the intensity of their conviction and sustained by the sycophancy of their fellow travellers in the temples of the money-changers. They are, in my experience, entirely allergic to any suggestion that the body of advice they tender is merely one among several possible approaches to the problems of economic management. ${ }^{326}$

It was widely suggested that the New Zealand Treasury was often providing a 'single stream' of advice to government and frequent comments are seen similar to the following: 'there is no doubt there has been a lack of alternative ideas in the public

\footnotetext{
324 Senate Hansard, 18 June 1991, Volume 153, p3916, Superannuation Guarantee Administration Bill 1992. Senator Kernot, Australian Democrats, Opposition.

Senate Hansard, 23 June 1991, Volume 153, p4353, Superannuation Guarantee Administration Bill 1992. Senator Sherry, ALP, Opposition. 
forum and particularly at cabinet level' and 'alternative sources of economic advice were virtually eliminated (from within the bureaucracy), ${ }^{327}$

The New Zealand Treasury position was reinforced from a number of people both from within and external to the institution at the time. New Zealand Respondent 13 stated:

The position that I took in Treasury was pretty straightforward. It was that anything which led you to tax one form of saving differently from another was going to, depending on your point of view, either cause a distortion, which means a bad thing, or cause a benefit which would be a good thing. But you are removing neutrality between savings forms and every time you do that you're going to get inefficiency as resources cluster around the exemption and try to exploit it and push more stuff through the hole - and that's the whole history of tax policy. The ideas and principles that were behind tax policy at the time were to try to minimise the distortions in the tax system by getting the rates down and expanding the base, which of course is where GST came from and also the abolition of all of these tax expenditures.

The Australian Treasury, while not appearing to have the same influence on the policy process as their New Zealand counterparts, were also sympathetic to the direction that policy was taking, even if the ideas were not originally those of the Treasury's. In relation to the Superannuation Guarantee, while acknowledging that the policy did not originate in the Treasury, Respondent 31 advised 'not that we were in any way antithetical to the proposition that superannuation should become more popular; quite the converse'.

Other institutions, such as the life insurance and superannuation industry or employer groups in both countries, did not demonstrate the same level of ideologically driven focus as that of the New Zealand Treasury. The only other key institution involved in this case study to have an ideology that shaped the framework for their discussion was the Australian trade union movement. As with the New Zealand Treasury and the Labour government, this ideology - perhaps better phrased as a 'social view' - was aligned with the Australian Labor government. This can be seen in the following comments from Australian Respondent 18:

I'll just make the observation that people in the trade union movement ... were never very big on the idea of inter-generational equity. They were about lifting the standard of living in retirement of working people, which is a social view. ... But their motive wasn't to rectify inter-generational equity; 
it was to lift living standards of ordinary working people in retirement. You could say that's a paternalistic, or maternalistic if you like, objective, but it's very much among the proponents of compulsory super who achieved those first couple of bridge-heads; it was a social view not an economic view.

This discussion highlights the focus of neutrality in the New Zealand context. It also acknowledges that economic efficiency was also a concern in the Australian environment, but these ideas did not appear to drive policy in the same way as in New Zealand; rather, it was a factor to be taken into account in the policy process, along with other objectives.

\subsection{Policy Objectives}

\begin{tabular}{|l|l|}
\hline \multicolumn{1}{|c|}{ New Zealand } & \multicolumn{1}{|c|}{ Australia } \\
\hline The vision of income replacement & Our belief is that the broad \\
over and above the adequacy floor & parameters of the Superannuation \\
remains a matter for individuals. & Guarantee Levy are potentially \\
That is not to say the state has no & consistent with the twin aims of the \\
general interest in the matter. But it & policy: to substantially improve \\
is to say that interest is somewhat & retirement income, and to generate \\
limited. & substantial per capita saving. \\
\hline
\end{tabular}

As observed by Appel (2000:524), 'during ... a period of great uncertainty and flux, identifying what policies best serve one's self interest or even the greater economic good is far from straightforward for political leaders, industrial specialists, and economic advisers'. However, it is clear that in both New Zealand and Australia the policy tools adopted for retirement savings were aligned with the ideas championed by the government. The Australian objective was maintenance of a similar standard of living into retirement and it was believed that compulsion, in conjunction with tax incentives, would provide the means to achieve this. In New Zealand, the policy objective for retirement savings has been to encourage private sector provision for retirement. This non-interventionist approach reflects a different level of interest in encouraging retirement savings than that seen in Australia, where it was more apparent that policy suggestions needed to be aligned with the overall philosophy, as noted by Australian Respondent 31:

The support of the ACTU for that proposition had to rely on the government being able to demonstrate that superannuation was not just a replacement for

\footnotetext{
$328 \quad$ Cullen (1992).

329 Submission to the Senate Select Committee on Superannuation, 1992, by Professor John Piggott, an Australian economist.
} 
the age pension system; that at the end of the day people who contributed to superannuation had to end up significantly better off than they would have been on the Age Pension. So it wasn't just privatisation of the Age Pension. That was an element of it certainly; but, more than that, it was a policy that was intended to produce higher retirement incomes for the vast bulk of the Australian work force.

The concept of equity was paramount in policy design in Australia. As noted by Respondent 31:

This was an important constraint, if you like, on the design of everything we did in the superannuation area. ... You had to be able to demonstrate that at the end of the day, even taking into account the impact of the age pension and so on, at the end of the day, the low-income people in particular had to be demonstrably better. If you couldn't prove that, then there's no way that people like Bill Kelty could have got the unions to agree to it. And without union agreement this wasn't going anywhere.

As the Australian government was taking a more prominent role in retirement savings policy, the New Zealand government was signalling the potential for a reduced role for the government in the future of retirement income provision. This can be seen in the following ministerial address by the New Zealand Minister for Social Welfare in 1992:

It is clear that there is a role for both public and private provision of retirement income. It is also clear that most New Zealanders would accept that the state will have to provide a substantial part of retirement income. Equally ... there is now a growing acceptance that the state cannot be expected to provide a universal superannuation entitlement at high levels for all those who reach retirement age. ${ }^{330}$

Policy change may come from ideas that provide solutions to specific policy issues. The ideas raised in both New Zealand and Australia were framed in such a way as to solve the policy problems within the boundaries of how the policy problems were framed. As noted in chapter three, Blyth (2002:10) asserts that ideas assist with defining a crisis 'as a crisis', which then allows for the proposal of policy solutions that are aligned with these ideas. As the overriding policy issue was the serious economic crisis in New Zealand and the ageing population in Australia, the ideas raised provided a theoretically appropriate solution in New Zealand, and a theoretically appropriate, and potentially practical, solution in Australia. Therefore, at the same time that the Australian government was implementing significant policy

$330 \quad$ Address by Jenny Shipley to the National Superannuation Reform Conference, May 1992. 
reform to support private retirement savings, New Zealand was moving further away from state involvement in the process.

\subsection{Summary}

The big difference between the two of them is that the Labor party here Hawke and Keating - were never fighting an ideological war. Whereas I suspect - I don't know about Lange - but Douglas certainly was. Douglas was a convinced market ideologue. Keating was not. ${ }^{331}$

In Australia there is ... that sort of fair go bloke/mate, "we've got our rights"
... nothing was ever just wiped and something more sensible put in its place-
everything was either grandfathered, ring-fenced. They made incremental
changes that we just didn't do in New Zealand. People said "we'll do that
tomorrow" - and it was changed. It was a totally different attitude among
both governments and employees. 332

The concept of ideas within historical institutionalism is one that is less developed than other views, such as power or path dependency. However, it is one of the most important, and most complex, influencing variables within this comparative case study. Ideas themselves are generated from within a policy, and thus institutional, environment. Therefore, it is important to consider ideas in tandem with other explanatory factors of change.

While it is suggested that ideas are not a prominent feature within historical institutionalism, historical institutionalism provides for ideas to be taken into account as they structure the environment from within which individuals act. As found by Blyth (1997:246) 'ideas can be seen as both facilitators of radical policy change and the prerequisite of it'. In the case of New Zealand, where retirement savings taxation policy change was not incremental, the underlying ideas both supported the justification of the policy amendments and provided an explanation into why the environment necessitated the radical changes.

Steinmo (2008b) suggests that the foundations of many of the tax reforms adopted throughout the OECD in the late $20^{\text {th }}$ century had broadly similar theoretical

\footnotetext{
$331 \quad$ Respondent 25.

332 Respondent 5.
} 
foundations. However, it is also apparent that 'the interpretation and implementation of these ideas has often been significantly different in different countries' (Steinmo 2008b:222). In New Zealand, there was a focus on tax neutrality and efficiency in capital markets. This focus, while certainly present in Australia, did not shape the framework for decision making to the same extent that can be witnessed in New Zealand in the time period investigated. The reforms in Australia were, at least in part, tempered with social justice objectives.

It may be self-evident, but, in order to be both politically and socially acceptable, ideas must be viable. Furthermore, as suggested by Hall (1989:361), ideas about what is efficient, expedient, and just ... motivate the movement from one line of policy to another'. This viability and justification may be supported by the environmental context from within which ideas are developed. In the case studies outlined in the thesis, the environment supported the ideas proposed in both countries: the necessary conditions existed to justify the significant change in policy direction. This was perhaps less because of a perceived failure of previous policy; instead, it was related to the potential to solve a range of current policy problems with the alternative ideas proposed.

What may also be relevant in this context is an apparent lack of alternative ideas. In both Australia and New Zealand, the choice appeared to be little more than either significant change or the status quo. There was only minor discussion, particularly in the New Zealand context, of incremental change. In Australia, the tax changes were more measured, but within a broader revolutionary retirement savings policy.

Reference to ideas in this analysis has highlighted a number of conditions that may not have become apparent in its absence. As suggested by Blyth (2002:35), it is ideas (not institutions) that reduce uncertainty in periods of economic crisis. Situating the New Zealand changes to the taxation of retirement savings within an economic crisis, but with a ready economic 'solution', assisted in reducing uncertainty in the New Zealand context. Similarly, in Australia, the changes to retirement savings policy offered 'solutions' to both economic and social issues (e.g. an ageing population and the desire to avoid inflationary wage increases). The analysis also emphasises the potential for the acceptance of these 'solutions' to be linked to how the problems are 
framed. As mentioned earlier, essentially both countries were facing broadly similar economic and social environments, but ideas, and how these ideas were framed, supported different policy outcomes.

Typically, institutions and those within institutions have certain preferences, which may be based on historical or cultural factors. An institution's identity can be linked to its ideology, which is likely to have formed over time and to have been reinforced through challenges and adaptation to a changing environment. The most influential institutions and individuals in this case study are those with the most evident ideologies. As found by Blyth (2003:700), individuals may use ideas to 'delegitimate, contest, and refashion existing institutions'. However, institutions also provide the environmental context for individual preferences. Institutions, such as the New Zealand Treasury and the trade union movement in Australia, together with individuals such as Paul Keating and Roger Douglas, communicated a cohesive and well-defined world view to support their policy preferences.

Perhaps one of the most important insights from this chapter is that the presence of a strong ideological position facilitated imposition of the policy reforms. While ideas will never be neutral, in this context they created a strong platform from which individuals and institutions were privileged. Where this thesis does not concur entirely with institutional thinking is with the potential for ideas to assist with 'collective action and coalition-building' (Blyth 2002:37). While this concept, in general, is supported by the findings in the thesis, an important caveat is that the collective action is only supported to the extent that it is aligned with the prevailing ideas held by elites. McNamara (1998) finds a similar result in her investigation of the adoption of monetary integration in the European Union.

The ideology provided a transparent framework for decision making and also provided a structure from within which meaning could be made. Appel (2000:539) raises the issue of ideological compatibility, suggesting that the implementation of ideas requires a degree of compatibility between elite and interest group philosophies and the ideas themselves. This 'fit' is important for ideas to gain acceptance. The ideas in both countries could be seen to have a strong fit within the prevailing environmental context. In New Zealand, this was to ameliorate, to the extent 
possible, the economic crisis. In Australia, it was to provide reward for labour without fuelling inflation, while simultaneously addressing forecast demographic issues.

A factor that is assisted by institutional theory in the Australian context is in demonstrating how values and world views can be emphasised above elements such as efficiency, whereas influential New Zealand institutions incorporated values and beliefs that were aligned to efficiency. It is not intended to imply that all New Zealand institutions were supportive of the market based approach, rather those that were had a privileged position insofar as policy making was concerned.

Institutional theorists argue that ideas are important for explaining differences in policy decisions, but these must be situated within the context that they are formed. Perhaps this is best captured by Steinmo (1998:502) who writes that 'neither interests nor values have substantive meaning if abstracted from the institutional context in which humans define them'. This is relevant with both New Zealand and Australian institutions demonstrating ideologies that clearly outlined the perspectives that they were likely to adopt in relation to policy direction. These institutions became important catalysts in promoting the ideas that were to play a key role in policy development.

The ideologies in both New Zealand and Australia allowed the elaboration of a set of ideas that would shape broader economic policy reforms. Once this set of ideas was in place, it became a framework from which decision making was pursued. This ideological framework provided not only a degree of transparency and consistency in decision making, it also provided coherent support for the decisions. This is of particular value when decisions are not aligned with the direction of the rest of the world or they are significantly different from historical policy, as was the case in both Australia and New Zealand at times over the decade investigated.

It has been suggested that particular policies are not typically the result of an explicit ideological framework (e.g. Simeon 1976:572), but the New Zealand situation provided a strong framework that limited other possible policy directions. With ideas rationalising the direction, this provided a coherent world view and a structure to the 
policy process from which actors were motivated to resist opposition to the proposed concept or to limit support for alternative concepts. Through reinforcement of the economic ideas, elites could act to restrain discussions that may emerge from a different belief system.

Perhaps it is appropriate that the final insight gained from the use of ideas in this analysis is that ideas provide for a degree of stability in policy. The use of ideas to validate change provides for growing alliances in support of these ideas, which in turn assists in their longevity. Blyth (2002:41) suggests that the use of ideas in policy development 'tell agents what possible futures to expect'. In New Zealand and Australia, ideas were used to justify the implementation of specific policy solutions and also to portray an image of how the future would look once these policies had been adopted. In Australia, projections were made of increased wealth in retirement when the Superannuation Guarantee had been in place for a number of years. In New Zealand, ideas that were used to justify the removal of tax incentives for retirement savings were used to support other reforms that were aligned with the 'level playing field' approach. Given the suggestion that ideas can assist in policy stability, it is noteworthy that the policy arrangements in Australia and New Zealand remained unchanged for many years after their implementation.

This research indicates that the concept of ideas should be afforded greater prominence in the policy development debate. This is not to suggest that the fundamental concepts of institutional theory, such as path dependency, are not also important, but these should be investigated in conjunction with the policy ideas that are promoted. In this research, ideas have proven to be a fundamental, if not the fundamental, explanatory variable. Not only did ideas provide justification for the policy direction pursued in each country, ideas also underpin the other explanatory variables utilised in the analysis, for example, there is a strong link between the ideological environment and power structures. Ideas provide legitimate power to actors and institutions that support the prevailing ideology; ideas supported the decision-making power afforded to organisations such as the New Zealand Treasury and the trade union movement in Australia. Ideas also linked to the environment in both New Zealand and Australia. In New Zealand, the environment supported the 
pursuit of innovative ideas, while the Australian environment endorsed ideas that maintained principles of equity, together with those of efficiency.

In this chapter, institutional theory has again provided a framework for analysis. It is possible that a theory that can incorporate the transfusion of ideas, or even emphasise the potential causality of ideas, may add another level of insight into this case study. What can be suggested at this point from a historical institutionalist interpretation is that the environment provided the receptive context, institutions provided the necessary framework, the power balances facilitated strong coalitions of support and the ideas provided the blueprint for the future.

The following chapter draws this thesis to an end, with some suggestions from the results of the analysis undertaken in previous chapters. 


\section{Chapter 12: Conclusion}

\subsection{Introduction}

The thesis has provided a historical account of policy development for retirement savings generally and the taxation of retirement savings more specifically in New Zealand and Australia. It has investigated the key influences on the policy process, including institutions, power and ideas, together with the environment from within which the changes have occurred. Exploration of any of these components in isolation does not do justice to the complex situation and interplay of variables in the case study.

At the outset, the thesis proposed to address questions of how institutional arrangements contribute to an explanation of the different policy approaches to retirement savings taxation policy in New Zealand and Australia. It also set out to provide an insight into the extent to which the policy development process privileged certain groups above others and to explain how institutional arrangements interact with other variables to influence retirement savings taxation policy. Further research objectives of the thesis were to explain how and why New Zealand and Australian governments have adopted different tax regimes for retirement savings, and to explain the antecedents of current policy in order to understand the political, social and historical context in which current policy emerged.

At its conclusion, having addressed the above research questions, the thesis aims to make two primary contributions. The first is to provide a comprehensive historical account of the events, personalities and environment that formed the policy for the taxation of retirement savings in New Zealand and Australia. The explanation incorporates both how and why the two countries came to different policy solutions. The aim is to explain how institutional arrangements have contributed to the different policy solutions to what appears to be a similar policy problems (providing for an increasing ageing population), incorporating the privileging of both ideas and institutions in the analysis. The second key objective of the research, in using institutional theory to assist with the first objective, is to provide some insights into the utility of institutional theory, and historical institutionalism in particular, in this case study. 
Accordingly, this chapter is structured in two sections. The first discusses the findings from the data analysis and outlines insights into the policy development process found from the analysis. This section also makes some tentative suggestions as to what may be in the future for the taxation of retirement savings policy in each country. The second section discusses the utility of historical institutionalism in this analysis. It outlines strengths and weaknesses of the theoretical framework in this case study and offers some suggestions as to its likely function in similar comparative case studies.

\subsection{Retirement Savings Taxation Policy in New Zealand and Australia}

\begin{tabular}{|l|l|}
\hline \multicolumn{1}{|c|}{ New Zealand } & \multicolumn{1}{|c|}{ Australia } \\
\hline $\begin{array}{l}\text { We did what we did because we } \\
\text { thought it was the right answer. }\end{array}$ & $\begin{array}{l}\text { The primary push was about lifting } \\
\text { standards of living in retirement. }\end{array}$ \\
\hline
\end{tabular}

The research findings indicate that the key independent variables highlighted in this research (the environment, institutions, power and ideas) contribute a contestable explanation to the policy directions adopted in each country.

Historically, a number of explanations have been provided for the changes to the tax treatment of retirement savings over the past 30 years. Typically, these include the economic crisis in both countries, ageing populations, declining levels of private savings and concern about the sustainability of existing schemes. It is also common to see individuals such as Paul Keating or Roger Douglas, or institutions such as the trade union movement in Australia or the New Zealand Treasury credited (or blamed) for policy implemented. At a certain level, all of these factors have some relevance. However, this analysis provides a deeper level of understanding.

The comparative history highlights some of the hidden assumptions within the more typically accepted interpretation of the situation. What can be seen from the generally accepted explanations of the reforms to retirement savings policy over the 1982 to 1992 period is the impact of the environment (ageing populations and the economic

\footnotetext{
$333 \quad$ Respondent 10.

$334 \quad$ Respondent 18.
} 
situation), institutions (the Australian trade union movement and the New Zealand Treasury) and the power dynamics (Paul Keating and Roger Douglas). What is less apparent, and is one of the elements typically given little emphasis in the history of the taxation of retirement savings, is the influence of the ideas. This factor stands out as the most influential factor in the case study. The strongest ideas were found in New Zealand, where reform was the most radical. However, in Australia a strong ideology can also be seen with a trend towards economic efficiency tempered by social justice perspectives.

The environmental factors, while still important, facilitated the power of institutions and individuals. However, in the absence of the prevailing ideology, which was communicated to the public to validate the policy suggestions, it is unlikely that the policy directions adopted in either country would have been suggested. While both the environment and the influence of certain institutions were important, ultimately the changes that occurred were unlikely to have had success in the absence of the support of the Minister of Finance in New Zealand and the Treasurer in Australia, together with the power that these key individuals had to ensure that the policy direction desired was adopted. What was driving this support and power was the ideology.

It is important to differentiate between the factors that enabled the policy suggestions and those that advanced the policy. Power, institutions and the environment all played an enabling role; it was the ideas that created the impetus and validation for the policy proposals. The ideas permitted a cohesive approach, both in the manner in which it was communicated and in the language used. Phrases such as 'level playing field', 'neutrality' and 'efficiency' became commonplace in New Zealand. Meanwhile, Australia's debate regularly referred to 'equity' and the 'social wage'.

Furthermore, changes in the four variables were also important in the outcomes seen. The environment, particularly in the New Zealand context, provided the 'crisis' that is frequently attributed as necessary for radical change. Economic difficulties also facilitated the superannuation and wages trade-off in the mid-1980s in Australia. Furthermore, influential institutions, in particular the New Zealand Treasury and the trade union movement, were afforded arguably greater authority in the policy making 
process than at any other time that century. These changes provided further foundation for the policy reforms that occurred.

While the analysis in this study has formed four separate components (environment, institutions, power and ideas), this is for structural clarity alone. It should not be interpreted that these components work in isolation; indeed their overlap is one of the fundamental insights in the analysis. Of the factors considered, each in isolation would not contribute an effective explanation to the policy outcomes witnessed; for example, the power dynamics were both enabled and constrained by factors such as the environment and institutions. The power dynamics were also influenced by the prevailing ideas, where those supporting the thinking of the time were provided with a privileged position in the decision making process. Furthermore, an idea cannot be pursued in the absence of backing from actors with political power.

The investigation of the institutional factors highlighted the lack of potential for interest groups to make their voices heard. Conversely, the privileging of certain interest groups, those aligned with the prevailing ideas, was also prevalent. The institutions with the strongest ideology were those that, through historical events or historical opportunity, were aligned with the state. It is difficult to determine, even with the benefit of hindsight, whether these ideologies were strengthened because they privileged the position of the institution, or whether the institutions were privileged because of their ideological beliefs.

While the corporatist approach adopted in Australia had the appearance of increased consultation, with the exception of minor policy amendments, interest groups with different perspectives to those of the unions and the government were afforded little attention. In New Zealand, the primary opportunity for input into the changes to taxation of retirement savings were the Committee processes in 1982 and 1988. In both cases, submissions had little impact, and in the case of the 1988 Consultative Committee on Superannuation, Life Insurance and Related Areas it would appear that the outcome was largely pre-determined.

It could be argued that other influences were equally as important as ideas, such as perhaps the influence of Roger Douglas and Paul Keating. In the absence of these 
two individuals it is questionable whether the same outcome would have been achieved. However, the power of both these individuals was legitimised by the fundamental ideas supporting the policy suggestion. Moreover, the New Zealand Treasury and the Australian trade union movement may be credited with identifying the policy options available, but in both cases the options tended to fit within the prevailing ideas, with which Roger Douglas and Paul Keating were aligned.

Both countries achieved legitimacy of the reforms through a high degree of public acceptance of the need for the changes or the benefit from the changes. In New Zealand, emphasis was placed on the economic crisis, the myriad of distorting practices in the tax environment (and thus the need to create a more neutral playing field) and that New Zealand had no need for increased levels of private saving. In Australia, emphasis was placed on demographic issues and the need to increase savings. These two different emphases provided, in their respective countries, coherent arguments to support the reforms to retirement savings policy.

In New Zealand, a consistent world view could be seen; economic policy broadly, incorporating taxation policy, should create a neutral environment. The use of economic frameworks for decision making provided a set of established ideas to support the direction adopted. This position in New Zealand assisted with communication of ideas and validation for trade-offs incurred in the process. Individuals were losing retirement savings incentives, but were gaining in other areas, such as reduced personal income tax rates. The coherence of this policy encouraged acceptance due to the inclusive nature of the reforms, whereas in Australia, the changes made were trade-offs within the same area of policy. Examples can be seen in the 'bringing forward' of the taxation of retirement savings, which could be argued as being tax neutral, and the mitigation of dissention in relation to taxing superannuation fund earnings with the inclusion of superannuation funds in the imputation regime.

This analysis is not intended to diminish the value of institutions. Ultimately, the power of the state is the enabling force for policy. Policy decisions need to have the support of key state actors, as well as being acceptable to the populace. This acceptance comes from the perception that they are effective tools to 'solve' a 
particular policy 'problem'. This is particularly relevant in situations where extant policy tools are no longer effective. Consideration of how policy ideas become broadly acceptable to populations leads back to the concept of ideas. Politicians and bureaucrats need to rationalise their actions and to do this a strong framework for marketing the concept is required; it needs legitimacy. This can be done with the support of a powerful ally (as is seen in both countries), and/or with a prevailing ideology to provide the theoretical foundation for the decision followed. The combination of powerful supporting actors providing the political support for the direction, combined with the ideas providing the rationale, is a powerful combination of factors in this comparative case study.

The thesis argues that ideas are the key dimension in the policy arrangements implemented for retirement savings taxation in the 1982 to 1992 period in both New Zealand and Australia. The basis for this claim is the validation for the reforms that the ideas provided, together with the facilitation of a cohesive world view to support the policy direction. This suggestion is not intended to propose that the other dimensions are not also important, but it is argued that they were strengthened by links to the prevailing ideas. Institutions provided strong coalitions to support the direction being pursued and the power arrangements that these coalitions facilitated privileged certain viewpoints above others. Both the coalitions and the power balances were supported by the prevailing ideas. Moreover, as noted in chapter eleven, the environment and structural arrangements supported the pursuit of radical ideas in New Zealand, and ideas that maintained principles of equity and efficiency in Australia.

\subsubsection{The future of retirement savings taxation}

Recent research from the Ministry of Social Development (2007:26) shows that, while disposable incomes have remained static, private income ${ }^{335}$ of the aged in New Zealand has declined since 1988. ${ }^{336}$ The median disposable family income in 2004

335 For the purposes of this research, private income is defined as income from all sources, excluding government transfers. The figures also do not include revenue from capital assets. These figures are adjusted for inflation to represent 2004 dollars. The figures are based on the median income available to New Zealanders aged over 65 years. 
was NZ $\$ 3,800$ per annum for a couple aged over 65 years and $N Z \$ 260$ per annum for a single person aged over 65 years. ${ }^{337}$ In 1988, these figures were, respectively, $\mathrm{NZ} \$ 5,800$ and NZ\$2,200. While there is no suggestion that these figures on their own provide any conclusion of causality, it may not be surprising that private incomes in retirement have declined since the late 1980s with the removal of tax incentives to save through traditional retirement savings vehicles. ${ }^{338}$ As well as the removal of tax incentives to encourage private retirement savings, the tax advantaged status of property, among other reasons, may also have contributed to reduced investment in traditional forms of retirement savings.

Furthermore, when levels of retirement savings or participation in occupational superannuation are contrasted across countries, New Zealand does not compare favourably. Australia now has in excess of $\mathrm{A} \$ 1.3$ trillion in managed funds and over 90 per cent of the workforce covered in occupational superannuation schemes. New Zealand has around NZ\$25 (approximately A $\$ 22$ ) billion in superannuation funds (including the now closed Government Superannuation Fund) and 13.4 per cent of active members in employer occupational schemes (including the Government Superannuation Fund) in 2007. ${ }^{339}$ There is no doubt that the Australian policy approach has increased household wealth. Whether it has increased private saving is a different question altogether and one that is yet to be resolved.

Despite the absence of evidence indicating that private savings has increased, there can be no question of the broader economic and individual benefit that can be seen from the Superannuation Guarantee in Australia. Australia now has the fourth largest investment fund asset pool in the world, and the largest in Asia. ${ }^{340}$ This has created

\footnotetext{
337 It is difficult to see what the reason for this significant drop in income for a single person. The report accepts that it may be due to the relatively small sample size in the research. Directly comparable statistics are not available for Australia, but as an indication of private incomes, Australian households where the head is over 65 years of age had an average private income of A \$11,362 per annum in 2001 (Harding, Lloyd and Warren 2004:22). New Zealand Government Actuary (2007). These figures exclude the KiwiSaver scheme that was implemented in July 2007. 2007. Australia is behind the USA, Luxembourg and France.
} 
the opportunity for Australia to be a significant actor in the global investment fund industry.

New Zealand's retirement savings figures and participation in occupational superannuation are among the lowest in the OECD. Australian retirees can expect to have an income of $70-80$ per cent of their final retirement income, after 40 years of Superannuation Guarantee participation. New Zealand retirees will, assuming National Superannuation continues unchallenged, at a minimum receive $60-65$ per cent of the average wage. The difference in standard of living that these amounts will support is significant. Australian retirees will be advantaged with some relationship between their pre-retirement and retirement income, a benefit which retirees in New Zealand will not have. What also cannot be ignored are the economic impacts that are likely to result from this, such as the impact of reduced consumption on economic growth, and greater reliance on the state in areas such as health and housing.

Statistics are not available that incorporate the most recent amendments to the taxation of retirement savings in New Zealand or Australia. However, Figures 12.1 and 12.2 respectively outline the net tax cost per unit of contribution to a retirement savings plan and the effective tax rates on private pensions in OECD countries, based on policies in place during 2000. The data provides some idea of the degree of state assistance provided in both countries to retirement savings. What is clear is that New Zealand is second only to Mexico in the low level of tax assistance provided. The apparent 'tax concession' in this data is not deliberate; rather, it stems from the difference in the highest marginal income tax rate of 39 per cent, and the 33 per cent tax rate applied to fund earnings, prior to 2007.

The net tax cost per unit of contribution shown in Figure 12.1 ranges from a high of nearly 40 cents per dollar of contribution (in the Czech Republic) to around zero in New Zealand and Mexico. Most countries accept a tax cost of at least ten cents per dollar of contribution, indicating a willingness to support retirement saving.

Figure 12.2 outlines the effective tax rates on private pensions and savings. The difference in the two is the tax preference given to retirement savings. What is 
apparent from Figure 12.2 is the generous tax treatment of retirement savings in Australia, when compared to other OECD countries and, in particular, New Zealand.

Figure 12.1: Net Tax Cost Per Unit of Contribution to a Retirement Savings

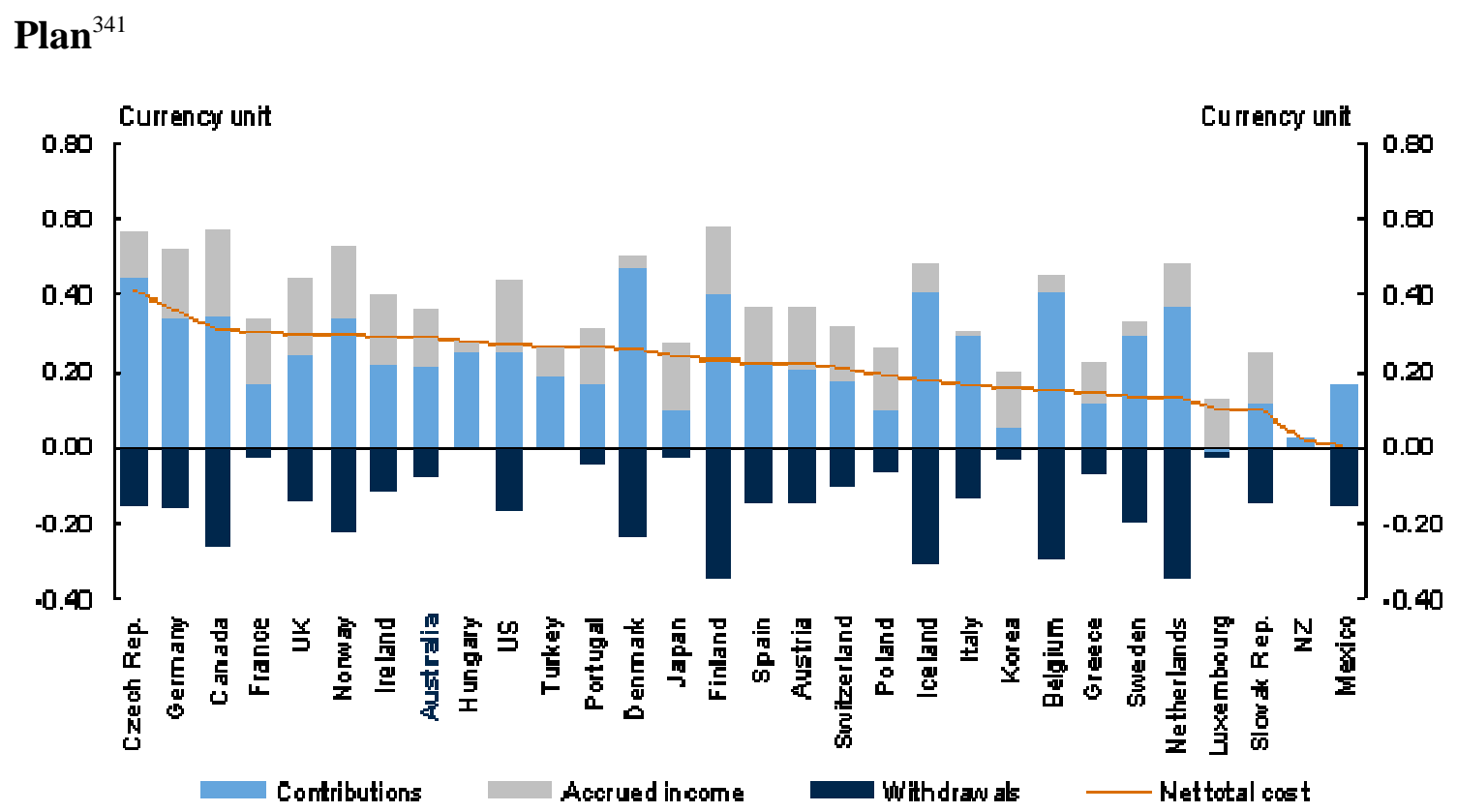

Figure 12.2: Effective Tax Rates on Private Pension and Benchmark Saving ${ }^{342}$

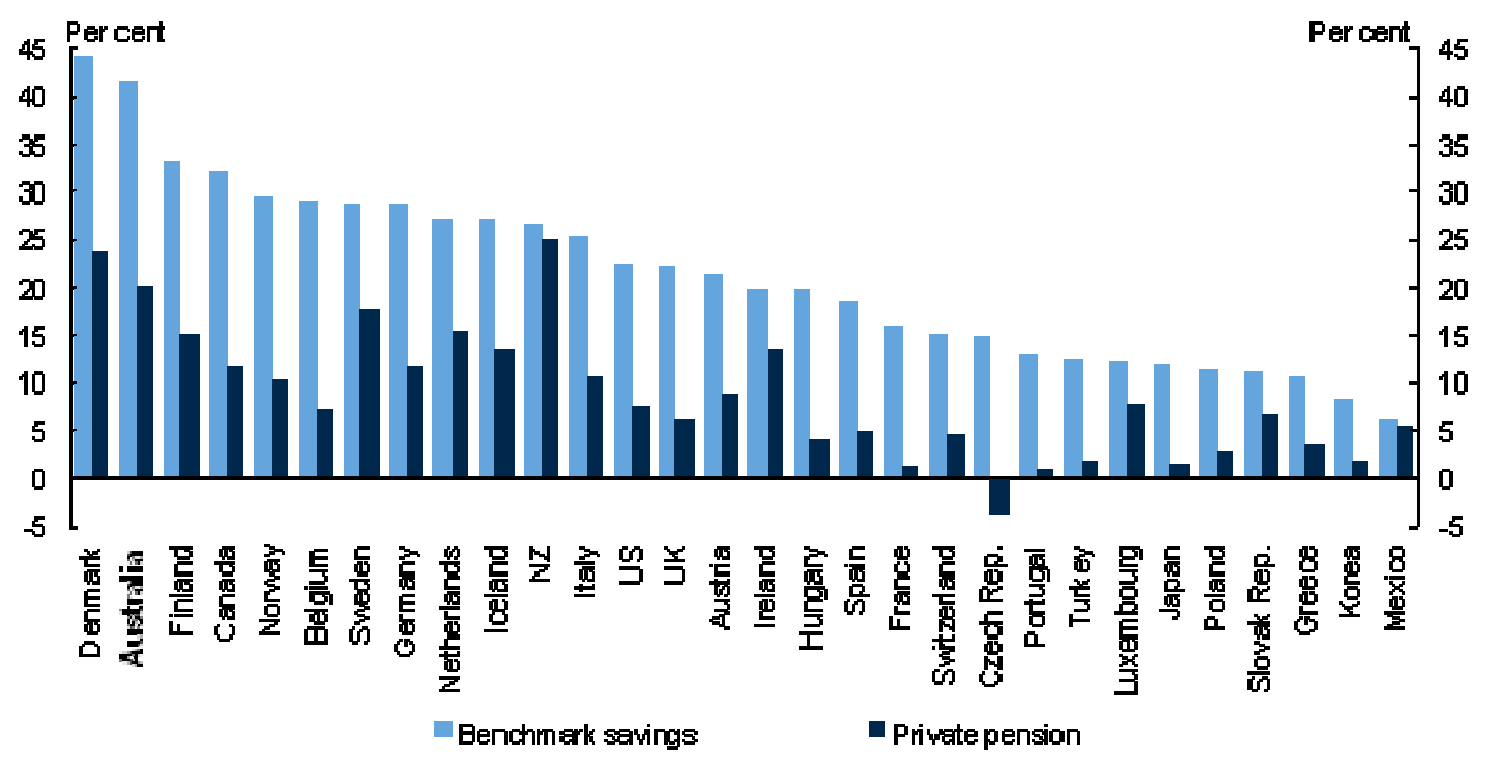

\footnotetext{
341 Age-group average. Source: Yoo and de Serres (2004:91)

342 Age-group average. Source: Yoo and de Serres (2004:92)
} 
This paper is not intended to be a critique of the New Zealand government for adopting tax policies that may have been detrimental to levels of retirement savings. New Zealand did not set out to increase retirement savings; it set out to increase efficiency. It may have achieved this, but that is not a question this thesis addresses. However, Australia did set out to increase retirement savings and standards of living in retirement, purposely adopting policy to achieve that objective. Was New Zealand remiss in not following the same policy objective as Australia? Perhaps, but again, that is not a question this thesis attempts to answer.

The above discussion leads to the question of the likely future development of the taxation of superannuation and retirement savings policy in New Zealand and Australia. As New Zealand has introduced a small tax incentive for retirement saving in 2007, Australia has adopted even more generous tax concessions. This has resulted in a surge of funds into superannuation schemes. The changes announced in the May 2006 federal budget (implemented in 2007) are estimated to have increased the total superannuation market by 60 per cent above what it would have been in the absence of the changes, with the average balance held by a member in all superannuation accounts increasing from $\mathrm{A} \$ 45,700$ in 2005 to $\mathrm{A} \$ 74,700$ in $2007 . .^{343}$

The importance of ideological considerations is clear when looking at this case study. The ideas that were proposed in both the New Zealand and Australian contexts became more influential once they were entrenched in the nation's consciousness. It is extremely unlikely that any Australian government would attempt to unravel the Superannuation Guarantee arrangements. The most recent increase in generosity of tax concessions for superannuation is also indicative of state support for retirement saving. While it could be argued that this was a vote-buying initiative in the year prior to a federal election, concessions such as this are difficult to unravel once the expectation of their provision becomes embedded in society. As with the Superannuation Guarantee in Australia, National Superannuation in New Zealand is unlikely to be challenged. Even in the face of mounting evidence challenging its

343 Rice Warner Actuaries, Media Release, November 2007, www.ricewarner.com, viewed December 2007. 
affordability, ${ }^{344}$ there is currently little political will to change either its application or level of provision.

The KiwiSaver scheme in New Zealand has been remarkably successful. In the nine months that it has been operational, over 600,000 members have joined. ${ }^{345}$ The introduction of KiwiSaver accounts may be indicative of the future, demonstrating that the current arrangements are unlikely to be sustainable at current levels. Assuming that the New Zealand public will continue to find compulsion unacceptable, it is likely that the only course of reasonable action in New Zealand will be a move to either limit application of New Zealand Superannuation (with the application of a means or income test) or the introduction of more deliberate incentives to encourage private saving. Given the absence of political appeal for the former suggestion, it is suggested that the latter course of action is the most likely approach.

The theory in this thesis is not intended to produce generalisable outcomes or predictions of what the future may hold for retirement savings in either country. Nevertheless, it does allow some tentative suggestions as to the possible directions that policy may adopt in each country. Clearly some policy options are no longer viable; for example, the dismantling of the compulsory scheme in Australia is extremely unlikely, for both social and political reasons. What may happen with tax incentives in Australia is open for debate. Whether the current generous provisions are sustainable is questionable, but it is likely they may become entrenched and sensitive to change. In New Zealand, the most likely and politically acceptable option is an increased focus on encouragement to save through the promotion of financial benefits, the start of which may be seen with the introduction of KiwiSaver accounts.

344 For example, Secretary of the Treasury, John Whitehead, in an address to invited guests from the public and private sector on 13 December 2007 in Wellington, commented in relation to retirement savings, 'population changes mean that, over the long-term, we simply can't keep doing what we are doing now'. Address available at www.treasury.govt.nz, viewed December 2007.

345 Press Release by Dr Michael Cullen, Minister of Finance, 12 June 2008. KiwiSaver numbers closing in on 700,000. www.beehive.govt.nz, viewed June 2008. 


\subsection{Historical Institutionalism}

Steinmo (2008a:163) suggests that "what the historical institutional scholar wants to know is why a certain choice was made and/or why a certain outcome occurred'. Historical institutionalism was selected as the theoretical framework in this thesis because of the importance it places on historical events: these historical events contribute towards an explanation of policy outcomes. At a more detailed level, institutional theory suggests that the structure of political institutions plays a key role in taxation policy change. This facilitates investigation of the way that institutions have structured the debates and discussions around the taxation of retirement savings in New Zealand and Australia.

An institutional perspective does not limit itself to the investigation of institutions per se and is careful to acknowledge the importance of the distribution of power and interactions between institutions and individual actors. It facilitates inclusion of other environmental factors, through emphasis on the way institutions are structured. Accordingly, this research does not suggest that institutions alone explain the situation witnessed; a number of factors, including institutional influences, contribute to the outcomes seen. The key dimensions of the environment, institutions, power and ideas, as outlined in the previous four chapters, are not competing factors; for the most part, they are complementary and in many cases allow for greater visibility of potential explanations when viewed collectively.

A further reason for the use of institutional theory in this analysis is because of the belief that it is necessary to take into account the policy process and policy makers in order to offer an accurate account of policy development. What it facilitates is an assessment of institutional factors on policy formation. However, this approach privileges institutions within the analysis. When the focus is not on institutions alone, the importance of other dimensions, such as ideas, is emphasised.

Perhaps one of the most interesting outcomes from the use of historical institutionalism in this comparative case study is in highlighting the important historical influences of the policy outcome in Australia; involvement of the trade unions and negotiated outcomes building on historic policy. Conversely, the New 
Zealand policy change had little historical foundation and was opposed to the historical welfare position adopted in New Zealand. While the 'safety net' of New Zealand Superannuation remained, the removal of state support for self reliance in old age challenges one of the fundamental facets of historical institutionalism: that policy changes have a historic foundation. However, the removal of state support for retirement saving is readily explained by reference to the environment, institutions, power and ideas as outlined over previous chapters.

While institutional theory emphasises the importance of 'multiple, competing logics', recognising that individual actors may not necessarily be aligned to the same world view, this is not apparent within the comparative case study examined. Conversely, it appears that it was individual alignment to the institutional ideology that contributed to the receptive environment for policy change. Institutional theory argues that this may reinforce the status quo but, as demonstrated in both case studies, this was not the case.

Certain elements of historical institutionalism have been helpful in structuring the analysis in this case study, such as the concept of path dependency. Patterns of path dependency are clear in both countries, with the continued provision of tax incentives in Australia and the grandfathering of previous tax arrangements with incremental changes. Path dependency is seen in the New Zealand context with the provision of National Superannuation, as it was in the 1980s, and New Zealand Superannuation as it is today. Moreover, in both countries, historical policy decisions influenced the debate on potential future options. The path dependency arguments are also useful when considering the possible future policy options in each country, as discussed in the previous section.

While path dependency arguments have a degree of 'fit' with the development of retirement savings taxation in New Zealand and Australia, it is clear that states are not restricted to their historical legacies in formulating future policies. The two key changes in New Zealand and Australia (the removal of tax incentives and the implementation of the Superannuation Guarantee, respectively) cannot be explained by path dependency arguments. In the case of New Zealand, removal of tax incentives may be attributed to a 'critical juncture'. Critical junctures assist with 
significant change at times of 'crisis'. The New Zealand environment was sufficiently difficult to warrant the 'crisis' description. In the Australian context, implementation of the Superannuation Guarantee cannot be attributed to either path dependency or critical junctures. Rather, the trade union movement interest in the 'social wage' created the ideologically based impetus for the start of compulsory retirement savings in Australia. This may be explained by the concept of punctuated equilibrium, as demonstrated with minimal change over an extended time period, followed by a period of rapid significant change, before revision to stability in a new form.

In New Zealand, this potential for constrained policy options is not as strong as in Australia. Since the removal of tax incentives in 1988, there has been a clean slate with which successive governments may potentially have implemented different arrangements. The absence of changes until 2007 indicates a degree of path dependency also, with a 20-year period of minimal state involvement in encouraging retirement savings. However, in New Zealand, at a time that is unlikely to be considered as being a 'crisis', the policy direction is showing signs of change, although these remain at an early developmental stage (with the introduction of KiwiSaver accounts in 2007). Again, path dependency arguments may assist, with the suggestion that it would be problematic, based on the 20-year absence of state involvement in retirement savings, for sudden significant involvement to be acceptable to the populace. An alternative, theoretically grounded explanation is that New Zealand may be entering a period of 'punctuation' and further changes may be expected over a relatively short period of time.

The path dependency arguments facilitate the discussion in section 12.2.1 in relation to the possible future direction of policy. Path dependency highlights the difficulty that Australia may have in changing paths for retirement savings in the future. The changes made throughout the 1982 to 1992 period have severely limited the potential for Australia to make radical reforms. As time has progressed, this option has become embedded into Australian society, limiting the ability of future policy makers to adopt policy options such as that adopted by New Zealand. 
The use of historical institutionalism, in emphasising ideas in the analysis, highlights the link between ideas and power. A key insight is the evidence indicating that ideas strengthened and validated the power structures, rather than the reverse, which is often considered to be the case in both the New Zealand and Australian contexts. Furthermore, the preferences of an institution are communicated and adapted with reference to the prevailing ideology of the institution.

It was suggested in chapter nine that the utility of historical institutionalism may be reflected by the level of detail both undertaken in the research and desired from the research output. Where this research differs from many other similar institutional studies on tax reform is in the comparison of a single policy decision in isolation. The benefit of this micro-analysis is that it allows for many of the more subtle influences to be highlighted and the detailed interactions between individuals and institutions to be explored.

It has been suggested that historical institutionalism is effective for the study of ' $b i g$, substantive questions' and to 'analyze macro contexts and hypothesize about the combined effects of institutions and processes' (Pierson and Skocpol 2000:3). These claims raise the possibility that historical institutionalism has less utility for a study of a more detailed component of policy, rather than broader structural tax reform. Much of the research to date using historical institutionalism for the study of tax reform is situated at a macro level (e.g. Heclo 1974, Pierson 1994, Skocpol 1992, and Weir and Skocpol 1985). These and many other well-known studies have adopted significant policy reforms to study, rather than individual policy changes. In these cases, historical institutionalism has proved to be an effective tool for analysis. This leads to the suggestion that perhaps historical institutionalism is best used for higher-level analyses and has less application for a detailed analysis, such as in this thesis.

This may, in turn, lend itself to an elucidation of why the key explanatory factor in this analysis, ideas, is not often highlighted in the research to date. It may be that variables such as ideas necessitate a more detailed analysis; and instead may become diluted among other policy debates when a high-level analysis is adopted. 
The analysis indicates that a focus on ideas is beneficial to a comparative case study such as this. Ideas provided a number of insights, including the potential for different interpretation of ideas in different countries; the importance of gaining support for ideas; the likelihood of increased acceptance of ideas that 'fit' with the prevailing environment and provide a credible 'solution' to the policy problem; the privileging of individuals and institutions that support the preferred ideology; and the value of providing a coherent world view, which actors were motivated to support. These findings indicate that it may be beneficial to place a stronger emphasis on the concept of ideas in policy analysis.

In summary, the ongoing ideological development in both New Zealand and Australia provided the necessary validation to implement radical policy reform that was relevant to the respective environment, but was also supported by institutions and the power arrangements in place at the time. In this thesis, historical institutionalism has facilitated an analysis combining political (institutions), social (ideologies and power) and economic (environmental) factors. Historical institutionalism has provided a framework for structuring the analysis and addressing the problem at a higher level. However, when a more detailed analysis was required in this case study, it was less useful. It is acknowledged that the observations made of one event in two countries are insufficient to prove or disprove elements within historical institutionalism. However, the indication that historical institutionalism may have greater utility for larger case study analyses may have application for future research.

\subsection{Concluding Comments}

The reforms of retirement savings and the taxation of retirement savings in both countries were radical in contrast to those adopted by the rest of the OECD. As stated at the outset, the historical approach is intended to permit an understanding of the options and limitations that exist at a particular time, in part resulting from decisions made at earlier junctures of policy development. With the benefit of hindsight, it could even be suggested that the outcomes in both countries were predictable. Australia's history of consultation and negotiation in the industrial arena was likely to produce a more paternalistic approach to retirement savings. New Zealand's history 
of social experimentation may also have provided some indication of its potential unique future direction.

Some acknowledgement must go to the element of 'chance' in the policy development process. The potential for unexpected events or individuals to combine to create an environment that at any other time would not have produced the same result remains a confounding factor in this research. Personalities, individuals, relationships, history and cultural expectations have all combined to create this unique story. Thus, there is little in the way of generalisable outcome from this research; instead, what the thesis provides is an explanation of the key variables that influenced policy direction and the interactions that have resulted in the policy outcomes seen today. This research demonstrates the importance of the four dimensions explored and the links between these dimensions, which allowed each to have the sustainable influence witnessed. Perhaps, in the absence of any structured path of policy formation, it is sufficient to suggest that to understand the outcomes that exist in the present day it is necessary to consider the historical events that have assisted in their formation. 


\section{Appendix: Interview Participants}

New Zealand employer group representative

New Zealand academic / commentator

Senior New Zealand bureaucrat

Senior New Zealand bureaucrat

New Zealand trade union representative

New Zealand Treasury official

New Zealand Task Force / Committee member

Senior New Zealand bureaucrat

New Zealand industry representative

New Zealand Member of Parliament

New Zealand Task Force / Committee member

New Zealand Member of Parliament

Senior New Zealand bureaucrat

New Zealand Task Force / Committee member

New Zealand Task Force / Committee member

New Zealand Member of Parliament

Australian industry member

Australian industry member

Australian Member of Parliament

Australian trade union representative

Government adviser (Australia)

Australian Member of Parliament

Australian academic/commentator

Senior Australian bureaucrat

Government adviser (New Zealand and Australia)

Australian Member of Parliament

Government adviser (New Zealand and Australia)

Australian Member of Parliament

New Zealand academic / commentator

Australian trade union representative

Senior Australian bureaucrat

Australian interest group representative

Australian industry member 


\section{Glossary}

Annuity - a pension that pays a regular income. Usually an annuity guarantees that an income will be received until an individual dies. The total amount paid may be more or less than invested (Olsberg 1997:200).

Approved Deposit Fund - an Australian trust fund that is established for termination payment investment. It can only accept termination payments and must meet the relevant tax law requirements in order to receive concessional tax treatment. The termination payment must be rolled over within 90 days of receipt.

Defined Benefits Fund - a superannuation scheme that pays a fixed or defined amount of money, linked to salary at the time of retirement.

Defined Contribution Fund - a pension plan in which the periodic contribution is prescribed and the benefit depends on the contribution plus the investment return (World Bank 1994:xxi).

Eligible Termination Payment - a lump sum paid on retirement, job termination or death in Australia. An eligible termination payment can be rolled over into a rollover fund.

Expenditure Tax Regime - funds contributed to a superannuation fund and returns accrued in that fund are both exempt from taxation. Benefits are taxed on withdrawal from the fund. This is known as the "exempt-exempt-taxed" (EET) approach.

Friendly Society - A society which by voluntary subscriptions provides for the relief or maintenance of its members and their families in sickness, old age, etc.

Household-Savings Ratio - the ratio of unspent household income to total household income. The household-savings ratio is considered a good indicator of an economy's savings performance. 
Income Tax Regime - savings are made out of taxed earnings and the accrued returns on funds are also subject to income tax. Withdrawal of funds are tax exempt. This is known as the "taxed-taxed-exempt" (TTE) approach.

Income test - an income test is used to establish eligibility to certain state provided benefits. When an income test exists, the benefit may be reduced depending on the recipient's level of income.

Industry Funds - industry funds are superannuation funds that are run either by industry or unions. They have been in place in Australia since 1984. Industry funds are not-for-profit organisations, with all profits retained for the benefit of members. Equal representation of members and employers is required on an industry fund Board of Directors.

Life Office - a firm that sells life insurance and other insurance products; for example, life cover, superannuation bonds, annuities and superannuation.

Means Test - a means test refers to an investigative process undertaken to determine eligibility for certain state provided benefits. A means test can relate to assets as well as income.

Neutral Taxation - a neutral taxation system neither favours nor penalises additional income generated from retirement savings when compared with other forms of additional income (Task Force on Private Provision for Retirement 1992:19). Neutrality within a taxation system is intended to minimise opportunities for tax planning, avoid distortion of decision making and improve equity.

Pay-As-You-Go/Smoothed Pay-As-You-Go - a pay-as-you-go superannuation scheme is where benefits are financed from current contributions and incomes of the scheme. No advance funding arrangements or actuarial reserves are in place. A smoothed pay-as-you-go scheme is partly funded from actuarial reserves or advance funds, such as the New Zealand Superannuation Fund. 
Pension - a regular income paid for life from a particular date or event (e.g. retirement).

Portability - allowing a superannuation plan to be transferred from one fund (or one employer) to another.

Preservation/Preservation Age - maintenance of a member's entitlements in a superannuation fund until a specified minimum age (usually at least 55 years), even when employment is changed.

Primary and Secondary Source Documents - reference to primary source documents relates to statements by eyewitnesses, or documents and other materials that are 'contemporary with the event they attest' (Evans 1997:88). Reference to secondary source documents refers to documents that relate to, and discuss, events that are not witnessed first-hand, but are gained indirectly from other authorities.

Productivity - the relationship between the total output of the economy and the resources used to produce it (ACTU 1986:5). Increased productivity means that more real wealth is being produced by the country's resources.

Reasonable Benefit Limit - the Reasonable Benefit Limit (RBL) is the maximum concessionary taxed superannuation benefit that a person can receive over a lifetime in Australia. Superannuation benefits received above the RBL are taxed at the highest marginal tax rate.

Retirement Income Savings/Retirement Savings - retirement income savings (also referred to as retirement savings) refers to savings that are put aside for the purpose of providing an income stream or lump sum on retirement. Retirement income savings differ from traditional savings in two principal respects. Typically, they are required to be 'locked in' for a substantial period. In addition, generally a substantial sum is required in order to be of benefit in retirement. Net worth is generally accumulated over a lifetime, and in many cases it is difficult for significant savings to take place 
once an individual has reached retirement. Generally, assets increase with age until retirement, at which point assets start to decrease with consumption. The level and form of savings that individuals enter into during their working lives will impact on their net asset position at retirement, and accordingly their level of retirement income and standard of living.

Retirement Savings Accounts - introduced in Australia in 1996, these retirement savings accounts were intended to be a simple, low-cost, low-risk alternative to conventional superannuation arrangements. They were provided by financial institutions, such as banks, building societies, credit unions, life insurance companies, friendly societies and other financial institutions. It was intended that employers may use retirement savings accounts as an alternative to making contributions to superannuation funds for employees and that individuals could also use them for individual superannuation contributions.

Rollover Funds - when a member changes jobs and takes an Eligible Termination Payment from a superannuation fund, approved deposit fund or deferred annuity fund, this lump sum can be transferred to other schemes without losing the tax advantage which attached to it. Rollover funds were introduced to encourage people changing employment or taking early retirement to preserve superannuation entitlements until retirement age is reached. Rollover funds receive concessional tax treatment insofar as the tax liability is deferred until retirement age.

Savings - savings are generally defined as the sacrifice of current consumption for future consumption. Savings are generally provided (directly or indirectly) to capital markets for productive investment (Claus and Scobie 2002:2). Saving decisions by individuals, firms or the state take into account a range of factors, including expected future income flows, labour supply, economic growth, government policy, individual preferences, the rationality of expectations and the role of credit institutions (Claus and Scobie 2002:2).

Superannuation/Superannuation Fund - superannuation is a long-term savings arrangement that operates primarily to provide income for retirement. A 
superannuation fund is an entity established for the purpose of providing benefits to members on retirement, death or disablement (Bateman and Piggott 1997:82).

Superannuation Guarantee Charge/Superannuation Guarantee Levy - the Superannuation Guarantee Levy is a compulsory contribution in Australia that an employer must make to a superannuation fund on behalf of most of its employees. The level is nine per cent of earnings. If an employer does not meet this contribution, a Superannuation Guarantee Charge is levied, which consists of the costs of the employee's entitlements plus penalty and interest charges.

Universal Pension - a universal pension is a flat-rate, fixed-amount pension paid to qualifying individuals on reaching a certain age. There are no income or asset tests associated with universal pensions. 


\section{References}

Age Concern. 1998. Employment and Retirement Issues for Older People in New Zealand. www.ageconcern.org.nz, viewed September 2006.

Agulnik, P. 2000. “Maintaining Incomes After Work: Do compulsory earningsrelated pensions make sense?” Oxford Review of Economic Policy, 16(1):45.

Almond, G.A., and Powell, G.B. 1969. Interest Articulation Structures: Interest 'Groups'. In J Blondel (Ed) Comparative Government. London: MacMillan \& Co Ltd.

Amenta, Edwin. 2003. What we Know about the Development of Social Policy: Comparative Historical Analysis in the Social Sciences. In J Mahoney and D Rueschemeyer (Eds) Comparative Studies in Comparative Policies. Cambridge: Cambridge University Press.

Antolin, Pablo, de Serres, Alain, and de la Maisonneuve, Christine. 2004. LongTerm Budgetary Implications of Tax-Favoured Retirement Plans. Paris: OECD Publishing.

Appel, Hilary. 2000. “The Ideological Determinants of Liberal Economic Reform: The case of privatization". World Politics, 52:520.

Apter, David, E. 1996. Comparative Politics, Old and New. In R Goodin and H-D Klingemann (Eds) A New Handbook of Political Science. Oxford: Oxford University Press.

Arrau, Patricio, and Schmidt-Hebbel, Klaus. 1995. Pension Systems and Reforms: Country experiences and research issues. The World Bank, Policy Research Department, Macroeconomics and Growth Division.

Ashton, T., and St John, S. 1988. Superannuation in New Zealand: Averting the Crises. Wellington: Victoria University Press.

Atkinson, Margaret, E., Creedy, John, and Knox, David, M. 1999. "Some Implications of Changing the Tax Basis for Pension Funds". Fiscal Studies, 20(2): 189. 
Attanasio, Orazio, P., Banks, James, and Wakefield, Matthew. 2004. Effectiveness of Tax Incentives to Boost (Retirement) Saving: Theoretical motivation and empirical evidence. The Institute for Fiscal Studies Working Paper 04/33.

Australian Bureau of Statistics. 2002. Australian Social Trends 2002 (No 4102.0). www.abs.gov.au, viewed November 2006.

Australian Bureau of Statistics. 2003. Measuring Australia's Economy: International Accounts and Trade Balance of Payments Current Account. www.abs.gov.au, viewed November 2005.

Australian Bureau of Statistics. 2006a. Australian Social Trends 2006 (No 4102.0). www.abs.gov.au, viewed January 2007.

Australian Bureau of Statistics. 2006b. Employee Earnings, Benefits and Trade Union Membership (No 6310.0). www.abs.gov.au, viewed January 2008.

Australian Bureau of Statistics. 2006c. Population Projections, Australia 2004 2101 (No 3222.0). www.abs.gov.au, viewed January 2007.

Australian Council of Trade Unions. 1985. Superannuation Through Productivity: An economic right for all workers. Melbourne: Australian Council of Trade Unions.

Australian Council of Trade Unions. 1986. Superannuation Negotiating Exhibit. Carlton: Australian Council of Trade Unions.

Australian Council of Trade Unions. 1989. National Retirement Incomes Policy. Melbourne: Australian Council of Trade Unions Social Welfare Committee.

Australian Treasury. 2006. A Plan to Simplify and Streamline Superannuation. Canberra: AGPS.

Avi-Yonah, Reuven, S. 2003. “Tax Stories and Tax Histories: Is There a Role for History in Shaping Tax Law?”. Michigan Law Review, 101(6):2227.

Barr, Nicholas. 2000. Reforming Pensions: Myths, truths and policy choices. IMF Working Paper WP/00/139.

Barro, Robert, J. 1974. “Are Government Bonds Net Wealth?” The Journal of Political Economy, 82(6);1095. 
Baskerville, Rachel, F. 2003. "Hofstede never studied culture". Accounting, Organizations and Society, 28(1):1.

Bateman, H. 2002. "Retirement Income Strategy in Australia". Economic Analysis and Policy, 32(1):49.

Bateman, H. 2005. Mandatory Private Savings Policies: What have we learnt? Centre for Pensions and Superannuation Discussion Paper 02/05.

Bateman, H. 2006. Retirement Provision in Scary Markets. Northampton, Elgar Publishing.

Bateman, H., and Kingston, G. 2007. Superannuation and Personal Income Tax Reform. Conference paper presented at the Personal Income Tax Reform Symposium, April 2007, ATAX, University of New South Wales, Sydney.

Bateman, H., Kingston, G., and Piggott, J. 1994. Equity, Efficiency and the Superannuation Guarantee. In D Knox (Ed) Superannuation: Contemporary issues. Melbourne: Longman Professional.

Bateman, H., Kingston, G., and Piggott, J. 2001. Forced Saving: Mandating Private Retirement Incomes. Cambridge: Cambridge University Press.

Bateman, H., and Piggott, J. 1992. “Australian Retirement Income Policy”, Australian Tax Forum, 9(1):1.

Bateman, H., and Piggott, J. 1997. Private Pensions in OECD Countries: Australia. OECD Labour Market and Social Policy Occasional Paper, No 23. Paris: OECD Publishing.

Bateman, H., and Piggott, J. 1999. "Mandating Retirement Provision: The Australian Experience". The Geneva Papers on Risk and Insurance, 24(1):95.

Bateman, H., and Piggott, J. 2000. Australia's Mandatory Retirement Savings Policy: A view from the new millennium. Working Paper (2000/4) Centre for Applied Economic Research.

Bateman, H., and Piggott, J. 2001. The Australian Approach to Retirement Income Provision. Conference paper presented at the International Seminar on Pensions, 5 7 March 2001, Sano-shoin, Hitotsubashi University, Tokyo, Japan. 
Beland, Daniel. 2005. "Ideas and Social Policy: An Institutionalist Perspective". Social Policy and Administration, 39(1):1.

Belich, James. 2001. Paradise Reforged: A history of the New Zealanders from the 1880s to the year 2000. Auckland: Penguin Press.

Bell, Stephen, and Head, Brian. 1994. Australia's Political Economy: Critical themes and issues. In S Bell and B Head (Eds) State, Economy and Public Policy in Australia. Melbourne: Oxford University Press.

Bernheim, B. Douglas. 2002. Taxation and Saving. In Alan J Auerbach and Martin Feldstein (Eds) Handbook of Public Economics Volume III. Amsterdam: Elsevier.

Bingham, Cliff, and Rothman, George. 2005. Incentives to Save More In Superannuation. Paper presented to the Thirteenth Colloquium of Superannuation Researchers, University of New South Wales, 4 and 5 July 2005.

Bloch, Marc. 1953. Towards a Comparative History of European Societies. London: George Allen and Unwin Ltd.

Bloch, Marc. 1967. Land and Work in Mediaeval Europe: Selected papers by Marc Bloch. London: Routledge and Kegan Paul Ltd.

Blundell, Richard. 1996. “Tax Policy Reform: Why we need microeconomics”. Fiscal Studies, 16(3):106.

Blyth, Mark. 1997. ““'Any More Bright Ideas?” The ideational turn of comparative political economy". Comparative Politics, 29(2):229.

Blyth, Mark. 2002. Great Transformations: Economic ideas and institutional change in the twentieth century. Cambridge: Cambridge University Press.

Blyth, Mark. 2003. "Structures Do Not Come with an Instruction Sheet: Interests, ideas, and progress in political science". Perspectives on Politics, 1(4):695.

Bollard, Alan. 1994. New Zealand. In J Williamson (Ed) The Political Economy of Policy Reform. Washington: Institute for International Economics.

Bollard, Alan, Hodges, Bernard, Briggs, Phil, and Smith, Mark. 2006. Household savings and wealth in New Zealand. Background paper prepared for Alan Bollard's presentation to INFINZ, Wellington, September 2006, Reserve Bank of New Zealand. 
Booth, Christopher, J. 1977. The National Party's 1975 Superannuation Policy. In G Palmer (Ed) The Welfare State Today. Wellington: Fourth Estate Books Ltd.

Boston, Jonathan. 1992. The Treasury: Its role, philosophy and influence. In H Gold (Ed) New Zealand Politics in Perspective $3^{\text {rd }}$ Edition. Auckland: Longman Paul Ltd.

Borsch-Supan, A. 2004. Mind the Gap: The effectiveness of incentives to boost retirement saving in Europe. Mannheim Research Institute for the Economics of Ageing, MEA Discussion Paper Series No 0452.

Bramble, Tom, and Heal, Sarah. 1997. Trade Unions. In C Rudd and B Roper (Eds) The Political Economy of New Zealand. Oxford: Oxford University Press.

Brosnan, Peter, Burgess, John, and Rea, David. 1991. Labour Institutions, Government Policy and Economic Change in Australia and New Zealand. Victoria University of Wellington Industrial Relations Centre Paper No 91/2.

Bryant, J., Teasdale, A., Tobias, M., Cheung, J., and McHugh, M. 2004. Population Ageing and Government Health Expenditures in New Zealand 1951 - 2051. New Zealand Treasury Working Paper 04/14.

Bulmer, Simon, J. 1998. "New Institutionalism and the Governance of the Single European Market”. Journal of European Public Policy, 5(3): 365.

Burman, Leonard, E., Gale, William, G., Hall, M., and Orszag, Peter, R. 2004. Distributional Effects of Defined Contribution Plans and Individual Retirement Accounts. Urban-Brookings Tax Policy Centre, Discussion Paper No 16.

Burrell, Gibson, and Morgan, Gareth. 1979. Sociological Paradigms and Organisational Analysis: Elements of the sociology of corporate life. London: Heinemann Educational Books.

Cagan, Phillip. 1965. The Effect of Pension Plans on Aggregate Savings: Evidence from a sample survey. New York: National Bureau of Economic Research.

Callister, Paul. 2003. Private Provision for Retirement: Case studies of Australia, Canada, Ireland, Germany, the United States and the United Kingdom. Retirement Income Research Centre, www.retirement.org.nz, viewed January 2006. 
Cameron, R., and Nicholl, P. 1975. Financial Implications of the New Zealand Superannuation Scheme. Discussion Paper 1, Money and Finance, Victoria University of Wellington.

Campbell, John. 1997. "Recent Trends in Institutional Political Economy". The International Journal of Sociology and Social Policy, 18(7/8):15.

Campbell, John. 2002. "Ideas, Politics, and Public Policy". Annual Review of Sociology, 28:21.

Campbell, R., and Kirk, A. 1983. After the Freeze: New Zealand unions in the economy. Wellington: Port Nicholson Press.

Carmichael, Jeffrey, and Plowman, Kathleen. 1985. "Income Provision in Old Age". The Australian Economic Review, $3^{\text {rd }}$ Quarter:130.

Carnegie, Garry, D., and Napier, Christopher, J. 1996. "Critical and Interpretive Histories: Insights into accounting's present and future through its past”. Accounting, Auditing and Accountability Journal, 9(3):7.

Carnegie, Garry, D., and Napier, Christopher, J. 2002. "Exploring Comparative International Accounting History”. Accounting, Auditing and Accountability Journal, 15(5):689.

Carr, Edward, H. 1961. What is History? London: MacMillan and Co Ltd.

Carroll, Chris, and Summers, Lawrence, H. 1987. "Why Have Private Savings Rates in the United States and Canada Diverged?” Journal of Monetary Economics, 20:249.

Castles, Francis, G. 1985. The Working Class and Welfare: Reflections on the political development of the welfare state in Australia and New Zealand, 1890 - 1980. Wellington: Allen and Unwin.

Castles, Francis, G., Gerritsen, Rolf., and Vowles, Jack. 1996. Setting the Scene for Economic and Political Change. In F Castles, R Gerritsen and J Vowles (Eds) The Great Experiment: Labour parties and public policy transformation in Australia and New Zealand. Auckland: Auckland University Press.

Clarke, F.G. 1992. Australia: A concise political and social history. Sydney: Harcourt Brace Jovanovich Publishers. 
Claus, Iris, and Scobie, Grant. 2002. Saving in New Zealand: Measurement and trends. New Zealand Treasury Working Paper 02/02.

Clements, R.T. 1984. Savings in New Zealand During Inflationary Times. Reserve Bank of New Zealand Research Paper No 38, May 1984.

Coleman, A. 1998. Household Savings: A survey of recent microeconomic theory and evidence. New Zealand Treasury Working Paper 98/08.

Collier, Ruth, and Collier, David. 1991. Shaping the Political Arena: Critical junctures, the labor movement, and regime dynamics in Latin America. Princeton: Princeton University Press.

Collins, David, B. 1977. Formulating Superannuation Policy: The Labour Party approach. In G Palmer (Ed) The Welfare State Today. Wellington: Fourth Estate Books Ltd.

Committee for Economic Development of Australia. 1981. Superannuation - at what cost? Melbourne: Committee for Economic Development of Australia.

Committee of Inquiry into the Australian Financial System. 1981. The Australian Financial System: Final report of the Committee of Inquiry. Canberra: AGPS.

Commonwealth Task Force on Occupational Superannuation. 1983. Final Report of the Commonwealth Task Force on Occupational Superannuation. Canberra: AGPS.

Connolly, Ellis, and Kohler, Marion. 2004. The Impact of Superannuation on Household Saving. Economic Research Department, Reserve Bank of Australia, Research Discussion Paper 2004-01.

Consultative Committee on Superannuation, Life Insurance and Related Areas. 1988. Report of the Consultative Committee on Superannuation. Wellington: New Zealand Government Printer.

Crawford, Sue, E.S. 1995. "A Grammar of Institutions". The American Political Science Review, 89(3):582.

Creedy, J., and Scobie, G. 2002. Population Ageing and Social Expenditure in New Zealand: Stochastic projections. New Zealand Treasury Working Paper 03/34.

Crotty, Michael. 1998. The Foundations of Social Research. Crows Nest: Allen and Unwin. 
Cullen, Michael. 1992. The Implications of a Future Change of Government for Superannuation. AIC Conference on Superannuation Reform, 25 and 26 May 1992, Wellington.

Dabscheck, Braham. 1989. Australian Industrial Relations in the 1980s. Oxford: Oxford University Press.

Daldy, Bridget, Hickey, Frances, and O’Neill, James. 1985. The National Superannuation Scheme: Economic and demographic considerations and options for reform. Population Studies Centre and Department of Sociology, University of Waikato, Working Paper No 24.

Davey, J. 2004. Social Monitoring and the Challenge of an Ageing Population. Paper prepared for The Visible Hand Symposium, Victoria University of Wellington, 19 November 2004.

Davey, J., and Gee, S. 2002. Life at 85 Plus: A statistical review. New Zealand Institute for Research on Ageing. www3.vuw.ac.nz/ageing-institute, viewed March 2006.

Davey, J., and Keeling, S. 2004. Combining Work and Elder Care: A study of employees in two City Councils who provide informal care for older people. www.retirement.org.nz, viewed March 2006.

Davies, Jonathan, S. 2004. “Conjuncture or Disjuncture? An Institutionalist Analysis of Local Regeneration Partnerships in the United Kingdom". International Journal of Urban and Regional Research, 28(3):570.

Davis, N., and Fabling, R. 2002. Population ageing and the efficiency of fiscal policy in New Zealand. New Zealand Treasury Working Paper 02/11.

Denzin, Norman, K., and Lincoln, Yvonna, S. 2005. The Discipline and Practice of Qualitative Research. In N Denzin and Y Lincoln (Eds) Handbook of Qualitative Research $3^{\text {rd }}$ Edition. Thousand Oaks: Sage Publications.

Department of Immigration and Ethnic Affairs. 1981. Review of Australia's Demographic Trends, Parliamentary Paper No 94/1981. 
Department of Social Security. 1984. Government Support of Retirement Incomes in Australia. Policy Review Branch, Development Division, Research Paper No 24. Canberra: AGPS.

Department of Social Security. 1988. Towards a National Retirement Incomes Policy: An Overview. Issues Paper No 6, Social Security Review. Woden: Department of Social Security.

Dilnot, Andrew, and Johnson, Paul. 1993. The Taxation of Private Pensions. London: The Institute for Fiscal Studies.

Disney, Richard, and Johnson, Paul. 2001. Pension Systems and Retirement Incomes Across OECD Countries. Cheltenham: Edward Elgar.

Dixon, John. 1977. Australia's Policy Towards the Aged: 1890 - 1972. Canberra Series in Administrative Studies 3, Canberra College of Advanced Education.

Dixon, John. 1981. The Age Pension: Developments from 1890 to 1978. In A Howe (Ed) Towards an Older Australia: Readings in social gerontology. St Lucia, University of Queensland Press.

Dixon, John. 1983. “Australia's Income Security System: its origins, nature and prospects". International Social Security Review, 1:19.

Donn, Clifford, B. 1983. The Australian Council of Trade Unions: History and economic policy. Lanham: University Press of America.

Eccleston, Richard. 2004. The Thirty Year Problem: The politics of Australian tax reform. Australian Tax Research Foundation Study No 42.

Eccleston, Richard. 2007. Taxing Reforms: The politics of the consumption tax in Japan, the United States, Canada and Australia. Cheltenham: Edward Elgar.

Eddie, Ian, A. 1991. “Asia Pacific Cultural Values and Accounting Systems”. Asia Pacific International Management Forum, 16(3):22.

Edey, Malcolm, and Gower, Luke. 2000. The Australian Economy in the 1990s. Reserve Bank of Australia: Canberra.

Edey, Malcolm, and Britten-Jones, Mark. 1990. Saving and Investment. In S Grenville (Ed) The Australian Macro-Economy in the 1980s. Canberra: Reserve Bank of Australia. 
Edwards, Sebastian. 1995. Why are Savings Rates So Different Across Countries? An international comparative analysis. National Bureau of Economic Research Working Paper 5097.

Engen, Eric, M., Gale, William, G., and Scholz, John, K. 1996. The Effects of TaxBased Saving Incentives on Saving and Wealth. National Bureau of Economic Research Working Paper 5759.

Evans, Richard, J. 1997. In Defence of History. London: Granta Books.

Evans, Peter, B., Rueschemeyer, Dietrich, and Skocpol, Theda. 1985. On the Road Towards a More Adequate Understanding of the State. In P Evans, D Rueschemeyer and T Skocpol Bringing the State Back In. Cambridge: Cambridge University Press.

Fechner, Harry, H.E., and Kilgore, Alan. 1994. "The Influence of Cultural Factors on Accounting Practice". International Journal of Accounting, 29:265.

Feldstein, Martin. 1996. “The Missing Piece In Policy Analysis: Social security reform". The American Economic Review, 86(2):1.

Fergusson, D., Hong, B., Horwood, J., Jensen, J., and Travers, P. 2001. Living Standards of Older New Zealanders. www.msd.govt.nz, viewed March 2006.

Fitzgerald, Vince, W., and Harper, Ian, R. 1992. "Superannuation - Preferred or "Level Playing Field?" - Implications for saving and the financial system". Australian Tax Forum, 9(2):193.

Fitzgerald, Vince, W. 1996. "Public Policy and National Saving”. Agenda, 3(1):3.

Fleischman, Richard, K., and Radcliffe, Vaughan, S. 2003. Divergent Streams of Accounting History: A review and call for confluence. In R Fleischman, V Radcliffe and P Shoemaker (Eds) Doing Accounting History: Contributions to the development of accounting thought. Amsterdam: JAI Elsevier Science.

Fleischman, Richard, K., and Tyson, Thomas, N. 1997. "Archival Researchers: An Endangered Species?" The Accounting Historians Journal, 24(2):91.

Fleischman, Richard, K., and Tyson, Thomas, N. 2003. Archival Research Methodology. In R Fleischman, V Radcliffe and P Shoemaker (Eds) Doing Accounting History: Contributions to the Development of Accounting Thought. Amsterdam: JAI Elsevier Science. 
Forward, Roy. 1983. Income in Old Age: Is National Superannuation the Answer? Current Issues Brief No 4, Legislative Research Service. Canberra: Parliament of the Commonwealth of Australia.

Fox, Louise, and Palmer, Edward. 2000. New Approaches to Multi-Pillar Pension Systems: What in the world is going on? Paper presented to the International Research Conference on Social Security, Helsinki, September 2000.

Freebairn, John, Porter, Michael, and Walsh, Cliff. 1989. Saving and Productivity: Incentives for the 1990s. Sydney: Allen and Unwin.

Funnell, Warwick. 1998. "The Narrative and its Place in the New Accounting History: The rise of the counternarrative". Accounting, Auditing and Accountability Journal, 11(2):142.

Gernon, H., and Olusegun Wallace, R.S. 1995. "International Accounting Research: A Review of its ecology, contending theories and methodologies". Journal of Accounting Literature, 14:54.

Gillion, Colin, Turner, John, Bailey, Clive and Latulippe, Denis. 2000. Social Security Pensions: Development and reform. Geneva: International Labour Organization.

Goh, Khoon. 2005. "Savings and the Household Balance Sheet". Reserve Bank of New Zealand Bulletin, 68(2):3.

Goldberg, L. 1974. “The Future of the Past in Accounting”. The Accountant's Magazine, 73(820):405.

Goodin, Robert, E. 1996. Institutions and Their Design. In R Goodin (Ed) The Theory of Institutional Design. Cambridge: Cambridge University Press.

Gray, H, Cerche, M., and Nolan, A. 1996. Superannuation: Recent developments and current issues. Melbourne: Leo Cussen Institute.

Gray, S. J. 1988. "Towards a Theory of Cultural Influence on the Development of Accounting Systems Internationally". Abacus, 24(1):1.

Grew, Raymond. 1980. "The Case for Comparing Histories". The American Historical Review, 85(4):763. 
Gruen, F.H. 1985. Australian Government Policy on Retirement Incomes. ANU Centre for Economic Policy Research, Discussion Paper No 119. Canberra: Centre for Economic Policy Research.

Guest, R., Scobie, G., and Bryant, J. 2003. Population Ageing in New Zealand: The impact on living standards and the optimal rate of saving with a flexible real exchange rate. New Zealand Treasury Working Paper 03/34.

Hague, R., Harrop, M., and Breslin, S. 1992. Comparative Government and Politics. London: The Macmillan Press.

Hale, Geoffrey. 2002. The Politics of Taxation in Canada. Peterborough: Broadview Press.

Hall, Peter, A. 1986. Governing the Economy. New York: Oxford University Press.

Hall, Peter, A. 1989. The Political Power of Economic Ideas: Keynesianism across nations. Princeton: Princeton University Press.

Hall, Peter, A. 1992. The Movement from Keynesianism to Monetarism: Institutional Analysis and British Economic Policy in the 1970s. In S Steinmo, K Thelen and F Longstreth (Eds) Structuring Politics: Historical Institutionalism in Comparative Analysis. Cambridge: Cambridge University Press.

Hall, Peter, A. 1993. "Policy Paradigms, Social Learning, and the State: The case of economic policymaking in Britain”. Comparative Politics, 25(3): 275.

Hall, Peter, A., and Taylor, Rosemary, C. 1996. "Political Science and the Three New Institutionalisms”. Political Studies, 44(5):936.

Hall, Peter, A., and Taylor, Rosemary, C. 1998. "The Potential of Historical Institutionalism: A response to Hay and Wincott”. Political Studies, 46(5):958.

Hansen, Susan, B. 1983. The Politics of Taxation: Revenue without representation. New York: Praeger Publications.

Harding, Ann, Lloyd, Rachel, and Warren, Neil. 2004. Income Distribution and Redistribution: The impact of selected Government benefits and taxes in Australia in 2001-02. Paper prepared for the $28^{\text {th }}$ General Conference of The International Association for Research in Income and Wealth, Cork, Ireland, August 2004. 
Harper, Ian, R. 1985. Taxation of Superannuation in New Zealand: Agenda for reform. Paper presented to a seminar on the Taxation of Superannuation in New Zealand, held at the Institute of Policy Studies, Wellington, 8 May 1985.

Hattam, Victoria C. 1992. Institutions and Political Change: Working-class formation in England and the United States, 1820 - 1896. In S Steinmo, K Thelen and F Longstreth (Eds) Structuring Politics: Historical Institutionalism in Comparative Analysis. Cambridge: Cambridge University Press.

Hay, Colin, and Wincott, Daniel. 1998. "Structure, Agency and Historical Institutionalism”. Political Studies, 46:951.

Heclo, Hugh. 1974. Modern Social Politics in Britain and Sweden: From Relief to Income Maintenance. New Haven: Yale University Press.

Hiebert, Paul. 2006. Household Saving and Asset Valuations in Selected Industrialised Countries. Reserve Bank of Australia Research Discussion Paper RDP 2006-07.

Hofstede, Geert. 1984. “Cultural Dimensions in Management and Planning”. Asia Pacific Journal of Management, 1(2):81.

Holmes, Kevin. 2001. The Concept of Income: A multi-disciplinary analysis. Amsterdam: IBFD Publications.

Holzmann, Robert. 1999. The World Bank Approach to Pension Reform. Social Protection Discussion Paper Series, The World Bank, No 9807.

Holzmann, Robert, and Hinz, Richard. 2005. Old Age Income Support in the $21^{\text {st }}$ Century: An international perspective on pension systems and reform. Washington: World Bank.

Hopkin, Jonathan. 2002. Comparative Methods. Basingstoke: Palgrave MacMillan.

Hubbard, R. Glenn, and Skinner, Jonathan, S. 1996. "Assessing the Effectiveness of Saving Incentives". Journal of Economic Perspectives, 10(4):73.

Immergut, Ellen, M. 1992. The Rules of the Game: The logic of health policymaking in France, Switzerland, and Sweden. In S Steinmo, K Thelen and F Longstreth (Eds) Structuring Politics: Historical Institutionalism in Comparative Analysis. Cambridge: Cambridge University Press. 
Immergut, Ellen, M. 1998. "The Theoretical Core of the New Institutionalism". Politics and Society, 26(1):5.

Ingles, David. 2001. Interaction of the Age Pension Means Test and the Taxation of Superannuation. ANU Public Policy Programme Discussion Paper No 84.

Institute of Chartered Accountants. 1999. Older Getting Wiser. London: Institute for Fiscal Studies.

International Monetary Fund. 2003. New Zealand: Selected Issues. IMF Country Report No 03/122, May 2003.

James, Michael. 1998. Savings and Pensions: Freedom versus compulsion in civil society. Wellington: New Zealand Business Roundtable.

Janiewski, Dolores, and Morris, Paul. 2005. New Rights New Zealand: Myths, moralities and markets. Auckland: Auckland University Press.

Jappelli, Tullio, and Pistaferri, Luigi. 2002. Tax Incentives for Household Saving and Borrowing. Centre for Studies in Economics and Finance, Working Paper No 83.

Jenkins, Keith. 1991. Re-thinking History. London: Routledge.

Jesson, Bruce. 1992. Lobbying and Protest: Patterns of political change at the informal level. In $\mathrm{H}$ Gold (Ed) New Zealand Politics in Perspective $3^{\text {rd }}$ Edition. Auckland: Longman Paul Ltd.

Jump, Gregory, V. 1982. Tax Incentives to Promote Personal Saving: Recent Canadian experience. Saving and Government Policy Conference held at Melvin Village, New Hampshire, October 1982. Conference Series No 25, Federal Reserve Bank of Boston.

Kato, Junko. 1996. "Institutions and Rationality in Politics: Three variations of neoinstitutionalists". British Journal of Political Science, 26(4):553.

Katona, George. 1965. Private Pensions and Individual Saving. Ann Arbor: University of Michigan Press.

Kelly, Paul. 1994. The End of Certainty: Power, politics and business in Australia. St Leonards: Allen and Unwin. 
Kewley, T.H. 1980. Australian Social Security Today: Major developments from 1900 to 1978. Sydney: Sydney University Press.

Kerin, John. 1991. Superannuation Guarantee Levy: An information paper. Information paper released by the Hon John Kerin, Treasurer of the Commonwealth of Australia, December 1991.

Keynes, John, Maynard. 1936. The General Theory of Employment, Interest and Theory. London: MacMillan Cambridge University Press.

King, Desmond, S., and Rothstein, Bo. 1993. "Institutional Choices and Labor Market Policy: A British-Swedish comparison". Comparative Political Studies, 26(2):147.

Knight, Jack. 1992. Institutions and Social Conflict. Cambridge: Cambridge University Press.

Knox, David, M. 1992. The Objectives and Distribution of the Taxation Support Provided to Occupational Superannuation in Australia. Sydney: Allen and Unwin.

Knudsen, Tim, and Rothstein, Bo. 1994. "State Building in Scandinavia". Comparative Politics, 26(2):203.

Krasner, Stephen, D. 1984. "Approaches to the State: Alternative conceptions and historical dynamics". Comparative Politics, 16(2):223.

Lacy, Judith. 1994. Dancing Back: A retrospective look at the early politics of the National Superannuation Scheme. A Thesis submitted to the Victoria University of Wellington in fulfilment of the requirements for the degree of Master of Arts in Politics.

Lally, Martin, and Marsden, Alastair. 2004. “Tax-Adjusted Market Risk Premiums in New Zealand: 1931-2002”. Pacific Basin Finance Journal, 12:291.

Lee, T.A. 1990. Accounting History and Thought. New York: Garland Publishing Inc.

Levine, Stephen, and Roberts, Nigel. 1993. Elderly People and the Political Process. In P G Koopman-Boyden (Ed) New Zealand's Ageing Society: The implications. Wellington: Daphne Brassel Assoc Press. 
Life Offices' Association of New Zealand. 1989. Superannuation Policy. Wellington: Life Offices’ Association of New Zealand.

Lister, Roger, J. 1983. "Accounting as History". International Journal of Accounting, 18(2):49.

Lowndes, Vivien. 2002. Institutionalism. Basingstoke: Palgrave MacMillan.

Mahoney, James. 2000. "Path Dependence in Historical Sociology". Theory and Society, 29(4):507.

Mair, Peter. 1996. Comparative Politics: An overview. In R Goodin and H-D Klingemann (Eds) A New Handbook of Political Science. Oxford: Oxford University Press.

March, James, G., and Olsen, Johan, P. 1984. "The New Institutionalism: Organizational factors in political life". American Political Science Review, 78:734.

March, James, G., and Olsen, Johan, P. 1989. Rediscovering Institutions: The organizational basis of politics. New York: The Free Press.

Matthews, T. 1994. Employers' Associations, Corporatism and the Accord: The politics of industrial relations. In S Bell and B Head (Eds) Economy and Public Policy in Australia. Melbourne: Oxford University Press.

McClure, Margaret. 1998. A Civilised Community: A history of social security in New Zealand. Auckland: Auckland University Press.

McKinnon, Malcolm. 2003. Treasury: The New Zealand Treasury, $1840-2000$. Auckland: Auckland University Press.

McLean, Denis. 2003. The Prickly Pair: Making nationalism in Australia and New Zealand. Dunedin: University of Otago Press.

McLeay, Elizabeth. 1995. The Cabinet and Political Power in New Zealand. Auckland: Oxford University Press.

McNamara, Kathleen, R. 1998. The Currency of Ideas: Monetary politics in the European Union. Ithaca: Cornell University Press.

Merino, Barbara, D. 1998. "Critical Theory and Accounting History: Challenges and opportunities". Critical Perspectives on Accounting, 9:603. 
Merino, Barbara, D., and Mayper, Alan, G. 1993. "Accounting History and Empirical Research". The Accounting Historians Journal, 20(2): 237.

Ministry of Social Development. 2003. A Description of New Zealand's Current Retirement Income Framework. Periodic Reporting Group Background Paper. www.treasury.govt.nz, viewed August 2004.

Ministry of Social Development. 2007. Positive Ageing Indicators 2007. www.msd.govt.nz, viewed August 2007.

Mitchell, Olivia, S. 1998. Developments in Pensions. Pension Research Council Working Paper 98-4. Wharton School Pension Research Council, University of Pennsylvania.

Morling, Steven, and Subbaraman, Robert. 1995. Superannuation and Saving. Economic Analysis Department, Reserve Bank of Australia, Research Discussion paper 9511.

Mulgan, Richard. 1989. Democracy and Power in New Zealand: A study of New Zealand politics $2^{\text {nd }}$ Edition. Oxford: Oxford University Press.

Mulgan, Richard. 2004. Politics in New Zealand $3^{\text {rd }}$ Edition. Auckland: Auckland University Press.

Munnell, Alicia. 1982. The Economics of Private Pensions. Washington: Brookings Institute.

Napier, Christopher, J. 1989. "Research Directions in Accounting History”. British Accounting Review, 21(3):237.

National Superannuation Committee of Inquiry. 1974. National Superannuation in Australia: Interim report. Canberra: AGPS.

National Superannuation Committee of Inquiry. 1976. A National Superannuation Scheme for Australia. Final report of the National Superannuation Committee of Inquiry - Part One. Canberra: AGPS.

National Superannuation Committee of Inquiry. 1977. Occupational Superannuation in Australia. Final report of the National Superannuation Committee of Inquiry - Part Two. Canberra: AGPS. 
New Zealand Government. 1986. Statement on Government Expenditure Reform. Wellington: Government Printer.

New Zealand Government. 1987. Economic Statement 1987. Wellington: Government Printer.

New Zealand Government. 1988. Consultative Document on Superannuation and Life Insurance, Volume 1. Wellington: Government Printer.

New Zealand Government Actuary. 2007. Report of the Government Actuary for the Year Ended 30 June 2007. www.isu.govt.nz, viewed October 2007.

New Zealand Institute for Research on Ageing. 2005. Aotearoa Ageing 2005: A bibliography of New Zealand research on ageing, 2001 - 2005. New Zealand Institute for Research on Ageing, www.nzira.ac.nz, viewed May 2006.

New Zealand National Party and New Zealand First. 1996. New Zealand National Party and New Zealand First Coalition Agreement. Wellington: Government Printer. New Zealand Planning Council. 1979. The Welfare State? Social policy in the 1980's. Wellington: New Zealand Planning Council.

New Zealand Treasury. 1984. Economic Management. Wellington: Government Printer.

New Zealand Treasury. 1987. Government Management: Brief to the Incoming Government 1987, Volume 1. Wellington: Government Printer.

New Zealand Treasury. 2001. Savings Incentive Options, Consultation and Analysis. New Zealand Treasury Report 7 December 2001. www.treasury.govt.nz, viewed December 2004.

New Zealand Treasury. 2007. A Synopsis of Theory, Evidence and Recent Treasury Analysis on Saving. New Zealand Treasury Report T2007/654.

Nobes, Christopher, and Parker, Robert. 2002. Comparative International Accounting, $7^{\text {th }}$ Ed. Harlow: Financial Times/Prentice Hall.

Nolan, David. 1985. Superannuation: An employer view. In National Mutual Life Association of Australia Superannuation and Industrial Relations. Melbourne: Industrial Relations Society of Victoria. 
Nolan, David. 1986. Superannuation from the Employers' Viewpoint. In R Mendelsohn (Ed) Finance of Old Age. Canberra: ANU Centre for Research on Federal Financial Relations.

Nordlinger, Eric, A. 1987. Taking the State Seriously. In M Weiner and S Huntington (Eds) Understanding Political Development. Prospect Heights: Waveland Press Inc.

North, Douglass, C. 1990. Institutions, Institutional Change and Economic Performance. Cambridge: Cambridge University Press.

O’Connell, Ann. 1995. “Taxation of Superannuation”. Bulletin for International Fiscal Documentation, 49(6):263.

O'Connell, Ann. 2003. "Retirement Income Policy and the Taxation of Superannuation in Australia”. Bulletin for International Fiscal Documentation, 57(89):431.

Office of the Retirement Commissioner. 2001. Measuring Household Saving in New Zealand. www.retirement.org, viewed March 2006.

Olsberg, Diana. 1997. Ageing and Money: Australia's retirement revolution. St Leonards: Allen and Unwin.

Organisation for Economic Co-operation and Development. 2005. Pensions at a Glance: Public Policies Across OECD Countries. Paris: OECD Publishing.

Organisation for Economic Co-operation and Development. 2007. Pensions at a Glance: Public Policies Across OECD Countries. Paris: OECD Publishing.

Palme, Joakim. 1990. Pension Rights in Welfare Capitalism: The development of old-age pensions in 18 OECD countries 1930 to 1985. Swedish Institute for Social Research Paper No 14.

Palmer, Geoffrey. 1977. Income Maintenance at the Cross-Roads. Wellington: Fourth Estate Books Ltd.

Palmer, R.C. and Gould, J.C. 1975. The Asprey Report and Superannuation and Life Insurance. Canberra: $\mathrm{CCH}$ Australia Limited. 
Parker, Lee, D. 1997. "Informing Historical Research in Accounting and Management: Traditions, philosophies and opportunities". The Accounting Historians Journal, 24(2):111.

Parker, R.H. 1971. "Some International Aspects of Accounting”. Journal of Business Finance, 2(4):29.

Parliament of the Commonwealth of Australia. 1983. Economic Statement May 1983. Delivered on 19 May 1983 by the Hon P J Keating, Treasurer of the Commonwealth of Australia.

Parliament of the Commonwealth of Australia. 1985. Reform of the Australian Tax System: White Paper. Canberra: AGPS.

Parliament of the Commonwealth of Australia. 1988a. Economic Statement May 1988. Parliamentary Paper No 98/1988. Canberra: AGPS.

Parliament of the Commonwealth of Australia. 1988b. A Guide to the Reform of the Taxation of Superannuation. Forming Part of the Economic Statement May 1988. Canberra: AGPS.

Parliament of the Commonwealth of Australia. 1996. Provisions of the Social Security Legislation Amendment (Further Budget and Other Measures) Bill. Schedule 1, Report, Parliament of Australia, Senate. www.aph.govt.nz, viewed November 2005.

Parsons, Wayne. 1995. Public Policy: An introduction to the theory and practice of policy analysis. Cheltenham: Edward Elgar Publishing Ltd.

Patmore, Greg, and Coates, David. 2005. "Labour Parties and the State in Australia and the United Kingdom”. Labour History, 88:1.

Peetz, David. 1998. Unions in a Contrary World: The future of the Australian trade union movement. Cambridge: Cambridge University Press.

Periodic Report Group. 1997a. Retirement Income Report: A review of the current framework. Interim Report, July 1997. Wellington: Government Printer.

Periodic Report Group. 1997b. 1997 Retirement Income Report: Building Stability. Concluding Report, December 1997. Wellington: Government Printer. 
Periodic Report Group. 2003. Retirement Income Report 2003. Wellington: Government Printer.

Peters, B. Guy. 1991. The Politics of Taxation: A comparative perspective. Cambridge: Blackwell.

Peters, B. Guy. 1998. Comparative Politics: Theory and methods. Basingstoke: Macmillan Press Ltd.

Peters, B. Guy. 1999. Institutional Theory in Political Science. London: Pinter.

Pierson, Paul. 1993. "When Effect Becomes Cause: Political feedback and political change". World Politics, 45(4):595.

Pierson, Paul. 1994. Dismantling the Welfare State? Reagan, Thatcher, and the Politics of Retrenchment. Cambridge: Cambridge University Press.

Pierson, Paul. 1996. "The Path to European Integration: A historical institutionalist analysis". Comparative Political Studies, 29(2):123.

Pierson, Paul., and Skocpol, Theda. 2000. Historical Institutionalism in Contemporary Political Science. Paper prepared for presentation at the American Political Science Association Meetings, Washington D.C., August 2000.

Pierson, Paul, and Weaver, R., Kent. 1993. Imposing Losses in Pension Policy. In R Weaver and B Rockman (Eds) Do Institutions Matter? Government Capabilities in the United States and Abroad. Washington: The Brookings Institution.

Plowman, David. 1989. Unions and the Industrial Relations Context: An overview. Melbourne: Macmillan Company of Australia.

Plowman, David, and Weaven, Garry. 1989. Unions and Superannuation. In B Ford and D Plowman (Eds) Australian Unions: An industrial relations perspective $2^{\text {nd }}$ Edition. Melbourne: Macmillan Company of Australia.

Poterba, James, M. 2002. Taxation, Risk Taking and Household Portfolio Behaviour. In A Auerbach and M Feldstein (Eds) Handbook of Public Economics, Volume 3. Amsterdam: Elsevier.

Powell, Walter, W., and DiMaggio, Paul, J. 1991. The New Institutionalism in Organizational Analysis. Chicago: University of Chicago Press. 
Preston, David. 2001. Retirement Income in New Zealand: The historical context. Wellington: Office of the Retirement Commissioner.

Previts, Gary, J., and Bricker, Robert. 1994. "Fact and Theory in Accounting History: Presentmindedness and capital market research". Contemporary Accounting Research, 10(2):625.

PricewaterhouseCoopers. 2005. Bridging the Savings Gap: An evaluation of voluntary and compulsory approaches to pension reform. Research report by PricewaterhouseCoopers for the ABI, June 2005.

Przeworski, Adam, and Teune, Henry. 1970. The Logic of Comparative Social Inquiry. New York: John Wiley and Sons.

Radaelli, Claudio, M. 1999. Taxation as Politics. In M Lamb and A Lymer (Eds) Interdisciplinary Research in Taxation: Research approaches and bibliographic survey. Research Report Sponsored by The Institute of Chartered Accountants in England and Wales, Centre for Business Performance.

Rafter, Bruce. 1986. Superannuation in Australia - the place of life offices. In R Mendelsohn (Ed) Finance of Old Age. Canberra: Centre for Research on Federal Financial Relations.

Ragin, Charles, C., Berg-Schlosser, Dirk., and de Meur, Gisele. 1996. Political Methodology: Qualitative methods. In R Goodin and H-D Klingemann (Eds) A New Handbook of Political Science. Oxford: Oxford University Press.

Ricoeur, Paul. 1965. History and Truth. Evanston: Northwestern University Press.

Robinson, Ian. 1992. Superannuation - A Policy Perspective. In K David and I Harper (Eds) Superannuation and the Australian Financial System. Sydney: Allen and Unwin.

Rothman, George. 2003. Tax Advantages of Investment in Superannuation - In Bad Times as Well as Good. Paper presented to the Eleventh Colloquium of Superannuation Researchers, University of New South Wales, Sydney, Australia, July 2003. 
Rothstein, Bo. 1996. Political Institutions: An overview. In R Goodin and H-D Klingemann (Eds) A New Handbook of Political Science. Oxford: Oxford University Press.

Royal Commission of Inquiry on Social Security. 1972. Social Security in New Zealand: Report of the Royal Commission of Inquiry. Wellington: Government Printer.

Royal Commission on Social Policy. 1988. Report of The Royal Commission on Social Policy: the April report Volume III part two - Future directions. Wellington: Government Printer.

Savage, John. 1999. Saving in New Zealand. Background paper prepared for the Office of the Retirement Commissioner 99/1. www.retirement.org.nz, viewed May 2006.

Savings Product Working Group. 2004. A Future for Work-Based Savings in New Zealand. Final report of the Savings Product Working Group. www.beehive.govt.nz, viewed August 2006.

Schwarzmantel, J.J. 1987. Structures of Power: An Introduction to Politics. Sussex: Wheatsheaf Books.

Scobie, Grant, Gibson, John, and Le, Trinh. 2004. Saving for Retirement: New Evidence for New Zealand. New Zealand Treasury Working Paper 04/12.

Scobie, Grant, Gibson, John, and Le, Trinh. 2005. Household Wealth in New Zealand. Wellington: Institute of Policy Studies.

Scobie, Grant, Le, Trinh, and Gibson, John. 2007. Housing in the Household Portfolio and Implications for Retirement Saving: Some initial findings from SOFIE. New Zealand Treasury Working Paper 07/04.

Selznick, Philip. 1996. "Institutionalism "Old" and "New"”. Administrative Science Quarterly, 41(2):270.

Senate Select Committee on Superannuation. 1992. Safeguarding Super: The regulation of superannuation. First report of the Senate Select Committee on Superannuation. Canberra: AGPS. 
Senate Select Committee on Superannuation. 1998. Super Taxing: An information paper on the taxation of superannuation and related matters. Canberra: AGPS.

Shaw, Richard. 2003. Advisers and Consultants. In R Miller (Ed) New Zealand: Government and politics $3^{\text {rd }}$ Edition. Oxford: Oxford University Press.

Sills, David, E. 1968. International Encyclopaedia of the Social Sciences, Volume 14. London: The Macmillan Company.

Simeon, Richard. 1976. "Studying Public Policy". Canadian Journal of Political Science, 9(4):548.

Sinfield, Adrian. 2003. Changing Tax Welfare. Presentation to the ESPANET Conference, Copenhagen, November 2003.

Singleton, Gwynneth. 1990. The Accord and the Australian Labor Movement. Melbourne: Melbourne University Press.

Skocpol, Theda. 1979. States and Social Revolutions: A comparative analysis of France, Russia and China. Cambridge: Cambridge University Press.

Skocpol, Theda. 1985. Bringing the State Back In: Strategies of analysis in current research. In P Evans, D Rueschemeyer and T Skocpol (Eds) Bringing the State Back In. Cambridge: Cambridge University Press.

Skocpol, Theda. 1992. Protecting Soldiers and Mothers: The political origins of social policy in the United States. Cambridge: Harvard University Press.

Smith, Graeme, J. 1987. The Role of Industrial Tribunals - Consent Awards and Other Industrial Awards. In Continuing Legal Education Programme and the Leo Cussen Institute Superannuation. Melbourne: Leo Cussen Institute.

Stake, Robert, E. 2000. Case Studies. In N Denzin and Y Lincoln (Eds) Handbook of Qualitative Research $3^{\text {rd }}$ Edition. Thousand Oaks: Sage Publications.

Stanford, Michael. 1986. The Nature of Historical Knowledge. Oxford: Basil Blackwell Inc.

Statistics New Zealand. 2001. The Net Worth of New Zealanders: A report on their assets and debts. www.stats.govt.nz, viewed August 2004. 
Statistics New Zealand. 2002. 2001 Census Snapshot 9 (Older People). www.stats.govt.nz, viewed March 2006.

Steinmo, Sven. 1993. Taxation and Democracy: Swedish, British and American approaches to financing the modern state. New Haven: Yale University Press.

Steinmo, Sven. 1998. Political Institutions and Tax Policy in the United States, Sweden, and Britain. Cheltenham: Edward Elgar.

Steinmo, Sven. 2001. The New Institutionalism. In B Clark and J Foweraker (Eds) The Encyclopaedia of Democratic Thought. London: Routledge.

Steinmo, Sven. 2003. "The Evolution of Policy Ideas: Tax policy in the $20^{\text {th }}$ century”. British Journal of Politics and International Relations, 5(2):206.

Steinmo, Sven. 2008a. What is Historical Institutionalism? In D Porta and M Keating (Eds) Approaches in the Social Sciences. Cambridge: Cambridge University Press.

Steinmo, Sven. 2008b. What Should the State Do? A political economy of ideas and institutions. In J Campbell and $\mathrm{P}$ Naargard (Eds) Institutions and Politics. Copenhagen: DJOF Press.

Steinmo, Sven, Thelen, Kathleen, and Longstreth, Frank. 1992. Structuring Politics: Historical institutionalism in comparative analysis. Cambridge: Cambridge University Press.

Steinmo, Sven., and Tolbert, Caroline, J. 1998. "Do Institutions Really Matter? Taxation in Industrialized Democracies”. Comparative Political Studies, 31(2):165.

Stephens, R.J. 1989. New Zealand Tax Reform. In Australian Tax Reform in Retrospect and Prospect, papers presented at a conference organised by the Centre of Policy Studies, Monash University. Sydney: Australian Tax Research Foundation.

Stephens, Robert. 2003. The Economic and Social Context for the Changes in Accident Compensation. Victoria University of Wellington Law Review, 2003.

Stephenson, John, and Scobie, Grant. 2002. The Economics of Population Ageing. New Zealand Treasury Working Paper 02/05. 
St John, Susan. 1992. National Superannuation: Or how not to make policy. In J Boston and P Dalziel (Eds) The Decent Society? Essays in response to National's economic and social policies. Auckland: Auckland University Press.

St John, Susan. 1993. Income Support for an Ageing Society. In P G KoopmanBoyden (Ed) New Zealand's Ageing Society: The implications. Wellington: Daphne Brassel Assoc Press.

St John, Susan. 1994. The State and Welfare. In A Sharp (Ed) Leap into the Dark: The changing role of the state in New Zealand since 1984. Auckland: Auckland University Press.

St John, Susan. 1999. Stability of Retirement Income Policy. Institute of Policy Studies IPS Policy Paper No 3.

St John, Susan. 2001. New Zealand Goes It Alone in Superannuation Policy. Presentation to the 9th Annual Colloquium of Superannuation Researchers, Sydney, Australia, July 2001.

St John, Susan. 2003. What is Wrong with the New Zealand Model for Pensions? Paper presented to the Australian Colloquium of Superannuation Researchers, Sydney, Australia, July 2003.

St John, Susan, and Heynes, Anne. 1993. The Welfare Mess. Department of Economics, University of Auckland, Policy Paper No 15, May 1993.

St John, Susan, and Willmore, Larry. 2000. Two Legs Are Better Than Three: New Zealand as a model for old age pensions. Paper presented to the International Research Conference on Social Security, Helsinki, Finland, September 2000.

Street, Maryan. 2003. Trade Unions. In R Miller (Ed) New Zealand: Government and politics $3^{\text {rd }}$ Edition. Oxford: Oxford University Press.

Task Force on Private Provision for Retirement. 1991. Private Provision for Retirement: The way forward - the issues. Interim Report of the Task Force on Private Provision for Retirement, December 1991.

Task Force on Private Provision for Retirement. 1992. Private Provision for Retirement: The way forward - final report. Final Report of the Task Force on Private Provision for Retirement, December 1992. 
Task Force on Tax Reform. 1982. Report of the Task Force on Tax Reform. Wellington: Government Printer.

Taxation Review Committee. 1975. Taxation Review Committee Full Report January 31 1975. Canberra: AGPS.

Tavits, Margit. 2003. "Policy Learning and Uncertainty: The case of pension reform in Estonia and Latvia". Policy Studies Journal, 31(4):643.

Teune, Henry. 1978. A Logic of Comparative Policy Analysis. London: Sage Publications.

Thelen, Kathleen. 1999. "Historical Institutionalism in Comparative Politics". Annual Review of Political Science, 2:369.

Thelen, Kathleen., and Steinmo, Sven. 1992. Historical Institutionalism in Comparative Politics. In S Steinmo, K Thelen and F Longstreth (Eds) Structuring Politics: Historical institutionalism in comparative analysis. Cambridge: Cambridge University Press.

Thomson, David. 1991. Selfish Generations? The Ageing of New Zealand's Welfare State. Wellington: Bridget Williams Books Ltd.

Thomson, George, and Gauld, Robin. 2001. "Finding the Unseen, Listening to the Unheard: Using primary sources for research in the New Zealand health sector". Social Policy Journal of New Zealand, 17:183.

Thorp, Clive, and Ung, Bun. 2000. "Trends in Household Assets and Liabilities Since 1978”. Reserve Bank of New Zealand Bulletin, 63(2):17.

Torfing, Jacob. 2001. "Path-Dependent Danish Welfare Reforms: The contribution of the new institutionalisms to understanding evolutionary change". Scandinavian Political Studies, 24(4):277.

Vowles, Jack. 1992. Business, Unions and the State: Organising economic interests in New Zealand. In $\mathrm{H}$ Gold (Ed) New Zealand Politics in Perspective $3^{\text {rd }}$ Edition. Auckland: Longman Paul Ltd.

Warren, Neil. 2000. Taxing Retirement Savings in Australia: From hybrid expenditure tax to comprehensive income tax? In H Petersen and P Gallagher (Eds) 
Tax and Tax Reform in Australia and Germany, Australia Centre Series, Volume 3, University of Potsdam, Germany.

Weaven, Garry. 1989. Superannuation and Retirement Incomes Policy: The crucial role of unions. Australian Insurance Institute, 12(2): 18.

Weaver, R., Kent. 2002. New Zealand: The supreme political football. Center for Retirement Research at Boston College, December 2002.

Weaver, R.K., and Rockman, B.A. 1993a. Do Institutions Matter? Government capabilities in the United States and abroad. Washington: The Brookings Institution.

Weaver, R.K., and Rockman, B.A. 1993b. When and How do Institutions Matter? In R Weaver and B Rockman (Eds) Do Institutions Matter? Government capabilities in the United States and abroad. Washington: The Brookings Institution.

Weir, Margaret, and Skocpol, Theda. 1985. State Structures and the Possibilities for "Keynesian" Responses to the Great Depression in Sweden, Britain, and the United States. In P Evans, D Rueschemeyer and T Skocpol (Eds) Bringing the State Back In. Cambridge: Cambridge University Press.

White, Jay, D. 1994. On the Growth of Knowledge in Public Administration. In J White and G Adams (Eds) Research in Public Administration: Reflections on theory and practice. London: Sage Publications.

Whiteford, Peter. 2004. Reforming Pensions: The Australian experience. In M Rein and W Schmahl (Eds) Rethinking the Welfare State: The political economy of pension reform. Cheltenham: Edward Elgar.

Whiteford, Peter, and Whitehouse, Edward. 2006. "Pension Challenges and Pension Reforms in OECD Countries", Oxford Review of Economic Policy, 22(1):78.

Whitwell, Greg. 1986. The Treasury Line. Sydney: Allen and Unwin.

Whyte, Gaynor. 2004. Beyond the Statute: Administration of old-age pensions to 1938. In B Dalley and M Tennant (Eds) Past Judgement: Social policy in New Zealand history. Dunedin: University of Otago Press.

Willmore, Larry. 1998. Public Versus Private Provision of Pensions. DESA Discussion Paper No 1, United Nations - Economic and Social Affairs. 
Willmore, Larry. 2000. Three Pillars of Pensions? A Proposal to End Mandatory Contributions. DESA Discussion Paper No 13.

Wills, Lester, and Ross, Donald. 2002. Exploring the Retirement Savings Gap: An Australian perspective. The Pensions Institute, Birkbeck College, University of London, Discussion paper PI-0209.

Wiseman, John. 1996. All for one or one for all? The past and future of the Australian Welfare State. In J Wilson, J Thomson and A McMahon (Eds) The Australian Welfare State: Key documents and themes. Melbourne: MacMillan Education Australia Pty.

World Bank. 1994. Averting the Old Age Crises. Oxford: Oxford University Press. Yoo, Kwang-Yeo, and de Serres, Alain. 2004. Tax Treatment of Private Pension Savings in OECD Countries. OECD Economic Studies No 39, 2004/02.

Zeff, Stephen, A. 1971. Forging Accounting Principles in Five Countries: A history and an analysis of trends. Champaign, Illinois: Stipes Publishing Company. 